\title{
(De)formierte Körper
}

Die Wahrnehmung und das Andere im Mittelalter
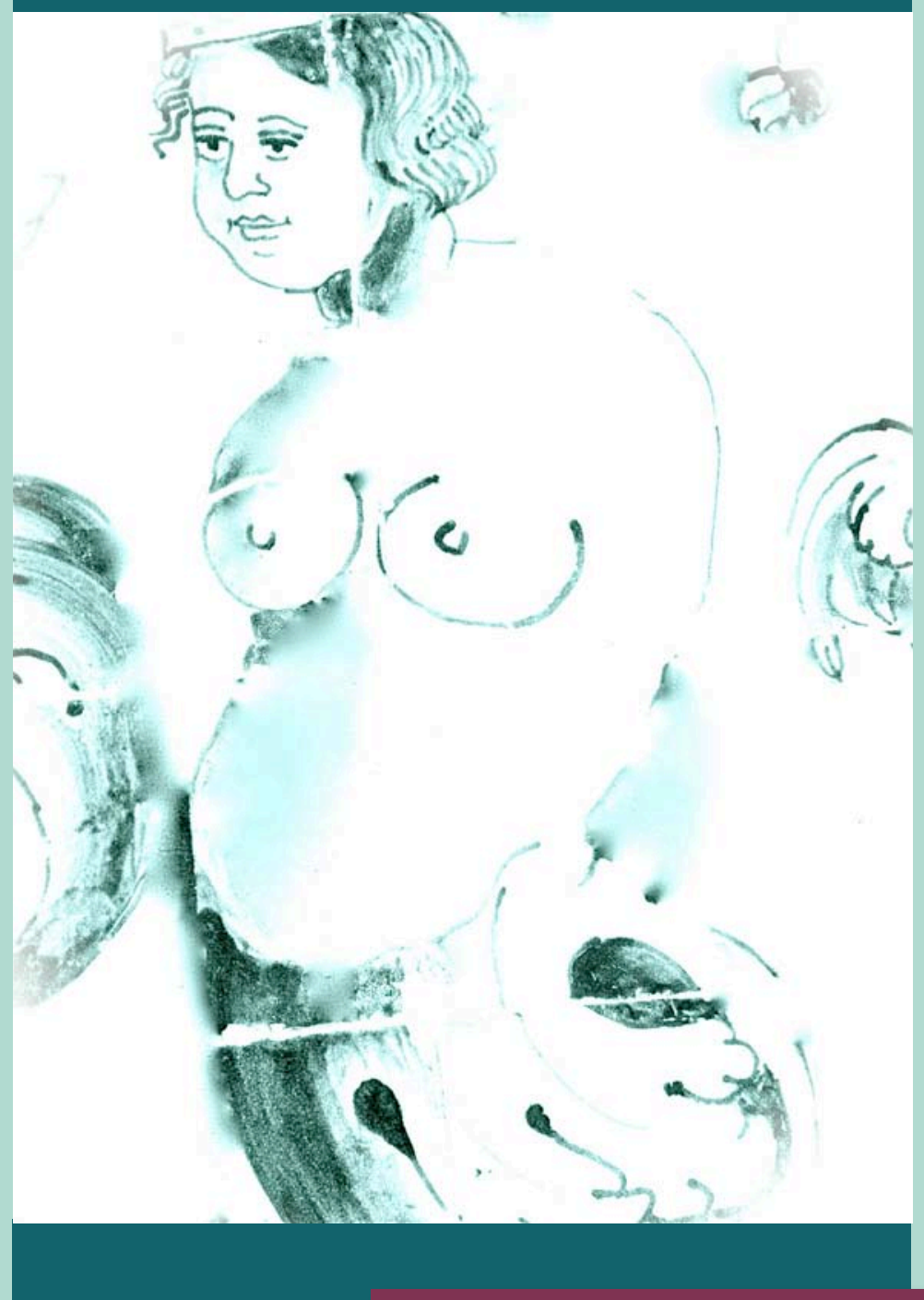

Gabriela Antunes, Björn Reich (Hrsg.)

Universitätsverlag Göttingen 

Gabriela Antunes, Björn Reich (Hrsg.)

(De)formierte Körper - Die Wahrnehmung und das Andere im Mittelalter

This work is licensed under the

Creative Commons License 3.0 "by-nd", allowing you to download, distribute and print the document in a few copies for private or educational use, given that the document stays unchanged and the creator is mentioned.

You are not allowed to sell copies of the free version.

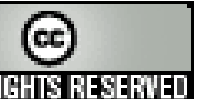


erschienen im Universitätsverlag Göttingen 2012 
Gabriela Antunes,

Björn Reich (Hrsg.)

\section{(De)formierte Körper}

\section{Die Wahrnehmung}

und das Andere im Mittelalter

«Corps (Dé)formés: Perceptions et l'Altérité au Moyen-Âge »

Interdisziplinäres Seminar

Straßburg, 19. März 2010

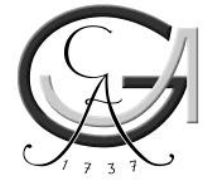

Universitätsverlag Göttingen 2012 


\section{Bibliographische Information der Deutschen Nationalbibliothek}

Die Deutsche Nationalbibliothek verzeichnet diese Publikation in der Deutschen Nationalbibliographie; detaillierte bibliographische Daten sind im Internet über $<$ http://dnb.ddb.de> abrufbar.

Anschrift der Herausgeber

e-mail: corpsdeformes@googlemail.com

Dieses Buch ist auch als freie Onlineversion über die Homepage des Verlags sowie über den OPAC der Niedersächsischen Staats- und Universitätsbibliothek (http://www.sub.uni-goettingen.de) erreichbar und darf gelesen, heruntergeladen sowie als Privatkopie ausgedruckt werden. Es gelten die Lizenzbestimmungen der Onlineversion. Es ist nicht gestattet, Kopien oder gedruckte Fassungen der freien Onlineversion zu veräußern.

Satz und Layout: Björn Reich

Umschlaggestaltung: Franziska Lorenz

Titelbild: Gabriela Antunes

(C) 2012 Universitätsverlag Göttingen

http://univerlag.uni-goettingen.de

ISBN: 978-3-86395-024-8 


\section{Remerciements}

Nous souhaitons exprimer notre gratitude à nos collègues et amis qui ont apporté une aide précieuse à la réalisation du projet «Corps (Dé)formés » et à cet ouvrage.

Nous remercions tout d'abord le Groupement d'Intérêt Scientifique « Mondes Germaniques », grâce auquel nous avons obtenu les moyens de réaliser de la première séance du Séminaire «Corps (Dé)formés: Perceptions de l'Altérité au Moyen-Âge » à Strasbourg le 19 mars 2010. Nous tenons à adresser nos sincères remerciements à Mme Christine Maillard, qui préside le conseil de gestion du GIS, et à Mme Magali Vogt, qui nous a épaulé, sur le plan technique comme sur le plan humain, tout au long des démarches. Nous remercions également à l'UFR des Langues Vivantes et à l'École Doctorale des Humanités pour le soutien financier, ainsi qu'à l'équipe du Collège Doctoral Européen, surtout à Mme Céline Montibeller, qui nous a offert l'espace pour la réalisation du Séminaire.

Nos remerciements les plus vifs vont également à l'Équipe d'Accueil 1341 «Mondes Germaniques », ainsi que l'École Doctorale des Humanités de l'Université de Strasbourg, pour le financement du présent ouvrage.

Que nos remerciements soient dirigés aux personnes ayant collaboré à la relecture des articles, notamment M. Peter Andersen, Mme Eva Bolta, Mme Hendrikje Hartung, M. Eric Hold, M. Walter Kofler, M. Benoît Mounier, M. Matthias Roick, M. Volker Scior et Mme Carmen Stange. Notre profonde gratitude aussi à Mme Cora Dietl pour son appui, et à M. Claude Lecouteux pour son soutien à la publication de ce livre.

Enfin, nous dédions ce volume à William Dang-Ha pour son assistance à la réalisation du Séminaire, et à João Neto, pour tout son appui et son aide toujours efficace. 



\section{Inhaltsverzeichnis}

(De)formierte Körper, die Wahrnehmung und das Andere im Mittelalter: Eine Einleitung

Gabriela Antunes/Björn Reich

Monströse Körper: Zur Deutung und Wahrnehmung von monstra im Mittelalter

Volker Scior

Der chimärische Hybridkörper im Artusroman

Eva Bolta

51

Die Darstellung der babylonischen Missgeburt in den Res Gestae und sechs davon abhängigen deutschen Dichtungen

Peter Hv. Andersen Vinilandicus

Oculi cordis: Verstümmelung, Wahrnehmung und Erkenntnis in Herrands von Wildonie Die treue Gattin

Carmen Stange

Des corps marginaux : regard sur les mendiants dans les poèmes d'Eustache Deschamps

Lola King 
Les difformités corporelles des lépreux : Aspects de l'imaginaire social au Moyen Âge

Nikoletta Giantsi

Auf der Suche nach Behinderung: Gedanken zur Wahrnehmung von deformierter Körperlichkeit in der bildlichen Überlieferung des Mittelalters

Sarah Harms

Der Schnitt am Körper: Die Wirkung des malerischen und plastischen Sujets der Enthauptung

Katrin Weleda

Lupus in fabulis et in templo: Les métamorphoses étranges du Saint Christophe dans l'Église Orthodoxe

Vesselina Vatchkova

Register 


\title{
(De)formierte Körper, die Wahrnehmung und das Andere im Mittelalter: Eine Einleitung
}

\author{
Gabriela Antunes / Björn Reich
}

„Was hat in den Klöstern, unter den Augen der mit Beten beschäftigten Fratres diese Galerie lächerlicher Ungeheuer zu suchen, diese verwirrende missgebildete Schönheit und diese schöne Missgebildetheit [deformis formositas ac formosa deformitas - d. Hrsg.] ... ?" Bernhards von Clairvaux berühmte Frage, ${ }^{1}$ die er in einem Brief dem Abt von St. Thierry stellte, ist in der Forschung immer wieder erörtert worden, ${ }^{2}$ denn seltsam gebildete Wesen finden sich überaus häufig unter den Fresken mittelalterlicher Kirchen und Klöster. Und nicht nur dort: Auch in anderen Bildwerken, wie z. B. Handschriftenillustrationen sind solche deformierten Wunderwesen zu finden. Dabei handelt sich um die schwer einzuordnenden Sheela na Gigs, ${ }^{3}$ um Teufelsdarstellungen, um Sünden- und Lasterallegorien ${ }^{4}$ oder auch einfach um mirabilia mundi - teilweise an prominenter Stelle abgebildet, wie etwa in der Apsis von St. Jakob in Kastelaz bei Tramin ${ }^{5}$ oder in der burgundischen Basilika Sainte-Marie-Madeleine de Vézelay, die im 12. Jahrhundert erbaut wurde und die

\footnotetext{
1 Zit. n. SchмiтT, Die Logik der Gesten, S. 178; vgl. Bernhard von Clairvaux, Opera, 12, 29.

2 Vgl. etwa: DinZelbacher, Mensch und Tier, S. 249; GrÜN, gestus, S. 17f.; MODE, Fabeltiere, S. 11; Rosenberg, Engel, S. 172; Rothmann, ex oculata fide, S. 361; Ders., Mirabilia vero dicimus, S. 404; SCHмIDT/SCHмIDT, Die vergessene Bildsprache, S. 20f.; SCHMITT, Die Logik der Gesten, S. 178.

3 Vgl. Andersen, The Witch; Freitag, Sheela-Na-Gigs; Kelly, Sheela-Na-Gigs; McMahon/RoBERTS, The Sheela-na-gigs.

4 ANDERGASSEN, Laster und Tugend.

5 Vgl. Dietheuer, Das Programm; Düriegl, Die Fabelwesen; Metzger, Die Apsisfresken; ReichARDT, De homine et portentis.
} 
als Teil des französischen Jakobswegs große historische Bedeutung trägt. ${ }^{6}$ Was allen diesen verschiedenen Darstellungen deformierter Wesen gemeinsam sein dürfte, ist ihre intendierte reflexionsanregende Wirkung auf den Betrachter. In der er- und abschreckenden, oder auch nur verwundernden Andersartigkeit ihrer Körper führen sie dem Schauenden die eigene Sündhaftigkeit vor Augen und machen zugleich deutlich, dass Gott auch für die absonderlichsten Dinge Platz in seinem Schöpfungsplan hat. Dass sich solche Reflexionsmomente an derartigen deformierten Wesen entzünden, dürfte kein Zufall sein: In der wesentlich auf Sichtbarkeit und Deixis abgestellten Kultur des Mittelalters ${ }^{7}$ nehmen Körper in ihrer äußeren Zeichenhaftigkeit eine zentrale Stellung ein, ${ }^{8}$ und der deformierte Körper ist gerade durch seine auffällige Andersartigkeit in der Lage, Dinge sichtbar zu machen. STEINICKE führt dies am Beispiel der monstra der östlichen Hemisphäre aus:

\begin{abstract}
Dem Ausnahmecharakter seiner [des monstrum] abweichenden, wider- oder sogar übernatürlichen Erscheinung eignet $[\ldots]$ eine besondere Signifikanz; es kann $[\ldots]$ als omnium, als Warnung oder Weisung göttlicher Mächte interpretiert werden, etwa als Zeichen einer gestörten Beziehung zwischen Makro- und Mikrokosmos, deren Ordnung wiederherzustellen durch das monstrum angemahnt wird. ${ }^{9}$
\end{abstract}

Diese monstra mit ihrer körperlichen De- oder Reformation des Bekannten, bilden einen Zerrspiegel der mittelalterlichen Lebenswelt, bilden das Andere und Fremde ab und erfüllen damit eine wichtige ethnographische Funktion; ${ }^{10}$ darüber hinaus fungieren sie aber auch schon früh als apokalyptische Bedeutungsträger. Letzteres gilt nicht nur für die monstra - deren etymologische Grundbedeutung im Spannungsfeld von monstrare (zeigen) und monere (warnen) das Signenhafte dieser deformierten Wesen bereits betont ${ }^{11}$ - in ihrer Gesamtheit (als Volk), auch den einzelnen monstrum eignet eine stets spürbare Valenz, indem sie bezüglich des göttlichen Heilsplans epistemologische Funktionen erfüllen. Solche monstra sind indessen nur ein Beispiel für die erkenntnis- und reflexionsanregende Funktion der deformierten Körper: Überall dort, wo es um den Wahrnehmungsbereich des Göttlichen geht, finden sich deformierte Wesenheiten unterschiedlichster Provenienz - Teufel, Lasterallegorien oder die in den Höllenqualen gemarterten

\footnotetext{
${ }^{6}$ Dazu STRickland, Saracens, S. 159-161 u. passim. Vgl. Friedman, The Monstrous Races, S. 77-80.

7 Vgl. dazu besonders die verschiedenen Arbeiten von Horst Wenzel. Etwa: Wenzel, Hören und Sehen; DERS., Spiegelungen; DERS., Wahrnehmung.

8 Dies dürfte seit KANTOROWICZ unbestritten sein. Vgl. insgesamt AgAmben, Homo sacer; CZERWInSKI, Gegenwärtigkeit; KantorowiCZ, Die zwei Körper; Kellermann, Entstellt, S. 40; DIES., Die körperliche Inszenierung; MAREK, Die Körper.

${ }^{9}$ STEINICKE, Apokalyptische Heerscharen, S. 6.

$10 \mathrm{Zu}$ den mirabilia mundi vgl. die noch immer grundlegenden Arbeiten von PERRIG, Erdrandsiedler u. WiTTKOWER, Marvels. Zur Wahrnehmung des Fremden im Mittelalter vgl. HARMS/JAEGER, Fremdes wahrnehmen; MrTSCH, Körper, S. 73f. und zuletzt GEISTHARDT, Die Potenzialität.

11 Vgl. MünkLER, Die Wörter, S. 32-41; dies gilt auch für den mhd. Begriff túter (von diuten), vgl. REICHARDT, De homine et portentis.
} 
Sünder sind genauso an ihrer Deformation erkennbar (und erkenntnisanregend) wie die Heiligen, die sich nicht selten in ihrer Nachfolge Christi durch die Ausstellung einer an Christus angelehnten Leidens-deformitas auszeichnen ${ }^{12}$ und in ihrer Darstellung wesentlich durch ihre beim Märtyrertod abgeschlagenen Häupter, ihre abgezogene Haut oder ihre von Pfeilen durchbohrten Leiber ebenfalls reflexionsanregend auf die Betrachter wirken. Für die Erkenntnis des Göttlichen spielt die Betrachtung des deformierten, entstellten, verzerrten Körpers eine entscheidende Rolle, weil die Deformationen rückgebunden bleiben an den enstellten und verzerrten Körper des Erlösers.

Das reflexive Moment, das sich am deformierten Körper entzündet, tritt nicht nur bei bildlichen Darstellungen, sondern auch in Texten auf, wo die Schilderungen und Beschreibungen von Deformationen ebenso prominent und phantasievoll sind wie eben in der Bildenden Kunst, und es ist auffällig, dass deformierte Wesen in der Literatur meist dort auftauchen, wo es um zentrale Anliegen der Texte geht. Der Einsatz von Deformationen in den mittelalterlichen Künsten folgt, so lässt sich insgesamt beobachten, einer ausgeklügelten Bild- bzw. Sprachrhetorik, die sich letztlich aus der Wahrnehmungsphysiologie und Imaginationstheorie der Zeit speist: Innerhalb des mittelalterlichen Darstellens und Erzählens geht es nämlich wesentlich darum, solche ,Bilder'/Vorstellungen zu schaffen, ${ }^{13}$ die (nicht zuletzt aufgrund ihrer die curiositas reizenden Funktion) ${ }^{14}$ eine besonders imaginationsstimulierende Wirkung auf den Betrachter haben. Es geht

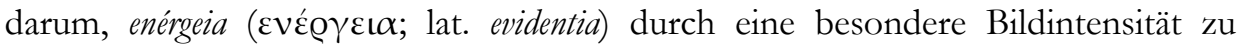
erzeugen. ${ }^{15}$ Welche ,Bilder ${ }^{6}$ eine derartige Intensität besitzen, und wie man sie generiert, wird dabei vor allem in mnemotechnischen Traktaten beschrieben, da es hier darum geht, memorierfähige, nachhaltige Bildcluster in der memoria und damit im Wahrnehmungsapparat zu schaffen. ${ }^{16}$ Innerhalb der dabei entworfenen, häufig recht absurd wirkenden ,Bilder ${ }^{6}{ }^{17}$ kommt den deformierten Körpern, gleichgültig ob es sich dabei um die Beschreibung wundersamer Wesen oder durch Zerstückelung deformierter Krieger handelt, schon früh eine besondere Wichtigkeit zu - Ansätze dafür finden sich bereits in der für das Mittelalter grundlegenden Rhetorica ad Herennium. ${ }^{18}$ Deformierte Körper besitzen aufgrund ihrer Besonderheit

\footnotetext{
12 Vgl. Antunes, Von bärtigen Prinzessinnen; Kellermann, Entstellt, S. 44 u. 49.

13 Zum mittelalterlichen Bildbegriff vgl. ReICH, Name und maere, S. 47; SCHLÜTER, Bild, Sp. 915; WeNZEL, Spiegelungen, S. 44-47.

14 Zur curiositas vgl. den Sammelband von KrÜGer (KRÜGer, Curiositas), sowie Daston/Park, Wonders; und MÜLLER, Curiositas.

15 Vgl. Reich, Name und maere, S. 35, sowie LAUSBERG, Handbuch, \$810; SCHEUER, numquam sine phantasmate, S. 384 u. WEBB, Ekphrasis.

16 Vgl. DIES., The Model, S. 474, sowie allgemein YATES, Gedächtnis.

17 Vgl. vor allem CARRUTHers, Book of Memory, S. 122-155, aber auch KeMP, Memoria, S. 274; sowie allgemein YATES, Gedächtnis.

18 Rhetorica ad Herennium, 3, 22, 37; vgl. ReICH, Der Mythos; DERS., Verkrüppelte Helden, aber auch den Aufsatz von LIENERT zur Nibelungenklage (LIENERT, Der Körper des Kriegers). Natürlich gibt es auch andere Möglichkeiten, intensivierte ,Bilder ${ }^{6}$ zu erschaffen (vgl. HABICHT/REICH, Die
} 
eine intensitätssteigernde und -stimulierende und damit die Wahrnehmung stark beeinflussende Kraft ${ }^{19}$ - die Verknüpfung von Körperforschung und Wahrnehmungstheorie ist damit gerade im Hinblick auf die mittelalterliche Kunst keine zufällige. ${ }^{20}$

Erst die Kenntnisse der imaginationsphysiologischen Grundlagen erklären die beständige Wechselwirkung zwischen Körper- und Wahrnehmungsphänomenen, denn wer einen deformierten Körper betrachtet, wird dadurch nicht nur auf eine abstrakt rationale Art und Weise zum Nachdenken angeregt. In der Betrachtung des deformierten Körpers wird nämlich das ,Bild ' des Deformierten über die Sinnesorgane aufgenommen und prägt sich in das körpereigene Pneuma ein, und dieser Vorgang verläuft durchaus nicht immer gefahrlos, wie etwa die medizinischen Ratschläge, Schwangere sollten z. B. keine Bilder von Ungeheuern o. ä. betrachten, um die körperliche Ausformung ihres eigenen ungeborenen Kindes nicht zu gefährden, belegen. ${ }^{21}$ Wer von den Bildern deformierter Körper nachhaltig beeinflusst wird, dessen eigenes Pneuma und dessen Wahrnehmungsapparat können dadurch korrumpiert werden. Da die Seele mittels des Pneumas durch die körperlichen Prozesse affiziert wird und umgekehrt der Zustand der Seele den Fluss des Pneumas (und damit letztlich wieder den Körper) prägt, sind Innen und Außen niemals vollständig zu trennen, ${ }^{22}$ jeder innere Prozess spiegelt sich im äußeren wider und umgekehrt. Der Körper ist daher nicht nur ein „poetisches Mittel“ für die Darstellung innerer Vorgänge:23 Das ,Andere“ des Körpers (und

Farbe; REICH, Name und maere, S. 61), den Körpern kommt aufgrund ihrer ohnehin prominenten Bedeutung im mittelalterlichen Kultursystem aber eine besonders zentrale Rolle zu.

${ }^{19}$ Das hängt auch damit zusammen, dass die Darstellungsmodi des Hässlichen prinzipiell vielfältiger sind, als die des Schönen, die einer stärkeren Kanonisierung folgen - wobei es freilich auch hier Regeln für die ,richtige' Darstellung gibt: vgl. grundlegend BRANDT, Die Beschreibung, aber auch Brinkmann, Zu Wesen, S. 65; CurTius, Europäische Literatur, S. 190, Anm. 2; Salmon, The Wild Man, S. $520 \mathrm{f}$.

${ }^{20}$ Insgesamt liegen mittlerweile so zahlreiche Studien zur Körperforschung einerseits, zur Wahrnehmungsforschung andererseits vor, dass hier eine Nennung auch nur der wichtigsten Publikationen geradezu unmöglich ist - angesichts einer derartigen Fülle an Forschungsliteratur mag es indessen erstaunen, dass beide Themengebiete häufig eben nur ansatzweise miteinander verschränkt und aufeinander bezogen werden. Aus der Flut der Publikationen seien hier nur einige neuere herausgehoben. Zur Körperforschung etwa: ACKERMANN, Im Spannungsfeld; FunK/BRÜCK, Körperkonzepte; HÜBLER, Das Konzept „Körper'; KIENING, Anthropologische Zugänge, S. 64f.; RIDDER/Langer, Körperinszenierungen; WARNING, Auf der Suche; WolfZETTEL, Körperkonzepte. Zur Wahrnehmungs- und Imaginationstheorie vgl. etwa AgAmBEn, Stanzen; BeRns, Film vor dem Film; LeCHTERMANN, Berührt werden; LOBSIEN/LOBSIEN, Die unsichtbare Imagination; ReICH, Name und maere; SCHEUER, Bildintensität; WENZEL, Hören und Sehen.

${ }^{21}$ Martin, Histoire des Monstres, S. 77-86; VAVRA, Menschen-Bilder, S. 13ff.

22 Das komplizierte Verhältnis von Innen und Außen, dessen Entsprechung in der mittelalterlichen Adelswelt immer wieder postuliert, zugleich aber auch problematisiert wird, kann hier nicht erschöpfend behandelt werden: Als Forschungsliteratur seien hier nur - im Anklang an das Tagungsthema ein paar Untersuchungen erwähnt, in denen diese Entsprechung vor allem im Hinblick auf das Thema der Hässlichkeit Erwähnung findet: ANTUNES, Entstellte Schönheiten; BuSCHINGER, L'homme laid; CARofF, Laideur; GouTteBroze, La laide demoiselle; LABBE, Une grande âme; Michel, Formosa deformitas; RidDer, Gelehrtheit; SChmolke-Hasselmann, Camuse chose; Wisbey, Die Darstellung.

${ }^{23}$ LINDEN, Körperkonzepte, S. 247. 
auch in diesem Sinne ist das ,Andere' des Tagungstitels zu verstehen), die Seele, steht eben in ständiger Wechselwirkung mit dem Körper. Sie ist abhängig von ihm, ${ }^{24}$ wohnt in ihm (oft genug wie in einem Kerker), ${ }^{25}$ bedient ihn aber auch vermittels des Pneumas und formt ihn dadurch. Form ist in diesem Zusammenhang als ein von der Seele abhängiger Körperzustand zu beschreiben, Deform-ation als ein Mangel in der ,Bedienerfunktion“ der leitenden Instanz und d. h. eben der Seelenfunktion, so dass der Körper nicht nur in allegorischer Entsprechung, sondern ganz physio-logisch zum äußeren Spiegel der Seele wird: Notgedrungen schließt daher „das Interesse am ,inneren“ Menschen zugleich ein Interesse am ,äußeren“ Menschen“" mit ein; ${ }^{26}$ Seelenlehre ist immer auch Körperlehre. So wie sich Affektionen, die die Seele betreffen, letztlich in Störungen oder Änderungen des eigenen Pneumaflusses und dadurch am Körper niederschlagen, ${ }^{27}$ bleiben umgekehrt auch die körperlichen Veränderungen nicht folgenlos für die Seele. Wo der eigene Körper in Mitleidenschaft gezogen ist, schlägt sich dies im inneren Pneumafluss nieder: „Wo der Körper defizient ist, kann sich auch die geistig seelische Potenz des Menschen nicht voll entfalten" ${ }^{28}$ - allerdings gilt dieser Fall gerade nicht immer: So zeigt sich etwa bei vielen literarischen Figuren, dass körperliche Deformationen auch Vorteile für den Pneumafluss mit sich bringen können und so sind es immer wieder Blinde, Impotente oder Entstellte, die aufgrund ihres körperlichen Mangels und ihres deformierten Körpers besondere Fähigkeiten bei der Steuerung von Phantasmen - etwa als Sänger, Seher, Magier oder Gelehrte ${ }^{29}$ - und das heißt bei der Beherrschung ihres eigenen Imaginationsapparates, entwickeln.

Dass gerade aufgrund dieser vielfältigen Entsprechungen von Körper und Wahrnehmung die bildliche oder literarische Darstellung deformierter Körper auch und gerade genutzt wird, um zur Reflexion über die einem Kunstwerk/Text selbst zugrunde liegenden epistemologischen Prämissen anzuregen, dürfte evident sein.

Die gemeinsame Betrachtung von Körperforschung und Wahrnehmungstheorie hat zunächst für die Betrachtung bildlicher oder textlicher Kunstwerke das Ziel, die Darstellung von deformierten Körpern neu in den Blick zu fassen: Die Rückwirkung der Bilder auf den Imaginationsapparat des Rezipienten, die Steuerung der Bilder durch Erzeugen von enérgeia seitens des Kunstschaffenden, bei denen den deformierten Körpern eine zentrale Stellung zukommt, all das sollte dazu führen, dass die verschiedenen pikturalen oder narrativen Körperdarstellun-

\footnotetext{
${ }^{24}$ PHILIPOWSKI, Der geformte [...] Körper, S. 71: „Ohne Körper kann sie [die Seele] nicht erkennen und nicht existieren, sie vergeht".

25 Vgl. ebd., S. 68.

26 Bumke, Die Blutstropfen; vgl. PHILIPOwsKi, Der geformte [...] Körper, S. 79.

27 Vgl. FeIstNer, Der Körper, S. 134.

${ }^{28}$ Ebd., Anm. 6; Fallbeispiele bei SCHREINER, Si homo non pecasset, S. 49, vgl. auch KERTH, Schreiende Kriegswunden.

${ }^{29}$ Vgl. ReICH, Verkrüppelte Helden; RIDDER, Gelehrtheit; ferner BRANDT, Die Beschreibung; KASTEN, Hässliche Frauenfiguren.
} 
gen nicht nur - wie dies vor allem in älteren Arbeiten etwa zu den mirabilia mundi, zu Riesen, Zwergen etc. immer wieder geschehen ist - motivgeschichtlich ausgewertet werden..$^{30}$ Natürlich kann das als Fremdartiges und dadurch als das ,Andere Erfahrene als verzerrtes Spiegelbildes des Eigenen oder als „Projektionsfläche“ eigener Wünsche dienen, ${ }^{31}$ und bereits so lassen sich aus den verschiedenen Textquellen anhand der dort vorgenommenen Stellungnahme zu den deformierten Wesen „differenzierte Wahrnehmungsmuster“ der mittelalterlichen Verfasser erschlieBen, ${ }^{32}$ aber wer die Wirkung deformierter Körper auf eine solch vereinfachte Hypothese der Selbstreflexivität reduziert, greift sicher zu kurz, wenn man insgesamt bedenkt, auf welche Weise durch die deformierten Wesen nicht nur „die eigenen kulturellen und epistemologischen Normen auf bedrohliche Weise in Frage" gestellt werden, ${ }^{33}$ sondern dass das Fremde darüber hinaus eine insgesamt epistemologisch (und physiologisch als solche fassbare) horizonterweiternde Funktion besitzt, der es gezielt nachzuspüren gilt.

Besonders wichtig scheint diese epistemologische Funktion, wie es das Eingangsbeispiel um Bernhard von Clairvaux bereits nahelegt, im Bereich der göttlichen Erkenntnis. Wieder greifen Körper und Wahrnehmung eng ineinander: Einerseits ist gerade die Erfahrung der eigenen Körperlichkeit zentrales Element religiöser Visions- und Erkenntnisprozesse, ${ }^{34}$ andererseits reizt der insbesondere deformierte Körper auch hier die Wahrnehmung: Gerade deformierte und groteske Körper spielen in der mönchischen Meditation eine bedeutende Rolle, ${ }^{35}$ aber auch überall dort, wo es insgesamt um Sichtbarmachung von Nicht-Sichtbarem und um ,Immanentmachung von Transzendentem geht. In Schwänken, ${ }^{36}$ Legendenerzählungen, ${ }^{37}$ ja in der Leidensgeschichte Christi selbst (als Urform einer Erzählung die an der Immanentwerdung des Transzendenten arbeitet) spielt die körperliche Deformation (bis hin zur Auflösung des Körpers) eine zentrale Rolle. Der deformierte Körper scheint nicht nur eine allgemeine wahrnehmungsstimu-

\footnotetext{
30 Vgl. etwa Ahrendt, Der Riese; Kappler, Monstres; Lecouteux, Les monstres; TARentul, Elfen, u. ä., sowie verschiedene Beiträge in dem Band Formes et difformités (BAYARD/GUILLAUME, Formes et difformités, bes. Guillaume, Dieu u. Thomasset, La cloche), und als Nachschlagewerke IZZI, Il Dizzionario u. MüLLER/WunderLICH, Dämonen. Ein Versuch sich von Motivuntersuchungen zu lösen, und Zwerge in ihrer metafiktionalen Funktion zu betrachten findet sich in: HABICHT, Der Zwerg. Dass diese motivgeschichtlichen Studien insgesamt natürlich nützlich und notwendig sind, um das Feld der verschiedenen Deformitäten abzustecken, steht außer Frage.

31 KoEBNER/Pickerodt, Der europäische Blick, S. 7.

32 MiтsCH, Körper als Zeichenträger, S. 76.

33 STEINICKE, Apokalyptische Heerscharen, S. 2.

34 LANGER, Die übersinnlichen Sinne, S. 83.

$35 \mathrm{Vgl}$. CARruthers, The Book of Memory, S. 137.

36 SCHEUER hat dies vor kurzem als ein zentrales Anliegen der mittelalterlichen Schwankliteratur plausibel gemacht (SCHEUER, Schwankende Formen) - und es dürfte kein Zufall sein, dass gerade dort, wo solche neuen Formen ,religiöser Kommunikation' zum Tragen kommen, eine derbe Körperlichkeit, die sich oft genug in Verstümmelungen oder Zerstückelungen niederschlägt, vorherrscht; vgl. Williams, Deformed Discourse.

37 ANTunes, Von bärtigen Prinzessinnen; BACHORSKI/KLINGER, Körper-Fraktur.
} 
lierende Funktion zu haben, sondern innerhalb des mittelalterlichen Wahrnehmungsmodells insbesondere den intellectus (als das Hirnventrikel der Gotteserkenntnis) zu stimulieren. ${ }^{38}$

Selbstverständlich hat es im Hoch- und Spätmittelalter kein einheitliches Körperkonzept, sondern nur partikulare Körperbilder innerhalb ganz verschiedener Diskurse gegeben. ${ }^{39}$ Dennoch ist der Versuch, die verschiedenen Diskurse in der gemeinsamen Betrachtung von Körperdeformation und Wahrnehmung zu bündeln, ein dringendes Anliegen dieser Tagung. Wenn hier zunächst vornehmlich künstlerische Darstellungen von Deformierten im Mittelpunkt der Betrachtung standen, so ist doch offenkundig, wie wichtig diese Thematik bei der Betrachtung der ,historischen Realität‘ ist. Deformierte - Missgebildete, Kriegsverstümmelte, durch Krankheit oder das Alter Entstellte - gehörten ja zum mittelalterlichen Lebensalltag $^{40}$ - wobei es auffällig ist, wie wenige Quellen sich z. B. über dauerhafte Kriegsverletzungen mittelalterlicher Adliger finden lassen: ${ }^{41}$ Ähnlich wie es auch in der Literatur der Zeit nur wenige deformierte Helden gibt, ${ }^{42}$ ja sich selbst die Beschreibung von Alterssymptomen ${ }^{43}$ oder schwerwiegender Krankheitssymptome eher selten finden lassen, ${ }^{44}$ wird auch in der Realität diese Problematik weitgehend ausgespart. ${ }^{45}$ Dass es Kriegsverstümmelte gegeben haben muss, lässt sich freilich nicht leugnen - interessant ist vielmehr der Umgang mit ihnen. KIENING konstatiert daher ein allgemeines mittelalterliches Desinteresse am Themenfeld der Kriegsversehrtheit und Krankheitsdeformation: „Als gefallener oder zerstückelter, beschädigter oder fragmentierter, zu heilender, zu kontrollierender oder zu neutralisierender ist der Körper primär Zeichen von Defizienz, nicht Quelle von Erfahrung. " ${ }^{66}$ Die These, dass der Körper aber nur als zeichenhafter interessant gewesen sei ,und nicht als konkret physischer, an dem die Mißlichkeiten des Alltags ihre Spuren hinterlassen " 47 verkürzt die mittelalterliche Körperdebatte um eine entscheidende Dimension: Sie legt dem vormodernen Körperdenken nämlich eine unausgesprochene Trennung von empirisch-medizinischer Erfahrungswissenschaft und zeichenhaftem Glaubenswissen zu Grunde,

\footnotetext{
38 Vgl. Camille, Before the Gaze, S. 198f.; Harvey, The Inward Wits, S. 43f.

39 Vgl. KIENING, Zwischen Körper und Schrift, S. 180.

${ }^{40}$ Vgl. den grundlegenden Sammelband von Nolte (Nolte, Homo debilis), sowie MeTZler, Disability u. Neumann, Der mißgebildete Mensch.

${ }^{41}$ Vgl. AugE, „So solt er [...]“. Das hängt natürlich grundlegend mit dem Adelsideal eines unversehrten Körpers zusammen. dass es aber im Mittelalter durchaus ein Problembewusstsein für den kranken Herrschaftskörper gegeben hat, belegen etwa folgende Aufsätze: HIESTAND, Kranker König; Jordan, Hoffnungslos siech; KeHnel, Defizienz; Mitcheld, Leprosy.

42 Vgl. HARTung, Von Dórolfr Höllenhaut; KERTH, Versehrte Körper; REICH, Verkrüppelte Helden.

43 Am prominentesten ist sicher der alternde Titurel in Wolframs gleichnamigen Werk, andere Beispiele auch bei GOLLER, „die jungen [...]“; vgl. außerdem Multrus, Voraussetzungen; MERTENS, Alter als Rolle.

44 Vgl. TOMASEK, Kranke Körper, S. 97.

45 Vgl. Auge, ,So solt er [...]“.

46 KIENING, Zwischen Körper und Schrift, S. 180.

47 Ebd., S. 181.
} 
wohingegen für das Mittelalter hier überhaupt keine strikte Trennung zu verzeichnen ist. Autobiographische Selbstzeugnisse von Krankheitsgeschichten ${ }^{48}$ findet man im Mittelalter durchaus genauso, wie ein ausgeprägtes Interesse an Pflegeeinrichtungen, so dass insgesamt ein differenzierter Umgang mit Kranken zu beobachten ist. ${ }^{49}$ Diese Diskurse und Schilderungen dürfen aber nicht von der Zeichen- und Wahrnehmungsthematik abgetrennt werden. Denn gerade hier stellt sich die Frage, wie sich auch an den ,realen' Körpern Wahrnehmungsprozesse entzünden oder auf andere Art fassbar werden. Dabei ist zum einen zu untersuchen, inwieweit Deformationen auch in der Realität als zeichenhaft wahrgenommen wurden (dies dürfte nicht nur bei relativ bekannten Fällen wie Missgeburten, sondern etwa auch in Selbstzeugnissen bei Krankheitsfällen u. ä. fassbar werden), zum anderen, ob auch in der Realität bestimmte Deformationen als mit einer spezifischen imaginativen Eignung korrelierend aufgefasst wurden: So wie in der Literatur die blinden Sänger und Seher oder die impotenten Magier eine besondere Macht über ihre inneren Bildprozesse erlangen, wäre zu fragen, ob derartige Fähigkeiten auch ,historischen' deformierten Personen unterstellt wurden..$^{50}$

Die Art der Deformation schien in dieser bisherigen Umkreisung des Feldes Wahrnehmung-Körper-Deformation zunächst zweitrangig zu sein - jede Abweichung hat prinzipiell einen bestimmten imaginationsreizenden Wert. Tatsächlich dürfte es aber durchaus einen Unterschied machen, ob es sich um eine echte Deformation, im Sinne einer Gestaltauflösung, um eine Formverzerrung, um eine fremdartige Formkombinationen (mirabilia mit Hundeköpfen) oder um Formverkürzungen (Kriegsverletzungen, Verstümmelungen) handelt. Der Zeichencharakter der verschiedenen Deformationsarten dürfte ein jeweils anderer sein, wobei insgesamt die Zeichenhaftigkeit der verschiedenen Deformationen, wie in einer topisch (auf die argumentative Fülle zielenden) geprägten Denkkultur nicht anders zu erwarten, durchaus vielfältig ist: Eine Missgeburt etwa kann sowohl als Zeichen für allgemeines Unheil, ${ }^{51}$ für Verfehlungen der Eltern, ${ }^{52}$ aber auch schlicht als medizinisches Problem angesehen werden. ${ }^{53}$ Einfache Zuschreibungen im Sinne von ,Deformation X bedeutet $Y^{\prime}$ lassen sich, gerade weil so vielfältige Diskurse in der Körper- und Wahrnehmungsforschung zusammenlaufen, verständlicherweise nicht machen. Was der Sammelband daher bietet und auch nur bieten kann, ist eine Auswahl an konkreten Einzelfällen, die in ihrer Gesamtheit freilich Anteil daran haben sollen, als Exempel einer so zu umgrenzenden copia an Möglichkeiten zu

\footnotetext{
48 Vgl. dazu den Beitrag von Frohne im Folgeband (Frohne, Signifikante Körper).

49 Vgl. Irsigler, Mitleid; Multrus, Voraussetzungen; Stanislaw-Kemenah, Von der Hand Gottes berührt; WALTER, „utiliter servire non possunt“, sowie allgemein HERZLICH/PIERRET, Kranke gestern.

${ }^{50}$ So ließe sich etwa die Frage stellen, ob die ,Abschiebung' von Krüppeln u. ä. in Klöster, tatsächlich nur auf eine Ausgliederung aus der Gesellschaft abzielte, oder ob dabei zusätzlich eine postulierte besondere Eignung der Deformierten für die Erkenntnis des Göttlichen zum Tragen kam.

${ }^{51}$ DASTON/PARK, Wonders; LOCHER, Zur Zeichenstruktur; RÖCKE, Erdrandbewohner.

52 LeCOUTEUX, Les monstres, S. 171ff.

${ }^{53}$ FIsCHER, De la genèse; LECOUTEux, Les monstres, S. 207ff.; ZÜRCHER, Monster.
} 
dienen. Die verschiedenen Beispiele sind daher auch bewusst aus unterschiedlichen Fachdisziplinen gewählt - Literaturwissenschaft und Kunstgeschichte, Dis/Ability Studies, Geschichtswissenschaft und Textphilologie kommen gleichermaßen zu Wort.

Eröffnet wird der Tagungsband mit dem Beitrag von VOLKER SCIOR zu den monstra, die in der Forschung bereits weitläufige Beachtung gefunden haben, wobei aber häufig ihr zentraler Aspekt der Wahrnehmungserweiterung und -reizung unbeachtet bleibt. SCIOR zeigt, mit Blick auf die philosophisch-theologische Debatte, wie schon seit der Spätantike mit den monstra gerungen wurde, wie immer wieder die Frage nach ihrer Sonderstellung innerhalb des göttlichen Kosmos und die damit einhergehende Aufgabe des Menschen, die monstra im Hinblick auf den göttlichen Willen zu deuten, gestellt wurde. Hinsichtlich der ontologischen Frage, ob diesen monströsen Wesen menschlicher Status zugeschrieben oder abgesprochen wird, zeigt sich der Unterschied zwischen Einzelerscheinungen (wie z. B. Missgeburten) und Völkerschaften: Obwohl beide vergleichbare Deformationen und Körperzeichen aufweisen, werden hier eklatante Unterschiede in ihrer epistemologischen Funktion deutlich.

EVA BOLTA beschäftigt sich in ihrem Beitrag mit chimärischen Hybridwesen innerhalb der mittelalterlichen Literatur: Der Formhybrid wird innerhalb der Wahrnehmungsphysiologie des Mittelalters als Beispiel für die Bilder verbindende Kraft der ratio aufgeführt: Auch wer nie den Pegasus gesehen hat, kann ihn sich (zusammengesetzt aus den Bildern/imagines des Pferdes und der Flügel) vorstellen. Dass gerade die Eindrücklichkeit solch kombinierter Körpercluster genutzt wird, um enérgeia zu erzeugen, ist, wie BOLTA anhand der Gralsbotin Cundrîe, dem Drachen Pfêtan im Wigalois und dem Boten des Königs Piure aus der Crône zeigt, kein Zufall, treten diese seltsamen Mischwesen doch stets an Schlüsselstellen der Texte auf und besitzen somit eine doppelte Funktion: Während sie einerseits als Wanderer zwischen den Welten (und dies nicht zufällig zwischen tierischunzivilisierter, höfisch-menschlicher und heilsorientiert-göttlicher Welt) den Wahrnehmungshorizont des Protagonisten erweitern, dienen sie gleichzeitig dem Rezipienten in ihrer imaginationsstimulierenden Funktion dazu, bestimmte Textmomente hervorzuheben.

Dass deformierte Wesen solche Schlüsselstellen markieren, nimmt auch PETER ANDERSEN-Vinilandicus zum Anlass, die verschiedenen Fassungen des Alexanderstoffes im Mittelalter anhand der Episode von der babylonischen Missgeburt zu vergleichen. Obgleich es sich im Corpus der Alexanderabenteuer um eine kurze und nahezu unscheinbare Passage handelt, zeigt sich doch bei näherem Hinsehen, wie gerade diese Episode von den verschiedenen Autoren immer wieder neu bearbeitet wurde: In den seltsamen Tierköpfen der Missgeburt werden dabei im einen Fall Verweise auf die lateinische Erzählung der Scylla, in anderen Fällen heilsgeschichtliche Konnotationen deutlich. Und auch Alexanders Umgang mit der Missgeburt und der ihr inhärenten Deutungsmöglichkeiten ist von Text zu Text ein immer wieder anderer, so dass sich die Episode um den deformierten Körper 
der babylonischen Missgeburt als eine zentrale Schnittstelle zwischen den verschiedenen Alexandererzählungen entpuppt.

Eine ganz andere Fragestellung verfolgt CARMEN STANGE, wenn sie sich mit dem Thema der Selbstverstümmelung anhand von Herrands von Wildonîe Treuer Gattin beschäftigt: Als der Gatte der Protagonistin im Kampf ein Auge verliert, wagt er sich nicht mehr nach Hause, woraufhin sich seine Gattin ebenfalls ein Auge aussticht, um das höfische Gleichgewicht zwischen beiden Eheleuten wieder herzustellen und ihrem Mann ihre Liebe zu signalisieren. Dabei geht es aber, wie STANGE plausibel macht, nicht nur um die Aufrechterhaltung der höfischen mâze, sondern vielmehr, und Herrand führt dies geschickt am Thema des verlorenen Auges als dem zentralen Wahrnehmungsorgan vor, um die Diskussion zweier konkurrierender Wahrnehmungsmodelle: Während der Ehemann sich an den äußeren Augenschein hält, verweist die Handlung der Gattin auf das richtige Sehen mit den oculi cordis - und während seine Wertvorstellungen einer von der aristotelischen Epistemologie beeinflussten Rationalität folgen, richtet sich das Handeln der Gattin implizit am augustinischem Denkmodell aus. Der deformierte Körper wird hier zum Brennpunkt verschiedener Wahrnehmungsmodelle.

LOLA KING widmet sich der Untersuchung des Werks des französischen Dichters Eustache Deschamps (1345-1404) aus historischer Perspektive. Deschamps, der vor allem für seine kritische Gesellschaftsbeobachtung bekannt geblieben ist, nimmt dabei mehrfach auf das Leben und die Existenz von Bettlern Bezug. KING liest diese literarischen Berichte als Zeugnis für die Erkenntnis der Funktion ,marginaler Körper' in der spätmittelalterlichen Gesellschaft. In der Identifizierung der Stellung von Missgebildeten, Kranken und Randfiguren in Deschamps' Darlegungen, gelingt es ihr, eine Parallele zur Situation der Bettler im Frankreich des 14. Jahrhunderts zu ziehen. Die Schilderung und Beschreibung der deformierten Körper bei Deschamps wird so zum epistemischen gesellschaftskritischen Reizpunkt für die adligen Zuhörer.

Auch NIKOLETTA GIANTSI befasst sich mit dem Phänomen historischer Krankheitssymptome, wobei sie sich auf eine der im Hinblick auf die Deformation des menschlichen Körpers markantesten Krankheiten des Mittelalters beschränkt: den Aussatz. Da man im Mittelalter in ständigem Kontakt mit der Realität dieser Krankheit stand, lässt sich anhand von Darstellungen Aussätziger in Kunst und Literatur die Wahrnehmung des ,nahen Anderen', dessen Trennung gegenüber dem Eigenen eben durch die Krankheit skizziert wird, herausarbeiten. GIANTSI zeichnet die Entwicklung der Bewertung dieser Krankheit nach, die nicht nur die medizinische Aspekte, wie etwa mögliche Behandlungstherapien, betrifft, sondern mit einem grundlegenden Wandel in der Beurteilung körperlicher Abnormitäten einherschreitet.

In einem grundlegenden Beitrag zu den Dis/Ability Studies diskutiert SARAH HARMS ein entscheidendes Problem, dass sich jedem modernen Rezipienten bei der Beschäftigung mit den Bildwerken deformierter Körper stellt und legt so das Fundament für die kunstgeschichtlichen Beiträge des Bandes: Bei der Suche nach 
,Behinderten` auf mittelalterlichen Kunstwerken zeigt sich, dass hier keineswegs die Darstellung des deformierten Körpers von primärer Bedeutung ist: Wichtiger scheinen äußere Attribute, wie Fußschemel oder Krücken, die von den ,Behinderten' ähnlich wie die Attributsgegenstände von Heiligen getragen werden. Obwohl sich, wie HARMS Vergleich zwischen mittelalterlichem und neuzeitlichem Bildmaterial zeigt, durchaus traditionelle Linien in der Darstellung von ,Behinderung ' erkennen lassen, ist es nicht immer zweifelsfrei möglich, die Darstellung eines ,Behinderten' tatsächlich als solche zu erkennen. Darin wird ein Problem in der Wahrnehmung Deformierter ersichtlich: Im Mittelalter fehlt eine adäquate Begrifflichkeit, die unserem modernen Begriff ,Behinderung' entspräche, und diese begriffliche Alterität spiegelt sich, wie HARMS eindrücklich vor Augen führt, auch in den mittelalterlichen Bildwerken wider.

Auch KATRIN WELEDA geht es um die Darstellung verstümmelter Körper. In ihrem Beitrag steht das Sujet der Enthauptung im Mittelpunkt des Interesses. Die Darstellung abgeschlagener Häupter, wie etwa dem Holofernes' oder Johannes des Täufers, soll durch ihre evidenzialisierende Drastik die Wahrnehmung des Betrachters reizen, um ihn letztlich einen Weg zur Gotteserkenntnis zu weisen. Die Art und Weise, wie dabei die abgeschlagenen Häupter dem Rezipienten präsentiert werden - Blutüberströmt, auf der Schnittfläche liegend oder diese wie eine schwärende Wunde vor sich her tragend -, all das ist, wie WELEDA deutlich macht, Teil einer ausgeklügelten Bildrhetorik.

Abgeschlossen wird der Band von VesselinA VATCHKOVA, die eine ganz andere Art der Deformierung des Hauptes präsentiert. In ihrem Beitrag geht es um unterschiedliche Darstellungsformen einer besonders in der orthodoxen Welt beliebten Figur: die des Hl. Christophorus. Als Kynocephale und Wolfskopf ist der Heilige, der zudem häufig als Riese auftaucht, eine der interessantesten Heiligenfiguren des christlichen Mittelalters. Dabei wurden mehrmals Versuche unternommen, die Abnormitäten des Heiligen zu tilgen umso im Laufe der Zeit eine neue, der rationalen Logik der Gegenwart besser anpassbare Figur zu schaffen, und es scheint, dass der monströse Heilige seine Stelle in der gegenwärtigen christlichen Tradition nur nach einem starken Entpersonalisierungsprozess sichern kann. Für die mittelalterlichen Darstellungen hingegen lässt sich gerade in der orthodoxen Kirche zeigen, dass es gerade die (auch körperliche) Vielschichtigkeit des Heiligen ist, der seine hohe Beliebtheit gewährleistete. 


\section{Literatur}

Bernhard von Clairvaux, Opera. Hrsg. v. JEAN LECLERQ. Rom 1957.

Rhetorica ad Herennium. Hrsg. und übersetzt von THEODOR NÜßLEIN. Zürich 1994.

\section{Forschung}

ACKERMANN, CHRISTIANE, Im Spannungsfeld von Ich und Körper. Subjektivität im ,Parzival' Wolframs von Eschenbach und im ,Frauendienst' Ulrichs von Liechtenstein. Köln u. a. 2009.

Agamben, Giorgio, Homo sacer. Die souveräne Macht und das nackte Leben. Frankfurt a. M. 2002.

DERS., Stanzen. Das Wort und das Phantasma in der abendländischen Kultur. Berlin/Zürich 2005.

ANDERGassen, LEO, Laster und Tugend. Babylon und Jerusalem. Die spätromanischen Fresken in der Frauenkirche in Brixen. In: Südtirol in Wort und Bild 45, 4 (2001), S. 35-40.

ANDERsEn, JørGEN, The Witch on the Wall. Medieval Erotic Sculpture in the British Isles. Kopenhagen 1977.

ANTUNES, GABRIELA, Entstellte Schönheiten: Überlegungen zum mittelalterlichen Bezug zwischen Hässlichkeit des Körpers und Schönheit der Seele. Erscheint in: ANTUNES, GABRIELA u. REICH, BJÖRN (Hrsg.), (De)formierte Körper, die Wahrnehmung und das Andere im Mittelalter 2, voraussichtlich Göttingen 2012.

DIES., Von bärtigen Prinzessinnen, wilden Weiber und Hermaphroditen. Geschlechtstäuchung in einigen mittelalterlichen Quellen. In: BUSCHINGER, DANIELLE (Hrsg.) Erotisme et Sexualité. Actes du Colloque International des 5, 6 et 7 mars 2009 à Amiens (Médiévales 47). Amiens 2009, S. 9-16.

AHREndt, ERnst HeRwig, Der Riese in der mittelhochdeutschen Epik. Diss. Rostock 1923.

AUGE, OLIVER, „So solt er im namen gottes mit mir hinfahren, ich were doch verderbt zu einem kriegsmann" - Durch Kampf und Turnier körperlich versehrte Adlige im Spannungsfeld von Ehrpostulat und eigener Leistungsfähigkeit. In: Medizin, Gesellschaft und Geschichte 28 (2009/2010), S. 21-46.

BACHORSKI, HANS-JÜRGEN u. KLINGER, BACHORSKI, Körper-Frakturen und herrliche Marter; Zu mittelalterlichen Märtyrerlegenden. In: RIDDER, KLAUS u. LANGER, OTTO (Hrsg.), Körperinszenierung in Mittelalterlicher Literatur; Kol- 
loquium am Zentrum für interdisziplinäre Forschung der Universität Bielefeld 18. bis 20. März 1999 (Körper, Zeichen, Kultur 11). Berlin 2002, S. 309-333.

Bayard, Florence u. Guillaume, Astrid (Hrsg.), Formes et difformités médiévales. Un hommage à Claude Lecouteux. Paris 2010.

BERNS, JÖRG JOCHEN, Film vor dem Film. Bewegende und bewegliche Bilder als Mittel der Imaginationssteuerung in Mittelalter und Früher Neuzeit. Marburg 2000.

BRANDT, Wolfgang, Die Beschreibung hässlicher Menschen in höfischen Romanen; Zur narrativen Integrierung eines Topos. In: GRM 35 (1985), S. 257278.

Brinkmann, Hennig, Zu Wesen und Form mittelalterlicher Dichtung. Darmstadt 21979.

BumKe, JOACHIM, Die Blutstropfen im Schnee. Über Wahrnehmung und Erkenntnis im ,Parzival' Wolframs von Eschenbach. Tübingen 2001.

BusChinger, DANiELLE, L'homme laid dans la littérature médiévale allemande. Un exemple: le Ackerkneht dans la Couronne de Heinrich von dem Türlin (1230). In: Le beau et le laid au Moyen Âge. Senefiance 43. Aix-en-Provence 2000, S. 57-66.

Camille, Michael, Before the Gaze. The Internal Senses and Late Medieval Practices of Seeing. In: NeLSON, ROBERT S. (Hrsg.), Visuality before and beyond the Renaissance; Seeing as Others Saw. Cambridge 2000, S. 197-223.

CAROFF, FANNY, Laideur, monstruosité et altérité physique dans les chroniques illustrées des croisades. In: Caiozzo, Anna u. Demartini, Anne-EmmaNUELLE (Hrsg.), Monstre et imaginaire social. Approches historiques. Paris 2008, S. 28-45.

CARruthers, Mary J., The Book of Memory. A Study of Memory in Medieval Culture. Cambridge 1990.

CURTIUS, ERNST ROBERT, Europäische Literatur und lateinisches Mittelalter. Bern/München ${ }^{31961 . ~}$

CZERWINSKI, PeTER, Gegenwärtigkeit. Simultane Räume und zyklische Zeiten, Formen von Regeneration und Genealogie im Mittelalter Exempel einer Geschichte der Wahrnehmung 2. München 1993.

Daston, Lorraine u. Park, Katherine, Wonders and the Order of Nature 1150-1750. New York 1998.

Dietheuer, Franz, Das Programm der Apsisfresken in St. Jakob zu Kastelaz ob Tramin. In: Der Schlern 65 (1991), S. 307-330. 
Dinzelbacher, Peter, Mensch und Tier in der Geschichte Europas. Stuttgart 2000.

DÜRIEGL, URSUlA, Die Fabelwesen von St. Jakob in Kastelaz bei Tramin. Romanische Bilderwelt antiken und vorantiken Ursprungs. Wien 2003.

FEISTNER, EDITH, Der Körper als Fluchtpunkt: Identifikationsprobleme in geistlichen Texten des Mittelalters. In: BenNewitz, INGRID u. TERvoOrEN, HeLMUT (Hrsg.), Manlîchiu wîp, wîplîch man. Zur Konstruktion der Kategorien „Körper' und ,Geschlecht' in der deutschen Literatur des Mittelalters. Internationales Kolloquium der Oswald von Wolkenstein-Gesellschaft und der Gerhard-Mercator-Universität Duisburg, Xanten 1997 (Beihefte zur ZfdPh 9). Berlin 1999, S. 131-142.

FISCHER, JEAN-LOUIS, De la genèse fabuleuse à la morphogénèse des monstres (Cahiers d'Histoire et de Philosophie des Sciences). Paris 1986.

FreitAG, BARBARA, Sheela-Na-Gigs: Unravelling an Enigma. London 2004.

Friedman, JOHN Block, The Monstrous Races in Medieval Art and Thought. Cambridge 1981.

FrOHNE, BIANCA, Signifikante Körper: Die Rede und das Wissen von körperlicher Deformation in spätmittelalterlichen Selbstzeugnissen. Erscheint in: ANTUNES, GABRIELA u. REICH, BJÖRN (Hrsg.), (De)formierte Körper, die Wahrnehmung und das Andere im Mittelalter 2, voraussichtlich Göttingen 2012.

FUnK, JUlikA u. BRÜCK, CORNELIA (Hrsg.), Körper-Konzepte. Tübingen 1999.

Geisthardt, CONSTANZE, Die Potenzialität des Monströsen. Zum medialen Verhältnis von impliziter Poetik und Text im Wilhelm von Österreich von Johann von Würzburg. In: GEBHARD, GUNTHER u. a. (Hrsg.), Von Monstern und Menschen. Begegnungen der anderen Art in kulturwissenschaftlicher Perspektive. Bielefeld 2009, S. 31-46.

GOLLER, DETLEF, „die jungen zir gelîchen, die alten zuo den alten“. Der Platz alter Menschen in der höfischen Literatur. In: NOLTE, CORDUlA (Hrsg.), Homo debilis. Behinderte - Kranke - Versehrte in der Gesellschaft des Mittelalters (Studien und Texte zur Geistes- und Sozialgeschichte des Mittelalters 3). Korb 2009, S. 149-163.

GoutTebroze, JeAn-Guy, La laide demoiselle du Conte du Graal. Le chant du deuil de la terre. In: Le beau et le laid au Moyen Âge. Senefiance 43. Aix-enProvence 2000, S. 177-184.

GRÜN, ClEMENS, gestus, gesta, gesticulatio. Gesten und ihre Klassifizierung anhand von Hugo von St. Victors ,De institutione novitiarum'. Studienarbeit. In: www.hausarbeiten.de/faecher/vorschau/107738.html\#inside (letzter Zugriff: 5.5.2011). 
GuILLAUME, ASTRID, Dieu, le diable et les loups/garous. Sémiotique des répresentations médiévales. In: BAYARD, FlORENCE u. GUILLAUME, Astrid (Hrsg.), Formes et difformités médiévales. Un hommage à Claude Lecouteux. Paris 2010, S. 205-220.

HABICHT, ISABEL, Der Zwerg als Träger metafiktionaler Diskurse in deutschen und französischen Texten des Mittelalters (GRM-Beihefte 38). Heidelberg 2010.

HABICHT, ISABEL u. REICH, BJÖRN, Die Farbe der Erinnerung. Erscheint beim Deutschen Mediävistenverband, voraussichtlich 2011.

HARMs, Wolfgang u. JAEger, C. StePhen (Hrsg.), Fremdes wahrnehmen fremdes Wahrnehmen. Studien zur Geschichte der Wahrnehmung und zur Begegnung von Kulturen in Mittelalter und früher Neuzeit. Stuttgart/Leipzig 1997.

HARTUNG, HendrikJE, Von Porolfr Höllenhaut ist das zu erzählen, dass er in schlechtem Rufe stand: Zur Wahrnehmung deformierter Körper in der altnordischen Sagaliteratur. Erscheint in: ANTUNES, GABRIELA u. REICH, BJÖRN (Hrsg.), (De)formierte Körper, die Wahrnehmung und das Andere im Mittelalter 2, voraussichtlich Göttingen 2012.

Harvey, E. Ruth, The Inward Wits. Psychological Theory in the Middle Ages and the Renaissance. London 1975.

HerZlich, Claudine u. Pierret, Janine (Hrsg.), Kranke gestern, Kranke heute. Die Gesellschaft und das Zeichen. München 1991.

Hiestand, Rudolf, Kranker König - Kranker Bauer. In: WunderLI, PeTER (Hrsg.), Der kranke Mensch in Mittelalter und Renaissance. Düsseldorf 1986, S. 61-77.

HÜBLER, AxEL, Das Konzept ,Körper' in den Sprach- und Kommunikationswissenschaften. Bern/München 2000.

IRSIGLER, FRANZ, Mitleid und seine Grenzen. Zum Umgang der mittelalterlichen Gesellschaft mit armen und kranken Menschen. In: NOLTE, CORDULA (Hrsg.), Homo debilis. Behinderte - Kranke - Versehrte in der Gesellschaft des Mittelalters (Studien und Texte zur Geistes- und Sozialgeschichte des Mittelalters 3). Korb 2009, S. 165-183.

IZZI, MASsIMO, Il Dizzionario illustrato dei Mostri. Angeli, diavoli, orchi, draghi, sirene e altre creature dell'imaginario. Rom 1989.

JORDAN, GESINE, Hoffnungslos siech, missgestaltet und untüchtig? Kranke Herrscher und Herrschaftsanwärter in der Karolingerzeit. In: NOLTE, CORDULA (Hrsg.), Homo debilis. Behinderte - Kranke - Versehrte in der Gesellschaft 
des Mittelalters. (Studien und Texte zur Geistes- und Sozialgeschichte des Mittelalters 3). Korb 2009, S. 245-262.

KantorowicZ, ERnst H., Die zwei Körper des Königs. Eine Studie zur politischen Theologie des Mittelalters. München 1990.

Kappler, Claude, Monstres, démons et merveilles à la fin du Moyen Âge. Paris 1981.

KASTEN, INGRID, Hässliche Frauenfiguren in der Literatur des Mittelalters. In: LUNDT, BEA (Hrsg.), Auf der Suche nach der Frau im Mittelalter. Fragen, Quellen, Antworten. München 1991, S. 255-276.

KEHNEL, ANNETTE, Defizienz und Zivilisationsprozess. Überlegungen zur ,Macht der Schwäche' am Beispiel des kranken Königs Hiskia auf der Wiener reichskrone. In: NolTe, CORDulA (Hrsg.), Homo debilis. Behinderte - Kranke Versehrte in der Gesellschaft des Mittelalters. (Studien und Texte zur Geistesund Sozialgeschichte des Mittelalters 3). Korb 2009, S. 263-290.

KELLERMANN, KARINA, Entstellt, verstümmelt, gezeichnet. Wenn höfische Körper aus der Form geraten. In: DENNELER, IRIS (Hrsg.), Die Formel und das Unverwechselbare. Interdisziplinäre Beiträge zu Topik, Rhetorik und Individualität. Frankfurt a. M. 1999, S. 39-58.

DIES., Die körperliche Inszenierung des Königs: ein mittelalterliches Kulturmuster. In: Kultur Poetik 1 (2001), S. 159-181.

Kelly, EAmonn, Sheela-Na-Gigs: Origin and Functions. Dublin 1985.

KEMP, WOLFGANG, Memoria, Bilderzählung und der mittelalterliche Esprit de Système. In: HAVERKAMP, ANSElm u. LACHMANN, RENATE (Hrsg.), Memoria. Vergessen und Erinnern. Poetik und Hermeneutik. Arbeitsergebnisse der Forschungsgruppe 15. München 1993, S. 263-282.

KERTH, SONJA, Schreiende Kriegswunden. Darstellungen kriegsbedingter Traumatisierung in mittelalterlicher heroischer Dichtung. Erscheint in: ANTUNES, GABRIELA u. REICH, BJÖRN (Hrsg.), (De)formierte Körper, die Wahrnehmung und das Andere im Mittelalter 2, voraussichtlich Göttingen 2012.

DIES., Versehrte Körper - vernarbte Seelen. Konstruktionen kriegerischer Männlichkeit in der späten Heldendichtung. In: ZfGerm N.F. 12 (2002), S. 262-274.

KIENING, CHRISTIAN, Anthropologische Zugänge zur mittelalterlichen Literatur. Konzepte, Ansätze, Perspektiven. In: SCHIEWER, HANS-JOCHEN (Hrsg.), Forschungsberichte zur Germanistischen Mediävistik, Bd. 5, 1. Bern/Frankfurt a. M. 1996, S. 11-129.

DERS., Zwischen Körper und Schrift. Texte vor dem Zeitalter der Literatur. Frankfurt a. M. 2003 
Koebner, Thomas u. Pickerodt, Gerhart, Der europäische Blick auf die andere Welt. Ein Vorwort. In: DIES., Die andere Welt. Studien zum Exotismus. Berlin 2000, S. 7-9.

KRÜGER, KLAUS (Hrsg.), Curiositas. Welterfahrung und ästhetische Neugierde in Mittelalter und früher Neuzeit. Göttingen 2002.

LABBE, ALAIN, Une grande âme en un corps disgracié. La laideur du héros dans la Chanson de Bertrand du Guesclin. In: Le beau et le laid au Moyen Âge. Senefiance 43. Aix-en-Provence 2000, S. 263-277.

LANGER, OTTO, Die übersinnlichen Sinne. In: RIDDER, KLAUS u. LANGER, OTTO (Hrsg.), Körperinszenierungen in mittelalterlicher Literatur. Kolloquium am Zentrum für interdisziplinäre Forschung der Universität Bielefeld (18. bis 20. März 1999). Berlin 2002, S. 175-192.

LECHTERMANN, CHRISTINA, Berührt werden. Narrative Strategien der Präsenz in der höfischen Literatur um 1200 (Philologische Studien und Quellen 191). Ber$\operatorname{lin} 2005$.

Lecouteux, Claude, Les monstres dans la littérature allemande du Moyen Âge. Göppingen 1982.

LIENERT, ELISABETH, Der Körper des Kriegers. Erzählen von Helden in der ,Nibelungenklage‘. In: ZfdA 130 (2001), S. 127-142.

LINDEN, SANDRA, Körperkonzepte jenseits der Rationalität. Die Herzenstauschmetaphorik im Iwein Hartmanns von Aue. In: WOLFZETTEL, FRIEDRICH (Hrsg.), Körperkonzepte im arthurischen Roman. Tübingen, 2007, S. 247-268.

LOBSIEN, VERENA OLEJNICZAK u. LOBSIEN, ECKHARD, Die unsichtbare Imagination. Literarisches Denken im 16. Jahrhundert. München 2003.

LOCHER, ELMAR, Zur Zeichenstruktur des monströsen Körpers. In: VAVRA, ELISABETH (Hrsg.), Bild und Abbild vom Menschen im Mittelalter. Klagenfurt 1999, S. 253-269.

MAREK, Kristin, Die Körper des Königs. Effigies, Bildpolitik und Heiligkeit. München 2009.

MARTIN, ERNEST, Histoire des monstres depuis l'Antiquité jusqu'à nos jours. Précédé de Le désenchantement des monstres par JEAN-JACQUES COURTINE. Grenoble 2002.

MCMAHON, JOANNE u. ROBERTS, JACK, The Sheela-na-gigs of Ireland and Britain: the Divine hag of the Christian Celts. An Illustrated Guide. Cork 2001.

Mertens, VOLKER, Alter als Rolle. Zur Verzeitlichung des Körpers im Minnesang. In: PBB 128 (2006), S. 409-430. 
Metzger, Wolfgang, Die Apsisfresken von St. Jakob in Kastelaz. In: Der Schlern 44 (1970), S. 200-222.

METZLER, IRINA, Disability in Medieval Europe: Thinking about physical impairment during the High Middle Ages, c. 1100-1400. New York 2006.

MiCHEL, PAUL, Formosa Deformitas. Bewältigungsformen des Hässlichen in mittelalterlicher Literatur (Studien zur Germanistik, Anglistik und Komparatistik 57). Bonn 1976, S. 27-65.

MitCHELL, PIERS D., Leprosy and the case of King Baldwin IV. of Jerusalem: Mycobacterial disease in the crusader states of the 12th and 13th centuries. In: Journal of Leprosy 61 (1993), S. 283-291.

MiTSCH, RALF, Körper als Zeichenträger kultureller Alterität. Zur Wahrnehmung und Darstellung fremder Kulturen in mittelalterlichen Quellen. In: KRAUSE, BURKHARDT (Hrsg.), Fremdkörper - Fremde Körper - Körperfremde. Kultur- und literaturgeschichtliche Studien zum Körperthema (Helfant-Studien S9). Stuttgart 1992, S. 73-109.

Mode, HeINZ, Fabeltiere und Dämonen. Die phantastische Welt der Mischwesen. Leipzig 21977.

MÜLLER, JAN-DIRK, Curiositas und erfarung der Welt im frühen Prosaroman. In: LUDGER GRENZMANN u. KARL STACKMANN (Hrsg.) Literatur und Laienbildung im Spätmittelalter und in der Reformationszeit. Symposion Wolfenbüttel 1989. Stuttgart 1984, S. 252-271.

MÜller, UlriCH u. Wunderlich, Werner (Hrsg.), Dämonen, Monster, Fabelwesen (Mittelalter Mythen 2). St. Gallen 1999.

MulTRUS, DiRK, Voraussetzungen und Möglichkeiten der Versorgung alter Menschen in den deutschen Landen im späten Mittelalter. In: HERMANN-OTTO, ELISABETH (Hrsg.), Die Kultur des Alterns von der Antike bis zur Gegenwart. St. Ingbert 2004, S. 33-62.

NeUmanN, JOSEF, Der mißgebildete Mensch. Gesellschaftliche Verhaltensweisen und moralische Bewertungen von der Antike bis zur frühen Neuzeit. In: HAGNER, MiCHAEL (Hrsg.), Der falsche Körper. Beiträge zu einer Geschichte der Monstrositäten. Göttingen 1995, S. 21-44.

Nolte, Cordula (Hrsg.), Homo debilis. Behinderte - Kranke - Versehrte in der Gesellschaft des Mittelalters (Studien und Texte zur Geistes- und Sozialgeschichte des Mittelalters 3). Korb 2009.

PERRIG, ALEXANDER, Erdrandsiedler oder die schrecklichen Nachkommen Chams: Aspekte der mittelalterlichen Völkerkunde. In: KOEBNER, THOMAS u. PICKERODT, GERHART, Die andere Welt. Studien zum Exotismus. Berlin 2000, S. 31-87. 
PHILIPOWSKI, KATHARINA, Der geformte und der ungeformte Körper. Zur ,Seele“ literarischer Figuren im Mittelalter. In: ZfdPh 123 (2004), S. 67-86.

REICH, BJÖRN, Der Mythos und die Zahl - Evidenz und Reflexion im Trojaroman Herborts von Fritzlar. In: GEBERT, BENT u. MAYER, UwE (Hrsg.), Mythos Zwischen Präsenz und Repräsentation. Erscheint voraussichtlich 2011.

DERS., Name und maere. Eigennamen als narrative Zentren mittelalterlicher Epik (Studien zur Historischen Poetik 8). Heidelberg 2011.

DERS., Verkrüppelte Helden, impotente Magier, kampfunfähige Liebhaber. Erscheint in: ANTUNES, GABRIELA u. REICH, BJÖRN (Hrsg.), (De)formierte Körper, die Wahrnehmung und das Andere im Mittelalter 2, voraussichtlich Göttingen 2012.

REICHARDT, GERD, De homine et portentis - die Apsismalereien von St. Jakob bei Tramin. Erscheint in: LOCHER, ElmAR u. SCHEUER, HANS-JÜRGEN (Hrsg.), Archäologie der Phantasie. Erscheint voraussichtlich Bozen 2011.

RIDDER, KLAUS, Gelehrtheit und Häßlichkeit im höfischen Roman. In: RIDDER, KLAUS u. LANGER, OTTO (Hrsg.), Körperinszenierungen in mittelalterlicher Literatur. Kolloquium am Zentrum für interdisziplinäre Forschung der Universität Bielefeld (18. bis 20. März 1999). Berlin 2002, S. 75-95.

RIDDER, KLAUS u. LANGER, OTTO (Hrsg.), Körperinszenierungen in mittelalterlicher Literatur. Kolloquium am Zentrum für interdisziplinäre Forschung der Universität Bielefeld (18. bis 20. März 1999). Berlin 2002.

RÖCKE, WERNER, Erdrandbewohner und Wunderzeichen. Deutungsmuster von Alterität in der Literatur des Mittelalters. In: BOVENSCHEN, SILVIA u. a. (Hrsg.), Der fremdgewordene Text. Festschrift für Helmut Brackert zum 65. Geburtstag. Berlin/New York 1997, S. 265-284.

Rosenberg, Alfons, Engel und Dämonen. Gestaltwandel eines Urbildes. München 1967.

ROTHMANN, MiCHAEL, ex oculata fide et probatione cotidiana. Die Aktualisierung und Regionalisierung natürlicher Zeichen und ihrer Ursachen im Liber de mirabilibus mundi des Gervasius von Tilbury. In: KRUPPA, NATHALIE u. WiLKE, JÜRGEN (Hrsg.), Kloster und Bildung im Mittelalter. Göttingen 2006, S. 355383.

DERS., Mirabilia vero dicimus, quae nostrae cognitioni non subiacent, etiam cum sint naturalia. Wundergeschichten zwischen Wissen und Unterhaltung: der ,Liber de mirabilius mundi‘ (,Otia Imperialia) des Gervasius von Tilbury. In: HEINZELMANN, MARTIN u. a. (Hrsg), Mirakel im Mittelalter. Konzeptionen Erscheinungsformen - Deutungen (Beiträge zur Hagiographie 3). Stuttgart 2002, S. 399-432. 
SALMON, PAul, The Wild Man in ,Iwein' and Medieval Descriptive Technique. In: MLR 56 (1961), S. 520-528.

SCHEUER, HANS JÜRGEN, Bildintensität. Eine imaginationstheoretische Lektüre des Strickerschen Artusromans ,Daniel von dem Blühenden Tal'. In: ZfdPh 124 (2005), S. 23-46.

DERS., Numquam sine phantasmate - Antike in mittelalterlicher Imagination. In: EHLICH, KONRAD (Hrsg.), Germanistik in und für Europa. Faszination - Wissen. Texte des Münchener Germanistentages 2004. Bielefeld 2006, S. 381-390.

DERS., Schwankende Formen. Zur Beobachtung religiöser Kommunikation in mittelalterlichen Schwänken. In: STROHSCHNEIDER, PETER (Hrsg.), Literarische und religiöse Kommunikation in Mittelalter und Früher Neuzeit. DFGSymposion 2006. Berlin 2009, S. 733-770.

SCHlÜter, D. u. Hogrebe, Wolfram, Bild. In: Historisches Wörterbuch für Philosophie, Bd. 1. Basel/Stuttgart. 1971, Sp. 913-919.

SCHMIDT, HEINRICH u. SCHMIDT, MARIA, Die vergessene Bildsprache christlicher Kunst. Führer zum Verständnis der Tier-, Engel- und Mariensymbolik. München 51995.

SCHMITT, JEAN-ClAUDE, Die Logik der Gesten im europäischen Mittelalter. Stuttgart 1992.

SCHMOlKe-Hasselmann, BEATE, Camuse chose: Das Hässliche als ästhetisches und menschliches Problem in der altfranzösischen Literatur. In: ZIMMERMANN, ALBERT (Hrsg.), Die Mächte des Guten und Bösen. Berlin/New York 1977, S. 442-552.

SCHREINER, KLAUS, Si homo non pecasset ... Der Sündenfall Adams und Evas in seiner Bedeutung für die soziale, seelische und körperliche Verfaßtheit des Menschen. In: SCHREINER, KLAuS u. SCHNITZLER, NORBERT (Hrsg.), Gepeinigt, begehrt, vergessen. Symbolik und Sozialbezug des Körpers im späten Mittelalter und in der frühen Neuzeit. München 1992.

STANISLAW-KEMENAH, ALEXANDRA-KATHRIN, Von der Hand Gottes berührt?! Krankheit, Alter und Armut im Spiegel von Bittgesuchen zur Aufnahme in Dresdner Hospitäler. In: NOLTE, CORDUlA (Hrsg.), Homo debilis. Behinderte - Kranke - Versehrte in der Gesellschaft des Mittelalters (Studien und Texte zur Geistes- und Sozialgeschichte des Mittelalters 3). Korb 2009, S. 225-244.

STEINICKE, MARION, Apokalyptische Heerscharen und Gottesknechte. Wundervölker des Ostens in abendländischer Tradition vom Untergang der Antike bis zur Entdeckung Amerikas. Berlin 2002.

Strickland, Debra Higgs, Saracens, Demons, and Jews. Making Monsters in Medieval Art. Princeton 2003. 
TARENTUL, EvGEN, Elfen, Zwerge und Riesen. Untersuchung zur Vorstellungswelt germanischer Völker im Mittelalter. Frankfurt a. M. u. a. 2001.

Thomasset, Claude, La cloche muette: de Thomas d'Aquin à Albert Dürer. In: BAyArd, Florence u. Guillaume, ASTRID (Hrsg.), Formes et difformités médiévales. Un hommage à Claude Lecouteux. Paris 2010, S. 91-99.

TOMASEK, TOMAS, Kranke Körper in der mittelhochdeutschen höfischen Literatur. In: LANGER, OTTO u. RIDDER, KLAUS (Hrsg.), Körperinszenierung in Mittelalterlicher Literatur. Kolloquium am Zentrum für interdisziplinäre Forschung der Universität Bielefeld 18. bis 20. März 1999 (Körper. Zeichen. Kultur 11). Berlin 2002, S. 97-115.

VAVRa, Elisabeth, Menschen-Bilder: Eine Einführung. In: DIES. (Hrsg.), Bild und Abbild vom Menschen im Mittelalter. Klagenfurt 1999, S. 13-30.

WALTER, CHRISTIANE, „utiliter servire non possunt“. Zum Umgang mit chronisch kranken, behinderten, alten oder aus anderen Gründen arbeitsunfähigen unfreien oder abhängigen Personen in der frühmittelalterlichen Grundherrschaft. In: NolTe, CORDula (Hrsg.), Homo debilis. Behinderte - Kranke - Versehrte in der Gesellschaft des Mittelalters (Studien und Texte zur Geistes- und Sozialgeschichte des Mittelalters 3). Korb 2009, S. 291-302.

WARNING, RAINER, Auf der Suche nach dem Körper. Das Imaginäre des geistlichen Spiels. In: ZIEGELER, HANS-JOACHIM (Hrsg.), Ritual und Inszenierung. Geistliches und weltliches Drama des Mittelalters und der Frühen Neuzeit. Tübingen 2004, S. 343-359.

WEBB, RUTH, Ekphrasis Ancient and Modern: the Invention of a Genre. In: Word and Image 15 (1999), S. 7-18.

DIES., The Model Ekphraseis of Nikolaos the Sophist as Memory Images. In: GRÜNBART, MICHAEL (Hrsg.), Theatron. Rhetorische Kultur in Spätantike und Mittelalter / Rhetorical Culture in Late Antiquity and the Middle Ages (Millenium-Studien 13). Berlin 2007, S. 463-475.

WenZEL, HORST, Hören und Sehen, Schrift und Bild; Kultur und Gedächtnis im Mittelalter. München 1995.

DERS., Spiegelungen. Zur Kultur der Visualität im Mittelalter (Philologische Studien und Quellen 216). Berlin 2009.

DERS., Wahrnehmung und Deixis. Zur Poetik der Sichtbarkeit in der höfischen Literatur. In: WenzeL, HORST u. JAEGER, C. STEPHEN (Hrsg.), Visualisierungsstrategien in mittelalterlichen Bildern und Texten (Philologische Studien und Quellen 195). Berlin 2006, S. 17-43.

Williams, DAVID, Deformed Discourses. The Function of the Monster in Medieval Thought and Literature. Montreal 1996. 
WisBey, RoY, Die Darstellung des Hässlichen im Hoch- und Spätmittelalter. In: Harms, Wolfgang u. Johnson, Peter (Hrsg.), Hamburger Colloquium 1973. Berlin 1975, S. 9-34.

WitTKOWer, Rudolf, Marvels of the East. A Study in the History of Monsters. In: Journal of the Warburg and Courtauld Institutes 5 (1942), S. 159-197.

WOLFZETTEL, FRIEDRICH (Hrsg.), Körperkonzepte im arthurischen Roman. Tübingen 2007.

YATES, FRANCES A., Gedächtnis und Erinnern. Mnemonik von Aristoteles bis Shakespeare. Berlin ${ }^{6} 2001$.

ZÜRCHER, URS, Monster oder Laune der Natur. Medizin und die Lehre von den Missbildungen 1780-1914. Frankfurt a. M. 2004. 


\title{
Monströse Körper: Zur Deutung und Wahrnehmung von monstra im Mittelalter
}

\author{
Volker Scior
}

\begin{abstract}
:
Monstrous individuals within society as well as monstrous people at the edge of the world are equally physically deformed. Both indicate ambiguity and a borderline position in several levels. For this reason, they bring up fundamental questions, e.g. on the derivation from the 'normal', from human and from a widely accepted and established 'order'. This paper compares the interpretation and perception of physically deformed individuals and people by focussing on examples from early to late medieval times and stresses a difference on the human status of monstra. While individuals were often seen as an indication or a hint to future incidents and caused scholar discussions as temporary deviations from the norm, monstrous peoples were perceived as mirabilia and symbolized the variety of God's creation. In both cases, the classification as monstra served as a concept to establish order. A process of formation of the body thus took place in the medieval discourses on deformed bodies.
\end{abstract}

Deformierte Körper bevölkern viele mittelalterliche Texte. Menschen mit zwei Köpfen kommen in ihnen ebenso vor wie acephale Wesen, wie überaus große und winzig kleine Gestalten, wie solche, deren Füße in die verkehrte Richtung zeigen, die übergroße Lippen haben oder wie Mischwesen zwischen Mensch und Tier und zwischen den Geschlechtern. Solche und ähnlich deformierte Wesen werden in zeitgenössischen Texten oft als monstra, zuweilen auch als homines monstruosi bezeichnet, als Monster oder monströse Menschen. Ihnen ist zunächst einmal gemeinsam, dass sie vom ,Normalen', vom Bekannten und Vertrauten, abweichen. Diese Devianz kann verschiedener Art sein, oft ist sie es in körperlicher Hinsicht, wenn monstra vom üblichen, erwartbaren $\mathrm{Maß}$ des menschlichen Körpers und sei- 
ner Form abweichen. ${ }^{1}$ Freilich existiert eine körperliche Deformiertheit nicht als solche und ein monstrum nicht als solches. Die ,Existenz ${ }^{6}$ von monstra ist vom Menschen abhängig. Sie wird medial vermittelt. Monster existieren lediglich als von Menschen so Bezeichnete und Gedachte. Das Monster dient als ein Konzept, um den Menschen zu denken, in Abgrenzung etwa zu dem, was als nicht mehr menschlich angesehen wird. Das Monströse tritt hier hervor als eine Form, in der etablierte Ordnungsschemata gerade durch ihre Übertretung sichtbar werden. ${ }^{2} \mathrm{Im}$ Mittelalter zeichneten sich nicht nur monströse Individuen, zum Beispiel Neugeborene mit extremen Missbildungen, durch Merkmale körperlicher Andersartigkeit aus, auch ganzen Völkerschaften schrieb man pathographische Merkmale zu.

Die beiden Arten körperlich deformierter mittelalterlicher monstra, Individuen und Völkerschaften, sind - trotz der generellen Popularität von Monstern in der interdisziplinären Forschung ${ }^{3}$ - durchaus unterschiedlich oft thematisiert worden. Anders als die monströsen Völkerschaften, die des Öfteren betrachtet wurden, ${ }^{4}$ sind die Individuen recht stiefmütterlich behandelt worden. ${ }^{5}$ Kaum einmal wurden beide Arten von monstra in einer Untersuchung stringent miteinander verbunden und wurden Gemeinsamkeiten und Unterschiede herausgearbeitet, ${ }^{6}$ obwohl sie beide in zeitgenössischen Quellen und bereits seit der Antike terminologisch im Begriff monstrum aufgehen können. Zwar ist der Prozess der Übertragung dieses Terminus' von der Antike ins Mittelalter komplex ${ }^{7}$ und enthält der Begriff monstrum verschiedene semantische Ebenen, immer jedoch bezeichnete er die Abweichung vom ,Normalen'. Hergeleitet wurde monstrum zumeist von monere - also von „,mahnen“, „ermahnen“. Monstrum war neben portentum, prodigium und ostentum einer der vier gängigen lateinischen Begriffe, mit denen das griechische té@ $\alpha \varsigma$ übersetzt wurde, ein Terminus, der bei Aristoteles unter anderem für Geschöpfe steht, die ihren Eltern nicht ähnelten, aufgrund körperlicher Deformitäten den üblichen Erwartungen bei der Geburt widersprachen und die er als Fehler der Natur be-

\footnotetext{
${ }^{1}$ Neben körperlicher Andersartigkeit, auf die ich mich, dem Tagungsthema gemäß, im Rahmen dieser Ausführungen beschränke, gibt es eine ganze Reihe weiterer Kategorien der Devianz von monstra, etwa eine moralische, religiöse oder ethnische Abweichung oder Alterität. Vgl. dazu FrIEDMAN, The Monstrous Races, S. 22-36. Mit dem Begriff des monstrum werden - sofern er auf existierende Individuen bezogen wird - bis in das 18. Jahrhundert hinein vor allem ,Missgebildete' bezeichnet. Vgl. GEBHARD/GEISLER/SCHRÖTER, Einleitung, S. 12.

2 Vgl. Daston/Park, Wunder, S. 14.

3 Vgl. die Beiträge in: GeISEnhanslüKe/Mein (Hrsg.), Monströse Ordnungen; GeBHARD/GeisLER/SCHRÖTER (Hrsg.), Von Monstern und Menschen; HAGNeR (Hrsg.), Der falsche Körper. Zu Monstren als Mischwesen vgl. auch FouCAult, Die Anormalen, S. 86.

${ }^{4}$ Vgl. statt vieler außer der bereits genannten, grundlegenden Untersuchung von FrIEDMAN, The Monstrous Races, etwa WiTTKOWER, Marvels of the East; MÜNKLER/RöCKE, Der ordo-Gedanke.

${ }^{5} \mathrm{Zu}$ den wenigen Untersuchungen über monströse Individuen im Mittelalter vgl. DASTON/PARK, Wunder; Neumann, Der mißgebildete Mensch. Zu körperlichen Deformitäten von Individuen außerhalb der Gruppe der monstra vgl. aus jüngerer Zeit besonders die Beiträge in: NOLTE (Hrsg.), Homo debilis.

${ }^{6}$ Eine der Ausnahmen bildet VAN DER LUGT, L'humanité des monstres.

${ }^{7}$ Vgl. hierzu vor allem Friedman, The Monstrous Races.
} 
trachtete. ${ }^{8}$ Wie die anderen lateinischen Termini wurde auch monstrum als Bezeichnung für ein göttliches Vorzeichen angesehen, das den Menschen Hinweise auf zukünftige Ereignisse gab. Zunehmend stand ein monstrum für ein einzelnes Phänomen, das bedrohlich und beängstigend war, weil es als Vorzeichen schrecklicher Ereignisse angesehen wurde. Diese negativen Implikationen bezog man auf die monstra direkt, die so als abweichende Einzelgeburten selbst zu schrecklichen und Unheil bringenden Wesen wurden. ${ }^{9}$

Mit monstrum bezeichnete Plinius in seiner Historia naturalis aus dem 1. nachchristlichen Jahrhundert eine individuelle außergewöhnliche Geburt, die erstens als Verstoß gegen den üblichen Lauf der Natur und zweitens als göttlicher Hinweis auf ein zukünftiges Ereignis interpretiert wurde. ${ }^{10}$ Plinius und nach ihm weitere Autoren wie Solinus in seinen Collectanea rerum memorabilium verwendeten den Terminus monstrum nicht nur im Sinne einer individuellen Missgeburt und als göttlichen Hinweis, sondern auch mit Blick auf ganze Völker, die außergewöhnlich waren. Die Anwendung des Terminus monstrum sowohl auf Individuen als auch auf ganze Völkerschaften wurde im Mittelalter aus der Antike übernommen. Die Völkerschaften lokalisierte man traditionell üblicherweise in der India (Indien) und Ethiopia (Äthiopien). Augustinus, dessen schriftliche Äußerungen über die monstra in De civitate Dei zu den einflussreichsten im Mittelalter gehörten, zählte im 5. Jahrhundert eine ganze Reihe dieser Völkerschaften (zum Teil ohne Nennung ihres Namens) auf, darunter die kleinwüchsigen pygmaei, die skiapodes mit riesigen Füßen, die kopflosen blemmyae und die hundsköpfigen cynocephali. ${ }^{11}$ Verschiedene Quellen erwähnten solche monstra, sowohl lexikalische und etymologische als auch historiographisch-ethnographische Texte. Der neben Augustinus für diese Thematik einflussreichste Autor, Isidor von Sevilla, gab im 7. Jahrhundert in seinen Etymologiae eine kurze Aufzählung von Kriterien, nach denen sich Monstrosität konstituiere. Monströs waren zum Beispiel Abweichungen des Körpers von der üblichen Größe der Menschen oder seiner Glieder, aber auch fehlende oder vervielfachte Gliedmaßen und die Vermischung von Tier- und Menschenkörpern. In einem Analogieschluss wandte er diese Kriterien für Monstrosität nicht nur auf Individuen, sondern auch auf ganze Völker an: „So wie es in einzelnen Völkern (gentes) monströse Menschen gibt, so gibt es auch im ganzen Menschengeschlecht

\footnotetext{
8 Aristoteles, Historia Animalium, 4, 4, 770b; Aristoteles, Metaphysik, 7, 7, 1032a. Die Bedeutungsnuancen der vier genannten Begriffe unterschieden sich im Frühmittelalter nur wenig. Vgl. FrIEDMAN, The Monstrous Races, S. 117f.; MÜNKLER/RÖCKE, Der ordo-Gedanke, S. 723.

9 So MÜNKLER/RÖCKE, Der ordo-Gedanke, S. 723. Plinius erblickte in der Vielgestaltigkeit der menschlichen Wesen „Spielarten der erfinderischen Natur“ (Historia Naturalis, 7, 32), über die sich die Menschen wundern. Die Nennung von monstra trägt bei Plinius und Solinus vor allem den Charakter von Aufzählungen mit dem Ziel der Vollständigkeit, die sich aus dem enzyklopädischen Kontext ergibt. Zu Unterschieden in der Terminologie vgl. Friedman, The Monstrous Races, S. 116-118; MÜNKLER/RÖCKE, Der ordo-Gedanke, S. 722-730.

${ }_{10}$ Plinius, Historia Naturalis, 2, 9, S. 18 (Völkerschaften), u. 3, 35, S. 35f. (Einzelgeburten).

11 Augustinus, De civitate Dei, 16, 8.
} 
(genus bumanum) monströse Völker."12 In einer langen Reihe listete er diejenigen auf, die er aus den historiographischen Beschreibungen der Antike kannte.

Sowohl missgestaltete Individuen als auch missgestaltete Völker wurden also mit dem Begriff monstrum bezeichnet, doch gab es gewichtige Unterschiede: Denn anders als monströse Individuen, deren Devianz immer körperlich war, schrieb man monströsen Völkern auch andere Eigenschaften zu, etwa ethnographische Merkmale. Auch waren ihr Ort in der mittelalterlichen Gesellschaft und ihre Bedeutung in den Diskursen, die über sie geführt wurden, durchaus verschieden. Es würde den Rahmen sprengen, hier die Deutung der Deformitäten individueller und kollektiver monstra umfassend miteinander zu vergleichen und in Beziehung zueinander zu setzen, doch möchte ich mich im Folgenden wenigstens in Ansätzen den unterschiedlichen Wahrnehmungen und Deutungen von körperlich deformierten monstra zuwenden und der Frage nachgehen, inwiefern man die monstra als Menschen konzipiert hat. Es geht also gewissermaßen um den humanitären Status von monstra als körperlich Andersartige. Dabei werde ich in zwei Abschnitten vorgehen: Der erste ist der Wahrnehmung und Deutung individueller Missgeburten gewidmet, der zweite thematisiert den Umgang mit körperlich deformierten monströsen Völkerschaften.

\title{
1 Monströse Individuen
}

\begin{abstract}
„Es gibt ja Kinder, die schon bei ihrer Geburt so deformiert und gezeichnet sind, dass man sie eher als Karikaturen denn als Menschen anzusehen geneigt ist. Es wäre vielleicht besser für sie, sie hätten niemals das Licht der Sonne erblickt, haben sie doch nichts weiter zu erwarten, als wie Monstren umhergezeigt und als Schauobjekte herumgereicht zu werden. Nicht wenige werden mit verstümmelten Gliedern oder stumpfen Sinnen geboren. Die Freunde erfasst bei ihrem Anblick Trauer, die Eltern fühlen sich durch solche Kinder beleidigt und die Verwandten scheuen sich, mit ihnen zu verkehren." ${ }^{\text {"13 }}$
\end{abstract}

Mit diesen Worten wurden um das Jahr 1194 körperliche Deformitäten Neugeborener geschildert und die Reaktionen beschrieben, die sie hervorriefen. Bei dem Verfasser des Textes, einem römischen Stadtadligen und Angehörigen der Familie Conti, Lothar von Segni, handelt es sich um den späteren Papst Innozenz III. Noch als Kardinaldiakon hatte er, ein gebildeter Jurist, der in Paris und Bologna studiert hatte, seine Schrift De miseria humane conditionis (,̈̈ber das Elend des

\footnotetext{
12 Isidor von Sevilla, Etymologiae, 11, 3, 12: „Sicut autem in singulis gentibus quaedam monstra sunt hominum, ita in universo genere humanum quaedam monstra sunt gentium, ut Gigantes, Cynocephali, et cetera."

13 Lothar von Segni, De miseria humane conditionis, 1, 5, S. 12: "Quidam enim tam deformes et prodigiosi nascuntur, ut non homines, sed abhominationes potius videantur; quibus forte melius fuisset provisum si nunquam prodiissent ad visum, quoniam ut monstra monstrantur et ostentui ostenduntur. Plerique vero diminuti membris et sensibus corrupti nascuntur, amicorum tristitia, parentum infamia, verecundia propinquorum. "Die deutsche Übersetzung folgt hier CARL-Friedrich GEYER; vgl. Lothar von Segni, Vom Elend des menschlichen Daseins, S. 46. Sie ist allerdings recht frei und übergeht sprachliche Finessen des Lateinischen, auf die im Folgenden noch eingegangen wird.
} 
menschlichen Daseins ${ }^{6}$ ) verfasst. ${ }^{14}$ Man kennt nicht die Motive, die Lothar dazu veranlasst haben, dieses Werk zu schreiben, ${ }^{15}$ das in der Folgezeit eine überaus weite Verbreitung fand. ${ }^{16}$ In drei Büchern beweint er darin wortreich die Unvollkommenheit und Gebrechlichkeit des Menschen, und allein im ersten Buch, aus dem der zitierte Abschnitt stammt, befasst er sich in dreißig Kapiteln mit „dem Elend, das mit dem Eintritt des Menschen in die Welt verbunden ist. "17 Der Mensch war für Lothar ein Mängelwesen, und zwar zunächst in körperlicher Hinsicht. Den Autor ekelte es, dass der „Mensch aus Staub, Kot und Asche [...], und noch gemeiner, aus unflätigem Samen“ gemacht wurde, ${ }^{18}$ und auch nach der Geburt blieb der Mensch letztlich ein einziges defizitäres Wesen, selbst im Vergleich mit Tieren schnitt er Lothar zufolge schlecht ab.

Körperliche Deformation verursachte dieser Schrift zufolge also ganz wesentlich das Elend des Menschen. Dass in einem mittelalterlichen Text der Mensch aus theologischer Perspektive als defizitäres, gebrechliches und infolge des Sündenfalls degeneriertes Wesen angesehen wird, kann kaum überraschen; nur all zu oft lässt sich diese Ansicht in zeitgenössischen Vorstellungen finden. ${ }^{19}$ Erstaunlich ist hingegen, dass Lothar von Segni keine dieser theologischen Implikationen explizit anführt. Er gibt keine religiöse Interpretation der missgebildeten Individuen, etwa als Zeichen Gottes, und in eben jenem insgesamt irdisch-weltlichen Grundtenor, mit dem das menschliche Elend aus körperlicher Ungeeignetheit und Deformation gedeutet wird, ist der Text ungewöhnlich. ${ }^{20}$

Dem eingangs erwähnten, kurzen Zitat lassen sich mindestens drei zentrale Aspekte entnehmen: Zum Ersten thematisiert Lothar darin die Wahrnehmung körperlich deformierter Individuen durch Freunde, Eltern und Verwandte; Trauer und Mitleid, Enttäuschung und Abstoßung, Vermeidung, ja Verweigerung des Kontakts mit den deformierten Wesen. Zum Zweiten nennt er die Praxis, diese missgebildeten Körper umherzuzeigen ,wie Monster“ - ut monstra. Zum Dritten

$14 \mathrm{Zu}$ Autor und Werk vgl. (außer Biographien über Innozenz) z. B. die Ausführungen Maccarrones im Praefatio zu seiner Edition des Textes, hier S. XI-XLII, und GeYers in seiner Einleitung zur dt. Übersetzung, S. 1-40.

15 Oft wird die Schrift in die Tradition der Contemptus mundi-Literatur eingeordnet, so etwa bei GnÄDInger, Contemptus Mundi; vgl. auch KERn, Poesie und Poetik, S. 196. Den älteren Annahmen, das Werk sei klar in die klassische Tradition der mittelalterlicher Contemptus Mundi-Literatur einzuordnen und es sei geschrieben worden, weil Lothar sich in einer depressiven, für seine Karriere ungünstig verlaufenden Lebensphase befunden habe, widersprach neben anderen MACCARRONE, Praefatio, S. XXXIII-XXXV, mit weiteren Nachweisen. Zur Einordnung der Schrift vgl. auch GEYER, Einleitung, S. 5-38, sowie MOORE, Innocent III's De miseria, der den satirischen Charakter betont.

16 Maccarrone, Praefatio, S. X-XXII, listet 435 Handschriften und 47 frühe Drucke auf; RuH, Innozenz III., kommt auf 670 Handschriften und 52 Drucke.

17 Lothar von Segni, De miseria humane conditionis, S. 5: „De mirabili bumane conditionis ingressu." Zur Übersetzung vgl. ders., Vom Elend des menschlichen Daseins, S. 42.

18 Lothar von Segni, De miseria humane conditionis, 1, 1, S. 8: Formatus est homo de pulvere, de luto, de cinere: quodque vilius est de spurcissimo spermate. Vgl. ders., Vom Elend des menschlichen Daseins, S. 42.

${ }_{19} \mathrm{Vgl}$. mit vielen Belegstellen GOETZ, „Debilis“.

${ }^{20}$ So zu Recht auch KEHNEL, Defizienz, S. 265: Der Text sei in dieser Hinsicht „unkonventionell“. 
lässt die Wahl der lateinischen Termini, anders als es die angeführte deutsche Übersetzung vielleicht erkennen lässt, auf eine große Achtsamkeit Lothars und auf seine profunde Kenntnis begrifflicher Traditionen schließen: In der Gegenüberstellung von homines und deformierten abbominationes - worunter sowohl eine Abart oder Scheußliches als auch Unmenschlichkeit und Sündhaftes verstanden werden kann -, setzt der Text sprachlich feine Akzentuierungen. Die „deformierten und gezeichneten“ Neugeborenen werden im Original deformes et prodigiosi genannt, Lothar bemüht damit also einen von prodigium abgeleiteten Begriff. Auch die Termini monstrum und das an ostentum angelehnte ostentus nennt er. Damit sind in der kurzen Passage gleich drei von vier gängigen Begriffen zur Bezeichnung individueller Missgeburten verwendet, die man als warnende Vorzeichen und Ausdruck göttlichen Willens deutete. ${ }^{21}$

Lässt sich der Text daher schon begrifflich leicht in Traditionen einordnen, so trifft dies auch inhaltlich zu. Denn auch für die Verortung zeitgenössischer Reaktionen zwischen Furcht, Ekel und Ablehnung auf der einen Seite und Faszination, Neugier und Sensationslüsternheit auf der anderen finden sich Parallelen in weiteren mittelalterlichen Texten: ${ }^{22}$ Ein Junge etwa, der im Januar 1317 in der Nähe von Florenz mit zwei Köpfen geboren wurde, rief ausweislich des Chronisten Giovanni Villani Furcht hervor. Man habe ihn nicht einmal in den palaggio, in den Stadtpalast, vorgelassen, mit der Begründung, es handle sich bei dieser Missgeburt gemäß der Meinung der Vorväter um ein monstrum, um ein Vorzeichen schlimmer Ereignisse in der Zukunft für den Ort seiner Geburt. ${ }^{23}$ Der Vorfall sorgte für Aufsehen. Auch Francesco Petrarca beschrieb ihn eine Generation später. ${ }^{24}$

Noch ein weiteres Jahrhundert danach verzeichnete man in der Nähe von Paris etwas Ähnliches: 1429 wurden nach dem Bericht eines Chronisten, des so genannten ,Bürgers von Paris', in Aubervilliers bei Paris zwei Kinder geboren. Sie waren an Bauch und Bauchnabel zusammengewachsen, hatten aber zwei Hälse und Köpfe sowie vier Arme, Beine und Füße. Wir würden heute von siamesischen Zwillingen sprechen. Nach ihrem Tod, der bereits eine Stunde nach ihrer Taufe als Agnès und Jehanne eingetreten war, wurden ihre deformierten Körper drei Tage lang als eine ,grande merveille“ für die Bevölkerung von Paris ausgestellt. Der Chronist

\footnotetext{
${ }^{21}$ Vgl. zu diesem Themenkomplex etwa ENGELS, Das römische Vorzeichenwesen. Zur Bedeutung der genannten Begriffe und zu ihrer Verwendung im Mittelalter s. o.

22 Vgl. für weitere Beispiele das Monstren gewidmete fünfte Kapitel von DASTON/PARK, Wunder, S. 205-252, dessen Unterabschnitte in die Reaktionsweisen „Grauen“, „Vergnügen“" und „Widerwillen“" unterteilt ist, das sich allerdings freilich vor allem dem Spätmittelalter und der Frühen Neuzeit widmet.

23 Villani, Nuova Cronica, 9, 79, hier Bd. 2, S. 284 (zu 1316 nach Florentinischer Datierung): „E nel detto anno, del mese di gennaio, a la signoria del detto conte [da Battifolle] nacque al Terraio in Baldarno uno fanciullo con due corpi così fatto, e fu recato in Firenze, e vivette più di XX dì; poi morì a lo spedale di Santa Maria della Scala, l'uno prima che l'altro: e volendo essere recato vivo a'priori ch'allora erano, per maraviglia non vollono ch'entrasse in palagio, recandolsi a pianta e sospetto di si fatto mostro, il quale secondo l'oppenione degli antichi ove nasce era segno di futuro danno." Vgl. hierzu auch DASTON/PARK, Wunder, S. 76; zu weiteren Fällen dieser Art ebd., S. 205-252.

${ }^{24}$ Vgl. Petrarca, Rerum memorandarum libri, 4, 120, S. $270 f$.
} 
fügt als Beleg für die Authentizität seiner Nachricht an, er habe sie selbst gesehen und sogar in den Händen gehalten. ${ }^{25}$

Die hier angeführten Quellen stehen als Beispiele für eine Vielzahl mittelalterlicher Texte, in denen missgebildete oder ungewöhnlich aussehende Neugeborene, Verstümmelte, siamesische Zwillinge und andere deformierte Körper von Zeit zu Zeit erwähnt wurden. In solchen Wesen - manchmal explizit als monstra bezeichnet - wurde das Monströse, das körperlich Abnorme, für alle sichtbar. Solche Individuen brachten die physische Deformation gewissermaßen in die Mitte der Gesellschaft. Der Umgang mit solchen monströsen Geburten gehörte zum Fundus mittelalterlicher Alltagserfahrungen. Sie konnten zu öffentlichem Massenauflauf führen, Stellungnahmen der politischen Eliten veranlassen und Angst erfüllte Interpretationen nach sich ziehen. Sie wurden als Zeichen gedeutet, die zukünftigen Schrecken ankündigten, als sichtbare Zeichen der Sündhaftigkeit - zum Beispiel der Eltern, aber auch eines ganzen Dorfes oder eines anderen Kollektivs. Die deformierten Körper warfen die Frage auf, woher sie kamen. Sie verweigerten die unmittelbare Auskunft über ihre Herkunft und über ihren Ort. Sie ließen im Unklaren, woher sie kamen und wohin sie gehörten. ${ }^{26}$

Das Deutungsspektrum lag zwischen Unheil bringenden Vorzeichen und dem Ausdruck göttlichen Zorns. Die mittelalterliche Verwendung von monstrum folgte hier semantisch antiken Termini wie den von Lothar von Segni genannten Begriffen prodigium und ostentum sowie dem von ihm nicht genannten portentum. In den monströsen Individuen wurde, sozusagen zeitlich befristet, ein kurzes Aussetzen der natürlichen Gewohnheiten sichtbar, fast ein Irrtum der Natur, vielleicht durch Gottes Zorn verursacht - sie waren sprichwörtlich greifbar für die Anwesenden (wie der Chronist bezeugt), und sie waren wahrnehmbar und deutbar für alle.

Es wäre jedoch verfehlt, würde man den mittelalterlichen Umgang mit monströsen Geburten lediglich zwischen Faszination und Schrecken einordnen wollen. Jenseits der von den genannten Chronisten beschriebenen Wahrnehmung der Bevölkerung warfen die monströsen Individuen für Gelehrte andere Fragen auf. Sie hingen mit dem Problem zusammen, ob und inwiefern es sich bei ihnen eigentlich um Menschen handelte. Entsprechende Überlegungen waren unter anderem abhängig von der Art des Diskurses, in dem sie angestellt wurden. Besonders leicht

\footnotetext{
25 Journal d'un bourgeois de Paris 1405-1449, ad a. 1429, S. 259f.: „Item, le 6e jour du mois de juin audit an 1429, furent nées à Aubervilliers deux enfants qui étaient proprement, ainsi comme cette figure est, car pour vrai je les vis et les tins entre mes mains, et avaient, comme voux voyez, deux têtes, quatre bras, deux cous, quatre jambes, quatre pieds, et n'avaient qu'un ventre et qu'un nombril, deux têtes, deux dos. Et furent christianées, et furent trois jours sur terre pour voir la grande merveille au peuple de Paris; et pour vrai, du peuple de Paris y fut les voir plus de dix mille personnes, bommes que femmes [...]. Elles furent nées environ sept heures au matin, et furent christianées en la paroisse Saint-Christophe, et la dextre fut nommée Agnès, la senestre Jeanne et vécurent après le baptême une heure. ndolsi a pianta e sospetto di sì fatto mostro, il quale secondo l'oppenione degli antichi ove nasce era segno di futuro danno." Außerdem fügte der Chronist seinem Bericht eine Zeichnung an und nannte Namen von Vater und Mutter der Zwillinge. Vgl. auch DASTON/PARK, Wunder, S. 77.

${ }^{26}$ Vgl. Macho, Vom Ursprung des Monströsen. Siehe auch VAN DER LugT, L'humanité des monstres, S. 2-4.
} 
lassen sich ein juristischer und ein theologischer Diskurs im ausgehenden Hochmittelalter in der Scholastik des 13. Jahrhunderts unterscheiden.

(a) Juristen an den aufstrebenden Universitäten des 13. Jahrhunderts waren an den rechtlichen Folgen interessiert, die sich mit der Frage nach dem humanitären Status monströser Einzelgeburten verbanden. Im Zentrum der Überlegungen, ob solche körperlich deformierten Individuen berechtigt waren, Eigentum zu erlangen und ein Erbe anzutreten, stand das Problem, ob sie (formal-)rechtlich legitim waren. Den Ausgangspunkt bildete das relativ strenge Römische Recht, das für monströse Geburten oft den Tod oder zumindest den Ausschluss aus der Gemeinschaft vorsah. ${ }^{27}$ Die im Mittelalter vor allem verwendete, abgemilderte Form der entsprechenden Vorschriften, die Digesta, enthielten unter anderem auch eine Interpolation, die sich konkret auf monstra bezog. Dort hieß es, dass es sich bei Wesen, die dem menschlichen Antlitz nicht ähnelten, auch nicht um Kinder handle. Wenn ein Lebewesen jedoch mehr Körperteile oder Glieder als gewöhnlich besitze, scheine es in gewisser Weise vollkommen zu sein und sei daher unter die Kinder zu rechnen. ${ }^{28}$ Unter dem Strich also konnte ein Kind, das körperlich zu sehr vom üblichen und erwartbaren Maß eines Menschen abwich, kein Erbe antreten anders als ein Kind mit sechs Fingern an einer Hand. Die Seele spielte hier für die Konstituierung des humanitären Status keine Rolle. Im 14. Jahrhundert war dies anders: In seinem Kommentar zur entsprechenden Digestenstelle konstatierte der Bologneser Jurist Baldo degli Ubaldi, dass ein Wesen ohne Menschenkörper (corpus hominis) auch keine menschliche Seele (anima hominis) haben könne, denn die Natur verleihe keine Seele, wo es keinen Körper gebe. Die Form verleihe den Dingen das Sein, und jemand ohne menschliche Form (forma hominis) sei kein Mensch und habe daher auch keinen Anspruch auf Freiheit. Wer jedoch auch nur etwas von der menschlichen Form habe, selbst wenn diese deformiert ist (forma deformis), besitze auch Freiheit. ${ }^{29}$

Das Interesse an den deformierten Körpern entsprang hier nicht zuletzt praktischen Notwendigkeiten des juristischen Alltags, der Beschäftigung mit Fragen des Eigentums- und Erbrechts. Gleichzeitig jedoch brachen sich in der Scholastik Ideen Bahn, die auf eine Kongruenz zwischen Körper und Seele zielten. Ein deformierter Körper konnte keine Seele beherbergen - in diesem Fall zunächst ein-

\footnotetext{
27 Vgl. hierzu etwa Müller, Der Krüppel, S. 49; Neumann, Der mißgebildete Mensch, S. 23-25; VAN DER LUGT, L'humanité des monstres, S. 4.

${ }^{28}$ Digeste, I,5,14 (unter dem Namen Julius Paulus): „Non sunt liberi qui contra formam bumani generis converso more procreantur, veluti si mulier monstrosum aliquid, aut prodigiosum enixa sit. Partus autem, qui membrorum humanorum officia ampliavit aliquatenus videtur efectus; et ideo inter liberos connumerabitur", zit. n. FRIEDMan, The Monstrous Races, S. 179. Vgl. zu diesem Beispiel ebd. sowie Schrage, Capable, S. 469476; Lefebvre-Teilard, Infans conceptus, S. 501 u. 505; MünkLer/RöCKe, Der ordo-Gedanke, S. 751.

${ }^{29}$ Baldi Vbaldi Pervsini in Primam digesti Veteris Partem, Venedig 1616, 1, 14, fol. 31v, zit. n. FrIEDman, The Monstrous Races, S. 180: „Quod non babet corpus hominis, animam bominis non presumat babere, quia presumitur, quod natura non ponet animam, vbi non est corpus. [...] Cum forma dat esse rei, qui non babet formam hominis, non est homo [...] qui caret formam hominis, caret libertatis nomine, sed quod babet aliquid forme bominis, licet forma sit deformis, libertatis tenet effectum."
} 
mal mit juristischen Folgen. Ähnliches lässt sich auch für den eher theologisch bestimmten Diskurs zeigen.

(b) Vor allem die Kanonisten beschäftigten sich mit der Frage der Relation zwischen der Form des Körpers und der Form der Seele. Daher interessierte sie, ob sich auch in einem deformierten Körper eine Seele befinde. ${ }^{30}$ Die Theologen räsonierten darüber, ob diese Wesen überhaupt christianisiert und missioniert werden konnten, denn nur Menschen, nicht aber Tiere, konnten getauft werden. Pietro Abano, ein italienischer Arzt und Philosoph an der Wende vom 13. zum 14. Jahrhundert, vertrat in seiner Interpretation der aristotelischen Problemata die Meinung, dass die Form des Kopfes entscheidend sei. „Es hängt von der Form des Kopfes ab, ob irgendein Tier zu unserer Art gerechnet werden darf. Wenn es einen völlig artgemäß geformten Kopf hat, gehört es zu uns, auch wenn es in vielen anderen Teilen monströs ist. "31 Hier also wurden unterschiedliche Körperteile unterschiedlich gewichtet, waren Deformitäten des Kopfes wichtiger als Deformitäten des restlichen Körpers.

Überhaupt spielte die Kopfform eine entscheidende Rolle bei der Bestimmung des humanitären Status monströsen Individuen. Ein anderer Kanonist des 14. Jahrhunderts, Guido von Baysio, der Erzbischof von Bologna, fragte, ob ein monstrum mit zwei Köpfen - gemeint waren siamesische Zwillinge - als eine oder als zwei Personen getauft werden sollte. Seine Antwort war folgende: Wenn das Wesen zwei Köpfe, Hälse und Oberkörper habe, habe es mit Sicherheit auch zwei Herzen und damit zwei Seelen - deshalb solle der Priester hier auch zwei Personen taufen. Wenn es aber nur einen Oberkörper habe, aus dem lediglich zwei Hälse und zwei Köpfe herausragten, handle es sich vielleicht nur um eine Person. Da man nicht sicher sein könne und die doppelte Taufe verboten war, solle der Priester beide Köpfe taufen, aber beim zweiten Kopf hinzufügen: „Wenn Du noch nicht getauft wurdest, dann taufe ich Dich jetzt.“'32 Während solche Erwägungen die Taufe betrafen, wurde auch die Ehefähigkeit siamesischer Zwillinge diskutiert, und der Erhalt entsprechender Rechte und Sakramente beschäftigte die Juristen und Theologen auch in Bezug auf die Hermaphroditen, die als Mischwesen zwischen den Geschlechtern die etablierten Ordnungsschemata auf andere Weise herausforderten und nicht den humanitären Status von monstra, sondern die Ge-

\footnotetext{
$30 \mathrm{Vgl}$. zu diesem Komplex auch VAN DER LuGT, L’humanité des monstres, bes. S. 4-7.

31 Petrus de Apano, Problemata Aristotelis, Paris 1520, 4, 13, fol. 57v, zit. n. FrIEDMAN, Monstrous Races, S. 252f., Anm. 9: „Et scias quod maxime decernitur in figuratione capitis si aliquid animal debet dici nostrum genitum: si enim caput habuerit plene vt generans figuratum: etiam si in multis aliis partibus sit monstruosus potuit dici nostrum: quid et doctores leges nostre considerantes percipiunt baptizari tanquam recipiendum sit in specie nostra." Vgl. auch MÜNKLER/RÖCKE, Der ordo-Gedanke, S. 752 mit Anm. 152; VAN DER LUGT, L'humanité des monstres, S. 8.

32 Vgl. Friedman, The Monstrous Races, S. 153. Vgl. auch MünKLER/RÖCKE, Der ordo-Gedanke, S. 752. Zu Taufe und Hochzeit siamesischer Zwillinge vgl. auch DASTON/PARK, Wunder; VAN DER LUGT, L'humanité des monstres, S. 14-17.
} 
schlechterrollen in Frage stellten. ${ }^{33}$ Anders als solche Wahrnehmungen und Deutungen individueller monstra verhielt es sich mit den Interpretationen von körperlichen Deformitäten, die ganzen Völkerschaften zugeschrieben wurden.

\section{Monströse Völkerschaften}

Im Gegensatz zu den individuellen monstra war der Ort der monströsen Völkerschaften nicht die Mitte der Gesellschaft. Letztere wurden vielmehr traditionell und schon seit der Antike üblicherweise am südlichen und östlichen Rand der Ökumene angesiedelt. Die Anwendung des Begriffs auch auf Völkerschaften und deren Lokalisierung übernahm man aus der Antike. ${ }^{34}$ Was die antiken Quellen jedoch nicht boten, waren Antworten auf neue und teilweise sehr komplexe Fragen, die sich im christlichen Mittelalter bei der Deutung monströser Völkerschaften ergaben. ${ }^{35}$ Die monströsen Menschenarten wurden im Mittelalter nicht etwa deshalb oft thematisiert, weil man in jener Zeit besonders stark an Fabelwesen geglaubt hätte, sondern weil nachgerade die monströsen Völker, mehr noch als die Individuen, Fragen nach der Transzendenz aufwarfen. ${ }^{36}$ Durch ihre Andersartigkeit - ich beschränke mich hier auf die körperliche Devianz und Alterität - evozierten sie grundlegende Fragen, die ins Zentrum des mittelalterlichen Weltverständnisses zielten. Waren diese Völker überhaupt von Gott erschaffen worden? Gehörten sie zu den Menschen? Wie war ihre Hässlichkeit zu erklären, wo doch der göttliche Schöpfungsordo durch Schönheit und Harmonie charakterisiert war? Aus solchen zentralen Problemfeldern, welche die Ordnung der Welt betrafen, erwuchs im christlichen Mittelalter geradezu ein Zwang zur Deutung der monströsen Völker und ihrer deformierten Körper.

Wegweisend war hier zunächst wiederum Augustinus, der die am Rand angesiedelten monströsen Völker in Gottes Schöpfung einschloss. Er leitete das Wort monstrum nicht von monere ab, sondern von monstrare, „zeigen“, und hob damit zunächst einmal auf die Zeichenhaftigkeit des Phänomens ab. Augustinus unterwarf die monstra einer christlichen Deutung. Seiner einflussreichen Meinung nach äußerte sich in den monstra die Allmacht Gottes. ${ }^{37}$ Er verknüpfte im Rahmen seiner christlichen ordo-Konzeption monströse Individuen und Völkerschaften direkt,

\footnotetext{
${ }^{33}$ Hermaphroditen mussten sich bei der Eheschließung für ein Geschlecht entscheiden, die Priesterweihe blieb ein diskutiertes Problem. Vgl. zu der Behandlung der Hermaphroditen zusammenfassend VAN DER LUGT, L'humanité des monstres, S. 17-21, mit weiteren Nachweisen.

${ }^{34}$ Gut erkennen lässt sich das an den mittelalterlichen Weltkarten. Zur Darstellung von monstra in der Kartographie vgl. an dieser Stelle aus der überaus reichen Literatur lediglich MÜNKLER, Monstra und mappae mundi.

35 Sehr instruktiv ist hier der Beitrag von MÜNKLER/RÖCKE, Der ordo-Gedanke, S. 701-716, bes. S. 715 .

36 Vgl. ebd., bes. S. $715 f$.

37 Augustinus, De civitate Dei, 16, 8, S. 293f. u. 295. Vgl. Friedman, The Monstrous Races, S. 119f.; MÜNKLER/RöCKE, Der ordo-Gedanke, S. 730-735.
} 
indem er schrieb: „Ebenso wie man die bei uns vorkommenden Missgeburten rechtfertigt, kann man auch etwaige missgestaltete Völker rechtfertigen. Gott ist der Schöpfer aller und weiß am besten, wo und wann es angebracht ist oder war, etwas zu schaffen. “38 Gott habe die monströsen Völker vielleicht gerade deshalb erschaffen, damit man nicht denke, ihm sei bei den individuellen Missgestalten ein Fehler unterlaufen. ${ }^{39}$ Die monstra wurden hier zum Ausdruck der schöpferischen Freiheit Gottes und zu Zeichen der göttlichen Allmacht, sie galten als Teil der Schöpfung. Trotz körperlicher Deformationen oder anderer Sitten stand Eines außer Frage: Wenn es diese Völker gab, waren sie von Gott geschaffen worden. Sie waren damit auch Bestandteile des sinnvollen, wohldurchdachten göttlichen Schöpfungsplans. Und mehr noch: Augustinus sprach den vereinzelt vorkommenden monströsen Individuen inmitten der Gesellschaft und den Völkerschaften am Rand der Welt eine aufeinander verweisende, eine sich gegenseitig legitimierende Funktion zu, und beiden wiederum eine zentrale Funktion für den Glauben, belegten sie doch die Allmacht Gottes.

Spätere Verfasser hochmittelalterlicher Enzyklopädien bezogen sich genau auf diese Äußerungen und Deutungen. Vincenz von Beauvais, Dominikaner und Verfasser des Speculum naturale, erklärte im 13. Jahrhundert die monströsen Völkerschaften zu Zeichen für Gottes permanente Schöpfungstätigkeit. ${ }^{40}$ Durch die meist nur kurze namentliche Aufzählung der monstra in den Enzyklopädien erfolgte einerseits ihre Integration in die von Gott geplante, vom Menschen nicht immer gänzlich durchdringbare Welt, und andererseits die Übertragung des geschlossenen ordo in die Schrift. ${ }^{41}$ Die monströsen Völker überstiegen das Verständnis der Menschen, sie galten als Wunder der Schöpfung. Im Hochmittelalter wird der Terminus monstrum mit dem Begriff des mirabilium in Verbindung gebracht, so bei Gervasius von Tilbury im 12. Jahrhundert in der Einleitung zum dritten Buch seiner Otia Imperialia.42 In die Aufzählung von 146 mirabilia reihte er neben vielen anderen Dingen, Ereignissen und Wesen auch die monströsen Völkerschaften ein.

Galten die monstra im Hochmittelalter als mirabilia, wurden sie dennoch durchaus für real existent gehalten. ${ }^{43}$ Anders als die monströsen Individuen kannte man die Völkerschaften allerdings nicht aus eigener Anschauung. Niemand war ihnen je persönlich begegnet. Die Wahrnehmung erfolgte aus Texten, denen man eine hohe

\footnotetext{
38 Augustinus, De civitate Dei, 16, 8, S. 295: „Qualibus autem ratio redditur de monstrosis apud nos hominum partibus, talis de monstrosis quibusdam gentibus reddi potest. Deus enim est creator omnium, qui ubi et quando creari quid oporteat vel portuerit, ipse novit, sciens universitatis pulchritudem quarum partium vel similitudinem vel diversitate contexat."

${ }^{39}$ Vgl. ebd.

${ }^{40}$ Vgl. Vincenz von Beauvais, Speculum Naturale, 1, 31, 118, S. $2387 \mathrm{f}$.

${ }^{41}$ MÜNKLER/RÖCKE, Der ordo-Gedanke, S. $728 \mathrm{f}$.

42 Wunderbar sei, was das Fassungsvermögen übersteige, auch wenn es natürlich ist, aber auch das, von dem man nicht erklären könne, warum es so ist, wie es ist. Gervasius von Tilbury, Otia Imperialia, 1, 3, S. 309.

$43 \mathrm{Zu}$ Recht sprechen MÜNKLER/RÖCKE, Der ordo-Gedanke, daher den mittelalterlichen monstraDarstellungen Elemente einer realistischen Weltbeschreibung zu.
} 
Autorität zumaß. Herodot, Plinius und andere hatten über sie ebenso berichtet wie Isidor von Sevilla. Populäre Texte schienen das Vorkommen solcher Völkerschaften zu bestätigen. Geschichten, die sich um Alexander den Großen als Eroberer des Ostens rankten und im so genannten Alexanderroman weit verbreitet wurden, Berichte um den Sagen umwobenen Priesterkönig Johannes, aber auch Chroniken, Bestiarien sowie Illustrationen in Handschriften und auf Weltkarten behaupteten die Existenz körperlich deformierter, monströser Völker. Die Völkerschaften wurden nun - was entscheidend ist - als Teil der Geschichte aufgefasst. Die entsprechenden Berichte fanden als historische Quellen Eingang in die Geschichtsschreibung. Frutolf von Michelsberg etwa inserierte die Alexandergeschichten kurz nach 1100 in seine Weltchronik, und Otto von Freising, der schon früh, in der Mitte des 12. Jahrhunderts, vom Reich des Priesterkönigs Johannes berichtete, griff ebenfalls auf dieses Wissen über Indien zurück. Die monströsen Völker wurden fast immer direkt mit der Erbsünde verknüpft. Entweder wurden sie als Nachfahren von Kain bezeichnet, der bekanntlich seinen Bruder Abel erschlagen hatte, oder als Nachfahren von Cham, dem verfluchten Sohn Noahs. Das Kainsmal, das Gott nach dem Bericht der Genesis Kain verliehen hatte, wurde als Schandmal gedeutet. Es lebte, so wurde kolportiert, in den deformierten Körpern der Nachkommen Kains fort. In beiden Fällen der Ableitung wurden die körperlichen Deformationen zu Zeichen der Sünde. Im Unterschied zu den ,normalen' Völkerschaften, bei denen es sich selbstverständlich ebenfalls um Sünder handelte, war den monströsen die Sünde äußerlich.

Weil die monströsen Völkerschaften so anders aussahen, kam der Frage nach ihrem humanitären Status besondere Bedeutung zu. Denn während missgebildete Neugeborene sichtbar von eindeutig menschlichen Eltern abstammten und daher meist relativ leicht den Menschen zugeordnet werden konnten, verhielt es sich mit den monströsen Völkerschaften anders: Thre Eltern wiesen dieselben Verformungen auf. Missgestaltete Individuen waren letztlich singulär, sie existierten meist nur kurz und konnten zum Beispiel als Folge der Sündhaftigkeit ihrer Eltern oder als Zeichen Gottes interpretiert werden. ${ }^{44}$ Die monströsen Völker hingegen, bei denen sich die Deformation fortpflanzte und zeitlich andauerte, verlangten einen festen Platz in Zeit und Raum. Die körperlichen Deformationen waren dem Wesen der Völkerschaften geradezu immanent, sie bildeten ein Zeichen der Art. Die deformierten Körper symbolisierten geradezu ihr Wesen. Dies führte schon fast zwangsweise zu Überlegungen, woher diese monstra kamen. Fragen nach ihrer Entstehung und Abstammung waren daher zentral. Die Bibel, die lediglich zwei der monströsen Völker erwähnte, machte keine Angaben zu diesen Fragen. Für die Frage, ob ein Wesen ein Mensch ist oder nicht, war nach der Meinung des Augustinus die Körperform nicht entscheidend: „Wer als Mensch geboren wird, das heißt als sterbliches, vernunftbegabtes Tier (animal rationale et mortale), stammt in

${ }^{44}$ Vgl. aber auch naturwissenschaftliche Erklärungen bei VAN DER LUGT, L'humanité des monstres, S. 3, Anm. 13. 
jedem Fall von Adam als dem Ersterschaffenen ab. Er ist ein Mensch, mag er uns in Körpergestalt, Farbe, Bewegung oder Stimme noch so fremdartig vorkommen, mag er Kräfte, Teile, Eigenschaften haben, welche er will. Daran darf kein Gläubiger zweifeln.“45

Schönheit und Harmonie des Universums traten bei manchen mittelalterlichen Interpreten umso deutlicher hervor durch die Andersartigkeit oder Hässlichkeit der monstra. Das Schöne ließ sich im Vergleich mit dem Hässlichen erkennen. Die deformierten Körper der monströsen Völker trugen so geradezu bei zur Schönheit der Schöpfung. Insofern kam den körperlichen Deformitäten hier gar eine ästhetische Funktion zu, die in der Scholastik noch ausgefeilter begründet wurde. ${ }^{46}$ Insbesondere hier, in den Disputationen der scholastischen Theologen im 13. Jahrhundert, wurde die Frage behandelt, ob die monströsen Völker Menschen seien, doch wäre es falsch, wenn man diese Auseinandersetzung erst mit dem ausgehenden Hochmittelalter ansetzen würde. Der berühmte Antwortbrief des Abtes Ratramnus von Corbie an Rimbert, den Missionar und späteren Erzbischof von HamburgBremen, etwa kann als (freilich seltener) Beleg dafür gelten, dass bereits im Frühmittelalter die Frage nach dem humanitären Status relevant werden konnte. ${ }^{47}$ Rimbert hatte in alten Schriften von den gynocephali gelesen und gehört, dass diese im Norden Europas, in seinem Missionsgebiet Skandinavien, vorkämen. Rimberts Interesse galt in erster Linie der Frage, ob diese Völkerschaft missionierbar seien. Es stellte sich demnach ein ganz ähnliches Problem wie bei der Frage nach der Tauffähigkeit monströser Individuen. Sehr sorgfältig wog Ratramnus die Argumente ab. Obwohl er zur Unterstützung auf die Meinungen älterer Kirchenväter zurückgriff, die den Ausschluss der gynocephali aus der Menschheit nahe legten, kam er zu einem gegenteiligen Schluss: Die Cynocephalen seien den Menschen zuzurechnen. Denn zwar handle es sich dem Aussehen, insbesondere der Kopfform, und der Sprache nach um Tiere, doch verwiesen andere Aspekte durchaus auf ihre Menschlichkeit: Sie bildeten eine Gemeinschaft, lebten in Städten, bebauten Felder und brächten Ernten ein, bedeckten ihre Scham mit Kleidern usw. Die physische Erscheinung und Ordnung des Körpers wurde hier abgewertet gegenüber der Ordnung der sozialen Gemeinschaft. ${ }^{48}$

Namentlich ab dem 13. Jahrhundert diskutierten Autoren die Frage des humanitären Status' monströser Völkerschaften erneut. Es wurde abgewogen, ob das

\footnotetext{
45 Augustinus, De civitate Dei, 16, 8, S. 293f.: „Verum quisquis uspiam nascitur bomo, id est animal rationale et mortale, quam libet nostris inusitatem sensibus gerat corporis formam, seu colorem, sive motum, sive sonum, sive qualibet vi, qualibet parte, qualibet qualitate naturae, ex illo uno protoplasto originem ducere, nullus fidelium dubitaverit."

${ }^{46}$ So etwa in der ,Summa Theologica' des Alexander von Hales oder in der Albertus Magnus zugeschriebenen Schrift ,De Secretis Mulierum‘. Vgl. zu diesem Aspekt der ästhetischen Funktion monströser Völkerschaften bereits Friedman, The Monstrous Races, S. 254, MÜNKLER/RöCKE, Der ordoGedanke, S. 734f.

47 Ratramnus von Corbie, Ep. 12 (Epistola de cynocephalis). Zu dem Brief vgl. WooD, The Missionary Life, S. 252f.

48 Vgl. hierzu und zum Folgenden auch MünKLER/RÖCKE, Der ordo-Gedanke, S. 754.
} 
Kriterium der äußeren Erscheinung oder das der inneren Ordnung maßgeblich sei. Schwierigkeiten bei der Einordnung machten insbesondere die acephalen Wesen, aber auch die Cynocephalen und die in der Bibel genannten pygmaei. Die Antworten fielen keineswegs einheitlich aus. Einige, wie Albertus Magnus, exkludierten monströse Völkerschaften, in diesem Fall die pygmaei, aus dem Status der Menschen, weil ihnen - trotz relativ großer physischer Ähnlichkeit - unter anderem die wahre Vernunft (usum rationis) fehle. ${ }^{49}$ Sie wurden in der Rangfolge der Lebewesen zwischen Affen und Menschen platziert. Die pygmaei ähnelten zwar den Menschen, ihnen fehle aber die Vernunft. Peter von Auvergne zählte die pygmaei in seiner ausführlichen quodlibetalen Abhandlung ebenfalls nicht zu den Menschen, unter anderem mit Verweis auf die zu geringe Körpergröße. ${ }^{50}$ Hier spielte also das Argument der körperlichen Devianz und Defizienz eine Rolle. Unter Verweis auf Aristoteles kam er zu der Ansicht, der Mensch unterliege wie alles andere in der Schöpfung Begrenzungen seiner Körpergröße. Menschen könnten nicht beliebig groß oder klein sein, ohne die Natur des Menschen zu verlieren. Da ein pygmaeus siebenmal kleiner als ein durchschnittlicher Mensch sei, könne er trotz seiner prinzipiellen physischen Ähnlichkeiten kein Mensch sein. Die äußere Form des Körpers musste hier auch quantitativ mit der inneren Form korrespondieren. Alexander von Hales bejahte die Frage, ob monströse Völkerschaften zu den Menschen zu zählen seien mit dem Argument, über die Menschlichkeit von Wesen entscheide nicht die äußere Anordnung und die (De-)Formität von Körperteilen, sondern die innere Ordnung von Körper und Seele. ${ }^{51}$ Scholastisch-spitzfindig verwendete er die körperlichen Deformitäten monströser Völkerschaften als Beleg für ihren humanitären Status: Wenn die körperlichen Deformitäten ein Zeichen für die Sündhaftigkeit seien, weil die monstra von Kain oder Cham abstammten, dann müssten sie den Menschen zugerechnet werden, denn Tiere könnten nicht sündigen. Andere gründeten die Humanität von Lebewesen auf soziale Verhaltensweisen, auf die soziale Ordnung von Völkerschaften, nicht auf die körperlichen Übereinstimmungen mit den Menschen.

Gleichwohl lässt sich nicht sagen, dass die körperlichen Deformationen für die Zuschreibung des humanitären Status zunehmend eine geringere Rolle gespielt hätten. In den scholastischen Diskussionen über die Menschlichkeit der monstra wurde zunehmend eine Kongruenz zwischen äußerer und innerer Form verlangt. Das machte es schwieriger, die Position des Augustinus - das körperliche Aussehen spielt für die Frage des Menschseins keine Rolle, entscheidend ist das Vorhandensein einer Seele - auf die monströsen Völker anzuwenden. Scholastische Denker konnten nicht mehr, wie Augustinus, alle körperlich deformierten Wesen, auch

\footnotetext{
49 Albertus Magnus, De Animalibus, 1, 1,3,46, S. 18: „Talia animalia, quae Pygmei dicuntur, usum rationis non habent, nec verecundiam, nec bonestatem, nec justitiam colunt, nec judicium Reipublicae exercent."

50 Peter von Auvergne, Sind die Pygmäen Menschen?, S. 209-213. Vgl. dazu MüNKLER/RöCKE, Der ordo-Gedanke, S. 756f.; VAN DER LUGT, L'humanité des monstres, bes. S. 7-11, mit weiteren Beispielen aus dem 14. Jh., S. 11-13.

51 Alexander von Hales, Summa Theologica, S. 576.
} 
die monströsen Völkerschaften, zu den Menschen zählen. Denn das Vorhandensein von Rationalität und innerer Ordnung war für sie auch von der äußeren Form des Körpers abhängig. Wer körperlich zu deformiert war und nicht mehr die Form eines Menschen besaß, konnte weder sprechen noch schreiben noch denken wie ein Mensch. ${ }^{52}$ Für die Zuschreibung des humanitären Status war nicht mehr entscheidend, sich innerhalb der Schöpfungsordnung zu befinden, sondern über eine Ordnung zu verfügen.

\section{Schlussbemerkungen}

Im Mittelalter werden zahlreiche Diskussionen über die Frage des humanitären Status von körperlich deformierten monstra geführt. Wahrnehmungen und Deutungen von monstra waren dabei nicht einheitlich, wobei der Brief Ratramnus' von Corbie als frühes Zeugnis erst später, etwa seit dem 13. Jahrhundert, um weitere explizite Belege ergänzt wird. Die individuellen Missgeburten wurden meist als Vorzeichen gedeutet, als negative, sündhafte Warnungen vor zukünftigen Ereignissen. Sie riefen oft Schrecken und Entsetzen hervor - ähnlich wie Unwetter oder Kometen, die in eben diesem Sinn gedeutet wurden. Sie wurden als eine gezielte Botschaft Gottes gedeutet und galten als zeitlich begrenzte Abweichungen vom Normalfall der etablierten Ordnung. In ihnen äußerte sich Gottes Missfallen. Körperlich deformierte monstra waren daher vor allem Zeichengeber. Daneben lösten monströse Individuen auch gelehrte Diskussionen aus und wurden als juristisches und theologisches Problem wahrgenommen. Im Großen und Ganzen war ihr humanitärer Status akzeptiert.

Die monströsen Völkerschaften galten - trotz derselben körperlichen Deformitäten - seit dem Hochmittelalter als wunderbar, als Mirabilien. Sie symbolisierten seit Augustinus Gottes Schöpfungsvielfalt. Sie waren keine Vorzeichen künftiger Ereignisse und existierten ohne intrinsische Bedeutung. Anders als die Individuen symbolisierten sie die Allmacht und Weisheit des Schöpfers, und sie waren ,Monstren ${ }^{`}$ - Zeichen - nur im übertragenen Sinn. Denn ihre körperlichen Deformitäten waren nicht geschaffen worden, um etwas Bestimmtes zu zeigen. Ab dem 12. und 13. Jahrhundert ist ihre Bedeutung allegorisch, sie fungieren zunehmend als Chiffren einer höheren theologischen oder moralischen Wahrheit, und sie werden im Übrigen auch immer seltener als monstra bezeichnet.

Beide Arten von monstra zeichneten sich durch ihre Uneindeutigkeit aus. Körperlich deformiert konnte es sich bei ihnen kaum um ,übliche“ Menschen handeln. Aus ihrer Grenzstellung erwuchsen Probleme, ihre Uneindeutigkeit forderte heraus, sie zwang gewissermaßen zur Deutung. Monstra dienten dazu, Wertigkeiten abzustecken und die etablierten Ordnungsschemata zu überprüfen. Sie bildeten ein gedankliches Konzept, um zentrale Fragen der Ordnung zu denken. In den monstra

52 Vgl. MÜNKLER/RöCKE, Der ordo-Gedanke, S. 758; VAN DER LUGT, L'humanité des monstres, S. 21. 
spiegelte sich das Menschliche wie das Nicht-Menschliche. Insofern war die mittelalterliche Auseinandersetzung mit den monstra letztlich eine Auseinandersetzung mit sich selbst.

Bei der Betrachtung von Deutungen und Wahrnehmungen körperlich deformierter monstra im Mittelalter lässt sich etwa ab dem 12. Jahrhundert stärker zwischen individuellen und kollektiven monstra differenzieren, da auf Letztere die augustinischen Ideen nicht mehr so gut anwendbar waren. Im Unterschied zu den augustinischen Ansichten über die Unmittelbarkeit aller Geschöpfe zu Gott brachte insbesondere die Rezeption antiker Autoren ein neues Naturverständnis. Die Interpretationen der natürlichen Ordnung rekurrierten zunehmend auf Aristoteles und anderen Autoren naturphilosophischer Texte. Körperliche Deformitäten galten nun nicht mehr ausschließlich als Folgen göttlicher Anordnung, ihnen wurde eine davon unabhängige innere Ordnung zugebilligt, die aus natürlichen Ursachenketten entstanden war. Im Hoch- und Spätmittelalter wurden daher die exotischen monströsen Völkerschaften und die monströsen Individuen deutlicher voneinander unterschieden. Diese Differenzierung betraf nicht das physische Erscheinungsbild. Denn beide Typen von monstra, sowohl die einzelnen als auch die kollektiven, waren körperlich deformiert. Aber sie unterschieden sich sowohl in der Bedeutung, die ihnen zugemessen wurde, als auch in der Art und Weise ihrer Wahrnehmung. Konzipiert als Grenzerscheinungen des menschlichen Körpers trugen die deformierten, monströsen Zwischenwesen nicht zuletzt zur Formierung des menschlichen Körpers bei.

\section{Literatur}

Albertus Magnus, De animalibus libri 26, Nach der Cölner Urschrift. Hrsg. v. Hermann Stadler, 2 Bde. (Beiträge zur Geschichte der Philosophie des Mittelalters. Texte und Untersuchungen). Münster 1916/20.

Alexander von Hales, Summa Theologica. Hrsg. v. BOnAventura MarRANi. Florenz 1928.

Aristoteles, Historia Animalium, Bd. 1. Hrsg. v. DAvid M. BELME. Cambridge 2002.

Aristoteles, Metaphysik, Bücher VII und VIII. Hrsg. v. WOLFGANG DETEL. Frankfurt a. M. 2007.

Augustinus, De civitate Dei, Hrsg. v. B. Dombart u. A. KalB. In: Corpus Christianorum, ser. lat. 47/48. Turnhout 1953/54.

Gervasius von Tilbury, Otia Imperialia. Kaiserliche Mußestunden. Hrsg. v. HeINZ E. STIENE (Bibliothek der Mittellateinischen Literatur 6). Stuttgart 2009. 
Isidor von Sevilla, Etymologiarum sive originum libri XX. 2 Bde. Hrsg. v. WALLACE MARTIN LINDSAY. Oxford 1911.

Journal d'un bourgeois de Paris 1405-1449. Hrsg. v. COLETTE BEAUnE. Paris 1990.

Lothar von Segni, De miseria humane conditionis. Hrsg. v. MICHELE MACCARRONE. Lucani 1955.

Lothar von Segni, Vom Elend des menschlichen Daseins. Aus dem Lateinischen übersetzt v. CARL-FrIEDRICH GEYER (Philosophische Texte und Studien 24). Hildesheim 1990.

Peter von Auvergne, Sind Pygmäen Menschen? Hrsg. v. JOSEPH KOCH. In: Archiv für Geschichte der Philosophie 40, 1931, S. 209-213.

Petrarca, Francesco, Rerum memorandarum libri IV. Hrsg. v. GIUSEPPE BILLANOVICH. Florenz 1943.

Plinius, Historia Naturalis libri VII. Hrsg. v. RODERICH KÖNIG. Zürich 1975.

Ratramnus von Corbie, Epistola 12 (Epistola de cynocephalis). Hrsg. v. ERNST DÜMMLER, in: MGH Epistolae 6, Epistolae Karolini Aevi 4. Berlin 1902, S. 155-157.

Solinus, Collectanea rerum memorabilium. Hrsg. v. THEOdOR MOMMSEN, 2. Aufl. Berlin 1895.

Villani, Giovanni, Nuova Cronica. 3 Bde. Hrsg. v. G. PORTA. Parma 1991.

Vincenz von Beauvais, Speculum quadruplex sive speculum maius. Douai 1624, Photomechanischer ND. Graz 1964.

\section{Forschung}

DAston, LORRAine u. PARK, KATHERINe, Wunder und die Ordnung der Natur: 1150-1750. Frankfurt a. M. 2002.

ENGELS, DAvID, Das römische Vorzeichenwesen (753-27 v. Chr.). Quellen, Terminologie, Kommentar, historische Entwicklung. Stuttgart 2007.

Foucault, MiCHEL, Die Anormalen. Vorlesungen am Collège de France (19741975). Frankfurt a. M. 2007.

FrIEDman, JOHN B., The Monstrous Races in Medieval Art and Thought. Cambridge (Mass.)/London 1981. 
GeBhARD, Gunther, GEISLER, Oliver u. SCHRÖTER, STEFFEN, Einleitung. In: DIES. (Hrsg.), Von Monstern und Menschen. Begegnungen der anderen Art in kulturwissenschaftlicher Perspektive. Bielefeld 2009, S. 9-30.

DIES. (Hrsg.), Von Monstern und Menschen. Begegnungen der anderen Art in kulturwissenschaftlicher Perspektive. Bielefeld 2009.

Geisenhanslüke, ACHIM u. Mein, GEORG (Hrsg.), Monströse Ordnungen. Zur Typologie und Ästhetik des Anormalen (Literalität und Liminalität). Bielefeld 2009.

GEYER, CARL-Friedrich, Einleitung. In: Lothar von Segni, Vom Elend des menschlichen Daseins. Aus dem Lateinischen übersetzt von DEMS. (Philosophische Texte und Studien, Bd. 24). Hildesheim 1990, S. 1-40.

GNÄDINGER, LOUISE, Contemptus Mundi. In: LexMA, Bd. 3. München 1986, Sp. $186 f$.

GOETZ, HANS-WERNER, „Debilis“. Vorstellungen von menschlicher Gebrechlichkeit im frühen Mittelalter. In: Homo debilis. Behinderte - Kranke - Versehrte in der Gesellschaft des Mittelalters. Hrsg. v. CORDUlA NOLTE (Studien und Texte zur Geistes- und Sozialgeschichte des Mittelalters 3). Korb 2009, S. 21-55.

HAGNER, MiCHAEL, Monstrositäten haben eine Geschichte. In: Ders. (Hrsg.), Der falsche Körper. Beiträge zu einer Geschichte der Monstrositäten. Göttingen 1995, S. 7-20.

KEHNEL, ANNETTE, Defizienz und Zivilisationsprozess. Überlegungen zur ,Macht der Schwäche' am Beispiel des kranken Königs Hiskia auf der Wiener Reichskrone. In: Homo debilis. Behinderte - Kranke - Versehrte in der Gesellschaft des Mittelalters. Hrsg. v. CORDula NolTE (Studien und Texte zur Geistes- und Sozialgeschichte des Mittelalters 3). Korb 2009, S. 263-289.

KERn, MiCHAEL, Poesie und Poetik der Vergänglichkeit in der weltlichen Dichtung des 12. bis 15. Jahrhunderts (Quellen und Forschungen zur Literatur- und Kulturgeschichte, Bd. 54). Berlin 2009.

LEFEBVRE-TEILARD, A., Infans conceptus. Existence physique et existence juridique. In: Revue historique du droit français et étranger 72 (1994), S. 499-525.

Maccarrone Michele, Praefatio. In: Lothar von Segni, De miseria humane conditionis. Hrsg. v. DEMS. Lucani 1955, S. IX-XLII.

Macho, Thomas H., Vom Ursprung des Monströsen. Zur Wahrnehmung des verunstalteten Menschen. In: HOLL, ADOLF (Hrsg.): Wie werden aus Menschen Monstren? (Manuskripte 109). Graz 1990, S. 55-94. 
MOORE, JOHN C., Innocent III's De miseria humanae conditionis: A speculum curiae? In: The Catholic Historical Review 67, 1981, S. 553-564.

MÜlLER, KLAUS E., Der Krüppel. Ethnologia passionis humanae. München 1996.

MÜNKLER, MARINA, Monstra und mappae mundi: Die monströsen Völker des Erdrands auf mittelalterlichen Weltkarten. In: GLAUSER, JÜRG u. KIENING, CHRISTIAN (Hrsg.), Text-Bild-Karte. Kartographien der Vormoderne. Freiburg 2007, S. 149-173.

MÜNKLER, MARINA u. RÖCKE, WERNER, Der ordo-Gedanke und die Hermeneutik der Fremde im Mittelalter. Die Auseinandersetzung mit den monströsen Völkern des Erdrandes. In: MÜNKLER, HERFRIED (Hrsg.), Die Herausforderung durch das Fremde. Berlin 1998, S. 701-766.

Neumann, Josef N., Der mißgebildete Mensch. Gesellschaftliche Verhaltensweisen und moralische Bewertungen von der Antike bis zur frühen Neuzeit. In: HAGNeR, MiCHAEL (Hrsg.), Der falsche Körper. Beiträge zu einer Geschichte der Monstrositäten. Göttingen 1995, S. 21-44.

Nolte, Cordula (Hrsg.), Homo debilis. Behinderte - Kranke - Versehrte in der Gesellschaft des Mittelalters (Studien und Texte zur Geistes- und Sozialgeschichte des Mittelalters 3). Korb 2009.

RUH, KURT, Innozenz III. In: VL 4 21983, Sp. 388-395.

SChrage, Eltjo J. H., Capable of Containing a Reasonable Soul. In: Collatio iuris romani. Festschrift für Hans Ankum, Bd. 2. Hrsg. v. ROBERT C. FEENSTRA. Amsterdam 1995, S. 469-488.

VAN DER LUGT, MAAIKE, L'humanité des monstres et leur accès aux sacrements dans la pensée médiévale. In: CAIOZZO, ANNA u. DEMARTINI, ANNE-EMMANUELLE (Hrsg.), Monstre et imaginaire social. Approches historiques. Paris 2008, S. 135-161.

WitTKOWER, Rudolf, Marvels of the East. A Study in the History of Monsters. In: Journal of the Warburg and Courtauld Institutes 5 (1942), S. 159-197.

WOOD, IAN, The Missionary Life. Saints and the Evangelisation of Europe, 4001050. Harlow 2001. 



\title{
Der chimärische Hybridkörper im Artusroman
}

\author{
Eva Bolta
}

\begin{abstract}
:
This essay will analyse the several hybrid figures which appear in various Arthurian romances based on their phantasmatic potency. The anthropozoomorphic appearance of Cundrie from Wolfram's von Eschenbach Parzival, Pfetan from Wirnt's von Grafenberg Wigalois and of the messenger of king Piure from Heinrich's von dem Türlin Diu Crône will be interpreted as a combination of different phantasmas with respect to the medieval cognition theory and teachings of perception. This combinatory principle will be traced back to the figure of thought of the chimera. This comes along with a description of rhetorical methods of pattern forming narration.
\end{abstract}

\section{Deformierte Einzelfiguren}

In der mittelalterlichen Artusliteratur spielen deformierte, d. h. in ihrer äußerlichen Gestalt von der höfischen Gesellschaftsnorm abweichende Wesen eine bedeutende Rolle. Ihre körperlichen Erscheinungen divergieren in einem oder mehreren Merkmalen von denen eines durchschnittlichen Menschen: Hyper- und Mikrosomie, zoomorphe Attribute, Modifikation gewöhnlicher Formen ins Extreme. Vor allem im späten Artusroman tauchen immer wieder Figuren auf, deren Konstitution sämtliche Klassifizierungsversuche zunichtemacht: chimärisch zusammengesetzte Gestalten wie Cundrîe, Pfetan u. a., die häufig unhinterfragt erscheinen und recht schnell wieder aus der Handlung verschwinden. Im Anschluss an HAUGS einschlägige Arbeiten versteht man sie vorwiegend als fantastische Vertreter der An- 
derwelt, als „Ausgeburten einer perversen Einbildungskraft“, ${ }^{1}$ welche der Freiheit des Fiktionalen geschuldet sind und schreibt dem späten Artusroman eine dämonisierte Gegenwelt zu, vor der sich der krisenlose Held umso glanzvoller abhebt, je wilder und ungebiurer seine Aventiure-Gegner erscheinen. ${ }^{2}$ Da die Begriffe ,fantastisch $^{6}$ und ,fiktional' jedoch nicht problemlos auf die mittelalterliche Literatur angewandt werden können, ${ }^{3}$ möchte ich eine Lesart vorschlagen, die sich weniger anachronistisch ausnimmt und auf der zeitgenössischen Wahrnehmungs- und Erkenntnislehre beruht. Meines Erachtens demonstrieren jene deformierten Figuren zunächst das Anliegen der mittelalterlichen Dichter, in ihren Rezipientenlebendige, anschauliche Vorstellungen hervorzurufen, also bilderzeugend zu erzählen. Der chimärische Hybridkörper bringt dies in besonderem Maße zur Anschauung: Er markiert die außerordentliche Fähigkeit der menschlichen Einbildungskraft, einzelne, z. T. widersprüchliche Vorstellungsbilder zu einem einzigartigen Resultat zu kombinieren. Des Weiteren enthüllt die einzeltextübergreifende Lektüre eine aufschlussreiche Gemeinsamkeit auf poetischer Ebene: Fast alle chimärischen Figuren besitzen eine vorausdeutende und/oder handlungsinitiierende Funktion, die sich über ihr außergewöhnliches Erscheinungsbild als monstra plausibilisieren lässt.

Zur Illustration ziehe ich zunächst das wohl berühmteste Hybridwesen heran: Wolframs von Eschenbach Cundrîe aus dem Parzival. ${ }^{4}$

\section{Cundrîe}

Kurz nachdem Parzival in Buch VI in die Tafelrunde aufgenommen wurde, erscheint eine Figur am Artushof, die sich durch ihre äußerliche Erscheinung nicht nur von der höfischen Norm, sondern auch von allen anderen Frauen in der höfischen Epik abhebt: ${ }^{5}$ es ist Cundrîe, la surziere. Zwar ist sie mit prachtvollen Gewändern nach französischer Mode angetan, doch ihr Körper ist entstellt:

si was genaset als ein bunt: / zwên ebers zene ir für den munt / giengen wol spannen lanc. / [...] / Cundrî truoc ôren als ein ber, / nibt nâch friundes minne ger: / rûch was ir antlütze erkant. / [...] / gevar als eines

\footnotetext{
${ }^{1}$ Vgl. Haug, Das Fantastische, S. 146.

2 Vgl. Cormeau, ,Wigalois‘ und „Diu Crone', S. 34ff.; sowie Haug, Das Fantastische, S. 143; DERS., Der Teufel, S. 80.

${ }^{3}$ Zur Fiktionalitätsdebatte in der Mediävistik vgl. GLAuCH, An der Schwelle; Haug, Geschichte; HeINZLE, Die Entdeckung; KNAPP, Fiktionales Erzählen; MÜLLER, Literarische und andere Spiele.

${ }^{4}$ Die Diskrepanz zwischen Hässlichkeit und Bildung ist seit der Studie von DeINERT, Ritter und Kosmos, Gegenstand der Forschung. Neuere Arbeiten zur Cundrîe-Figur Wolframs liegen vor von: KASTEN, Häßliche Frauenfiguren; BLEumer, Das wilde wîp; BöHLAND, Integrative Funktion; RIDDER, Gelehrtheit.

${ }^{5}$ Mit Ausnahme der Sibillen-Figur der Aeneas-Erzählungen, die als Modell für Wolframs Cundrîe in Frage kommt, so RuH, Höfische Epik, S. 86 und in dessen Nachfolge KASTEN, Häßliche Frauenfiguren, S. 258f.
} 
affen bût / truoc hende diz. gabe trût. / die negele wâren nibt ze lieht; / wan mir die âventiure giebt, / sie stüenden als eins lewen klân.

(Parz. 313, 21-314, 9; „Auch war sie wie ein Hund benast; aus ihrer Schnauze ragten spannenlang zwei Eberzähne; [...] Cundrie mit Ohren wie ein Bär, und ihr Gesicht war ganz behaart - nicht so, wie sich’s ein Liebender wünscht! [...] Hände wie mit Affenfell. Die Fingernägel wuchsen wild: wie mir die histoire berichtet, ragten sie wie Löwenkrallen." $)^{6}$

Cundrîes Körper fügt sich aus humanoiden und animalischen Elementen zusammen und repräsentiert deutlicher als jede andere literarische Figur die Komplexität des Hybridwesens. Ihr außergewöhnliches Erscheinungsbild steht in ausdrücklicher Beziehung zu Parzivals innerer Unvollkommenheit: ,ich dunke iuch ungehiure, / und bin gehiurer doch dann ir" (Parz. 315, 24f.). ${ }^{7}$ Schon die Demoiselle sur la mule aus dem Perceval des Chrétien de Troyes fällt durch ihre anthropozoomorphe Gestalt aus dem Rahmen schlichter Hässlichkeit: Wie Cundrîe trägt auch sie tierische Züge am humanoiden Körper. Indem er Cundrîes Beschreibung gegenüber seiner französischen Vorlage noch ausweitet, forciert Wolfram die Bildintensität des deformierten Körpers nach den rhetorischen IdBolta x8ealen enérgeia und enárgeia (lat. evidentia). ${ }^{8}$ Welche Rolle spielt dies für die Wahrnehmung der Figur?

Um diese Frage beantworten zu können, muss zunächst die mittelalterliche Epistemologie in ihren Grundzügen erarbeitet werden: Seit der Antike arbeiten Mediziner und Philosophen in Verbindung mit einer Seelenlehre an einer Hirnpathologie, die als Drei-Ventrikel-Theorie bekannt ist. Ihr zufolge ist das menschliche Gehirn in drei Kammern unterteilt, die jeweils unterschiedliche Funktionen erfüllen: Über das Pneuma (einem feinstofflich gedachten Vermittler zwischen Körper und Seele) werden die Sinnesreize empfangen und als Vorstellungsbilder in die imaginatio bleibend eingeprägt. ${ }^{9}$ Die ratio empfängt dieses eingeprägte Phantasma und verknüpft es mittels ihres Unterscheidungsvermögens und ihrer Urteilskraft mit einer Bedeutung, bevor sie es in die memoria weiterleitet, wo dem Erin-

\footnotetext{
6 Übersetzung v. DiETER KÜHN.

7 „In Euren Augen bin ich häßlich - bin nicht so häßlich wie Ihr selbst!“ - Übersetzung: DiETER KÜHN. Sehr früh hat BLUMSTEIN auf die Spiegelbildlichkeit der beiden Figuren hingewiesen: „Cundrie $[\ldots]$ constantly draws open or implied comparisons between Parzival's outward beauty and inward ugliness and weakness on the one hand, and her own loathsome features and her inner loyalty and strength on the other hand." (Blumstein, The Structure, S. 163) Im Rahmen dieses Aufsatzes muss dieser Hinweis auf die ausführliche Diskussion über die poetologische Verbindung zwischen Parzival und Cundrîe genügen.

8 evidentia bezeichnet ,ausschließlich Mittel, die auf nicht-diskursive Weise, nämlich im Wege der Veranschaulichung, zur Einsicht führen.“ Der Unterbegriff enérgeia umfasst „Verfahren der Verlebendigung, der Vergegenwärtigung des Abwesenden“, während enárgeia „Verfahren der Detaillierung“ meint. Zitiert nach: Ueding, Historisches Wörterbuch, Sp. 39f. Vgl. auch: Campe, Vor Augen Stellen, S. 208-225.

${ }^{9}$ Zur antiken Pneumatologie Vgl. Agamben, Stanzen, S. 148f.; Culianu, Eros und Magie, S. 28f..
} 
nerungsbild ein Speicherort zugeteilt wird. Mit Thomas von Cantimpré kurz gesagt: „Prima concipit, secunda discernit, tertia discussa et diiudicata custodit."“10

Über die Übersetzungen arabischer Medizin durch das Kolleg von Salerno und über die Autoren des sog. Chartreskreises, z. B. Wilhelm von Conches und Bernardus Silvestris, wird diese antike Hirnphysiologie dem lateinischen Westen vermittelt und geht in mehrere Enzyklopädien des 12. Jahrhunderts ein, so bei Gregor von Montesacro, Bartholomäus Anglicus und dem eben erwähnten Thomas von Cantimpré. ${ }^{11}$ Im 13. Jahrhundert wird diese dreistufige Seelenlehre modifiziert und unter Berufung auf den Aristoteles-Kommentator Avicenna zu einem fünfstufigen Modell ausgearbeitet. ${ }^{12}$

Schon Aristoteles betont die Angewiesenheit des Denkens auf die Leistungen

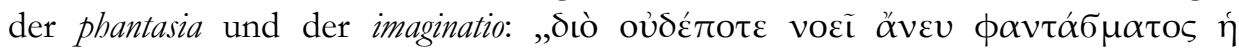
$\phi v \chi \eta ் . " 13$ Dabei ist die Erkenntnis nicht an eine aktuale Wahrnehmungssituation gebunden. Denn über die Phantasmenproduktion ist die Imagination in der Lage „Erscheinungen zusammen[zu]fügen, um ein komplexes Bild von Dingen zu erzeugen [...], die weder in der Wirklichkeit als zusammengesetzte vorkommen noch auch nur vorkommen können [...]." ${ }^{\text {"14 }}$ Auf diese Weise wird ein Denken über Dinge möglich, die nicht in der realen Welt existieren. Wie bereits Aristoteles

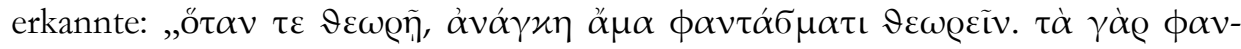

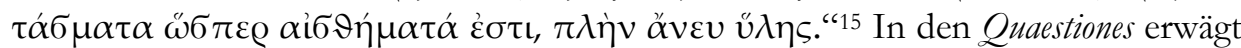
Thomas von Aquin die formae cognitivae von Nichtseiendem anhand der Vorstellung von goldenen Bergen oder Chimären. ${ }^{16}$ Der Status der Chimäre als Objekt der Imagination oder als unmöglicher Gegenstand wird seit der Antike diskutiert. Dies geschieht in unmittelbarer Nachfolge der dialektischen Auseinandersetzung Aristoteles' mit dem tragelaphos (Bockhirsch), der ebenfalls eine zusammengesetzte Gestalt ist. In den Analytica posteriora kommt Aristoteles zu dem Schluss, der tragelaphos gehöre zum Nichtseienden, obwohl seine beiden Komponenten jeweils als einzelne ein Vorstellungsbild ergeben können. ${ }^{17}$ Bei seinem mittelalterlichen Kommentator Averroes, der den Tragelaph und die Chimäre zusammenbringt, werden

\footnotetext{
10 Thomas von Cantimpré, Liber de natura rerum, I, 2: „Die erste stellt es sich vor, die zweite synthetisiert, die dritte bewahrt die Urteile und Entscheidungen“ - eigene Übersetzung.

${ }^{11} \mathrm{Vgl}$. MeIER, Imaginatio, S. 162f.

12 Hierbei tritt die aristotelische phantasia als sensus communis zur bekannten Trias der Kräfte hinzu, während das bislang als ratio bekannte Vermögen in die vis estimativa und vis cogitativa unterteilt wird.

13 Aristoteles, De anima, III, 7, 431a - „Deshalb erkennt die Seele vernünftig nie ohne Vorstellungsbilder." Übersetzung v. W. THEILER.

14 DoYLE, Gedankendinge, S. 221.

15 Aristoteles, De anima, III, 8, 432a - „Und deshalb könnte jemand ohne Wahrnehmung nichts lernen, noch auch begreifen. Und wenn man etwas [theoretisch, sic.] betrachtet, dann muß man es zugleich mit einem Vorstellungsbild betrachten.“ Übersetzung v. W. THEILER.

${ }^{16}$ DOYLE, Gedankendinge, S. 215.

${ }_{17}$ Aristoteles, Analytica posteriora, II, 7, 92b.
} 
jedoch beide als Vorstellungsbilder zu etwas Seiendem (ens veridicans), da ihre gegensätzlichen Komponenten jeweils im Intellekt existieren. ${ }^{18}$

Unabhängig von der philosophischen Diskussion über ihren Status als möglicher oder unmöglicher Gegenstand ist die Chimäre im Hochmittelalter als literarische Metapher aus der Ars poetica des Horaz bekannt, der zu den auctores des trivium gehört. Sein Werk hat bis in die Neuzeit großen Einfluss auf Literaten und Poeten. Losgelöst aus seinem unmittelbaren Zusammenhang und entfremdet von der Intention seines Autors entwickelt das Bild der Chimäre eine eigenständige Wirkung, die sich im Auftauchen ähnlicher Figuren in divergierenden Erzähltraditionen und Sinnzusammenhängen niederschlägt.

In einem ersten resümierenden Rückblick ist zu konstatieren, dass die Chimäre als ein aus verschiedenen, z.T. widersprüchlichen Komponenten zusammengesetztes Wesen gedacht wird. Nach mittelalterlicher Wahrnehmungs- und Erkenntnislehre nimmt sie in der menschlichen Imagination Gestalt an, indem ihre Einzelkomponenten jeweils aus der Erinnerung abgerufen und durch die Verstandeskräfte als etwas bereits Bekanntes erfasst werden. Diese einzelnen Phantasmen werden nun in der imaginatio zu einer neuen Form zusammengesetzt. So entsteht ein Wesen, das die Gesetzmäßigkeiten der realen Welt überschreitet - ein Wesen wie Wolframs Cundrîe. Vor dem Hintergrund der mittelalterlichen Epistemologie wird verständlich, dass es sich bei Wolframs descriptio keineswegs um einen simplen Vergleich handelt. Cundrîe verkörpert mehr als nur eine hässliche Frau: Sie ist ein chimärisches monstrum.

An dieser Stelle werden terminologische Reflexionen nötig. Der neuhochdeutsche Begriff ,Monster' geht zwar ,über das substantivierende Derivat monestrum “ auf lat. monere zurück und „bildet dabei einen lexikalischen Zusammenhang mit monstrare [...], monstrosus [...] und monstrositas [...], außerdem mit miraculum $[\ldots]$, portentum $[\ldots]$, ostentum $[\ldots]$ und prodigium $[\ldots]^{\text {", }},{ }^{19}$ die eindeutig positiven semantischen Besetzungen wie ,erinnern', ,raten', zeigen', ,hinweisen', ,lehren', ,wunderbar', ,Wunderding' und ,Vorzeichen' sind jedoch im heutigen Sprachgebrauch nicht mehr erhalten. ${ }^{20}$ Es zeigt sich dagegen eine Bedeutungsverengung auf ,ungeheuerlich', ,missgestaltet ${ }^{6}$ und ,furchteinflößend'. Durch diese Verengung wird der neuhochdeutsche Ausdruck der semantischen Fülle des antik-mittelalter-

\footnotetext{
18 DOYLE, Gedankendinge, S. 218.

19 Overthun, Das Monströse, S. 47.

20 ToggweILER, Kleine Phänomenologie, bemerkt hierzu: „wir [haben] es mit einem relativ unspektakulären und neutralen Wesen zu tun“.20 Die ursprüngliche Funktion der monstra scheint die des Zeigens zu sein, erschöpft sich aber noch nicht in der durch die Alteritätsforschung aufgestellten Hypothese der Selbstreflexivität, die im Fremdartigen lediglich das verzerrte Spiegelbild des eigenen sieht, sondern muss im literaturwissenschaftlichen Zusammenhang vor dem jeweils eigenen werkspezifischen Hintergrund neu diskutiert werden. Diesem Vorhaben gehe ich in meiner Dissertation zum Thema: sungebiure crêatiure - die Chimäre als dialektische Denkfigur und poetologisches Prinzip im späten Artusromanı nach, die 2012 erscheinen soll.
} 
lichen Begriffs und insbesondere einer ambivalenten Figurenzeichnung nicht gerecht. ${ }^{21}$

So fällt auf, dass Wolframs Cundrîe dem mittelalterlichen Kalokagathie-Ideal, das eine Übereinstimmung zwischen äußerer Erscheinung und inneren Werten annimmt, gerade nicht entspricht. Trotz ihrer äußerlichen Hässlichkeit beweist Cundrîe während beider Begegnungen triwwe, zubt und herzen riuwve. Auch mag überraschen, dass ausgerechnet diese unhöfische Figur Parzivals Schicksal enthüllt und die Suche des Helden nach dem Gral initiiert - bedenkt man jedoch die positiven Konnotationen der monstra, so wird die vorausdeutende Funktion des Hybridwesens plausibel.

\section{Pfetan}

Im Wigalois Wirnts von Grafenberg begegnen dem Helden eine ganze Reihe sonderbar anmutender Kreaturen, u. a. der Drache Pfetan. Der Kampf gegen ihn weicht durch die lange und aufwändige Beschreibung vom bislang in der Heldenund Artusepik bekannten Drachenkampf-Schema ab, das von einer detaillierten Darstellung absieht und lediglich die bekannten Attribute wie Feuerspeien, übler Geruch und enorme Körperkräfte aneinanderreiht. Wirnt von Grafenberg jedoch schiebt eine 51 Verse lange descriptio ein, um ein detailliertes Vorstellungsbild in die imaginatio seines Helden und seiner Zuhörer zu zeichnen:22

\footnotetext{
in sînem giele hêt er / lange žene als ein swîn; / [...] / von dem boubet bin ze tal / stuont ûf im ein scharfer grât, / als der kokodrille bât, / [...] / der wurm hêt nach wurmes sit / einen zagel langen; / [...] / einen kamp hêt er als ein han, / wan daz er ungevüege was; / [...] / zwei ôren hêt er als ein mûl; / [...] / ouch hêt er vil

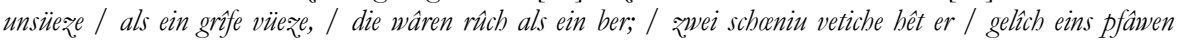
gevider; / [...] / sin drozze gar von knurren was, / als ein steinbockes horn.

(Wig. 5025-5076; , in seinem Rachen hatte er Zähne so lang wie die eines Ebers [...] vom Kopf den Rücken hinab zog sich einer hoher scharfer Grat wie bei einem Krokodil, [...] Der Drache besaß nach Drachenart einen langen Schwanz; [...] Er hatte einen Kamm wie ein Hahn, nur dass er gewaltig war; $[. .$.$] seine Ohren waren wie die eines Maultiers; [...] Außerdem hatte er$ sehr unförmige Füße wie ein Greif; sie waren behaart wie die bei einem Bären; zwei schöne Flügel hatte er, die wie Pfauenfedern schillerten; [...] Seine Kehle war ganz wie aus dem Horn eines Steinbocks gemacht").23
}

\footnotetext{
${ }^{21}$ Vgl. auch den Beitrag von VOLKER SCIOR in diesem Band.

22 Aus Platzgründen kann hier nicht die gesamte Beschreibung wiedergegeben werden. Zahlreiche Abbildungen mittelalterlicher Darstellungen von Drachen finden sich bei BALTRUŠAITIS, Réveils et prodiges. Das Erscheinungsbild Pfetans bildet auch vor diesem kunsthistorischen Hintergrund eine Ausnahme.

23 Übersetzung hier und im Folgenden v. SABINE u. Uwe SEelbach.
} 
Der Drache Pfetan setzt sich aus den Phantasmen von nicht weniger als acht verschiedenen Tieren zusammen. ${ }^{24}$ Durch die gesteigerte Phantasmenüberlagerung kommt es zu einer Realitätszersetzung, die zunächst die ratio des Helden außer Kraft setzt und ihn in eine Ohnmacht sinken lässt, welche ihn für fast 700 Verse, die Länge einer kompletten Episode, aus dem Handlungsgeschehen nimmt. Als er wieder erwacht, ist seine memoria betroffen:

michel wunder in des nam / wie er dar komen ware / [...] / Gwîgâlois, mabtu mir sagen: / waz wunders hât dich her getragen / od wie stêt dîn dinc alsô?

(Wig. 5797f. u. 5802-5804; „Er wunderte sich sehr darüber, wie er dorthin gekommen war [...] Wigalois, kannst du mir sagen, auf welch wundersame Weise du hierher gelangt bist oder wie es um dich steht?").

Er kann sich weder daran erinnern, wie er an den Ort seines Erwachens gekommen ist, noch, wer oder was ihn derart übel zugerichtet hat. Die Analogie zum Identitätsverlust Iweins wurde bereits mehrfach festgestellt, ${ }^{25}$ die Differenz sollte jedoch nicht ignoriert werden: Iwein weist seine vergangenen Heldentaten einem Traum zu und spricht diesem jeden Realitätsgehalt ab. Demgegenüber ist sich Gwîgâlois seiner Vergangenheit durchaus bewusst, er kann sich an seine Eltern, seine Kindheit in Jorams Reich, die Zeit in Karidôl und die Aventiure von Korntîn entsinnen (Wig. 5814-5830). Woran es ihm mangelt, ist einerseits die Erinnerung an das unmittelbar vorausgehende Geschehen, andererseits das eigene Phantasma: „deiswâr, gestuont dîn herze ie hô / von minnen, ode wurd ie rîch, / dem bistu leider ungelîch. " (Wig. 5805ff.) ${ }^{26}$ Sein Äußeres deckt sich nicht mit dem eines Ritters, da ihm während seiner Ohnmacht Rüstung und Waffen gestohlen wurden. Hier zeigt sich sowohl ein kausallogischer Erzählzusammenhang mit dem Drachenkampf ${ }^{27}$ denn Gwîgâlois wäre nicht in diese Situation gekommen, hätte ihn Pfetan nicht seines Bewusstseins beraubt - als auch ein epistemologisches Erzählkalkül: Während des Anblicks Pfetans überlagern sich manigfaltige Phantasmen, wodurch es $\mathrm{zu}$ einer völligen Überforderung des hirnphysiologischen Apparates des Helden kommt, die letzten Endes den Verlust des eigenen Identitätsphantasmas verursacht.

Darüber hinaus steht die Begegnung mit Pfetan in poetologischem Zusammenhang mit der Hauptaventiure, denn in der Beschreibung des Endgegners Roaz

\footnotetext{
${ }^{24}$ Claude Lecouteux führt die einzelnen Details kenntnisreich auf antike Autoren, den Physiologus, Bestiarien, Heiligenlegenden und die mittelalterliche Naturkunde zurück; vgl. LECOUTEUX, Der Drache, S. 25-29.

25 So u. a. von Bleumer, Das wilde wîp, S. 84 ${ }_{s}$ Cormeau, ,Wigalois‘ und ,Diu Crone‘, S. 42f.; MerTens, Der deutsche Artusroman, S. 182; DERs., Iwein und Gwigalois, S. 19.

26 „Wahrlich, wenn du je ein hohes Herz trugst in Liebesdingen, oder wenn du jemals beglückt wurdest, dem entsprichst du jetzt überhaupt nicht."

27 Seine Feststellung „n̂े bin ich ungebiure“ („Nun aber bin ich ein Wilder“ - Wig. 5831) verweist einerseits auf die Bezeichnung der Kreatur Pfetan, die jede natürliche Ordnung aufhebt (Wig. 50205024), andererseits wird sie als Kennzeichnung seines eigenen widernatürlichen Zustandes verwendet und erzeugt so eine weitere, diesmal wörtliche Verknüpfung zwischen Drachenkampf und Identitätsverlust.
} 
finden sich Reminiszenzen an sie: Das Phantasma des Drachen taucht als heraldische imago wieder auf: ${ }^{28}$ Roaz trägt den Drachen als Wappentier (Wig. 7365-7368) und eine entsprechende aufwändige Helmzier (Wig. 7389-7391). Im heraldischen Schema verschmelzen diese beiden Gegner zu einer Einheit, obwohl die beiden Episoden weit auseinander liegen. ${ }^{29}$ So verweist auch dieses chimärische monstrum zum Zeitpunkt seines Auftauchens auf zukünftiges Geschehen, welches, analog zu Parzivals Weg zum Gral, über das Schicksal des Helden Gwîgâlois entscheiden wird.

\section{Der Bote des Königs Piure}

Mein drittes Beispiel beziehe ich aus der Crône Heinrichs von dem Türlin. Dort herrscht zu Beginn gedämpfte Stimmung am Artushof, man wartet einmal mehr auf eine Aventiure. Sie erreicht den Hof in der Gestalt eines sonderbaren Boten:

Sein antlütz was nibt gestalt / Sam ander anplike. / Sein vel, daz was dike / Erwachsen von squamen. / [...] / Dike weit was sein munt. / Den dachten gran hie und da. / Seiniu ougen waren eisgra, / Groz sam ein strauzes ey. / [...] / Seins houptes obdach / Was har sam vischflozen. / [...] / Ein vrömdiu varbe überzoch / Swartz, gra und ysenvar / Hend und antlütr. gar

(Crône 957-977; „,Sein Gesicht war nicht so geformt wie andere Antlitze. Seine Haut war völlig von Schuppen bedeckt. [...] Sein Mund war sehr weit. Den bedeckten hier und da Gräten. Seine Augen waren eisgrau, groß wie ein Straußenei. [...] Die Bedeckung seines Kopfes bestand aus Haar, das Fischflossen ähnelte. [...] Eine merkwürdige Farbe überzog gänzlich Hände und das Gesicht, schwarz, grau und eisenfarben"). ${ }^{30}$

Ähnlich wie Cundrîe spricht auch dieser Bote formvollendet französisch und übermittelt Artus die Grüße seines Herren, des Meereskönigs Piure, sowie ein magisches Geschenk in Form eines Bechers. Die nun folgende Tugendprobe deckt die Unzulänglichkeiten sämtlicher Mitglieder des Hofstaates - ausgenommen des Königs - auf und lässt sie durch das Verschütten von Wein sichtbar werden. ${ }^{31}$ Das Arrangement der Episode lässt mittels der magischen Requisite, „die das Innere sichtbar nach außen kehrt"32, eine Inversion der Wahrnehmung erahnen: Das

\footnotetext{
28 WANDHOFF und HARTMANN sehen u. a. in Wappenbildern ,besonders markierte ,memorial centers', über deren imaginative Vergegenwärtigung sich im nachhinein die Handlungsfäden des Textes rekonstruieren und seine Sinndimensionen kontemplieren lassen." Vgl. WANDHOFF, Ekphrasis, S. 326; HARTMANN, Grundformen, S. 32.

29 Aufgrund des großen Abstandes wurden diese beiden Kämpfe bisher, soweit ich überblicke, nicht miteinander in Beziehung gesetzt; statt dessen spricht z. B. CORMEAU dem Drachenkampf jede Bedeutung ab, die über das Postulat eines episodenhaften Hindernisses hinausginge (CORMEAU, ,Wigalois“ und ,Diu Crone', S. 49); EMING spricht sogar von einer Auflösung ihrer kausalen und handlungsmäßigen Verknüpfung zu Gunsten zweier unabhängiger Episoden (EMING, Funktionswandel, S. 196).

30 Eigene Übersetzung.

31 Zur Visualisierung der Tugendproben vgl. KeLLERMAnN, Entblößungen.

32 Kaminski, Wâ ez, S. 227.
} 
bizarre Äußere des Überbringers steht im Widerspruch zu seinem höfischen Auftreten und seiner Sprache. Auch die Tugendprobe enthüllt einen Bruch mit dem Kalokagathie-Ideal, indem die schönen Repräsentanten des Hofes einen inneren Makel preiszugeben gezwungen werden. Hier Hässlichkeit und innere courtoisie dort Schönheit und innere Unvollkommenheit. ${ }^{33}$

Auf funktionaler Ebene bringt der Bote des Königs Piure die Handlung in Gang und visualisiert die gattungstypische, initiale Krise des Artushofes. Ferner deutet er auf die zweite Tugendprobe im letzten Drittel der Erzählung voraus (Crône 22990-24730), die eine Art typologischen Bezug herstellt: die angedeuteten Verfehlungen der ersten Probe, Ginovers ehebrecherische Liäson mit Gasoein und Gawans neue Rolle als Protagonist, die ihn mittels persönlicher Motivation ${ }^{34}$ aus dem Hof entfernt, liegen in der Vergangenheit und sind keine Bedrohungen mehr. Demgegenüber wird durch die zweite Tugendprobe eine erfolgreiche Gemeinschaftsaktion initiiert, die die Harmonie der arthurischen Runde restituiert. ${ }^{35}$

\section{$5 \quad$ Fazit}

Anhand der Beispiele aus dem Parzival, dem Wigalois und der Crône ließ sich eine vorausdeutende oder handlungsinitiierende Funktion jener Figuren herausarbeiten, die durch eine komplexe Zusammensetzung ihrer Körper aus der Masse sowohl des höfischen wie auch des anderweltlichen Figurenarsenals des Artusromans hervorstechen. Mit dem außergewöhnlichen Erscheinungsbild geht eine unsichtbare Zeichenhaftigkeit einher: So steht ihr Erscheinungsbild in unmittelbarem Bezug zur Fremd- oder Selbstwahrnehmung des Helden oder der Artusgesellschaft. Cundrîes äußerliche Erscheinung entspricht während des ersten Aufeinandertreffens Parzivals innerer Entstellung, die es auf seinem langen Weg zum Gral zu revidieren gilt. Sie beeinflusst damit unmittelbar die Fremdwahrnehmung des Helden durch die Artusgesellschaft und - vielleicht noch wichtiger - die Vorstellung des Rezipienten. Eine zerstörte Selbstwahrnehmung in Folge eines überlasteten Wahrnehmungsapparates belegt die Begegnung mit dem Drachen Pfetan. Zuletzt markiert der Bote des Meereskönigs Piure die Unvollkommenheit der arthurischen Gesellschaft, indem er sichtbar werden lässt, was sonst verborgen unter der idealen Oberfläche liegt.

Wie es scheint, spielen die Dichter des Artusromans an diesen Figuren die Stärken und Schwächen des Kalokagathie-Ideals durch, denn ebenso oft wie dieses

\footnotetext{
${ }^{33}$ Das auffällige Erscheinungsbild des Boten kann daher nicht als belanglos abgetan werden, wie dies FELDER in ihrem Kommentar nahelegt: „Sein seltsames Äußeres ist demzufolge wohl eher als Kennzeichnung des Märchenhaften und Fremdartigen seiner Herkunft und so als Kuriosität abzutun." (FELDER, Kommentar, S. 71).

${ }^{34} \mathrm{Zu}$ den verschiedenen Rollen der Figur als Hofakteur und Protagonist Vgl. SCHMITZ, Gauvain, insbes. S. 289.

35 Vgl. MeYER, Die Verfügbarkeit, S. 76f.
} 
in Bezug auf die Helden und ihre Damen vorbehaltlos zutrifft, wird es anhand jener hybriden Einzelfiguren invertiert. ${ }^{36}$ Diese Ambivalenz verweist auf die Tradition der Chimäre, den Inbegriff aller Mischwesen und des Hybridmonstrums. Die Grenzen und Spielräume dieser Denkfigur, die das Unmögliche miteinander kombiniert, spiegeln die Aspekte der mittelalterlichen Epistemologie par excellence.

\section{Literatur}

Aristoteles, De anima - Über die Seele. Mit Einleitung, Übersetzung (nach W. THEILER) und Kommentar hrsg. v. HORST SEIDL. Griechischer Text in der Edition v. WiLHELM BIEHL u. OTTO APELT. Hamburg 1995.

Aristoteles, Analytica posteriora. In: Werke in deutscher Übersetzung. Begründet v. ERnst GrumaCh. Hrsg. v. Helmut Flashar. Bd. 3, Teil 2. Übersetzt und erläutert v. WOLFGANG DETEL. Darmstadt 1993.

Heinrich von dem Türlin, Die Krone (Verse 1-12281). Nach der Handschrift 2779 der Österreichischen Nationalbibliothek nach Vorarbeiten v. ALFRED Ebenbauer, Klaus Zatloukal u. Horst P. PÜtz. Hrsg. v. Fritz Peter KNAPP u. MANUELA NIESNER. Tübingen 2000.

Thomas Cantimpratensis, Liber de natura rerum. Berlin 1973.

Wirnt von Grafenberg, Wigalois. Text der Ausgabe v. J.M.N. KAPTEYN, übersetzt, erläutert und mit einem Nachwort versehen v. SABINE SEELBACH u. UlRICH SEELBACH. Berlin 2005.

Wolfram von Eschenbach, Parzival. Nach der Ausgabe KARL LACHMANNS, revidiert und kommentiert v. EBERHARD NELLMANN, übertragen v. DIETER KÜHN. Bd. 1. Frankfurt a. M. 2006.

\section{Forschung}

Agamben, Giorgio, Stanzen. Das Wort und das Phantasma in der abendländischen Kunst. Zürich/Berlin 2005.

ANTUNES, GABRIELA, Entstellte Schönheiten: Überlegungen zum mittelalterlichen Bezug zwischen Hässlichkeit des Körpers und Schönheit der Seele. Erscheint in: ANTUNES, GABRIELA u. REICH, BJÖRN (Hrsg.), (De)formierte Körper, die Wahrnehmung und das Andere im Mittelalter 2, voraussichtlich Göttingen 2012.

\footnotetext{
36 Zum Spiel mit der Kalokagathie vgl. den Beitrag von Gabriela ANTUNES, Entstellte Schönheiten, der im Folgeband (De)formierte Körper 2 erscheinen wird.
} 
BALTRUŠAITIS, JÜRGIS, Réveils et prodiges: le gothique fantastique. Paris 1960.

Bleumer, HARTMUT, Das wilde wîp. Überlegungen zum Krisenmotiv im Artusroman und im ,Wolfdietrich`B. In: ROBERTSHAW, ALAN u. WOLF, GERHARD (Hrsg.), Natur und Kultur in der deutschen Literatur des Mittelalters. Colloquium Exeter 1997. Tübingen 1999, S. 77-89.

Blumstein, ANDREE KaIn, The Structure and Function of the Cundrie Episodes in Wolfram's Parzival. In: The German Quaterly LI (1978), S. 160-169.

BÖHLAND, DOROTHEA, Integrative Funktion durch exotische Distanz. Zur Cundrie-Figur in Wolframs Parivival. In: GAEBEL, UlRIKE u. KARTSCHOKE, ERIKA (Hrsg.), Böse Frauen - Gute Frauen. Darstellungskonventionen in Texten und Bildern des Mittelalters und der Frühen Neuzeit. Trier 2001, S. 4557.

CAMPE, RÜDIGER, Vor Augen Stellen. Über den Rahmen rhetorischer Bildgebung. In: NeUmANN, GerHARD (Hrsg.), Poststrukturalismus. Herausforderung an die Literaturwissenschaft. Stuttgart/Weimar 1997, S. 208-225.

CORMEAu, CHRistoph, ,Wigalois‘ und „Diu Crône‘. Zwei Kapitel zur Gattungsgeschichte des nachklassischen Aventiureromans. München 1977.

Culianu, IoAn Petru, Eros und Magie in der Renaissance. Frankfurt a. M./ Leipzig 2001.

Deinert, Wilhelm, Ritter und Kosmos im Parzival. Eine Untersuchung der Sternkunde Wolframs von Eschenbach. München 1960.

DOYLE, JOHN P., Gedankendinge und Imagination bei den Jesuiten des 17. Jh. In: DEWENDER, ThOMAs u. Welt, ThOmas (Hrsg.), Imagination - Fiktion Kreation. Das kulturschaffende Vermögen der Phantasie. München/Leipzig 2003, S. 213-228.

EMING, JUTTA, Funktionswandel des Wunderbaren. Studien zum Bel Inconnu, zum Wigalois und zum Wigoleis vom Rade. Trier 1999.

FELDER, GUdRUN, Kommentar zur `Crône` Heinrichs von dem Türlin. Berlin 2006.

GLAuCH, SONJA, An der Schwelle zur Literatur. Elemente einer Poetik des höfischen Erzählens. Heidelberg 2009.

Haug, WALTER, Das Fantastische in der späteren deutschen Artusliteratur. In: GÖLLER, KARL HEINZ (Hrsg.), Spätmittelalterliche Artusliteratur. Ein Symposion der neusprachlichen Philologien auf der Generalversammlung der GörresGesellschaft Bonn, 25.-29. September 1982. Paderborn 1984, S. 133-149. 
DERS., Der Teufel und das Böse im mittelalterlichen Roman. In: DERS., Strukturen als Schlüssel zur Welt: Kleine Schriften zur Erzählliteratur des Mittelalters. Tübingen 1989, S. 67-85.

DERS., Geschichte, Fiktion und Wahrheit. Zu den literarischen Spielformen zwischen Faktizität und Phantasie. In: KNAPP, FrITZ PETER u. NIESNER, MANUELA (Hrsg.), Historisches und fiktionales Erzählen im Mittelalter. Berlin 2002, S. 115-131.

HARTMANN, HEIKO, Grundformen literarischer Heraldik im Mittelalter am Beispiel der ,Krone' Heinrichs von dem Türlin. In: Das Mittelalter 11 (2006), S. 28-52.

HEINZLE, JOACHIM, Die Entdeckung der Fiktionalität. Zu Walter Haugs Literaturtheorie im deutschen Mittelalter. In: PBB 112 (1990), S. 55-80.

KAMINSKI, NiCOLA, „Wâ ez sich êrste ane vienc, Daz ist ein teil unkunt“: Abgründiges Erzählen in der „Krone“ Heinrichs von dem Türlin. Heidelberg 2005.

KASTEN, INGRID, Häßliche Frauenfiguren in der Literatur des Mittelalters. In: LUNDT, BEA (Hrsg.), Auf der Suche nach der Frau im Mittelalter. München 1991, S. 255-276.

KELlERmann, Karina, Entblößungen. Die poetologische Funktion des Körpers in den Tugendproben der Artusepik. In: Das Mittelalter 8 (2003), S. 102-117.

KNAPP, FRITZ PETER, Historiographisches und fiktionales Erzählen in der zweiten Hälfte des 12. Jahrhunderts. In: WOLFZETTEL, FRIEDRICH (Hrsg.), Erzählstrukturen der Artusliteratur. Forschungsgeschichte und neue Ansätze. Tübingen 1999, S. 3-22.

Lecouteux, Claude, Der Drache. In: ZfdA 108 (1979), S. 13-31.

MEIER, CHRISTEL, Imaginatio und phantasia in Enzyklopädien vom Hochmittelalter bis zur Frühen Neuzeit. In: DEWENDER, THOMAS u. WELT, THOMAS (Hrsg.), Imagination - Fiktion - Kreation. Das kulturschaffende Vermögen der Phantasie. München/Leipzig 2003, S. 161-181.

MEYER, MATTHIAS, Die Verfügbarkeit der Fiktion. Interpretationen und poetologische Untersuchungen zum Artusroman und zur aventiurehaften Dietrichepik des 13. Jahrhunderts. (GRM-Beiheft 12). Heidelberg 1994.

MERTENS, VOLKER, Der deutsche Artusroman. Stuttgart 1998.

DERS., Iwein und Gwigalois - der Weg zur Landesherrschaft. In: GRM N.F. 31 (1981), S. 14-31.

MÜLLER, JAN-DIRK, Literarische und andere Spiele. Zum Fiktionalitätsproblem in vormoderner Literatur. In: Poetica 36 (2004), S. 281-311. 
Overthun, Rasmus, Das Monströse und das Normale. Konstellationen einer Ästhetik des Monströsen. In: GEISENHANsLÜCKE, ACHIM u. MEIN, GEORG (Hrsg.), Monströse Ordnungen. Zur Typologie und Ästhetik des Anormalen. Bielefeld 2009, S. 43-79.

RIDDER, KLAUS, Gelehrtheit und Häßlichkeit im höfischen Roman. In: RIDDER, KLAUS u. LANGER, OTTO (Hrsg.), Körperinszenierungen in mittelalterlicher Literatur. Kolloquium am Zentrum für interdisziplinäre Forschung der Universität Bielefeld (18.-20. März 1999). Berlin 2002, S. 75-95.

RUH, KURT, Höfische Epik des deutschen Mittelalters. Bd. 2. Berlin 1980.

SCHMITZ, BERnHARD ANTON, Gauvain, Gawein, Walewein. Die Emanzipation des ewig Verspäteten. Tübingen 2008.

ToggweIler, MiCHAEL, Kleine Phänomenologie der Monster. Arbeitsblatt Nr. 42, Institut für Sozialanthropologie, Universität Bern, Bern 2008. In: http://www.anthro.unibe.ch/content/publikationen/arbeitsblaetter/arbeitsbla tt_42/index_ger.html (letzter Zugriff: 28.04.2011).

UEDING, GERT (Hrsg.), Historisches Wörterbuch der Rhetorik. Bd. 3. Darmstadt 1996.

WANDHOFF, HAIKO, Ekphrasis. Kunstbeschreibungen und virtuelle Räume in der Literatur des Mittelalters. (Trends in Medieval Philology 3). Berlin/New York 2003. 



\title{
Die Darstellung der babylonischen Missgeburt in den Res Gestae und sechs davon abhängigen deutschen Dichtungen
}

\author{
Peter Hv. Andersen Vinilandicus
}

\begin{abstract}
:
In his Res Gestae from the beginning of the $4^{\text {th }}$ century, Julius Valerius described a Babylonian monster. Its lower part was living beasts fighting each other, its upper part a dead human body. According to a seer, it predicted Alexander's death and the wars of the Diadochi. This monster partly changed its shape in the different versions of the medieval Alexander romance. The study focuses on the Latin and German descriptions.
\end{abstract}

Die Dichtkunst stellt beobachtete Gegenstände nicht wahrheitsgetreu und objektiv dar; ihre gesellschaftliche Rolle besteht vielmehr darin, die Welt zu deuten und ihren Zeitgenossen und der Nachwelt ihre Perspektive zu vermitteln.

In der Fiktion sind Wesen, die in ihrem Aussehen von der Norm abweichen, häufig an unbekannten und ungewöhnlichen Orten anzutreffen. Auch weil die Erdkugel heute größtenteils als erforscht und bekannt gilt, zeigen z. B. moderne Filmemacher häufig Anormalität durch außerirdische Monster. Bis zum Ende des Mittelalters war hingegen nur ein kleine Teil der Erdfläche bekannt, und das gab den Dichtern in Bezug auf die Ansiedlung ,fabulöser Wesen' auf der Erde größeren Spielraum als heute. Damals waren die entferntesten bekannten Gebiete etwa Thule im Norden, die Brendaninsel im Westen, Äthiopien im Süden und China und Indien im Osten. Derjenige, der bis zu Marco Polos Lebzeiten den Orient am gründlichsten erforscht hatte, war Alexander der Große. In Indien war er mit der 
neuen Welt konfrontiert, und die späteren Berichte über orientalische Monster berufen sich oft auf seine persönlichen Erlebnisse und gehen in gewissen Fällen tatsächlich darauf zurück, allerdings in zufällig entstellter oder bewusst verklärter Gestalt.

Die Berichte, die im Mittelalter über Alexanders orientalische Entdeckungen im Umlauf waren, beruhten weitgehend auf antiken Quellen, aber vieles wurde im Laufe der Jahrhunderte verändert. Seit langem schon ist die Literatur zu diesem Thema unüberschaubar geworden, und die Komplexität der Quellenfragen hat zu einer gewissen Forschungsmüdigkeit geführt. Im Wirrwarr der zahlreichen Fassungen des Alexanderstoffs findet sich niemand leicht zurecht, eine Tatsache, die jegliche Einzelinterpretation erschwert, weil diese hier besonders stark von der Quellenlage abhängig ist.

Das Leben und die Taten des großen Eroberers sind uns durch zwei getrennte Überlieferungsstränge bekannt. Einerseits haben wir die nüchternen Historiker, wie Plutarch, Diodor, Arrian, Quintus Curtius und auch Justin, andererseits die unglaubwürdigen Berichte von fabelhaften Ereignissen und Begegnungen mit allerlei übernatürlichen Wesen. Ein Großteil dieser fiktionalen Berichte stammt aus dem antiken Alexanderroman, auf dem fast die gesamte volkssprachliche Literatur zum Makedonier beruht. In den letzten Jahren hat die Forschung auf dem Feld der Quellenfrage große Fortschritte verzeichnet, und es hat den Anschein, als ob man fortan zu einem besseren Verständnis der intertextuellen Zusammenhänge kommen könnte. Im Folgenden soll am Beispiel einer berühmten Einzelepisode aus dem letzten Teil des Alexanderromans dargelegt werden, wie der antike Stoff im Mittelalter rezipiert wurde. Die Erzählung von der babylonischen Missgeburt eignet sich besonders gut für eine Analyse der verschiedenen Fassungen, da diese Episode mit ihrem deformierten Körper nicht nur eine besondere evidenzialisierende und die Erzählung intensivierende Kraft besitzt, sondern darüberhinaus der Körper der Missgeburt im Gegensatz zu den vielen sonderbaren indischen Lebewesen, die manchmal beliebig von der Norm abweichen, eine starke symbolische und literarisch fundierte Botschaft enthält. Nach einer Interpretation der lateinischen Vorstufen werde ich mein Hauptaugenmerk auf die wichtigsten deutschsprachigen Alexanderdichtungen richten.

Von einer mehrjährigen Indien-Expedition nach Persien zurück gekehrt, ließ sich Alexander in seiner Hauptstadt Babylon nieder und starb dort am 13. Juni 323 vor unserer Zeitrechnung in einem Alter von weniger als 33 Jahren. Nach seinem Tod brachen die Diadochenkriege aus und setzten dem kurzweiligen griechischen Imperium ein schroffes Ende. Dies wissen wir aus den historischen Quellen.

Der antike Alexanderroman, der nach allgemeiner, aber vermutlich unberechtigter Meinung nicht erhalten geblieben ist, ${ }^{1}$ reicht nicht zu den Diadochenkriegen,

\footnotetext{
1 ZACHER, Julii Valerii epitome, S. iii: „Der griechische Text des sogenannten Pseudocallisthenes der ältesten, um das Jahr 200 n. C. in Alexandria aufgezeichneten zusammenfassung der Alexandersage, und hauptgrundlage aller späteren bearbeitungen - ist nur in sehr mangelhafter überlieferung
} 
denn er endet mit der Vergiftung des Eroberers durch Antipater. Nur ein Vorzeichen spielt auf die späteren Ereignisse an. Es besteht seit Langem Einigkeit darüber, dass der Roman am treuesten durch eine lateinische Fassung vertreten ist. Da diese Version in letzter Instanz als Grundlage für alle zu besprechenden volkssprachlichen Dichtungen gedient hat, lohnt es sich, sie in vollem Wortlaut wiederzugeben. So lautet der Anfang der Passage von der babylonischen Missgeburt in den Res Gestae Alexandri Macedonis (III, 30):

Cum a Babylonia iret Alexander, mirum portentum atque evidens ad exitium fuit. Nuntiata quippe est mulier fetum eiusmodi peperisse cuius prior [is] corporis pars pube tenus ad hominem congruebat, enimvero quae insecuta corporis erant omnia beluina prorsusque qualem Scyllam bomines fabulantur, nisi hoc uno diverterat: Non enim caninis rictibus lupinisve, enim leoninis atque pardorum, suum etiam vel ursorum omnem inguinis ambitum texerat, spirantibus etiam bestiis, sed pars superna humanaque emortua iam et colore atro cum desitu spiritus visebatur.

(„Als er Babylon verließ, geschah ein erstaunliches Vorzeichen, das erweislich auf sein Ende hinwies. Ihm wurde nämlich angekündigt, eine Frau habe ein Kind geboren, und es sah so aus: bis zum Schamberg hatte es einen menschlichen Körper, war aber weiter unten wie ein wildes Tier, ganz wie Scylla beschrieben wird, bis auf einen Unterschied. Um die Leiste herum hatte es Mäuler, aber nicht wie Hunde und Wölfe, sondern wie Löwen, Leoparden, Schweine und Bären, und diese Tiere lebten, während der menschliche Oberkörper ersichtlich tot, schwarz und ohne Atem war." $)^{2}$

Die Mutter dieses Monstrums deckt es sofort zu und bringt es persönlich dem König. Nachdem er es gesehen hat, befiehlt er seinen Auslegern, die Erscheinung zu deuten, und einer von ihnen sagt ihm insgeheim (III, 30):

Eheu [...] malorum omnium, eheu, mi rex! Non enim iam bonis, vitae fruere $\mathbf{q n e q u e ~ i n t e r ~ v i v o s ~ h o m i n e s ~ u l t r a ~}$ nominabere [...]. Sed cur ista sentiret interpres cum rex diligentius quaereret, baec addit: „O quid enim, “ inquit, „o vir summe, quidquid ex homine fetus bic habet ad te pertinet, quod vero est subter atque beluile quicumque tibi subditi sunt et subiecti. Si igitur ea pars quae superna est viveret et motaretur, sicuti haec quae infra sunt faciunt, tu sane obtineras ac dominarere cunctorum, sed quoniam secus est, in contrarium intellegendum, nisi quod hi quoque ipsi dissidebunt neque congruent; vides enim dispares formas neque inter se amicas ac prorsus beluile saevientes. Atque bi quidem inter se omnes te oppetente dissentient dimicabuntque.

(„Ach, dies ist ein Vorzeichen von allerlei Unglück, ach, mein König! Du wirst nicht mehr die Wohltaten des Lebens genießen noch zu den Atmenden gezählt werden [...]. O höchster Herr, alles, was an diesem Kind menschlich ist, bezieht sich auf Dich, aber das Niedrigere und Tierische bezeichnet Deine Diener und Untertanen. Wenn der Oberkörper lebte und sich so bewegte, wie es die unteren Teile tun, so würdest Du in Wahrheit alles erreichen und alle unterjochen, aber weil es sich anders verhält, ist das Gegenteil zu verstehen, abgesehen davon, dass die Anderen sich dazu noch streiten und uneinig sein werden. Du siehst nämlich unter-

zu uns gekommen [...]. Um so wertvoller sind drei alte noch aus der alexandrinischen textgestalt geschöpfte übersetzungen, eine syrische und eine armenische, beide aus dem 5. jahrhunderte, und eine lateinische [...]. Von dem verfasser der lateinischen übersetzung wissen wir nichts weiter, als den in ihren handschriften erhaltenen namen Julius Valerius." Diese 1867 als einleuchtendes Faktum dargestellte Auffassung stammt aus der Kindheit der Alexanderforschung und hat sich bis heute unverändert und bis 2003 unwidersprochen erhalten.

2 Julius Valerius, Res Gestae, S. 179. Eigene Übersetzung. 
schiedliche Arten, die sich feindlich sind und sich wie wilde Tiere bekämpfen. Nach Deinem Tod werden sich die Leute zerwerfen und bekriegen.") 3

Nach dieser Wahrsagung ging der Ausleger hinaus und vernichtete das bedrohliche Vorzeichen durch Feuer. Alexander war erschüttert, stieß eine Klage aus und bereitete sich gefasst auf den Tod vor.

Der Verfasser dieses Textes lebte am Anfang des vierten Jahrhunderts und liefert somit das älteste Zeugnis vom Alexanderroman. Er nannte sich Julius Valerius und stellte im Titel sein Werk als eine Übersetzung eines griechischen Originals des Äsop dar (Res Gestae Alexandri Macedonis translatae ex Aesopo graeco). ${ }^{4}$ Niemand hält jedoch diesen Fabeldichter für den Autor des weltberühmten Romans. Dieser anscheinend anonyme Text wurde im Mittelalter verschiedenen Autoren zugeschrieben, insbesondere Alexanders persönlichem Historiographen Kallisthenes. Dieser Mann kann den Roman aber aus einem einfachen Grund nicht verfasst haben: er wurde auf Alexanders Befehl hingerichtet.

Nach einer noch ungedruckten, aber wohlargumentierenden und in jeder Hinsicht überzeugenden These ist der geheimnisvolle Verfasser des antiken Alexanderromans mit Julius Valerius identisch. ${ }^{5}$ Die Berufung auf Äsop ist in Wirklichkeit als eine Quellenfiktion mit Hinweis auf den symbolischen Charakter des Werks zu interpretieren. Als Dichter hielt sich Valerius nicht an die historische Wahrheit und ging sehr frei mit seinen Quellen um. Sein Buch ist kein Geschichtswerk, sondern eine Fabel, und sie war an Konstantin den Großen gerichtet. Der oströmische Kaiser sollte sich als Stadtgründer mit der makedonischen Hauptfigur identifizieren. Kurz vor seinem Tod bereitete sich der Begründer von Konstantinopel auf einen Feldzug gegen Persien vor. Er war also im Begriff, in Alexanders Fußstapfen zu treten.

Die Res Gestae Alexandri Macedonis zeugen von der Gelehrsamkeit des Autors. In der zitierten Passage vergleicht er die babylonische Missgeburt mit Scylla und bezieht sich dabei auf Ovid. In der Odyssee beschreibt Homer dieses mythologische Weibswesen als ein sechsköpfiges Monster mit welpenartiger Stimme und zwölf Füßen. ${ }^{6}$ Erst Ovid schildert, wie ein Gürtel von bellenden Hunden die Leiste der Nymphe umschließt. ${ }^{7}$

Beim Vergleich verweist Valerius also auf die lateinische Darstellung des weiblichen Monsters. Er unterstreicht allerdings, dass die Missgeburt sich von der ovidianischen Scylla unterschied. Sie hatte keine Hunde und Wölfe um die Leiste herum, sondern Löwen, Leoparden, Schweine und Bären. Diese Tierliste stammt zum Teil aus dem Buch des Propheten Daniel. Nach Nebukadnezars Traum von der Statue aus Gold, Silber, Erz und Eisen (Dan. 2) träumt Daniel selbst von vier

\footnotetext{
${ }^{3}$ Ebd., S. 180. Eigene Übersetzung.

${ }^{4}$ Ebd., S. 1.

5 Vgl. BRENEZ, Julius Valérius.

${ }^{6}$ Homer, Odyssee, XII, 85-98.

${ }^{7}$ Ovid, Metamorphoses, XIV, 59-67.
} 
großen Tieren, die aus dem Meer heraussteigen. Der jüdische Eunuch sieht einen beflügelten Löwen, einen Bären mit großen Zähnen, einen vierköpfigen und ebenfalls beflügelten Leoparden und schließlich ein viertes Tier mit zehn Hörnern:

Ich, Daniel, sah ein Gesicht in der Nacht, und siehe, die vier Winde unter dem Himmel stürmten widereinander auf dem großen Meer. Und vier große Tiere stiegen heraus aus dem Meer, ein jedes anders denn das andere. Das erste wie ein Löwe und hatte Flügel wie ein Adler. Ich sah zu, bis dass ihm die Flügel ausgerauft wurden; und es ward von der Erde aufgehoben, und es stand auf zwei Füßen wie ein Mensch, und ihm ward ein menschlich Herz gegeben. Und siehe, das andere Tier hernach war gleich einem Bären und stand auf der einen Seite und hatte in seinem Maul unter seinen Zähnen drei große, lange Zähne. Und man sprach zu ihm: Stehe auf und friss viel Fleisch! Nach diesem sah ich, und siehe, ein anderes Tier, gleich einem Parder, das hatte vier Flügel wie ein Vogel auf seinem Rücken, und das Tier hatte vier Köpfe; und ihm ward Gewalt gegeben. Nach diesem sah ich in diesem Gesicht in der Nacht, und siehe, das vierte Tier war greulich und schrecklich und sehr stark und hatte große eiserne Zähne, fraß um sich und zermalmte, und das übrige zertrat's mit seinen Füßen; es war auch viel anders denn die vorigen und hatte zehn Hörner. Da ich aber die Hörner schaute, siehe, da brach hervor zwischen ihnen ein anderes kleines Horn, vor welchen der vorigen Hörner drei ausgerissen wurden; und siehe, dasselbe Horn hatte Augen wie Menschenaugen und ein Maul, das redete große Dinge. (Dan. 7, 2-8)

Valerius war ein Heide, aber er wandte sich an einen christlichen Kaiser. Diese religiöse Lage erklärt die sonderbare Verstrickung von ovidianischen und biblischen Bauelementen. Die vier Tiere, von denen Daniel träumt, steigen in ähnlicher Weise wie Scylla aus dem Meer. Diese Episode ist ein glänzendes Beispiel für Valerius' durchgängige Tendenz zum Synkretismus. Sie hat in hohem Grad zum weltweiten Erfolg seines Romans beigetragen.

Das vierte Tier wird gewöhnlich mit Alexanders Imperium identifiziert, indem bis zum Seleuzidenreich genau zehn Könige über Judäa herrschten. Alexander selbst war der erste von ihnen und ist also nach allgemeiner Meinung durch das erste Horn vertreten. Diese Interpretation liefert ein negatives Bild vom Makedonier. Deshalb wird das vierte Tier von Valerius durch ein Schwein ersetzt.

Durch diese Veränderung bringt der Alexandriner die Tierreihe in Übereinstimmung mit derjenigen der Kirchenväter. In seinem Daniel-Kommentar deutet Hieronymus das vierte Tier als einen Eber. ${ }^{8}$ Er bezieht sich dabei auf einen Psalm, in dem Asaf bedauert, dass ein wilder Eber den Weinstock Gottes zerstört hat. ${ }^{9}$ Darüber hinaus stellt der Kirchenvater ausdrücklich die vier Tiere mit Nebukadnezars Paralleltraum zusammen. In dem Leoparden erkennt er daher Alexander, den Vertreter des dritten Weltreichs. Nach Hieronymus steht der Eber für das römische Reich.

Der Kirchenvater wurde erst einige Jahre nach dem Tod Konstantins des Großen geboren und kann deshalb nicht als unmittelbare Quelle für die Res Gestae gedient haben. Valerius muss die besprochene Traumdeutung aus irgendeiner

8 Vgl. PL 25, Sp. 530 (Sancti Eusebii Hieronymi Commentariorum in Danielem liber).

9 Ps. 80, 14: „Devastavit eam aper de silva." 
früheren Schrift christlicher Prägung gekannt haben. Hieronymus' Interpretation setzte sich im Mittelalter durch und taucht am Ende des 11. Jahrhunderts im Annolied auf. ${ }^{10}$

Valerius bringt die Reihenfolge der vier Tierarten durcheinander, so dass der Bär als Nachfolger des Löwen, des Leoparden und des Schweins auftritt. Dieser Bär muss daher Konstantin den Großen verkörpern. Valerius wollte mit anderen Worten zeigen, dass mit diesem Kaiser ein neues Zeitalter angebrochen war, das Zeitalter des friedlichen Zusammenlebens von Heiden und Christen, von Gläubigen aller Religionen überhaupt, das Zeitalter der Toleranz.

Soviel ist zwischen den Zeilen des genialen Alexandriners herauszulesen, wenn wir uns Mühe geben, die Quellenlage genau zu untersuchen. Was wurde im Mittelalter aus dieser feinfühligen Symbolik?

Es ist bekannt, dass der Alexanderroman in zahlreichen Sprachen bearbeitet wurde. Er erzielte einen Erfolg, der bis in die Neuzeit von keinem anderen weltlichen Buch übertroffen wurde. Schon Isidor von Sevilla legt ein Zeugnis von dieser unüberschaubaren Verbreitung ab. In einem Abschnitt über Vorzeichen fasste der Wisigote die besprochene Passage ganz kurz zusammen (Etymologiae, XI, 3, 5):

Alexandro ex muliere monstrum creatum, quod superiores corporis partes hominis, sed mortuas habuerit, inferiores diversarum bestiarum, sed viventes, significasse repentinam regis interfectionem: supervixerant enim deteriora melioribus. Sed haec monstra, quae in significationibus dantur, non diu vivunt, sed continuo, ut nata fuerint, occidunt.

(„Es wurde Alexander mitgeteilt, das von der Frau geborene Monster mit dem menschlichen, aber toten Oberkörper und dem lebendigen aus verschiedenen Tieren bestehenden Unterkörper kündige den baldigen Tod des Königs an, denn die Schlechteren würden die Besseren überleben. Aber diese Monster, die als Vorzeichen angesehen werden, leben nicht lange, sondern werden sofort nach der Geburt getötet"). ${ }^{11}$

Isidor bezog sich im frühen 7. Jahrhundert auf das Originalwerk und verstand die Tiersymbolik, denn er hatte als christlicher Autor Hieronymus' Daniel-Kommentar im Kopf. In seiner Wiedergabe der Valerius-Stelle nannte Isidor kein einziges Tier beim Namen. Ihm ging es nicht um die biblische Idee der translatio imperii, sondern darum, dass Missgeburten immer eine prophetische Funktion haben. Isidor sah offenbar den fiktionalen Bericht als ein historisches Zeugnis, obwohl Valerius den fabelhaften Charakter der Episode durch den diskreten Verweis auf Ovid hervorgehoben hatte. So wenig wie die Griechen und die Römer an die reale Existenz der Scylla glaubten, so wenig hielten die spätantiken Leser die Res Gestae für ein Geschichtsbuch. Sie verstanden deshalb, dass die beschriebene Missgeburt lediglich der Phantasie des Dichters entsprungen war und nie wirklich von einer erschrockenen Mutter vor Alexander ausgetragen wurde.

10 Annolied, V. 179-262.

${ }^{11}$ Eigene Übersetzung. 
Im 9. Jahrhundert wurde Valerius' Werk erheblich gekürzt. Diese Kurzfassung ist als die Epitome Julii Valerii bekannt. Sie fand eine weit größere Verbreitung als das detaillierte Original. Die Passage mit der babylonischen Missgeburt wurde jedoch verhältnismäßig wenig gekürzt. Der Hinweis auf Scylla und die Auflistung der vier Tierarten wurden beispielsweise beigehalten. Nur die Schweine wurden vom anonymen Bearbeiter durch Drachen ersetzt (Epitome Julii Valerii, III, 30):

Quaedam mulier infantem pareret, cuius superior pars, bominem pertinens, iam quidem putrefacta et semiviva videbatur, inferior vero beluinis capitibus, qualem Scyllam ferunt fabulae poetarum; prater quod non caninis, sed lupinisve, enimvero leonum et pardorum, ursorum atque draconum capitibus inguina infantuli cingebantur.

(„Eine Frau gebar ein Kind, dessen oberer und menschlicher Teil schon verfault und halbtot aussah, dessen unterer Teil aber mit Tierköpfen umgeben war, so wie es die Fabeln der Dichter von Scylla berichten, abgesehen davon, dass die Leiste des kleinen Kindes nicht mit hundartigen, sondern mit wolfartigen Köpfen umzingelt war, und zwar mit Köpfen von Löwen, Panthern, Bären und Drachen." $)^{12}$

Alexanders heidnische Anrufung an Jupiter fiel weg. Eine vorsichtige Christianisierung der Episode ist festzustellen. Die Weglassung der Schweine zugunsten der Drachen bedeutet einen Verzicht auf Hieronymus' Erklärungsmodell und eine Rückkehr zur Bibel. Hier wird das vierte Tier als schrecklich und außerordentlich stark beschrieben. Es frisst um sich, zermalmt alles mit seinen eisernen Zähnen oder zertritt es mit seinen Füßen. Die Schilderung legt nahe, dass es sich um einen Drachen handelt. Zu Hieronymus' Lebzeiten war dieses Fabelwesen kaum bekannt. In Westeuropa ist der Drache wohl eher ein typisch mittelalterliches Monster und gewann hier eine Sonderstellung durch seine Verknüpfung mit dem Teufel.

Um die Mitte des 10. Jahrhunderts reiste der neapolitanische Erzpriester Leo nach Konstantinopel. Er brachte eine griechische Bearbeitung der Res Gestae Alexandri Macedonis mit zurück. In Süditalien übertrug er seine byzantinische Vorlage ins Lateinische unter dem Titel Nativitas et victoria Alexandri Magni regis. Die unleugbare Verwandtschaft dieses Textes mit einer syrischen Fassung bestätigt, dass Leos Reisebericht und Quellenfund nicht als Fiktion anzusehen sind. Zwischen dem 4. und dem 10. Jahrhundert muss Valerius' Werk über Syrien nach Konstantinopel gewandert sein. Alle bekannten griechischen Handschriften des Alexanderromans sind allerdings jünger als Leos Übertragung, und keine davon stimmt inhaltlich damit überein.

Die Nativitas et victoria Alexandri Magni regis ist am besten durch eine in Italien hergestellte Abschrift bekannt. Die Handschrift befindet sich heute in Bamberg und kam vermutlich schon am Anfang des 11. Jahrhunderts nach Deutschland. Der gelehrte Hinweis auf Scylla ist in Leos Fassung getilgt, und die vier Tierarten sind zu Hunden geworden. Diese Vereinfachung könnte durch Missverständnis entstanden sein, denn Valerius erklärt ausdrücklich, Scylla habe so ausgesehen.

${ }^{12}$ Julii Valerii epitome, S. 61f. Eigene Übersetzung. 
Gleichzeitig wird die ganze Passage in der ersten Person wiedergegeben. Alexander erzählt nämlich seiner Mutter von der Missgeburt in einem Brief. Leos Version ist jedoch bis zu einem gewissen Grad unverständlich, denn entweder vergisst er zu erklären, dass der Oberkörper tot war, oder er trifft bewusst die Entscheidung, dies nicht zu erwähnen (Nativitas et victoria Alexandri Magni regis, III, 30):

Cum essem in Babilonia, antequam exissem de hoc seculo, vidi mulierum, quae genuit filium, qui erat ab umbilico et sursum ut homo, ab umbilico usque ad pedes erat bestia, similitudinem habebat canis.

(„Als ich vor meinem Abscheiden aus dieser Welt in Babylon war, sah ich eine Frau, die einen Sohn gebar. Er war von der Nabel hinauf wie ein Mensch, von der Nabel bis zu den Füßen ein Tier, und sah wie ein Hund aus." $)^{13}$

Durch die Tilgung der vier Tierarten verschwand der Bezug zu Daniels Traum. Gleichzeitig rückte die Missgeburt in die Nähe des ovidianischen Weibswesens, das jedem mittelalterlichen Dichter bekannt war. Die Metamorphoses waren nicht nur Pflichtlektüre, sondern dienten durch das ganze Mittelalter hindurch als Schulbuch in allen westeuropäischen Ländern. Leo entchristianisierte also vermutlich die Episode mit Absicht.

Die Bamberger Handschrift diente als Hauptquelle für eine lateinische Kompilation, die im 12. Jahrhundert in Bayern entstand und heute in der Pariser Nationalbibliothek aufbewahrt wird. Diese Kompilation trägt den Titel Liber Alexandri Magni. Als Nebenquelle zog der bayrische Redaktor die Epitome Julii Valerii heran und benutzte sie insbesondere für die Schilderung der Missgeburt. Die Wahl des Bayern lag vermutlich daran, dass Leo in dieser Passage einen besonders verworrenen Text bot. Im Verhältnis zur Epitome Julii Valerii ließ der Redaktor nur den Hinweis auf Scylla weg:

Quedam mulier infantem pareret, cuius superior pars, ad hominem pertinens, iam quidam putrefacta ac semiviva videbatur. Enim vero leonum et parthorum, ursorum ursorumque atque draconum capitibus inguina infantuli cingebantur. Leonum et pardorum, ursorum atque draconum capitibus inguina infantuli cingebantur. ${ }^{14}$

Die bayrische Redaktion der Nativitas et victoria Alexandri Magni regis enthält also nur die biblische Tierdeutung und verzichtet auf den Hinweis auf den heidnischen Dichter Ovid.

Der Liber Alexandri Magni befand sich noch im 15. Jahrhundert im Kloster Tegernsee und wurde damals im Auftrag des bayrischen Herzogs Albrecht III. und seiner Frau von ihrem Leibarzt Johannes Hartlieb ins Deutsche übertragen. Das Prachtexemplar des Herzogspaars wurde am 29. September 1454 von einem österreichischen Schreiber vollendet und befindet sich heute in Sankt Gallen.

Hartlieb hielt sich ziemlich genau an seine Vorlage, aber er erweiterte sie und dramatisierte die Szene. Im Puech des grozzen Alexandri nimmt der mitleidsvolle Ausleger Rücksicht auf den König und weigert sich zunächst, die furchtbare Botschaft

\footnotetext{
13 Der Alexanderroman, S. 122. Eigene Übersetzung.

14 Liber Alexandri Magni, S. 207 (V. 2118-2121). Übersetzung s. o.
} 
zu enthüllen. Erst nach reifer Überlegung entschließt er sich, Alexander die Wahrheit zu sagen:

Darum thett er aber lennger vercziechen vnd woltt dem kunig nichtcz, sagen vnd vermaynttm die sach damitt dem kunig aus den awgen vnd synne zuschlachenm daz aber nichtt gesein mochtt. Wann Alexannder woltt yee wißen, was die sach bedänttett.

(„Deshalb zögerte er lange und wollte dem König nichts erzählen. Er wähnte, die Sache in dieser Weise von den Augen und Gedanken des Königs fernhalten zu können, aber das gelang ihm nicht, denn Alexander wollte trotzdem die Bedeutung der Sache wissen." ${ }^{15}$

Den Hinweis auf Daniels Traum scheint Hartlieb nicht verstanden zu haben, denn er verändert die Reihenfolge, so dass der Leopard als viertes Tier nach dem Lindwurm erwähnt wird. Da Hartliebs bayrischer Herzog keine Rolle für die translatio imperii spielte, dürfte der Umtausch der beiden letzten Tiere durch Zufall entstanden sein und keine tiefsinnige Bedeutung gehabt haben. Eine nähere Analyse der weltgeschichtlichen Selbstauffassung des Herzogs Albrecht III. könnte allerdings eine andere Interpretationsmöglichkeit ergeben.

Ungefähr ein Jahrhundert vor Hartliebs Alexanderbuch diente die Bamberger Handschrift direkt oder indirekt als Vorlage für eine ganz andere Kompilation in deutscher Sprache. Aus verschiedenen religiösen Büchern und Chroniken erstellte ein anonymer Geistlicher mit eher norddeutscher Herkunft eine Exempelsammlung über die zehn Gebote. Er nannte sie den Seelentrost. Die letzte, längste und wichtigste der etwa 200 Exempel dieses Erbauungsbuchs ist eine Erzählung über Alexander. Sie sollte als Warnbeispiel gegen die Gier dienen. Der Seelentrost Alexander beruht auf zwei Hauptquellen, einer der Bamberger Handschrift nahestehenden Fassung der Nativitas et victoria Alexandri Magni und einer Kurzfassung der Res Gestae Alexandri Macedonis, die in vielen Episoden von der Epitome Julii $V$ alerii abweicht. Diese Kurzfassung wird nach dem Aufbewahrungsort des Codex unicus die Liegnitzer Epitome genannt. In der Beschreibung der babylonischen Missgeburt stimmt sie ausnahmsweise mit der durch etwa hundert Handschriften bekannten Epitome Julii V alerii überein.

Der Verfasser des Seelentrosts hält sich eher an Leo als an Valerius, gibt aber die Stelle auf Deutsch so gerafft wieder, dass die genaue Quelle sich nur bei näherem Hinschauen bestimmen lässt. Um den exemplarischen Charakter der Alexandererzählung zu verstärken, ließ der Autor fast alle Eigennamen weg. So erfahren wir im Selentrost weder aus welchem Land Alexander kommt noch wo er sein Leben endet. Babylon ist in diesem Text zu einer beliebigen anonymen Stadt geworden. Trotz der drastischen Kürzung der Vorlage durch den Seelentrost-Verfasser ist die Passage durchaus verständlich geblieben. Dem Geistlichen gelang es, das Vorzeichen ohne ein einziges überflüssiges Wort zu beschreiben. Er verzichtete absichtlich auf die Auflistung der biblischen Tierreihe und sprach von einem unspezifischen Tier:

${ }^{15}$ Johann Hartlieb, Alexander, S. 315 (V. 6956-6959). Eigene Übersetzung. 
Darna quam he in eyne stad, dar was eyn fruwe, de hadde eyn kint, dat was halff eyn mynsche unde halff eyn deer. Do vragede konningk. Allexander eynen wisen man, wat dat mochte beduden. He sprak: ,Konningk, dat menet so uele, dat yd dyneme dode nalet, dat du steruen schalt. Dat eyne deel, dat gelijk ys eynem mynschen, dat bistu. Dat andere deel dat ys de koningk, de na dij komen schal. 'Do wart Allexander sere bedrouet.

(„Danach kam er in eine Stadt, wo eine Frau war. Sie hatte ein Kind, das halb Mensch, halb Tier war. Da fragte König einen weisen Mann, was das bedeuten könne. Dieser sprach: „König, das bedeutet folgendes: es nahet Dein Tod und der Tag, an dem Du sterben sollst. Der erste Teil, der wie ein Mensch ist, bist Du. Der andere Teil sind die Könige, die nach Dir kommen sollen'. Da wurde Alexander sehr betrübt." ${ }^{16}$

Diese kurze Stelle macht deutlich, dass es dem Seelentrost-Verfasser um die Allgemeingültigkeit des Exempels ging.

Unabhängig von der Bamberger Handschrift wurde Leos dürftiger Text im 11. Jahrhundert anonym bearbeitet und durch verschiedene Nebenquellen erweitert. Diese interpolierte Fassung fand im Mittelalter eine riesige Verbreitung und diente als Vorlage für die meisten volkssprachlichen Dichtungen. Sie ist als die Historia de Preliis bekannt und liegt in drei verschiedenen Hauptfassungen vor. Die erste, zweite und dritte interpolierte Fassung heißen in der Forschung gewöhnlich $J^{1}, J^{2}$ und $J^{3}$.

Im Abschnitt über die babylonische Missgeburt begnügte sich der Urheber der Historia de Preliis $J^{1}$ damit, Leos Missverständnisse und Unklarheiten zu beheben. Die Passage wurde zunächst wieder in der dritten Person erzählt. Alexander wurde dabei in Übereinstimmung mit der historischen Wahrheit vom König zum Kaiser erhoben. Nach Isidor wurde zum besseren Verständnis erklärt, dass der Oberkörper tot war. Die Erwähnung der Hunde wurde gestrichen, vielleicht durch Vergleich mit der Epitome Julii Valerii, vielleicht durch einfache Kürzung. Im Gegensatz zu den vier biblischen Tierarten hatten Leos Hunde keine literarische Daseinsberechtigung und trugen nicht zur symbolischen Botschaft bei. In der Historia de Preliis ist daher von keinem spezifischen Tier die Rede. Die Kürze dieser Fassung erlaubt allerdings weitere Interpretationsmöglichkeiten.

Die Historia de Preliis hat die volkssprachliche Literatur fast ausschließlich durch die beiden jüngeren Fassungen beeinflusst. Schon im 12. Jahrhundert entstand die Historia de Preliis $J^{2}$, deren Verfasser sich an Orosius' Alexanderbericht orientierte. Die Historiae adversum paganos dieses spätantiken christlichen Theologen beruhten auf Justinus, der seinerseits ein verlorenes Geschichtswerk zusammengefasst hatte. Valerius' Alexanderfabel wurde also nach historischen Quellen korrigiert und gleichzeitig mit christlichem Geist bereichert.

Eine Handschrift der Historia de Preliis $J^{2}$ diente in der Mitte des 14. Jahrhundert als Hauptquelle für ein österreichisches oder bayrisches Alexanderlied von

16 Der große Seelentrost, S. 286, 17-22. Eigene Übersetzung. Die lange, in einer Kopenhagener Handschrift unikal überlieferte Fassung entspricht dem Original. Alle übrigen Versionen gehen auf eine schon im 14. Jahrhundert entstandene Kürzung zurück. SCHMITT gibt zu Unrecht der Mehrheit Recht, indem sie die lange Fassung für eine jüngere Erweiterung hält. Ein näherer Vergleich mit den lateinischen Quellen stellt eindeutig die Priorität der Kopenhagener Handschrift gegenüber der übrigen Überlieferung unter Beweis. 
9081 Versen. Der Dichter nannte sich Seifrit und beendete nach eigener Angabe sein Werk am 11. November 1352. Er hielt sich meist genau an seine lateinische Vorlage, aber zog mehrere Veränderungen vor, um den Titelhelden in ein positiveres Licht zu stellen. Die Passage von der Missgeburt umfasst 84 Verse. So beschreibt Seifrit den Oberkörper des Kindes (V. 8127-8128): „der leib uncz dem napel was / ain schoner mensch, gelaubt das! " (Bis zur Nabel war der Leib ein schöner Mensch, glaubt mir das!) ${ }^{17}$ Im Gegensatz zu seinen Vorgängern unterstreicht dieser Dichter die Schönheit der Missgeburt und bezeichnet sie als Mensch ohne Rücksicht auf das Geschlecht. Außerdem reitet Alexander selbst zur Frau, um das Wunder in Augenschein zu nehmen (V. 8142): „er rait haymelichen dar" (er ritt insgeheim dorthin). ${ }^{18}$ Seifrit verwandelt seine Hauptfigur in einen aktiven Herrscher, der sein Schicksal mehr in die Hand nimmt als in den übrigen Fassungen. Alexander scheint in dieser Episode besonders von der Neugierde getrieben zu werden.

Nach der Deutung des Vorzeichens wird der Kaiser in Übereinstimmung mit der Vorlage betrübt, aber er rafft sich auf und verheimlicht seine Traurigkeit. Im deutschen Gedicht zieht er sich diskret zurück, um Jupiter sein Unglück zu beklagen.

Alle älteren deutschen Alexanderdichtungen übergehen aus verschiedenen Gründen die babylonische Missgeburt. Der Vorauer Alexander aus der Mitte des 12. Jahrhunderts entspricht vermutlich Lamprechts Original. Diese Kurzfassung bricht nach Alexanders Sieg über Darius ab. Eine vollständige Fassung ist durch den Straßburger Alexander aus dem Ende des 12. Jahrhunderts vertreten. Sie endet schroff nach Alexanders Reise zum Paradies. Der durch Antipater angestiftete Mordanschlag wird nur in einem einzigen zweideutigen Vers angedeutet. Je nach der Auslegung versteht der Leser, dass Alexander vergiftet wurde oder dass er am Ende seines Lebens Vergebung erlangte (V. 7271-7272): „Dô wart ime vergeben. / Sint ne mohter niwit leben." (Danach wurde er vergiftet. Daher konnte er nicht am Leben bleiben). ${ }^{19}$ In ihrer Übersetzung erinnert sich ELISABETH LIENERT an das gewöhnliche Ende, das sie, wie schon das mittelalterliche Publikum, aus allen übrigen Fassungen kennt. Es ist allerdings eine Tatsache, dass der Verfasser des Straßburger Alexanders absichtlich die Vergiftungsepisode unterdrückte. Nur ein zweideutiges Verb verbindet seine Fassung mit der Tradition. Wortwörtlich und unabhängig vom antiken Alexanderroman bedeutet die Stelle: ,Da wurde ihm vergeben. Danach konnte er nicht am Leben bleiben'. Der Dichter spielte also mit der Publikumserwartung. Nur wenn man versucht, sich von der Tradition loszulösen, versteht man das Novum.

Am Anfang des 15. Jahrhunderts wurde eine dem Straßburger Alexander nahestehende Fassung von Lamprechts Werk durch die Historia de Preliis $J^{2}$ ergänzt

\footnotetext{
17 Seifrits Alexander, S. 132. Eigene Übersetzung.

${ }^{18}$ Ebd.

${ }^{19}$ Ebd.
} 
Peter Hv. Andersen Vinilandicus

und in stark veränderter Form in die Sächsische Weltchronike einverleibt. Dieser Basler Alexander beschreibt deshalb die babylonische Missgeburt nach derselben lateinischen Vorlage wie Seifrit, aber viel treuer und viel kürzer. Mit 44 Versen ist die Episode nur halb so lang in der Weltchronik wie in Seifrits Gedicht. ${ }^{20}$

Im Laufe des 13. Jahrhunderts entstanden zwei große deutsche Alexanderdichtungen. Um 1245 verfasste Rudolf von Ems sechs Bücher und mehr als 21.600 Verse über den großen Eroberer, aber er brachte sein Werk nicht zu einem Ende und erzählte deshalb nicht von der babylonischen Missgeburt. Um 1280 vollendete Ulrich von Eschenbach seinerseits die umfangreichste deutschsprachige Alexanderdichtung aller Zeiten. Sie gliedert sich in zehn Bücher und umfasst 28.000 Verse. Da Ulrich sich auf die um 1180 von Gautier von Châtillon verfasste Alexandreis als Hauptquelle stützte, kam er nicht auf die körperliche Prophetie zu sprechen. Die Missgeburt kommt lediglich in den vom antiken Alexanderroman abhängigen Texten vor. Keine der historischen Quellen erwähnt diese Episode, und die Alexandreis ist stofflich von Quintus Curtius' eher historisch verlässlichem Werk hervorgegangen.

Am Ende des 12. Jahrhunderts entstand die Historia de Preliis J3. Sie endet mit mehreren Verseinlagen und einem längeren Bekehrungsbrief. Der Verfasser der dritten und letzten interpolierten Fassung änderte nichts Wesentliches in der Passage über die babylonische Missgeburt. Seine treue Wiedergabe der Historia de Preliis $J^{1}$ diente am Ende des 14. Jahrhunderts als Quelle für einen der ersten deutschen Prosaromane. Dieses Alexanderbuch ist das Werk eines norddeutschen Verfassers, der sich Meister Wigbold nannte. Er war vielleicht mit einem Seeräuber identisch, der 1402 in Hamburg hingerichtet wurde. Der sonst unbekannte Autor stellte aus fünf lateinischen Texten eine Kompilation zusammen und übertrug sie möglichst treu in seine niederdeutsche Mundart. Seine Beschreibung der Missgeburt entspricht deshalb fast wortwörtlich der Historia de Preliis $J^{3}$ und daher auch $J^{1}{ }^{21}$

Die dritte interpolierte Fassung der Historia de Preliis diente nicht nur als Vorlage für Wigbolds niederdeutschen Prosaroman, sondern auch für ein lateinisches Gedicht von 3914 Versen. 1238 vollendete der italienische Dichter Quilichinus von Spoleto seine Historia Alexandri Magni und widmete sie Friedrich II. Der deutschrömische Kaiser war nach der Theorie der translatio imperii als Alexanders ferner Nachfolger anzusehen. Der Italiener gab seine Prosavorlage im Allgemeinen

\footnotetext{
20 Vgl. Die Basler Bearbeitung (Missgeburt: V. 4346-4389).

21 Vgl. Andersen, Deux témoins en prose (Missgeburt: S. 167, 34-168, 16). Der Verfasser nennt sich im Epilog, aber nur drei von siebzehn Textzeugen enthalten diesen Schlussteil. Die einzigen überlieferten Namensformen sind Babiloth, Wybolt und Wichwolt. Früher war lediglich die besonders entstellte Lesung Babiloth bekannt. Nach der Wiederentdeckung von zwei weiteren Handschriften wurde in der Forschung Wichwolt bevorzugt. In der editio princeps wurde der Text unter der rekonstruierten Form Wichbolt herausgegeben. Diese Form entspricht aber nur dem süddeutschen Archetypus. Als Norddeutscher muss sich der Verfasser selbst Wigbold genannt haben. Zu dieser komplizierten Verfasserfrage, siehe ANDERSEN, Wigbolds Alexanderbuch, bes. S. 191-192.
} 
treu wieder, aber in der Passage über die babylonische Missgeburt war er etwas unklar in seiner Formulierung und stellte das Kind als zweiköpfig dar (V. 35113514):

Horrendum natum peperit tunc femina quedam / Vultibus aduersis, nam fuit ille biceps. / Et supra uentrem parebat forma uirilis, / Et pecus ut brutum corporis iam parent.

(„Eine Frau gebar einen schrecklichen Sohn mit gegeneinander gewandten Gesichtern, denn der Junge war zweiköpfig."). ${ }^{22}$

Hier handelt es sich kaum um ein Missverständnis, sondern eher um eine bewusste Veränderung, denn die beiden entgegen gesetzten Köpfe werden ausdrücklich vom babylonischen Ausleger auf die künftige Teilung des Reichs bezogen (V. 3531): „Aduersi uultus designant scismata regni" (die entgegen gesetzten Gesichter bedeuten die Teilung des Reichs). ${ }^{23}$ Quilichinus' Prophezeiung bewahrheitete sich. Friedrich II. träumte davon, ein Alexander des 13. Jahrhunderts zu werden, aber er stellte sich kaum vor, dass er posthum in die Fußstapfen des Makedoniers treten sollte. Nach dem Tod des deutschrömischen Kaisers ging sein zweigliedriges Reich genauso schnell zu Grunde wie ehemals Alexanders Imperium. Die zwei Köpfe der babylonischen Missgeburt dürften also einerseits auf Sizilien, andererseits auf das Heilige Römische Reich nördlich der Alpen hinweisen.

Um 1390 wurde Quilichinus' Werk von einem ungeschickten und ungebildeten Alemannen ${ }^{24}$ zu einem deutschen Versroman umgewandelt. Die deutsche Fassung ist unikal überliefert und wird gewöhnlich nach dem ehemaligen Aufbewahrungsort des Codex unicus der Wernigeroder Alexander genannt. Seit dem Zweiten Weltkrieg befindet sich die Handschrift in Krakau (Biblioteka Jagiellońska, Berol. Mgq 1869).

Die Eingriffe des Italieners in die babylonische Episode hatten verheerende Folgen im alemannischen Gedicht. Der deutsche Dichter stellt sich zunächst vor, dass die zweiköpfige Missgeburt wie ein Affe aussieht und dass die beiden Gesichter nach hinten gewandt sind. Nach Quilichinus' Schilderung waren die Gesichter gegeneinander gewandt, etwa wie Sizilien und der deutschsprachige Teil des damaligen Reichs. ${ }^{25}$ Der Alemanne scheint nie einen realen Affen gesehen zu haben. Es muss dahingestellt bleiben, um die Umdeutung des oberen Teils der Missgeburt in dieses menschenähnliche, aber negativ konnotierte Tier, eine besondere Signifikanz hat. Der Alemanne dürfte seine Vorlage nur aus irgendwelchen

\footnotetext{
22 Quilichinus, Historia Alexandri Magni, S. 177. Eigene Übersetzung.

${ }^{23}$ Ebd., S. 179. Eigene Übersetzung.

${ }^{24}$ Vgl. das vernichtende Urteil von Gustav Ehrismann, Der Große Alexander, S. 58-59: „Die Sprache ist ungewandt, der Ausdruck hölzern, der Versbau flüchtig und nachlässig. Dichten hieß für den Verfasser in der Hauptsache soviel wie reimen [...]. Dieses Werk [...] kann nur als ein Beispiel dienen für den Rückgang der Kunst des späteren Mittelalters.“"

25 In der lateinischen Vorlage des Wernigeroder Alexander stand vielleicht „vultibus reversis“ statt „vultibus adversis".
} 
Peter Hv. Andersen Vinilandicus

Gründen missverstanden haben. Im Übrigen verstand er auch nicht ariolus, ein ungewöhnliches Wort für Wahrsager. Er fasste es als einen Eigennamen auf, und deshalb heißt der Ausleger im deutschen Gedicht Meister Ariolus. ${ }^{26}$ Seine begrenzte literarische Bildung liegt auf der Hand.

Quilichinus trägt dagegen die Verantwortung für ein anderes Missverständnis. In Übereinstimmung mit seiner Prosavorlage wollte der Italiener erklären, dass die Missgeburt einen menschlichen Oberkörper hatte, aber seine unklare Formulierung lässt sich am besten in folgender Weise übersetzen: „Oberhalb des Bauchs war eine männliche Form zu sehen." In der Historia de Preliis und schon bei Leo und Valerius steht homo für ,Mensch’ im Gegensatz zu bestia. Dies gibt der Italiener einengend mit virilis wieder. Sein Adjektiv bezieht sich aber nur auf die Hälfte der Menschheit. Darüber hinaus benutzt er das mehrdeutige Nomen forma im Sinne von ,Gestalt‘. Sein alemannischer Ausleger stellt sich das Aussehen der Missgeburt ganz anders vor, denn er erklärt: „Auf dem leib ain manlich gert [= Stab] / Het im die natür beschert" (V. 5945-5946). Diese Deutung ist insofern logisch, als es sich bei Quilichinus ausdrücklich um einen Jungen handelt. ${ }^{27} \mathrm{Im}$ Sinne von Penis scheint das mittelhochdeutsche Wort gerte ansonsten aber nicht belegt zu sein.

Wenn wir abschließend eine Bilanz über die besprochene Episode ziehen, ist festzustellen, dass die babylonische Missgeburt in der deutschsprachigen Alexanderliteratur sechsmal Aufnahme fand und dass fünf verschiedene lateinische Vorlagen herangezogen wurden. Johannes Hartlieb benutzte die durch das Liber Alexandri Magni vermittelte Epitome Julii Valerii, der Seelentrost-Verfasser Leos durch die Bamberger Handschrift oder eine davon abhängige Abschrift vertretene Nativitas et victoria Alexandri Magni, Seifrit und der Basler Bearbeiter von Lamprechts Alexanderlied die Historia de Preliis J2, Wigbold die Historia de Preliis $J^{3}$ und der Dichter des Wernigerode Alexander Quilichinus' Historia Alexandri Magni.

Es kann nicht verwundern, dass gerade das letztgenannte alemannische Gedicht am meisten von den Res Gestae Alexandri Macedonis abweicht. Das dürfte daran liegen, dass der Wernigerode Alexander als einzige deutsche Alexanderdichtung aus einer Versvorlage hervorgegangen ist. Bei Hartliebs und Wigbolds Prosaromanen ist die relative Originaltreue andersherum verblüffend. Im Laufe der Überlieferung hat sich die tausendjährige Episode in den meisten Fällen erstaunlich gut erhalten.

Von den sechs deutschen Fassungen gelangten nur zwei ins Ausland. Der Seelentrost Alexander wurde im 15. Jahrhundert in die Noordnederlandse Historiebijbel aufgenommen und kehrte um 1470 durch die Lübecker Historienbibel nach Deut-

\footnotetext{
${ }^{26}$ V. 5942-5944: „Gleich ainem affen / Het ez. zwai angesibt, / Die warnd binder sich geribt.“ V. 5951-5953: „Er erscbrak ze mol ser / Und biez im pald komen her / Ariolum den maister sein." Zit. n. Der Grosse Alexander, S. 85-86 (Missgeburt: V. 5935-5996).

27 V. 3511: „Horrendum natum peperit tunc femina quedam“ (eine Frau gebar dann einen schrecklichen Jungen). Vgl. Julius Valerius, Res gestae, V. 1279: ,fetus" (Kind). Leo spricht als Erster von einem Sohn.
} 
schland zurück. ${ }^{28}$ Anlässlich der Gründung des Brigittinerklosters in Vadstena wurde der Seelentrost auf Veranlassung der ersten Äbtissin Katarina ins Schwedische übertragen (um 1375). Bei der Gründung des Tochterklosters in Maribo auf Lolland entstand eine dänische Fassung (um 1425). ${ }^{29}$ Hartliebs Roman wurde mehrmals gedruckt, und die Frankfurter Ausgabe von 1570 wurde vierzehn Jahre später vom schonischen Pastor Peder Pedersen Galthen ins Dänische übersetzt. ${ }^{30}$

Der dänische Prosaroman ist einer der allerletzten Zweige des riesigen Baums, der in der Spätantike auf afrikanischem Boden gepflanzt wurde. In seiner Darstellung der Missgeburt gab der schonische Pastor seine deutsche Vorlage extrem treu wieder. Hartlieb hatte seinerseits nichts Wesentliches hinzugefügt. In der besprochenen Episode hielt sich der bayrische Arzt weitgehend an das Liber Alexandri Magni. Diese lateinische Kompilation hing in diesem Abschnitt von der Epitome Julii Valerii ab, und diese Kurzfassung entsprach dem Original bis auf die Ersetzung der Schweine durch mittelalterliche Drachen. 1584 kam Julius Valerius also fast unversehrt nach Dänemark. Die christliche Kirche hatte sich im vergangenen Jahrtausend verändert, aber der letzte Bearbeiter kannte die Bibel genauso gut wie der ursprüngliche Dichter. Galthen dürfte ohne Schwierigkeiten verstanden haben, was mit den vier Tierarten gemeint war.

Als Fazit kann festgestellt werden, dass sich die Episode von der babylonischen Missgeburt mehr als tausend Jahre lang einer großen Beliebtheit erfreute. Sie regte Dichter aus vielen Ländern und Epochen zu unterschiedlichen Interpretationen an. Alle Beschreibungen hielten allerdings an dem Grundschema fest: das Kind war halb Mensch, halb Tier und wies auf künftigen Tod und Untergang hin. Mit anderen Worten wurde der Körper mit seiner jeweiligen Deformität immer als Omen, als Ausdruck künftigen Unheils aufgefasst.

\footnotetext{
8 Vgl. De Noordnederlandse historiebijbel (Missgeburt: S. 753, 6-10) und Die Lübecker Historienbibel (Missgeburt: S. 240, 19-25).

${ }^{29}$ Vgl. Siælinna Thrøst (Missgeburt: S. 387, 35-388, 7 und Sjælens Trøst (Missgeburt: S. 128, 16-22).

${ }^{30}$ Der dänische Roman ist in zwei Handschriften erhalten, aber noch unediert (Missgeburt: fol. 162r$163 \mathrm{r}$ in der besseren Stockholmer Handschrift, Kungliga Biblioteket, D 129a).
} 
Übersicht über die Vorstufen der deutschen Alexanderdichtungen

Julius Valerius: Res Gestae (Anfang des 4. Jh.)

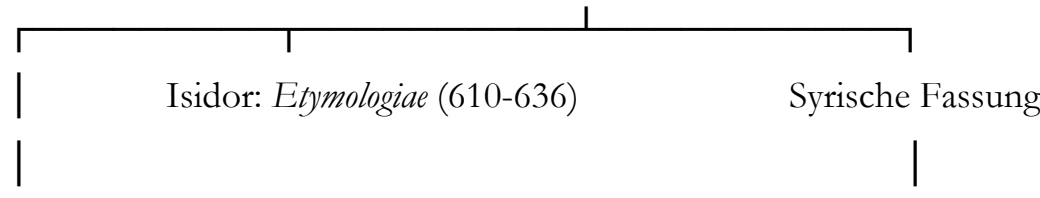

Griechische Fassung

Epitome (9. Jh.)
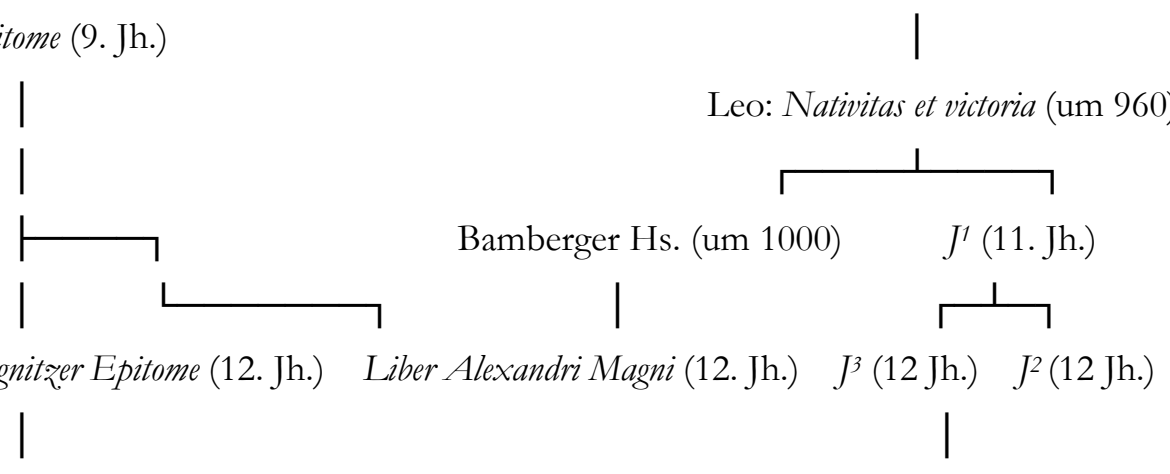

Liegnitzer Hs. (15 Jh.)

Quilichinus: Historia Alexandri Magni (1238)

Vorlagen für die Episode der Missgeburt in den deutschen Alexanderdichtungen

$J^{2} \quad>\quad$ Seifrit: Alexanderlied (1352)

Nativitas et victoria (oder Liegnitzer Epitome) > Anonym: Seelentrost (um 1360)

$J^{3} \quad>\quad$ Wigbold: Alexanderbuch (um 1390)

Historia Alexandri Magni $\quad>\quad$ Anonym: Wernigerode Alexander (1390-1391)

$J^{2} \quad>$ Anonym: Basler Alexander (um 1420)

Liber Alexandri Magni (= Epitome) $\quad>\quad$ Hartlieb: Puech des grozzen Alexandri (1454) 


\section{Literatur}

Andersen, Peter Hv. (Hrsg.), Deux témoins en prose du Roman d'Alexandre à la fin du Moyen Age en Allemagne: l'Alexandre du ,Grosser Seelentrost' et l'Alexandre de Wichbolt. Amiens 2001.

Das Annolied, Mittelhochdeutsch/Neuhochdeutsch. Hrsg. v. EBERHARD NELLMANN. Stuttgart 1999.

Die Basler Bearbeitung von Lambrechts Alexander. Hrsg. v. RICHARD M. WERNER (Bibliothek des Litterarischen Vereins in Stuttgart 154). Tübingen 1881.

Sancti Eusebii Hieronymi Commentariorum in Danielem liber. In: PL 25.

Der Große Alexander aus der Wernigeroder Handschrift. Hrsg. v. GUSTAV GUTH (Deutsche Texte des Mittelalters 13). Berlin 1908.

Der Große Seelentrost, Ein niederdeutsches Erbauungsbuch des vierzehnten Jahrhunderts. Hrsg. v. MARGARETE SCHMITT (Niederdeutsche Studien 5). Köln/Graz 1959.

Hartlieb, Johann, Alexander. Hrsg. v. REINHARD PAWIS. München/Zürich 1991.

Homer, Odyssee. Hrsg. u. übersetzt v. ROLAND HAMPE. Stuttgart 2010.

Ivli Valeri Res Gestae Alexandri Macedonis translatae ex Aesopo graeco. Hrsg. v. MiCHAELA ROSELLINI. München/Leipzig 2004.

Julii Valerii epitome. Hrsg. v. JULIUS ZACHER. Halle 1867.

Lambrecht (Pfaffe), Alexanderroman, Mittelhochdeutsch/Neuhochdeutsch. Hrsg. v. ELISABETH LIENERT. Stuttgart 2007.

Leo (Archipresbyter), Alexanderroman. Hrsg. v. FRIEDRICH PFISTER. Heidelberg 1913.

Liber Alexandri Magni. Hrsg. v. RÜDIGER SCHNELL. München 1989.

Die Lübecker Historienbibel. Die niederdeutsche Version der nordniederländischen Historienbibel. Hrsg. v. MARGARETE ANDERSSON-SCHMITT (Niederdeutsche Studien 40). Köln u. a. 1995.

De Noordnederlandse historiebijbel, Een kritische editie met inleiding en aantekeningen van hs. Ltk. 231 uit de Leidse Universiteitsbibliotheek. Hrsg. v. MARIANUS K. A. VAN DEN BERG. Hilversum 1998.

Ovid, Metamorphosen. Hrsg. u. übersetzt v. MiCHAEL VON ALBRECHT. Stuttgart 1994. 
Siælinna Thrøst, første delin aff the bokinne som kallas Siælinna thrøst, efter cod. Holm. A 108 (f. d. cod. Ängsö), kritisk upplaga. Hrsg. v. SAMUEL HENNING (Samlingar utgivna av Svenska fornskriftsällskapet 209, 211, 217). Uppsala 1954-1956.

Seifrits Alexander aus der Straßburger Handschrift. Hrsg. v. PAUL GEREKE (Deutsche Texte des Mittelalters 36). Berlin 1932.

Sjælens Trøst (,Siæla Trøst'). Hrsg. v. NiELS NiELSEN. København 1937. Nachdruck 1952.

Quilichinus de Spoleto, Historia Alexandri Magni, nebst dem Text der Zwickauer Handschrift der Historia de preliis Alexandri Magni, Rez. J33. Hrsg. v. WOLFGANG KIRSCH. Skopje 1971.

\section{Forschung}

Andersen, Peter Hv., Wigbolds Alexanderbuch: eine Pionierarbeit. In: DrITTENBASS, CATHERINE u. SCHNYDER, ANDRÉ (Hrsg.), Eulenspiegel trifft Melusine. Der frühneuhochdeutsche Prosaroman im Licht neuer Forschungen und Methoden. Akten der Lausanner Tagung vom 2. bis 4. Oktober 2008 in Zusammenarbeit mit Alexander Schwarz (Chloe 42). Amsterdam/New York 2010, S. 183-200.

BRENEZ, INGRID, Julius Valérius et le corpus alexandrin du IVe siècle, Présentation et traduction, suivies d'une étude de synthèse. Diss. 2003. Metz 2010 .

EHRISMANN, GuSTAV, Der Große Alexander. In: VL 1, 1933, Sp. 58-59. 


\title{
Oculi cordis: Verstümmelung, Wahrnehmung und Erkenntnis in Herrands von Wildonie Die treue Gattin
}

\author{
Carmen Stange
}

\begin{abstract}
:
Herrands von Wildonie Diu getriu kone ('The faithful wife') narrates the story of a man who looses his eye in a battle. When he decides not to return home because of his disfigurement, his wife gouges one of her eyes out too. In this paper are examined the different ways in which husband and wife, the court and the author comment on the relationship between beauty, ugliness and deformation of the couple. As a detailed interpretation shows, different concepts of perception and knowledge (refering to the difference between 'outer' and 'inner senses') are used and combined in these comments.
\end{abstract}

\section{Herrand und Die treue Gattin: Literaturgeschichtliche Einordnung, Forschungsüberblick und Vorüberlegungen}

„Das Wesentliche ist für die Augen unsichtbar“, 1 sagt der Fuchs zum Titelhelden in Der kleine Prinz. Diese wohl meistzitierte Textstelle aus dem Gesamtwerk von Antoine de Saint-Exupéry könnte auch aus dem Mund der treuen Gattin aus der gleichnamigen Versdichtung des Mittelalters stammen. ${ }^{2}$ Obwohl die makellose

${ }^{1}$ Saint-Exupéry, Der kleine Prinz, S. 96.

2 In der einzigen Handschrift, die den Text überliefert, ist er mit Ditz püchel haysset die getrew kone (Wien, Österreichische Nationalbibliothek, Cod. Series nova 2663, fol. 217ra) überschrieben. Vgl. GRUBMÜLLER, Herrand, S. 1068. 
Frau mit einem kleinen, hässlichen Mann verheiratet ist, erscheint ihr dieser „schœene als Absolôn / und sterker danne Sampsôn" („schön wie Absalom / und stärker als Samson"). ${ }^{3}$ Ihr Ehemann hadert dagegen mit seinem Äußeren: , ir wirt was an dem lîbe ein man, / daz er was nibt sô wolgetân, / als er ez gerne het gese-

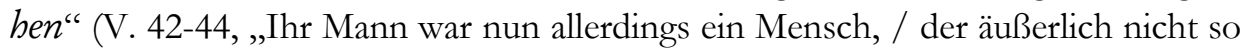
gut geraten war, / wie er es gerne gesehen hätte"). Nachdem er in einem Kampf auch noch ein Auge verloren hat, fühlt er sich so entstellt, dass er es ablehnt, zu seiner Gemahlin heimzukehren. Diese sticht sich daraufhin selbst ein Auge aus, um ihren Gatten zur Rückkehr zu bewegen, was ihr mit ihrer Tat auch gelingt. Deshalb wird die Namenlose sowohl auf der Figuren- wie auf der Erzählerebene des Textes für ihre Treue gerühmt, und die Darstellung endet mit dem Lob aller treuen Ehefrauen und der Selbstnennung des Verfassers: ${ }^{4}$

Swaz noch getriuwer konen sî, / die tuo got alles leides frî. / den allen sol ich sin bekant / von Wildonie Herrant. (V. 273-276)

(„Alle treuen Ehefrauen, die es sonst noch gibt, / befreie Gott von allem Leid. / Die mögen mich alle im Gedächtnis behalten: / Herrant von Wildonie.“)

Diese Schlusssignatur ermöglicht eine Identifizierung des Verfassers mit einem politisch einflussreichen Angehörigen eines Ministerialengeschlechts. Herrand II. von Wildonie (um 1230-1278/82) war Truchsess von Steier. Zahlreiche Urkunden dokumentieren sein Leben zwischen den Jahren 1248 und 1278 und verraten, dass er stark in die Ereignisse des Interregnums (1256-1273) verstrickt war. Aufgrund der umfangreichen politischen Betätigung erstaunt es wenig, dass das literarische Werk Herrands nicht allzu umfangreich ist. Es stammt wohl aus den frühen sechziger Jahren des 13. Jahrhunderts und umfasst drei Lieder, denen eine „konventionelle] Machart" ${ }^{\text {"5 }}$ bescheinigt wird, und vier kleine Verserzählungen, deren literaturgeschichtlicher Wert höher geschätzt wird. Die Anregungen für seine Dichtungen erhielt Herrand wahrscheinlich in erster Linie von Ulrich von Liechtenstein, mit dessen Tochter Perchta er verheiratet war. So erwähnt er seinen Schwiegervater namentlich als Gewährsmann in seiner Verserzählung Der betrogene Gatte. ${ }^{6}$ Möglicherweise waren Herrands Werke ausschließlich für den Familienkreis gedacht, wofür die gemeinsame unikale und späte Überlieferung der vier Erzähltexte im Ambraser Heldenbuch aus den ersten Jahren des 16. Jahrhunderts ein Indiz

\footnotetext{
${ }^{3}$ Herrand von Wildonie, Die treue Gattin, V. 49f. Im Folgenden zitiere ich den Text und die Übersetzung nach der Ausgabe von KLAUS GrubmüLLER und gebe deshalb die Versangaben in runden Klammern direkt im Anschluss an die Zitate an.

${ }^{4}$ Vgl. zu Inhalt und Struktur WAGNER, Gottesbilder, S. 199, dessen Textverständnis, obwohl er einen anderen methodischen Ansatz verfolgt, bisweilen mit der folgenden Interpretation übereinstimmt.

${ }^{5}$ Curschmann, Herrand, Sp. 1145.

${ }^{6}$ Vgl. zur Biographie insgesamt Curschmann, Zur literaturhistorischen Stellung, S. 56f.; DERS., Herrand, Sp. 1144f.; Fischer, Studien, S. 162f.; Grubmüller, Herrand, S. 1064; STRASSER, Ein mündiger Poet, S. 249.
} 
sein könnte. ${ }^{7}$ Da das Auftragswerk von Kaiser Maximillian I. im Anschluss an Herrands Texte das Frauenbuch Ulrichs von Liechtenstein überliefert, hat SCHRÖDER vermutet, dass die gemeinsame Vorlage erstmals aus dem Familienbesitz heraus in die Hände des Schreibers Hans Ried übergeben wurde. ${ }^{8}$ Die Überlieferungsgemeinschaft der vier Verserzählungen hat außerdem dazu geführt, dass die Texte zumeist als Zyklus mit einer übergreifenden Aussage interpretiert wurden.? So gilt etwa die Diskussion über die triuwe, sowohl in der Ehe als auch in Lehnsbeziehungen, als verbindende Thematik der Erzählungen, ${ }^{10}$ oder es wird angenommen, dass in allen vier Texten die „Problematik von Schein und Sein“ erörtert wird. ${ }^{11}$ Dementsprechend wird Die treue Gattin als eine „Geschichte von unverbrüchlicher Gattenliebe“12 interpretiert, in der die triuwe der Ehefrau durch das geopferte Auge als Liebesbeweis pointiert werde ${ }^{13}$ und in der die erzählte eheliche Gemeinschaft nicht auf ästhetischen, sondern auf ethischen Werten gründe. ${ }^{14}$ Der Text repräsentiere somit eine Liebesethik, „die sich nicht schon mit Konvention und höfischem Schein zufrieden gibt, sondern die ganze Person fordert"..15 Der Titel der Verserzählung in der handschriftlichen Überlieferung, die Bewertung des Handelns der Protagonistin als Treuebeweis durch einen Dritten (V. 227-229), ihre abschließende Würdigung (V. 265-272) und die Generalisierung des Lobpreises auf alle treuen Ehefrauen (V. 273-275) bestätigen diese Lesart. Durch sie wird außerdem verständlich, warum eine Geschichte von Verstümmelung und Selbstverstümmelung im Prolog als eine gute, angenehme Geschichte angekündigt wird, die die Rezipienten erfreuen soll (V.1-22). ${ }^{16}$

\footnotetext{
7 Wien, Österreichische Nationalbibliothek, Cod. Series nova 2663, fol. 217ra-220va.

8 Vgl. SCHRÖDER, Herrand, S. 57-59; sowie FISCHER, Studien, S. 163; GrubMÜLLER, Herrand, S.1064; Minm, Überlieferung, S. 28. Dagegen argumentieren Curschmann, Zur literaturhistorischen Stellung, S. 56-58 u. DeIGHTON, Die ,nichtpolitischen' Erzählungen, S. 111f.

9 Vgl. Curschmann, Zur literaturhistorischen Stellung; LinKe, Schein und Sein; MArgetTs, Scenic Significance, bes. S. 146; MinM, Überlieferung, S. 28. Obwohl DeIGHTON, Die ,nichtpolitischen' Erzählungen, zunächst Kritik an der These einer geschlossenen Konzeption der vier Texte äußert (S. 111-114), bescheinigt auch er abschließend „Herrands Oeuvre [...] inhaltliche[ Kohärenz“ (S. 120). Dagegen interpretieren ORTMANN/RAGOTZKY, Zur Funktion, bes. S. 90-94 u. 102-109; sowie WAGNER, Gottesbilder, S. 199-222, ausschließlich Die trene Gattin. STRASSER, Ein mündiger Poet, konzentriert sich auf die beiden Dichtungen Die Katze und Der betrogene Gatte.

10 Vgl. Curschmann, Zur literaturhistorischen Stellung, S. 76f.; Deighton, Die ,nichtpolitischen' Erzählungen, S. 114-120; MARGETTS, Scenic Significance, S. 146.

${ }^{11}$ LiNKE, Schein und Sein, S. 1.

${ }^{12}$ Ebd.; vergleichbar auch ebd., S. 2 sowie CurSChMANN, Herrand, Sp. 1145f.; DERS., Zur literaturhistorischen Stellung, S. 72; DEIGHTON, Die ,nichtpolitischen' Erzählungen, S. 116; GruBMÜLLER, Herrand, S. 1066f.; OrTMANn/RAGOTZKY, Zur Funktion, S. 90-94; STRASSER, Vornovellistisches Erzählen, S. 179.

13 Vgl. Ortmann/RagotZKy, Zur Funktion, S. 105.

${ }^{14}$ Vgl. Linke, Schein und Sein, S. 3.; WAGNER, Gottesbilder, unterscheidet körperliche und ethische Qualitäten des Leibes. Während der Ehemann sich fälschlich auf das Körperliche beziehe, gelänge der Frau durch die Rückbindung an religiöse Werte die Überwindung des höfischen Wertesystems.

15 GrubmülLer, Herrand, S. 1067.

16 Zum Prolog Ortmann/RagotZky, Zur Funktion, S. 92f.; Wagner, Gottesbilder, S. 200-203.
} 
Allerdings bestehen zwischen den vier Erzählungen erhebliche formale und inhaltliche Unterschiede. So zeigen sich Differenzen etwa hinsichtlich der Quantität der Texte sowie bezüglich des Vorhandenseins und der Ausgestaltung der Prologe und Epiloge. Insbesondere die Gattungszuordnungen sind umstritten und weichen voneinander ab. ${ }^{17}$ Im Allgemeinen gelten Die treue Gattin und Der betrogene Ehemann als Mären, ${ }^{18}$ Der nackte Kaiser als Mirakel-19 oder Exempelerzählung ${ }^{20}$ und Die Katze als Tierbîspel. ${ }^{21}$ Ob Die treue Gattin nun aber ein ,höfisch-galantes' ${ }^{62}$ ein ,moralisch-exemplarisches ${ }^{23}$ oder ein ,schwankhaftes Märe ${ }^{24}$ ist, wird diskutiert. Entweder gilt der höfische Kontext, in dem die Handlung spielt, als entscheidendes Zuordnungskriterium oder aber das Lob treuer Ehefrauen in den Schlusszeilen wird als überständische Öffnung des Textes höher bewertet. Der Epilog wird dementsprechend entweder als Vermittlungsstrategie für eine allgemeingültige Lehre über die eheliche Treue oder als Signum für die typische Veränderung höfischen Erzählens zur schwankhaften Kurzform in der Gattungsgeschichte des Märes verstanden. Als Vorbild gilt eine Episode aus dem altfranzösischen Versroman Ille et Galeron von Gautier d'Arras (1167-1184), aber auch ein Minnecasus von Andreas Capellanus könnte anregend gewirkt haben. ${ }^{25}$ Für die Existenz einer Vorlage spricht Das Auge, ein anonym überliefertes Märe aus der ersten Hälfte des 13. Jahrhunderts, das die Geschichte sehr ähnlich erzählt. ${ }^{26}$ Andererseits ist die Grundkonzeption der beiden Mären weit verbreitet und die mehrfache (Wieder-)Aufnahme könnte auch einfach der Aktualität der Thematik geschuldet sein. ${ }^{27}$

Da die Definition und die Typologie des Märenbegriffs von FISCHER aufgrund der unspezifischen Festlegungen und seines induktiven Vorgehens bis heute um-

\footnotetext{
17 Vgl. Deighton, Die ,nichtpolitischen Erzählungen', S. 112-114.

18 Vgl. Curschmann, Herrand, Sp. 1145; Deighton, Die ,nichtpolitischen` Erzählungen, S. 112; Fischer, Studien, S. 162; GrubMüLLER, Herrand, S. 1064-1067; MARGETTS, Scenic Significance, S. 142f., 145f. mit Anm. 23; OrTmann/RAgOtZKY, Zur Funktion, S. 89f.; Schirmer, Stil- und Motivuntersuchungen, S. 22 u. 23 Anm. 79; STRASSER, Ein mündiger Poet, S. 249; DERS., Vornovellistisches Erzählen, S. 171, 178f.; WAGNER, Gottesbilder, S. 199-222.

${ }^{19}$ Vgl. Deighton, Die ,nichtpolitischen`Erzählungen, S. 112; Fischer, Studien, S. 162.

${ }^{20}$ Vgl. LiNKE, Schein und Sein, S. 1.

21 Vgl. Deighton, Die ,nichtpolitischen` Erzählungen, S. 112; Fischer, Studien, S. 162; Linke, Schein und Sein, S. 1.

22 Vgl. Ortmann/Ragotzky, Zur Funktion, S. 89 sowie den Titel von Wagner, Gottesbilder.

23 Vgl. SCHIRMER, Stil- und Motivuntersuchungen, S. 23.

${ }^{24}$ Vgl. STRAsSER, Vornovellistisches Erzählen, S. 171-173.

25 Vgl. Curschmann, Zur literaturhistorischen Stellung, S. 71; STRASSER, Vornovellistisches Erzähen, S. 179.

26 Vgl. Curschmann, Zur literaturhistorischen Stellung, S. 71-75; Williams-Krapp, Das Auge, Sp. $516 \mathrm{f}$.

${ }^{27}$ Vgl. GrubMüLLER, Herrand, S. 1065-1067.
} 
stritten sind, ${ }^{28}$ verwundern die Zuordnungsschwierigkeiten nicht. ${ }^{29} \mathrm{Um}$ dieses Problem zu umgehen wird in einigen Darstellungen der Begriff ,Märe ${ }^{6}$ ohne genauere Einordnung verwendet. ${ }^{30}$ Ganz auf diese Bezeichnung wird ungern verzichtet, ${ }^{31}$ weil Herrand von Wildonie als Märendichter in zweifacher Weise eine besondere Rolle zugesprochen werden kann: „er ist [...] der einzige Märendichter, der unterhaltsame und lehrhafte Kleinepik mit der alten Standeskunst des Minnesangs verbindet, und er ist der erste adlige Dilettant in ihren Reihen.“"32

Die treue Gattin ist aber nicht nur als erste Märendichtung eines Adligen etwas Besonderes. Obwohl Verstümmelung kein Einzelschicksal in der Welt des Mittelalters war, denn Turnier- und Kriegsverletzungen waren die häufigste Erkrankungsform und Todesursache des adligen Mannes im Mittelalter, ${ }^{33}$ wird kaum darüber und über deren Wahrnehmung durch die Versehrten selbst, ihre Angehörigen und die Gesellschaft in der deutschsprachigen Literatur des Mittelalters erzählt. Zwar ist der Tod als Folge von ritterlichen Zweikämpfen und kriegsbedingten Kampfhandlungen in den verschiedensten Texten und über einen längeren Zeitraum hinweg präsent, ${ }^{34}$ aber Überlebende mit bleibenden Kampfverletzungen sind als Figuren in der Dichtung selten und ihr weiteres Schicksal bleibt im Dunkeln. ${ }^{35}$ Verletzte werden in der Literatur zumeist ohne bleibende Schäden geheilt,

\footnotetext{
${ }^{28}$ Nach FISCHER, Studien, S. 62f., ist ein Märe: ,„[...] eine in paarweise gereimten Viertaktern versifizierte, selbständige und eigenzweckliche Erzählung mittleren (d. h. durch die Verszahlen 150 und 2000 ungefähr umgrenzten) Umfangs, deren Gegenstand fiktive, diesseitig profane und unter weltlichem Aspekt betrachtete, mit ausschließlich (oder vorwiegend) menschlichem Personal vorgestellte Vorgänge sind." Die so definierten literarischen Texte schreiten nach FISCHER zwölf Themenkreise $\mathrm{ab}$ und lassen sich nicht immer eindeutig den drei Haupttypen zuordnen, sondern sie erscheinen auch als Mischformen (ebd., S. 93-137). Die Kritik an Fischers Konzept kann hier nur angedeutet werden. Einerseits geht es um eine Präzisierung des Begriffs (vgl. z. B. GrubMüLLER, Die Ordnung; SCHIRMER, Stil- und Motivuntersuchungen; STRASSER, Vornovellistisches Erzählen), andererseits wird die Notwendigkeit einer eigenen Gattungsbezeichnung für Mären infrage gestellt und für deren literaturgeschichtliche Integration in die Tradition der Novellistik plädiert (vgl. v. a. die Arbeiten von HEINZLE, von denen im Literaturverzeichnis nur eine Auswahl genannt werden kann).

${ }^{29}$ Deshalb zielen Ortmann/Ragotzky, Zur Funktion, mit ihrem Beitrag auf eine Präzisierung des Begriffs ,höfisch-galantes Märe“ als „Funktionstyp exemplarischen Erzählens“ (S. 87).

30 Vgl. Curschmann, Herrand, Sp. 1146; GrubmülLer, Herrand, S. 1064.

31 Vgl. aber LinKe, Schein und Sein.

${ }^{32}$ Fischer, Studien, S. 163. So auch Curschmann, Herrand, Sp. 1145.

33 Vgl. JANKRIFT, Mit Gott, S. 73-79.

${ }^{34}$ Laut HAFERLACH, Die Darstellung, S. 27, finden sich die häufigsten letalen Kampfverletzungen im Bereich des Kopfes und des Halses. Die Konstruktion der mittelalterlichen Rüstung bedingt, dass der Grenzbereich zwischen Kettenhemd und Helm besonders gefährdet ist. Sowohl in der Heldenepik (z. B. Volker und Iring) als auch im höfischen Roman (z. B. Ither, Ascalon und Morolt) werden Kämpfer an dieser Stelle tödlich getroffen.

${ }^{35}$ Dies gilt auch für die lateinische Hexameterdichtung Waltharius, die als zweiter Heldenepos der deutschen Literaturgeschichte nach dem Hildebrandslied gilt, weil in ihm germanischer Heldensagenstoff verarbeitet ist. Auch mit der auffallenden Häufung von Kriegsversehrten, mit der das Epos endet, ist der Text „eine Ausnahmeerscheinung der Literaturgeschichte“ (VOGT-SPIRA, Der ,Waltharius', S. 5). Der abschließende Dreikampf führt zur Verstümmelung aller Kampfteilnehmer: Gunther verliert ein Bein, Walther eine Hand und Hagen ein Auge sowie sechs Backenzähne (Waltharius, V. 1360-1396). Die Wunden werden verbunden und den Verletzten wird ein stärkender Wein gereicht
} 
oft auf wundersame Weise. ${ }^{36}$ In Herrands Märe sind dagegen die Kriegsverletzung und die anschließende Selbstverstümmelung der Ehefrau irreparabel. Sie und ihre Wahrnehmung durch die Ehepartner bestimmen die Handlungen beider Protagonisten. Hinzu treten Wahrnehmungsbeschreibungen sowohl auf der Erzähler- wie auf der Figurenebene, die die Ansichten der höfischen Gesellschaft und eines Neffen widerspiegeln. Somit wird der nur 276 Verse umfassende Text stark von diversen Diskursen über schöne, hässliche und deformierte Körper bestimmt, die hier erstmals in den Blick genommen und vor dem Hintergrund mittelalterlicher Konzepte über den Zusammenhang des Äußeren und des Inneren und über den Weg vom Sehen zur Erkenntnis gründlich analysiert werden. ${ }^{37}$

Seit dem 12. Jahrhundert entwickelt sich eine neue Sichtweise über den Zusammenhang zwischen dem äußeren Erscheinungsbild und dem Zustand des Inneren des Menschen heraus. Während Körper und Seele in der christlichen Anthropologie traditionell als Gegensätze verstanden werden, etabliert sich nun zusätzlich die gegenteilige Vorstellung des Körpers als Spiegel der Seele. ${ }^{38}$ Zur gleichen Zeit gibt es auch zwei unterschiedliche Auffassungen darüber, wie der Mensch zur Erkenntnis gelangen kann. Aus der antiken Tradition seit Aristoteles stammt die Annahme, dass die sinnliche Wahrnehmung (sensus corporeus) durch die innere Vorstellungskraft zu einem Bild geformt wird (imaginatio), das mit bereits bekannten Bildern verglichen wird (memoria). Dadurch wird das Nachdenken über das Gesehene in Gang gesetzt (ratio) und die Erkenntnis eingeleitet. Im Mittelalter entwickelte Augustinus daneben die wirkmächtige Idee vom unmittelbaren und unreflektierten Erkennen alles Wahrgenommenen im Herzen durch die Kraft der Liebe: 39

Cor tuum et uidet et audit, et cetera sensibilia diiudicat; et quo non aspirant corporis sensus, iusta et iniusta, mala et bona discernit. Ostende mibi oculus, aures, nares cordis tui [...]. In carne tua alibi audis, alibi uides; in corde tuo tibi audis, ubi uides.

(„Dein Herz sieht und hört und beurteilt auch die übrigen Sinneswahrnehmungen. Und wohin die äußeren Sinne des Körpers nicht reichen, da unterscheidet es Gerechtes und Ungerechtes, Böses und Gutes. Zeige mir die Augen, die Ohren, die Nase deines Herzens [...]. In deinem

\footnotetext{
(ebd., V. 1401-1416). Wie die weitere Therapie aussieht und wie das Leben der Verstümmelten weitergehen wird, ist allerdings nicht zu erfahren. Die Ernsthaftigkeit der Thematik wird im Gegenteil sogar dadurch komisch gebrochen, dass sich die Schwerverletzten alsbald wieder verbal verspotten können (ebd., V. 1417-1450; VOGT-SpiRA, Der,Waltharius', S.18f.). Vgl. auch HAFERLACH, Die Darstellung, S. 25-27, sowie zur analogen Situation hinsichtlich historischer Quellen AUGE, So solt er, S. 24-27.

36 Vgl. HAFerLach, Die Darstellung, S. 27, 35-47, 55-75 u. 77-84; KerTH, Versehrte Körper, S. 272; sowie die Beiträge von SONJa KerTH und BJÖRn REICH im Folgeband (KerTh, Schreiende Kriegswunden; REICH, Verkrüppelte Helden).

37 Vgl. auch den Beitrag von Lola KING in diesem Band, sowie von Gabriela ANTUNES im Folgeband (ANTUNES, Entstellte Schönheiten).

${ }^{38} \mathrm{Vgl}$. Bumke, Die Blutstropfen, S. 21; sowie ANTunES, Entstellte Schönheiten.

${ }^{39}$ Vgl. Bumke, Die Blutstropfen, S. 43.
} 
Leib hörst du an einer Stelle und siehst an einer anderen. In deinem Herzen hörst du da, wo du auch siehst." ${ }^{40}$

Wenn die treue Gattin also mit dem Herzen gut sieht, so beruht ihre subjektive Erkenntnis auf dem, was ihre ,Augen des Herzens“ (oculi cordis) nach Augustinus sehen. ${ }^{41}$ Außerdem ist für sie dann das Äußere nicht der Spiegel des Inneren ihres Mannes. Der Ehemann kommt dagegen zur rationalen Erkenntnis seiner Hässlichkeit und urteilt vor dem Hintergrund des entgegen gesetzten Verständnisses von innerer und äußerer Schönheit. Diese Lesart soll im Folgenden entsprechend der Entwicklungsreihenfolge der beiden Wahrnehmungs- und Erkenntnistheorien vorgeführt werden, um abschließend zu prüfen, welche Auswirkungen eine solche Lektüre auf das bisherige Textverständnis hat. Die Relevanz des gewählten wahrnehmungs- und erkenntnistheoretischen Interpretationsansatzes für Herrands Die treue Gattin macht ein kurzer vergleichender Blick in das verwandte Märe Das Auge deutlich: Hier verlässt der Mann seine Ehefrau nach seiner Verstümmelung, weil er deren Verachtung fürchtet, bei Herrand möchte er ihr dagegen seinen unerfreulichen Anblick ersparen. ${ }^{42}$

\section{Der Ehemann: Wahrnehmung und rationale Erkenntnis}

Im Anschluss an den Prolog wird die treue Gattin direkt als schöne Frau des Ritters in das Märe eingeführt. Die Liebe ihres Mannes wird vom Erzähler als berechtigt gewertet, weil sie nicht nur schön, sondern gleichzeitig auch gut war:

Ein ritter het ein schœe wîp, / diu was im liep als sîn lîp. / daz was billîch: ir schœene was / durchliubtic als ein spiegelglas; / dar zuo was sî den vollen guot. / swâ ein wîp ist sô gemuot, / daz sî bî schoene güete hât, / der lîp billî̀ch ze loben stât. / diu reine was sô êrbære, / daz ir man kein herzensware / von den dingen nie gewan; / dâ von mohte er sî gerne hân. (V. 23-30)

(„Ein Ritter hatte eine schöne Frau, / die liebte er wie sein Leben. / Das war berechtigt: Ihre Schönheit / war klar wie ein Spiegel; / überdies war sie vollkommen gut. / Wenn eine Frau von solcher Art ist, / daß sich Schönheit mit gutem Charakter verbindet, / dann darf man sie zu Recht rühmen. / Diese edle Frau war so makellos, / daß ihr Mann nie / ihretwegen Kummer hatte; / deswegen liebte er sie.")

\footnotetext{
${ }^{40}$ Sancti Aurelii Augustini In Iohannis evagelium tractatus, 18, 10, S. 186. Übersetzung nach BuMKE, Die Blutstropfen, S. 16.

41 Vgl. ebd.

${ }^{42}$ Vgl. Curschmann, Zur literaturhistorischen Stellung, S. 72f., der noch weitere Unterschiede verzeichnet, und WAGNER, Gottesbilder, S. 220f. Trotz der interessanten und zum Teil sicher anschlussfähigen Zusatzinformationen, die aus einem vollständigen Textvergleich gewonnen werden könnten, konzentriere ich mich im Folgenden im Rahmen meiner textimmanenten Vorgehensweise allein auf Die treue Gattin, um zu prägnanteren Einsichten im Kontext der gewählten Methode zu gelangen.
} 
Die namenlose Protagonistin entspricht voll und ganz dem bereits in der Antike formulierten Kalokagathie-Ideal. ${ }^{43}$ Ihre innere Gutheit wird durch ihre Schönheit nach außen repräsentiert, so dass es keinen Grund für ihren Mann gibt, sie nicht zu lieben. Seine berechtigte Liebe beruht auf ihrer körperlichen und geistigen Vollkommenheit. Während seine Ehefrau makellos ist, erfährt man als allererstes über den Protagonisten, dass er seine eigene Unansehnlichkeit bedauert (V. 42-44). Diese herausgehobene Stellung der Selbstwahrnehmung lässt bereits ahnen, dass für den Fortgang der Handlung das Negativurteil des Ritters über sein Aussehen von entscheidender Bedeutung sein wird. Zwar wird die Selbsteinschätzung des unansehnlichen Äußeren durch den Erzähler bestätigt, der ihn als ,gerumphen unde klein“ (V. 45, „runzlig und klein“) beschreibt, und auch das Umfeld des Mannes registriert seine körperlichen Mängel: ,der ritter vor den liuten schein, / als er wær bundert jâr alt“ (V. 46f., „Den Leuten kam der Ritter vor, als wäre er hundert Jahre alt"). Doch bevor von der Verstümmelung im Kampf erzählt wird, wendet sich der Erzähler den ritterlichen Qualitäten des Protagonisten zu, von denen er deutlich ausführlicher berichtet als über dessen Aussehen. Zudem betont er, dass er von dem Ritter wegen seiner Vorbildlichkeit im Kampf berichtet (V. 75-78), während weniger tapfere Kämpfer ihn nicht zum Erzählen anregen (V. 84). Schönheit und Hässlichkeit werden dagegen nicht als Auswahlkriterium angesprochen.

Der Ehemann folgt wie üblich einem Kampfaufruf, von dem er Nachricht erhielt, und kämpft dann so überragend, dass er als bester aller Teilnehmer gepriesen wird (V. 67-74). Auch seine Verletzung, die ihm im Anschluss zugefügt wird, deutet der Erzähler als doppelten Beweis seiner hervorragenden Fähigkeiten. Zum einen prädestiniert den Ritter seine Führungsrolle zum Angriffsziel, während weniger ambitionierte Kämpfer in den hinteren Reihen der Kampfformation sicherer sind. Zum anderen wird ihm sein Auge gezielt von einem Gegner ausgestochen, der ihn wegen seiner Tüchtigkeit seit langem beneidet (V. 79-88). Das unansehnliche Äußere hat beim Gegner augenscheinlich keine Neid senkende oder Mitleid erregende Wirkung. Während der Erzählerbericht die Bedeutung des Aussehens relativiert, urteilt die männliche Hauptfigur dagegen weiterhin auf dieser Grundlage. ${ }^{44}$ Nach dem Verlust seines Auges beauftragt er den Sohn seiner Schwester (,siner swester sun“, V. 95) ${ }^{45}$ seiner Frau eine Botschaft zu überbringen. Diese beginnt mit einer Reflexion über die Schamgefühle, die ihn wegen seines Aussehens schon immer quälten. Nach seiner Verstümmelung empfindet er sie als so unerträglich, dass er beschließt, seine Frau und seine Heimat zu verlassen:

\footnotetext{
${ }^{43}$ So auch LinKe, Schein und Sein, S. 1; vgl. allgemein Ehrismann, Ehre und Mut, S. 189-194.

${ }_{44}$ Damit spiegelt der Text zeitgenössische Diskurse wider, in denen Versehrtheit ,als Beeinträchtigung der Ehre und Leistungsfähigkeit [...] oder als Auszeichnung“ (NOLTE, „Behindert“, S. 15; vgl. auch ebd., S. 11-14) gedeutet wurden, wie insbesondere die Untersuchung von AugE, So solt er, zeigt. 45 WaGner, Gottesbilder, S. 210, bezeichnet den Knappen fälschlich als „Neffe der Dame“.
} 
getriuwer friunt, nu var / und sage der einen süezen klâr, / mîn dinc sich habe gefüeget sô, / daz ich sî iemer mêr unfrô. / ich was ê nibt ein flætic man; / nu babe mir got alsô getân, / daz ich mich schame, daz sî billîch, / und welle ouch alliu tiutschiu rîch / rûmen und alliu diu lant, / dâ ich bînamen bin bekant. (V. 99-108)

(,[...], Treuer Freund, reite los / und sage der edlen, liebenswerten, strahlenden Frau, / daß sich meine Sache so gefügt hat, / daß ich in Zukunft nie mehr glücklich sein werde. / Ich war bisher schon kein schöner Mann; / jetzt hat Gott mir etwas angetan, / was zu Recht mein Ehrgefühl verletzt, / und deswegen werde ich Deutschland / verlassen und alle anderen Länder, / in denen man meinen Namen kennt. [...]“")

Hier zeigt sich, dass für das Selbstbild des Protagonisten seine ritterliche Tüchtigkeit keine Rolle spielt, verschwendet er doch bei seiner Entscheidungsfindung nicht einen Gedanken daran. Seine Selbstwahrnehmung und der daraus resultierende Erkenntnisprozess entsprechen den Vorstellungen des aristotelischen Modells: Die Konfrontation mit seinem eigenen Anblick führt zur Imagination seiner Gestalt, die dem Vergleich mit dem abgespeicherten Idealbild des schönen höfischen Körpers nicht standhält. Beim Nachdenken über das Gesehene scheint zudem die Vorstellung, dass die inneren Qualitäten durch das Äußere repräsentiert wird, den Ritter in seinem Entschluss zu bestärken, sein bisheriges Dasein hinter sich zu lassen, da seine Überlegungen ausschließlich um sein Äußeres kreisen.

Obwohl der Erzähler bei seiner Beschreibung des Protagonisten auf dessen ritterliche Taten verweist, diffamiert er dessen Position nicht als grundsätzlich falsch, grausam oder egoistisch, denn es findet sich kein kritischer Erzählerkommentar. Außerdem wird die Liebe betont, die der Ehemann für seine Frau empfindet, und als zentraler Grund für seine Entscheidung herausgestrichen. So heißt es gleich nach dem Verlust des Auges, dass den Ritter mehr als sein körperlicher Schmerz die Vorstellung quält, dass seine Ehefrau bei seinem Anblick seinetwegen Qualen erleiden müsse (V. 89-92): „wan ir leit daz was daz sin, / sin leit was ouch ir leides pîn“ (V. 93f., „Denn ihr Leid war das seine, / sein Leid war auch ihr Schmerz"); außerdem soll der Bote der Ehefrau ausrichten, dass das Herz ihres Mannes auch nach dessen Aufbruch in die Ferne immer bei ihr sein wird, egal wohin es ihn verschlägt (V. 109f.). Allerdings deutet der Ritter das, was seine Frau seiner Ansicht nach beim Anblick seines verstümmelten Äußeren quält, von seinem Standpunkt der objektiven Erkenntnis des Äußeren als Beleidigung ihrer Schönheit:

ir schœenem lîbe, ir varwe klâr, / den müese ich sîn ein marter gar, / solte ich ir fürbaz wonen bî. / der marter sol sî wesen frî. (V. 121-124)

(„Für ihre Schönheit, ihre strahlende Erscheinung, / müsste ich eine Qual sein, / wenn ich weiter mit ihr leben würde. / Diese Qual soll ihr erspart bleiben.")

Der Neffe teilt der Ehefrau seines Onkels die ihm aufgetragene Nachricht inhaltsgetreu mit, so dass die Auffassungen des Mannes nochmals in komprimierter Form wiederholt und damit als Verständnishorizont des Ritters bestätigt werden: Als erstes wird seine Entscheidung als Tat der Liebe zu seiner Frau, der er auch wei- 
terhin verbunden sein wird, angekündigt (V. 138-140). Dann wird die Selbsteinschätzung seines Aussehens vor der Verstümmelung wiedergegeben und die Diskrepanz zwischen dem Äußeren beider Ehepartner wird als Zeichen der besonderen Vorbildlichkeit der schönen Protagonistin gedeutet, die ihren hässlichen Mann stets respektvoll behandelt hat (V. 142-145; vgl. V. 112-118). Gleichzeitig wird die Ehefrau damit zur Repräsentantin des Ideals der Identität von innen und außen stilisiert, dem der auf sein Aussehen fokussierte Ritter verpflichtet ist. Weil er seine Verstümmelung als Verschärfung der Situation versteht, beschließt er nicht mehr heimzukehren (V. 146-149).46

Da der Protagonist bei seinen Überlegungen den Wert seiner Rittertaten nicht berücksichtigt hat, fehlt in seiner Mitteilung jedwede Information über das Kampfgeschehen. Deshalb muss die treue Gattin den Auslöser für seine Entscheidung beim Neffen erfragen. ,[D]er bote sprach: ,ein ouge er hât / verlorn und doch vil ritterlich“ (V. 152f.: „Der Bote sagte: ,Ein Auge hat er / verloren, im ritterlichen Kampf"). Wie zuvor schon der Erzähler nimmt auch der junge Verwandte die Umstände und den Wert der Handlungen des Ritters wahr und urteilt im Gegensatz zu seinem Onkel auf dieser Basis. Aus diesem Grund weint er, als er von dessen Entscheidung hört (V. 128) und als er diese der Ehefrau überbringt (V. 137). Auch anschließend kommt er aus dem Weinen nicht mehr heraus. ${ }^{47}$ Als Erster wird er mit dem Anblick der Protagonistin konfrontiert, nachdem diese sich ein Auge ausgestochen hat (V. 193-197), und muss anschließend diese Nachricht seinem Onkel überbringen (V. 211-219). Nachdem er von der Selbstverstümmelung seiner Ehefrau gehört hat, beklagt der Ritter, dass er nicht selbst zu seiner Gattin geritten ist. Aus Trauer über sein Fehlverhalten malträtiert er sich selbst mit Schlägen, verflucht den Tag seiner Geburt und reißt sich Haare aus:

der ritter sich zen brüsten sluoc. / er sprach: „owê mir iemer wê! / ich het dar baz geriten ê. / ach, daz ich ie wart geborn! / wie hât mîn schoene wîp verlorn / ir ouge. wê, daz ich ie wart!" / der hêrre von der swarten zart / sin hâr. (V. 220-227)

(„,Der Ritter schlug sich gegen die Brust. / Er rief: ,O weh mir, immer nur weh! / Ich wäre besser früher hingeritten. / Ach, daß ich jemals geboren wurde! / Daß meine schöne Frau ihr Auge verloren hat! / Weh mir, daß ich am Leben bin!' / Der Herr riß sich das Haar aus dem Kopf.")

Da dem Ehemann die Bedeutung der Tat von einem anderen Ritter gedeutet werden muss, bereut er hier wohl nicht das Vorhaben, seine Frau und sein Land zu verlassen zu haben, sondern beklagt eher, dass er einen Boten als Überbringer seines Beschlusses ausgesendet hat, anstatt sich persönlich zu erklären. Wie zuvor kreist sein Denken um seine eigenen Fehler und um das Äußere seiner Frau. Seine verbalen Selbstbezichtigungen und Klagegesten beziehen sich auf die Erkenntnis,

\footnotetext{
${ }^{46}$ Vgl. auch LinKe, Schein und Sein, S. 1f.

${ }^{47}$ Zum Weinen vgl. auch WAGNER, Gottesbilder, S. 211, 214f. (hier auch Aussagen zum Sehen) u. 217.
} 
dass seine schöne Frau nun einäugig und verstümmelt ist. Über die körperlichen Schmerzen, die sie für ihn erduldet, und den seelischen Kummer, den er ihr mit seiner Botschaft bereitet hat, macht er sich hier noch keine Gedanken. Das Eingreifen des anderen Ritters beendet die Selbstanklage. Dieser bezieht sich auf die Tat der Ehefrau, lobt deren Treue und ruft zur Dankbarkeit ihr gegenüber auf (V. 227-229). Dieses Deutungsangebot geht, so der Erzähler, dem Ehemann so nahe, dass er daraus die Kraft gewinnt, ${ }^{48}$ seinen Jammer zu überwinden. Er übernimmt die Sichtweise des Fremden und beschließt, zu seiner treuen Gattin zurückzukehren und die Verstümmelte aufgrund ihrer Tat noch mehr zu lieben als zuvor (V. 231-236). Damit löst er sich von seinen bisherigen Annahmen und Erkenntnissen über das Äußere und das Inneres des Menschen, weshalb er seine Gemahlin seinem Neffen gegenüber immer noch als rein und makellos („vil reinen wandels $f r \hat{\imath}$, V. 241) bezeichnet, als er ihn bittet vorauszureiten, damit sich die Protagonistin keinen weiteren Schaden zufügt (V. 237-244). Seine neue Perspektive befähigt ihn außerdem dazu, ihren Schmerz zu erkennen und zu beweinen (V. 245-247, 251-256). Damit handelt und urteilt er am Ende des Märes wie seine Ehefrau während des gesamten Handlungsverlaufes.

\section{Die Ehefrau: Wahrnehmung und subjektive Erkenntnis}

Bereits zu Beginn der Verserzählung deutet sich an, dass sich die Ehefrau von Äußerlichkeiten nicht beeindrucken lässt. Während ihr Ehemann und der Erzähler ihre Schönheit und ihr höfisches Verhalten preisen, findet sich im Text keine Aussage darüber, wie die Frau sich selbst wahrnimmt (V. 23-40). Ihren Mann findet sie dagegen schön und stark (V. 49f.), obwohl er selbst, die höfische Gesellschaft und der Erzähler seine objektive Hässlichkeit feststellen (V. 41-48). Die Ehefrau wird für ihre subjektive Sichtweise vom Erzähler jedoch nicht getadelt oder belächelt, sondern ihre Perspektive wird als zusätzliche Bestätigung ihrer Vollkommenheit gedeutet und als Zeichen ihrer Befähigung, die Ehrenhaftigkeit und die Leistungen ihres Mannes anzuerkennen. Die Berechtigung ihrer Erkenntnis wird durch die ausführliche Schilderung der höfischen Gesinnung und der ritterlichen Taten ihres Ehemannes belegt: 49

in ir herzen wart nie man, / den sîfür in wolte hân. / daz machte ir grôziu frümikeit, / daz ander: er was gar bereit / ze alle diu, daz iemer man / an allen êren mac begân. / daz tet er allez völliclîch, / als ob er wære ein keiser rîch / gewesen und ein der schoenste man, / den al diu werlt ie gewan. / willic sînes muotes, / sînes lîbes, sînes guotes, / was er gar den undertân, / an den er êre sollte begân. / dâ von wart sîn unflætikeit / in allen landen bingeleit. (V. 51-66)

\footnotetext{
${ }^{48}$ V. 231f.: ,daz wort im alse nâhen gie, / daz er ein kraft dâ von gevie“. GRUBMÜLLER übersetzt hier: „Diese Rede ging ihm so zu Herzen, / daß er Kraft daraus zog“.

${ }^{49}$ Vgl. auch Deighton, Die ,nichtpolitischen` Erzählungen, S. 116.
} 
(„In ihrem Herzen gab es nie einen Mann, / den sie statt seiner hätte haben wollen. / Das kam von ihrer Redlichkeit, / und zum andern war es deswegen: Er war immer / zu allem bereit, was man / Ehrenvolles tun konnte. / Das führte er alles ohne Tadel aus, / als ob er ein mächtiger Kaiser sei / oder der schönste Mann, / der je auf dieser Welt lebte. / Bereitwillig stellte er sein Denken, / sein Leben und seinen Besitz zur Verfügung / und war denen untertan, / denen er Ehren erweisen sollte. / Deswegen spielte seine Häßlichkeit / überhaupt keine Rolle.")

Folgerichtig lässt sich die Protagonistin auch von der Verstümmelung ihres Mannes nicht von ihrem Standpunkt abbringen, der sich damit als ausgesprochen gefestigt erweist. ${ }^{50}$ Nachdem sie durch ihre Nachfrage vom Boten erfahren hat, dass ihrem Ehemann im Kampf eines seiner Augen ausgestochen wurde, fordert sie den Neffen spontan dazu auf, sofort zu seinem Onkel zurück zu reiten und ihn in ihrem Namen zur Heimkehr aufzufordern (V. 154-157). Während ihr Mann ihr aus Liebe seinen Anblick ersparen möchte, argumentiert die Frau nicht mit der Wahrnehmung des Äußeren, sondern mit dem körperlichen Schmerz, der mit der Verwundung einhergeht. Weil sie als Eheleute ein Leib seien, so die treue Gattin, sei seine körperliche Qual auch die ihre: ,des smerzen babe ich mit im phlibt / billîchen, wan ez ist ein lîp“ (V. 158f., „An seinem Schmerz habe ich gerechterweise gleichen Anteil, / denn wir sind ein Leib"). Diese Ansicht der Frau ist durch die heilige Schrift abgesichert, ${ }^{51}$ so dass implizit auch ihre Auffassung über das Aussehen und ihre Art des Erkenntnisgewinns in einem positiven Licht erscheinen.

Die Eheleute unterscheiden sich also nicht nur hinsichtlich ihres Verständnisses, in welchem Verhältnis das Äußere und das Innere eines Menschen zueinander stehen, sowie in Bezug auf die Erkenntnisse, die sie aus Wahrgenommenem gewinnen, sondern auch in der Frage, was Liebe bedeutet. Die Ehefrau möchte neben der Freude auch das Leid ihres Mannes mit ihm teilen. Um die Stärke ihrer Liebe zu verdeutlichen, bedient sich die Protagonistin anschließend eines Vergleiches, der auf das Aussehen ihres Mannes und auf dessen hinzugetretene Verstümmelung metaphorisch zurückgreift: Selbst wenn der Ehemann zuvor tausend Augen gehabt und damit gut ausgesehen hätte, würde sie trotzdem den Einäugigen lieben und sich wünschen, seinen Kummer mit ihm zu teilen (V. 160-168).

Nachdem der Bote ihre Bitte abgelehnt hat, seinen Onkel in ihrem Namen nochmals um seine Rückkehr zu ersuchen, weil der Ehemann seiner Ansicht nach dem Wunsch nicht nachkommen wird (V. 169-174), geht die Frau in ihren Überlegungen noch einen Schritt weiter. Sie bedauert, dass nicht sie anstelle des Ritters verstümmelt wurde. Außerdem wünscht sie sich, dass ihr Mann so schön wäre, wie es seinen Vorstellungen entspricht (V. 175-178). Auf diese Weise wird der Gegen-

\footnotetext{
${ }^{50}$ Die Besonderheit der Haltung der Gattin belegt die Notwendigkeit, Ehescheidungen aufgrund von Krankheiten und Körperschäden seit dem 6. Jahrhundert im kanonischen Recht zu verbieten (vgl. NOLTE, „Behindert“, S. 12 Anm. 9 u. 15 [mit Hinweis auf Herrands Text]). Insofern bietet das Märe auch eine Ehelehre, der in einem anderen Zusammenhang nachgegangen werden sollte.

51 Vgl. Mt. 19, 4-6. Dazu auch LiNKE, Schein und Sein, S. 2. Vgl. außerdem die Interpretation von WAGNER, Gottesbilder, bes. S. $206 f$.
} 
satz der Positionen nochmals profiliert und die Überzeugung hervorgehoben, mit der die Frau ihre Einstellung vertritt. Obwohl sie eine getreue Gattin ist, ist sie nicht bereit, sich der Meinung ihres Mannes anzuschließen. Stattdessen greift sie, immer noch ausdrücklich als gut bezeichnet, zur Schere und verstümmelt sich selbst. Die Ungeheuerlichkeit dieser Tat wird durch die drastische Schilderung der Selbstverletzung und ihre Wahrnehmung durch den Boten betont, der trotz seiner Erfahrungen als Knappe seines Onkels (V. 95-97) und der Konfrontation mit dessen Kampfverletzung den Anblick der blutverschmierten Protagonistin als das Schlimmste bezeichnet, das ihm je unter die Augen gekommen ist (vgl. V. 211f.):

diu guote gienc von im zehant / in ir kemenâten, dâ sî vant / ein schære, und stach vil balde dar / ir selben $\hat{u} z$ ein ouge gar, / daz ez ir über ir wengel ran. / alsô bluotic gie sî dan / für den boten. der erkam; / mit beiden handen er sich nam / ze hâre und schrei: „wê iemer ach, / sô grôziu dinc ich nie gesach! / frouwe guot, waz sol daz sîn?" (V. 187-197)

(„Die brave Frau ging schnell / in ihre Kemenate; dort nahm sie / eine Schere und stach sich auf der Stelle / selbst ein Auge aus, / daß es ihr über die Wange lief. / Blutüberströmt trat sie dann / vor den Boten. Den erfaßte großer Schrecken; / mit beiden Händen griff er sich / in die Haare und schrie: ,Weh und immer weh, / Schlimmeres habe ich noch nie gesehen. / Edle Frau, was hat das zu bedeuten?"“)

Nach der Selbstverstümmelung fordert die Ehefrau den schockierten Neffen erneut auf, ihren Mann zu holen. Dieser soll zu ihr kommen, um nach ihrem Anblick zu entscheiden, ob sie immer noch zu schön für ihn sei. In diesem Fall sei sie bereit, sich auch ihr zweites Auge auszustechen. Bemerkenswert ist ihre Begründung dafür: „sô liep ist er dem berzen mîn" (V. 202, „so lieb ist er meinem Herzen“52). Neben der konventionellen Bedeutung, dass die Frau ihren Ehemann von ganzem Herzen liebt, bestätigt dieser Vers auch ihre Wahrnehmungsweise, die ihr von Anfang an zugeschrieben wird. Sie sieht, versteht und liebt mit dem Herzen und wünscht sich, dass auch ihr Ehemann in Zukunft so denkt und handelt. Um ihrem Mann ihren Wunsch zu vermitteln, als dieser sie fragt, wie er das Leid, das er verursacht hat, wiedergutmachen könne, greift sie auf das Bild der tausend Augen zurück. Der Protagonist soll darauf vertrauen, dass seine Frau ihn trotz seiner Hässlichkeit und Verstümmelung einschränkungslos liebt. Aber auch er möge sich - unabhängig von ihrem Aussehen - an ihr und ihrer Liebe erfreuen. Sogar tausend Augen wären für sie wertlos, wenn ihm nicht ein einziges davon an ihr gefiele (V. 257-264).

Am Ende der Verserzählung folgen alle der subjektiven Wahrnehmung der treuen Gattin: Der Ehemann liebt seine vormals schöne Gattin nach ihrer Selbstverstümmelung mehr als zuvor (V. 233-235), der Erzähler verwendet die gleichen Charakterisierungen zur Beschreibung der Dame wie zu Beginn der Erzählung (V. 246, 248, 257) und auch die Hofgesellschaft erfreut sich am Anblick der Verstüm-

\footnotetext{
52 GRUBMÜLLER übersetzt hier: ,so sehr liebe ich ihn“.
} 
melten mehr als vorher an ihrer makellosen Schönheit. ${ }^{53}$ Dabei gilt sie allen aufgrund ihrer Tat nicht nur als Vorbild ehelicher Treue, sondern vor diesem Hintergrund auch immer noch als schön. Die Berechtigung dieser Sichtweise wird durch den Erzähler betont und zusätzlich dadurch hervorgehoben, dass er die Einäugige als würdiger für die Lobpreisungen befindet als viele Unverstümmelte:

Swer vor die frouwen gerne sach / durch die schœene, der man ir jach, / der sach sî nu vil lieber an / durch die triuwe, die sî ir man / erzeiget het; daz was billîch, / wan sî̀ was schoene unde triuwen rîch. / dâ von sî baz ze loben stât / dan manigiu, diu zwei ougen hât. (V. 265-272)

(„Alle, die die Dame vorher / wegen ihrer vielgepriesenen Schönheit gerne gesehen hatten, / die sahen sie jetzt noch viel lieber / wegen der Treue, die sie ihrem Mann / erwiesen hatte; das war richtig, / denn sie war gleichzeitig voller Schönheit und Treue. / Davon gebührt ihr mehr Preis / als manch einer, die zwei Augen hat.")

\section{Verstümmelung, Wahrnehmung und Erkenntnis in Die treue Gattin: Zusammenfassung und Ausblick}

Wenn am Schluss der Verserzählung der Ehemann beginnt, mit dem Herzen zu sehen, und diese Sichtweise durch das Verhalten der anderen Figuren im Märe und durch die Kommentare des Erzählers als gut bestätigt wird, so erweist sich der Text vom Ende her betrachtet als Plädoyer für das mittelalterliche Konzept der subjektiven Wahrnehmung nach Augustinus. Trotz dieser Ausrichtung am zeitgenössischen Diskurs ist diese ,moderne' Vorstellung vom unmittelbaren, unreflektierten Erkenntnisgewinn mit dem traditionellen Verständnis der Differenz zwischen der äußeren Gestalt und den inneren Qualitäten des Menschen verknüpft, denn gerade die Hässlichen und Verstümmelten sind in Herrands von Wildonie Dichtung Die treue Gattin die Guten, die für ihr vorbildliches Handeln zu loben sind. Umgekehrt ist die dem älteren aristotelischen Modell folgende rationale Erkenntnis, die über weite Teile des Handlungsverlaufs am männlichen Protagonisten vorgeführt wird, ein Ergebnis der jüngeren Ansicht vom Körper als Spiegel der Seele. Diese Überkreuzverknüpfung beider Auffassungen bestätigt, dass im Mittelalter zwischen ihnen kein Widerspruch gesehen wurde. Nicht nur in theoretischen Abhandlungen zur Erklärung von Wahrnehmungs- und Erkenntnisprozessen finden sie nebeneinander oder in wechselnden Verbindungen miteinander Verwendung, ${ }^{54}$ sondern - wie Die treue Gattin zeigt - auch in der Literatur. Dementsprechend verwundert es nicht, dass der Ehemann im gesamten Märe positiv gezeichnet ist und an keiner Stelle im Text für seine über lange Zeit vertretene rationale Sichtweise und sein Verständnis der Relation zwischen Körper und Seele getadelt

\footnotetext{
53 Vgl. aber LINKE, Schein und Sein, S. 4, der den gleichen Formulierungen, die zur lobenden Beschreibung der Ehefrau verwendet werden, veränderte Bedeutungen zuschreibt.

${ }^{54}$ Vgl. Bumke, Die Blutstropfen, S. 22, 43f.; auch WAGNER, Gottesbilder, S. 218f. (konträr aber S. 216).
} 
wird. ${ }^{55}$ Zudem bedienen sich sowohl die Hofgesellschaft als auch der Erzähler beider Möglichkeiten der Wahrnehmung und des Erkenntnisgewinns. Sie nehmen die objektive Schönheit und Hässlichkeit sowie später die Verstümmelungen der Protagonisten rational wahr. Außerdem erkennen sie zu Beginn der Handlung die Identität von Schönheit und Gutsein bei der Ehefrau. Zur gleichen Zeit achten sie aber auch den Ehemann für seine Rittertaten und seine Herrschaftsfähigkeit, obwohl bei ihm seine innere Idealität nicht von seinem Äußeren gespiegelt wird..$^{56}$ Damit erweisen sie zugleich ihre Befähigung, zur subjektiven Erkenntnis zu gelangen, was durch ihre Haltung gegenüber der verstümmelten Protagonistin am Ende der Erzählung nochmals hervorgehoben wird.

Erst durch die gezielte wahrnehmungs- und erkenntnistheoretische Lektüre der Verserzählung wird der differenzierte Umgang mit Schönheit, Hässlichkeit und Verstümmelung in der Verserzählung sichtbar, der von der Forschung bisher nicht erkannt wurde, weil die Suche nach einem geschlossenen Konzept oder einer eindeutigen Lehre den Blick dafür verstellt hat. Von einer grundsätzlichen Abwendung vom Kalokagathie-Ideal und der Vermittlung einer neuen Wertewelt, in der die Ästhetik der Ethik grundsätzlich untergeordnet ist, ${ }^{57} \mathrm{kann}$ ebenso wenig die Rede sein, wie vom Erlernen „der Fähigkeit der richtigen Werterkenntnis“58 durch den Ehemann. Die Gattin ist nicht erst als Entstellte lobenswert, sondern bereits als Abbild des höfischen Schönheitsideals, zumal sie als solches zur Selbstverstümmelung aus Liebe fähig ist. ${ }^{59}$ Deshalb ist auch die Verehrung der zunächst schönen Frau durch ihren Mann und seine Liebe zu ihr eine berechtigte Wertschätzung, die ihm gleich zu Beginn des Textes zugeschrieben wird. Diese Form der Werterkenntnis wird durch die Sichtweise, die ihm später vermittelt wird und seine Frau vertritt, nicht explizit ersetzt, sondern ergänzt. Auch hinsichtlich der Liebesdiskurse im Text hat sich gezeigt, dass es nicht nur um die Autotomie als außergewöhnliches Liebesopfer der Protagonistin geht, das der „Verherrlichung der Gattentreue "60 und damit der eigentlichen Textaussage dient. Der Ehemann handelt ebenso aus Liebe wie seine Gattin, die die einzige in der Dichtung ist, die

\footnotetext{
55 Vgl. aber Linke, Schein und Sein, S. 1; OrTmann/Ragotzky, Zur Funktion, S. 91.

${ }^{56}$ Vgl. dagegen WAGNER, Gottesbilder, S. 204.

57 Vgl. LinKE, Schein und Sein, S. 3f., WAGNER, Gottesbilder, S. 216f. (konträr dazu aber S. 218f.).

58 ORTMANN/RAGOTZKY, Zur Funktion, S. 90;

${ }^{59}$ Autoaggressionen als Treuebeweise, Signum der ethisch-moralischen Vorbildlichkeit oder Akt der Selbstbestimmung, insbesondere von Frauen, werden in der Hagiographie häufiger als in der höfischen Dichtung thematisiert (vgl. die Deutung des Handelns der getreuen Gattin im religiösen Kontext durch WAGNER, Gottesbilder, S. 213f.). Im beschränkten Rahmen dieser Untersuchung konnte ebenso wenig vergleichend darauf eingegangen werden, wie auf die Gemeinsamkeiten und Unterschiede zu den Körpermanipulationen als zum Minnemartyrium gesteigerte Form des Liebeswerbens des Protagonisten im Frauendienst Ulrichs von Liechtenstein, was aufgrund der verwandtschaftlichen und künstlerischen Verknüpfung der Verfasser besonders relevant scheint. Bereits einleitend wurde angedeutet, dass auch ein detaillierter Vergleich von Herrands Erzählung mit dem Ille et Galeron von Gautier d'Arras und mit dem Märe Das Auge weitere Einsichten verspricht.

${ }^{60}$ Curschmann, Zur literaturhistorischen Stellung, S. 72.
} 
sich seinem Wunsch des Rückzuges widersetzt. Zwar scheint die Ansicht der Ehefrau, Leid gemeinsam zu tragen, durch ihre verbale Nähe zur Bibelstelle aus dem Matthäus-Evangelium (Mt. 19, 4-6) besser begründet. Doch bei genauem Hinsehen zeigt sich, dass der Wunsch des Mannes, seine Frau vor seinem Anblick zu bewahren, dem gleichen Verständnishorizont entstammt. Wenn er davon ausgeht, dass das Leid des einen auch das des anderen ist, so steht auch hinter seinen Überlegungen die Vorstellung, dass sie als Eheleute ein Leib sind. Wiederum bietet die Dichtung keine eindeutige Bewertung, welche Auslegung zu bevorzugen ist.

Diese Offenheit im Umgang mit den im Text aufgeworfenen Fragen ermöglicht den Rezipienten eine unvoreingenommene Auseinandersetzung mit ihnen, die durch die Darstellung von Verstümmelung und Selbstverstümmelung befördert wird. Nicht nur die Figuren im Märe müssen zu den körperlichen Veränderungen Stellung nehmen, sondern auch bei den Zuhörern und Lesern werden Wahrnehmungs- und Erkenntnisprozesse in Gang gesetzt, denn sie werden zur Imagination des Aussehens der Protagonisten angeregt und kommen zu eigenen Bewertungen. Damit kommt den Deformationsbeschreibungen auch eine rhetorische Funktion zu, der an anderer Stelle nochmals gezielt nachgegangen werden müsste. Dies gilt auch für die sichtbar gewordene Verknüpfung der Wahrnehmungs- mit der Identitätsthematik. Das differenzierte Verhältnis von Selbst- und Fremdwahrnehmungen und die dazu gehörenden Beurteilungen, Einschätzungen und Handlungen liefern reichhaltiges Material für eine identitätstheoretische Interpretation des Textes. Auch wenn viele Themenbereiche an dieser Stelle unbearbeitet bleiben müssen, so hat die Auseinandersetzung mit den Themen Verstümmelung, Wahrnehmung und Erkenntnis das Verständnis von Herrands von Wildonie Die treue Gattin in vielerlei Hinsicht befördert. Es konnte weit mehr sichtbar gemacht werden als die Haltung der Gattin: „Man sieht nur mit dem Herzen gut.“

\section{Literatur}

Sancti Aurelii Augustini In Iohannis evagelium tractatus CXXIV. Post Maurinos textum edendum curavit D. RADBOD WILLEMS. Turnhout 1954.

Herrand von Wildonie, Die treue Gattin. In: GrubMÜlLER, KLAuS (Hrsg.), Novellistik des Mittelalters. Märendichtung. Frankfurt a. M. 1996.

Antoine de Saint-Exupéry, Der kleine Prinz. Mit Zeichnungen des Verfassers. Ins Deutsche übertragen von GRETE u. JOSEF LEITGEB. Düsseldorf 1999.

Waltharius. Lateinisch/Deutsch. Hrsg. v. GREGOR VOGT-SPIRA. Stuttgart 1994. 


\section{Forschung}

ANTUNES, GABRIELA, Entstellte Schönheiten: Überlegungen zum mittelalterlichen Bezug zwischen Hässlichkeit des Körpers und Schönheit der Seele. Erscheint in: ANTUNES, GABRIELA u. REICH, BJÖRN (Hrsg.), (De)formierte Körper, die Wahrnehmung und das Andere im Mittelalter 2, voraussichtlich Göttingen 2012.

Auge, Oliver, So solt er im namen gottes mit mir hinfahren, ich were doch verderbt zu einem kriegsmann. Durch Kampf und Turnier körperlich versehrte Adelige im Spannungsfeld von Ehrpostulat und eigener Leistungsfähigkeit. In: Medizin, Gesellschaft und Geschichte 28 (2009), S. 2146.

BumKE, Joachim, Die Blutstropfen im Schnee. Über Wahrnehmung und Erkenntnis im ,Parzival' Wolframs von Eschenbach. Tübingen 2001.

Curschmann, Michael, Herrand von Wildonie. In: VL 3 21981, Sp. 1144-1147.

DERS., Zur literaturhistorischen Stellung Herrands von Wildonie. In: DVjs 40 (1966), S. 56-79.

Deighton, Alan, Die ,nichtpolitischen' Erzählungen Herrands von Wildonie. In: GRUBMÜLLER, KLAUS u. a. (Hrsg.), Kleinere Erzählformen im Mittelalter. Paderborner Colloquium 1987. Paderborn 1988, S. 111-120.

EHrismann, OTFRID, Ehre und Mut, Aventiure und Minne. Höfische Wortgeschichten aus dem Mittelalter. München 1995.

FISCHER, HANNS, Studien zur deutschen Märendichtung. Tübingen1968.

Grubmüller, Klaus, Die Ordnung, der Witz und das Chaos. Eine Geschichte der europäischen Novellistik im Mittelalter. Fabliau - Märe - Novelle. Tübingen 2006.

Ders., Herrand von Wildonie, Die treue Gattin. In: Ders. (Hrsg.), Novellistik des Mittelalters. Märendichtung. Frankfurt a. M. 1996, S. 1064-1070.

HAFERLACH, TORSTEN, Die Darstellung von Verletzungen und Krankheiten und ihrer Therapie in mittelalterlicher deutscher Literatur unter gattungsspezifischen Aspekten. Heidelberg 1991.

HeINZLE, JOACHIM, Altes und Neues zum Märenbegriff. In: ZfdA 117 (1988), S. 277-296.

DERS., Boccaccio und die Tradition der Novelle. Zur Strukturanalyse und Gattungsbestimmung kleinepischer Formen zwischen Mittelalter und Neuzeit. In: Wolfram-Studien 5 (1979), S. 41-62. 
DERS., Märenbegriff und Novellentheorie. Überlegungen zur Gattungsbestimmung der mittelhochdeutschen Kleinepik. In: ZfdA 107 (1978), S. 121 138.

DERS., Vom Mittelalter zur Neuzeit? Weiteres zum Thema ,Boccaccio und die Tradition der Novelle‘. In: JANOTA, JOHANNES u. a. (Hrsg.), Festschrift Walter Haug und Burghart Wachinger. Bd. 2. Tübingen 1992, S. 661-670.

JANKRIfT, Kay Peter, Mit Gott und schwarzer Magie. Medizin im Mittelalter. Darmstadt 2005.

KERTH, SONJA, Schreiende Kriegswunden. Darstellungen kriegsbedingter Traumatisierung in mittelalterlicher heroischer Dichtung. Erscheint in: ANTUNES, GABRIELA u. REICH, BJÖRN (Hrsg.), (De)formierte Körper, die Wahrnehmung und das Andere im Mittelalter 2, voraussichtlich Göttingen 2012.

DIES., Versehrte Körper - vernarbte Seelen. Konstruktionen kriegerischer Männlichkeit in der späten Heldendichtung. In: ZfGerm. 12 (2002), S. 262-274.

LINKE, HANSJÜRGEN, Schein und Sein in den Erzählungen Herrands von Wildonie. In: BRUNNER, HORST u. WilliaMS-KRAPP, WERNER (Hrsg.), Forschungen zur deutschen Literatur des Spätmittelalters. Festschrift für Johannes Janota. Tübingen 2003, S. 1-13.

MARGETTS, JOHN, Scenic Significance in the Work of Herrand von Wildonie. A note on 11. 235f. of ,der verkerte wirt'. In: Neophil. 54 (1970), S. 142-148.

MiHM, AREND, Überlieferung und Verbreitung der Märendichtung im Spätmittelalter. Heidelberg 1967.

NolTE, CORDUlA, „Behindert“, beeinträchtigt, bresthafftigen leibs im Mittelalter: Bemerkungen zu einem aktuellen Forschungsfeld. In: Medizin, Gesellschaft und Geschichte 28 (2009), S. 9-20.

ORTMANN, CHRISTA u. RAgOTZKY, HEDDA, Zur Funktion exemplarischer triuwe-Beweise in Minne-Mären: ,Die treue Gattin“ Herrands von Wildonie, ,Das Herzmäre" Konrads von Würzburg und die ,Frauentreue‘. In: GRUBMÜller, Klaus u. a. (Hrsg.), Kleinere Erzählformen im Mittelalter. Paderborner Colloquium 1987. Paderborn 1988, S. 89-109.

REICH, BJÖRN, Verkrüppelte Helden, impotente Magier, kampfunfähige Liebhaber. Erscheint in: ANTUNES, GABRIELA u. REICH, BJÖRN (Hrsg.), (De)formierte Körper, die Wahrnehmung und das Andere im Mittelalter 2, voraussichtlich Göttingen 2012

SCHIRMER, KARL-HEINZ, Stil- und Motivuntersuchungen zur mittelhochdeutschen Versnovelle. Tübingen 1969. 
SCHRÖDER, EDWARD, Herrand von Wildon und Ulrich von Lichtenstein. In: Nachrichten von der Königlichen Gesellschaft der Wissenschaften zu Göttingen. Phil.-hist. Klasse (1923), S. 33-62.

STRASSER, INGRID, Ein mündiger Poet. Tradition und Neuerung in zwei Erzählungen Herrands von Wildonie. In: EBENBAUER, AlFRED (Hrsg.), Die mittelalterliche Literatur in der Steiermark. Bern u. a. 1988, S. 249-267.

DIES., Vornovellistisches Erzählen. Mittelhochdeutsche Mären bis zur Mitte des 14. Jahrhunderts und altfranzösische Fabliaux. Wien 1989.

VOGT-SPIRA, GREGOR, Der Waltharius im Bezugsfeld lateinischer Schriftkultur, mündlicher Heldensage und der Ethik des Christentums. In: DERS. (Hrsg.), Waltharius. Lateinisch/Deutsch, Stuttgart 1994, S. 5-26.

WAGNER, SILVAN, Gottesbilder in höfischen Mären des Hochmittelalters. Höfische Paradoxie und religiöse Kontingenzbewältigung durch die Grammatik des christlichen Glaubens. Frankfurt a. M. u. a. 2009.

WiLliams-KrapP, WERnER, Das Auge. In: VL 1 21978, Sp. $516 f$. 



\title{
Des corps marginaux : regard sur les mendiants dans les poèmes d'Eustache Deschamps
}

\author{
Lola King
}

\begin{abstract}
:
The representations of marginality and specifically of deformity in medieval literature illustrates poorly documented social realities. This article explores the question of deformity in the Middle Ages through the perception of a $14^{\text {th }}$ century witness, Eustache Deschamps. After studying what types of diseases the poet mentions based on how he describes the symptoms, the present paper examines how deformity is perceived and morally condemned by Eustache Deschamps, and what place the poet has given to deformed people in the society of his time.
\end{abstract}

S'interroger sur la nature de la marginalité au Moyen Âge et proposer de comprendre quels sont la place et le rôle des marginaux dans la société médiévale amènent à s'interroger dans une plus large mesure sur la notion de perception de l'altérité. ${ }^{1}$ Ainsi, par définition, le marginal est un "Autre», un individu ou un groupe d'individus qui sont rejetés ou qui se mettent d'eux-mêmes en marge de la vie sociale et évoluent à la périphérie, adoptant des attitudes contraires aux normes de comportement en vigueur. L'étude des marginaux met ainsi en relief certaines dimensions ignorées ou négligées tant de l'imaginaire que de la pratique sociale

\footnotetext{
${ }^{1}$ Nous ne tenterons pas dans cet article de retracer la réalité du quotidien des individus difformes au Moyen Âge, mais nous nous limiterons à en évoquer les representations littéraires tout en nous interrogeant sur les rapports entre l'image littéraire de la difformité et sa perception sociale. Nous nous référons à la méthode utilisée par GEREMEK dans son ouvrage Les fils de Caïn. Plus spécifiquement, en ce qui concerne l'étude des poèmes d'Eustache Deschamps en tant que témoin de son temps, nous nous plaçons dans la continuité de l'ouvrage collectif publié sous la direction de BOUDET et MiLLET, Eustache Deschamps.
} 
d'une société, et permet à l'historien de saisir et de fixer la perception de cet «Autre », ne serait-ce que dans la brièveté d'un instant, au cœur de la subjectivité de la parole d'un littérateur à la fin du 14 ème siècle. De plus, les marginaux constituent d'excellents indicateurs des tensions qui habitent une société, leur étude nous permettant donc d'apporter des éclairages sur la norme de cette société, sur le type d'homme reconnu comme «normal» dans son système de valeurs et de son point de vue. L'in-firme, celui dont le corps est dé-formé, a-normal, semble bien tomber du côté de la marge.

Les représentations de la marginalité et, plus spécifiquement, de la difformité dans la littérature du Moyen Âge sont autant d'images et d'apparences de diverses réalités sociales. Ainsi, si a priori il n'y a aucune vérité de l'apparence, puisque celleci n'est qu'imitation ou représentation d'une idée, certaines vérités peuvent néanmoins être révélées par le sensible dans la littérature. L'apparence ne cache pas l'essence mais la révèle, la production littéraire offrant une perspective sur le monde et sur la réalité à travers l'esprit de son auteur. "Esse est percipi », être c'est être perçu, écrit BERKELEY,2 faisant ainsi de l'apparence l'origine absolue de toute vérité, « comme la géographie à l'égard du paysage où nous avons d'abord appris ce que c'est qu'une forêt, une prairie ou une rivière ». ${ }^{3}$

Dans les ouvrages de certains historiens ayant travaillé sur la question des marginaux au Moyen Âge, ${ }^{4}$ il apparaît qu'il est très difficile de traiter la question de la difformité physique et de l'infirmité, indépendamment de la question de la pauvreté. ${ }^{5}$ En effet, en nous référant à la plupart des sources à la disposition des historiens, en particulier les sources judiciaires et littéraires, ${ }^{6}$ les infirmes se mêlent et se confondent à la masse des marginaux et des indigents. La malnutrition et le manque d'hygiène, qui constituent les premières causes de malformations au Moyen Âge, touchent d'abord les couches les plus misérables de la population, ce qui expliquerait la place des infirmes dans la masse des pauvres. Derrière l'image du mendiant, du monstre et du truand, se profilerait celle de l'infirme, empruntant ses traits aux trois à la fois ou successivement. Les poèmes d'Eustache Deschamps ne font pas exception. Ainsi, la dizaine de poèmes ${ }^{7}$ que nous avons ici choisi pour

\footnotetext{
2 Berkeley, Principes, p. 23.

${ }^{3}$ Merleau-Ponty, Phénoménologie, p. 3.

${ }^{4}$ GeremeK, Inutiles au monde; GeremeK, Les marginaux; GeremeK, Les fils de Caïn ; Goglin, Les misérables ; LEGUAY, Pauvres et Marginaux ; MOLLAT, Les pauvres.

${ }_{5}^{5}$ C'est également le point de vue de STIKER, Corps infirmes.

${ }^{6}$ GEREMEK a abordé la question de la marginalité à partir de sources judiciaires (cf. Les marginaux), mais également sur la base de témoignages littéraires (cf. Les fils de Caïn).

7 Dans les 11 volumes des Cuvres complètes d'Eustache Deschamps, 1878-1903 : Rondeau 607, t. 4, p. 66 ; Rondeau 609, t. 4, p. 68 ; Ballade 1229, t. 6, p. 230f. ; Ballade 1230, t. 6, p. 232f. ; Ballade 1233, t. 6, p. 237 f. ; Ballade 1259, t. 6, p. 279f. ; Ballade 1299, t. 7, p. 52f. ; Ballade 1300, t. 7, p. 54f. ; Ballade 1349, t. 7, p. 22f. ; Ballade 1356, t. 7, p. 32f. ; aussi bien que «Le Miroir de Mariage », notamment la partie 24 «Cy moustre que c'est pon gloire d'avoir enfans difformés» [ceci montre que c'est peu de gloire d'avoir des enfants difformes], t. 9, p. 81f.
} 
étudier la question de la difformité - même s'ils nous renseignent sur certaines infirmités - concerne avant tout les mendiants.

Eustache Deschamps est un poète champenois né vers 1346 et mort aux alentours de 1407. Son œuvre étonne par ses proportions inhabituelles (plus de 82000 vers) et fourmille de détails liés à la vie quotidienne et aux pratiques sociales de son temps. ${ }^{8}$ Elle est riche d'enseignements sur les manières d'être et de penser de ses contemporains. Écuyer du roi Charles VI, Eustache Deschamps a également occupé des fonctions d'administrateur et de juriste, et a donc une expérience du milieu criminel et du monde de la mendicité. Poète à la cour des rois Charles V et Charles VI, ses œuvres sont, dans un premier temps, destinées à un public lettré. Au delà de sa fonction de divertissement pour les nobles de la cour, les dimensions exceptionnelles de l'œuvre de Deschamps semblent indiquer que le poète compose aussi pour lui-même. ${ }^{9}$ Il prend plaisir à mettre en scène les hommes et les femmes de son temps, quelles que soit leurs origines sociales, et cherche à tirer des conclusions morales du comportement de ses contemporains. Tenu en haute estime par des esprits aussi distingués que Philippe de Mézières, Geoffrey Chaucer et Christine de Pisan, ${ }^{10}$ " ce disciple de Machaut fait en réalité beaucoup penser à Rutebeuf, et peut-être sans lui François Villon n'aurait-t-il pas trouvé sa vrai mesure. ».11

La présente étude propose donc d'aborder la question de la difformité au Moyen Âge à travers le prisme de la perception de ce témoin de la seconde moitié du 14ème siècle, Eustache Deschamps, selon trois angles de vue. Dans un premier temps, nous verrons quels sont les types de maladies et de difformités évoqués par Eustache Deschamps, en nous intéressant au regard que pose le poète sur les corps déformés. Le deuxième axe de cette étude mettra l'accent sur les aspects liés au jugement de valeur que porte l'auteur sur les mendiants qu'il accuse de simuler des difformités. Enfin, nous tenterons de connaître la place que le poète accorde aux mendiants infirmes dans la société de son temps.

\footnotetext{
8 Sur Eustache Deschamps, voir BoudeT/Millet, Eustache Deschamps. Voir aussi la biographie d'Eustache Deschamps dans le premier volume des CEuvres complètes.

9 Sur la vie et l'oeuvre d'Eustache Deschamps, son public, ses sources et la récepion de ses oeuvres, voir Eustache Deschamps, Euvres complètes, vol. 11, pp. 9-112 et pp. 113-324.

${ }^{10}$ Le 10 février 1404, Christine de Pisan adresse à «son cher maitre et ami » une assez longue épître (cf. Oeuvres poétiques de Christine de Pisan, t. 2, pp. 295-301). Eustache Deschamps la remercie en termes chaleureux, il la déclare «femme unique en son genre dans tout le royaume de France» (Ballade 1242, vol. 6 des Oeuvres Complètes d'Eustache Deschamps, p. 251).

${ }^{11}$ Sabatier, Histoire de la poésie, pp. 306-307.
} 


\section{Premiers regards sur des corps déformés : de l'humour au mépris}

Une demi-douzaine de ballades décrit les mendiants qui se pressent aux portes des églises dans l'attente de quelque obole. Tous souffrent de maux divers, de maladies de longue durée qui ont altéré leur apparence physique, allant parfois jusqu'à la difformité. Donnons quelques exemples de ces maladies et difformités, puis, penchons-nous sur le regard que pose le littérateur sur les êtres déformés.

Dans la forme du discours, Eustache Deschamps utilise deux façons pour décrire les maladies dont souffrent les mendiants. Dans certains poèmes, ${ }^{12}$ il se place dans la position d'un observateur qui décrit sur un mode purement narratif les maladies et les difformités qui affectent les mendiants. Dans d'autres, ${ }^{13}$ il les met en scène, leur donnant la parole sous la forme de dialogues. Dans un cas comme dans l'autre, les maux dont se plaignent les mendiants sont innombrables. Nous pouvons en distinguer trois catégories, en fonction de leur gravité : les maladies de longue durée, qui affectent le corps du malade, et transforment son apparence physique, sans toutefois lui occasionner une lourde infirmité ; les maladies mentales pouvant laisser apparaître une difformité ; et les infirmités plus lourdes, handicapantes, ainsi que les difformités apparentes. Il serait possible de noter tout d'abord que le poète fait souvent référence aux « maulx de quoy Dieu pent guerir / Et de tous ceuls dont les sains sont reclamez. ${ }^{14}$ [maux que Dieu peut guérir / Et de tous ceux pour lesquels les saints sont invoqués]. ${ }^{15}$ En effet, la médiation des saints protecteurs, ainsi que le pèlerinage dans les lieux saints où étaient conservées leurs reliques auxquelles on attribuait des pouvoirs thaumaturgiques, étaient souvent invoqués dans l'espoir de la guérison. C'est ce qui explique la dénomination vernaculaire de certaines maladies en fonction des mérites propres à tel thaumaturge. ${ }^{16}$

La plupart de ces maladies provoquent des souffrances aiguës, mais n'ont pas nécessairement pour conséquence d'handicaper lourdement celui qui en est atteint. ${ }^{17}$ Dans la Ballade 1229, un mendiant se plaint qu'il se «languit » [souffre] du « mal de saint Fiacre » et qu'il se trouve " en grief dolour» [en grande douleur]. Cette grande douleur dont il se plaint est provoquée par des hémorroïdes. Selon la tradition, les pèlerins qui se rendaient sur le tombeau de saint Fiacre prétendaient qu'il suffisait de s'asseoir sur la pierre sur laquelle le saint avait l'habitude de méditer pour être guéri. Il s'agissait d'une maladie courante et très peu handicapante. Autre maladie courante, le « mal de saint Maur», c'est-à-dire la goutte, touche plusieurs des

\footnotetext{
12 Rondeau 607 ; Rondeau 609 ; Ballade 1229 ; Ballade 1259 ; Ballade 1299 ; Ballade 1349 ; Ballade 1356.

13 Ballade 1230 ; Ballade 1233 ; Ballade 1300.

14 Ballade 1229.

15 Ici comme dans les autres cas, traduction de l'auteur.

${ }^{16}$ Ballade 1259.

17 Sur les maladies médiévales, voir Touati, Maladie et société ; SAunier, «Le pauvre malade»; AlexAndre-Bidon/Riviere, La santé. Voir particulièrement la bibliographie d'AnNiE SAunier, «Le pauvre malade ». Voir aussi l'article de NikOLETTA GiANTSI dans le présent volume.
} 
mendiants décrits par Eustache Deschamps. C'est la goutte qui oblige le malade à se déplacer avec des béquilles. Eustache Deschamps fait mention à deux reprises de «potenciers» [boiteux] (Ballade 1300) et de «potencieres» [boiteuses] (Ballade 1299) parmi la foule des mendiants. L'attribut de Saint Maur dans certaines représentations iconographiques est d'ailleurs une béquille - il est notamment le saint patron des estropiés. On invoquait aussi « saint Riquier» pour être guéri de quelque maladie ou infirmité, sans que l'on puisse dire avec précision de quelle infirmité il s'agissait. ${ }^{18}$ Dans un autre registre, celui des maladies mentales, ${ }^{19}$ nous pouvons signaler que, bien que rarement mentionnées dans notre corpus de texte, elles sont tout de même évoquées par le poète. Parmi les maladies mentales citées par Eustache Deschamps, se trouve le «mal de saint Leu» (Ballade 1299), qui provoque des convulsions : il s'agit de l'épilepsie. Le mendiant qui en est atteint est décrit comme tombant souvent, le poète dit qu'il « chiet souvin» [chute souvent] (Ballade 1299), en « escumant» [écumant] (Ballade 1300). Celui qui est atteint du « mal de Saint Aquaire » (Ballade 1300) s'adresse ainsi au poète : «Sire, je suy en frenaisie! » [Sire, je suis fou!] (Ballade 1230), nom communément employé pour désigner une maladie mentale, la folie ou la mélancolie. Puis, un troisième mendiant « se fait batre des escourgies » [se fait fouetter] (Ballade 1299) : il se fait donner la discipline par celui qui l'accompagne et est «com hors du sens» [comme fou] (Ballade 1299), dit le poète.

Enfin, que nous apprennent les poèmes d'Eustache Deschamps sur les infirmités lourdes? Le thème littéraire du mendiant aveugle, victime de son infirmité est très fréquent au Moyen Âge, ${ }^{20}$ et Eustache Deschamps s'inscrit dans cette mouvance, puisque lui aussi évoque la cécité. Un mendiant apostrophe ainsi le poète à l'entrée d'une église: "Pour Dieu, donnez maille ou denier / A ce povre qui ne voit goutte! » [Au nom de Dieu, donnez maille ou denier / A ce pauvre aveugle!] (Ballade 1230). Il évoque aussi la surdité, qu'il appelle «mal de saint Flour» (Ballade 1300). Ces deux infirmités sont véritablement handicapantes. Également douloureux et handicapant est le «mal de Saint Quentin» (Ballade 1300), c'est-à-dire l'hydropisie ou oedème généralisé. Le corps du malade gonflait, et la maladie entraînait un essoufflement et une fatigue intense. L'évolution de la maladie conduisait parfois à l'amputation des mains ou des pieds, les membres situés aux extrémités étant les premiers atteints par la gangrène. C'est donc bien une maladie qui pouvait conduire à la difformité. Les conséquences sont similaires pour celui qui est atteint du «mal de Saint Antoine » (Ballade 1230), ou mal des ardents, dû à la consommation de seigle ergoté et qui fait dire à un mendiant que «le feu au corps [le] boute » [la fièvre (lui) brûle le corps] (Ballade 1230). La fièvre faisait entrer les malades dans un état de transe et de prostration, en général accompagné de maux de tête, d'une soif intense et de problèmes cardio-vasculaires.

\footnotetext{
18 «Les infirmes qui vinrent prier avec foi sur son tombeau trouvèrent leur guérison », dans Vies des Saints, t. 4 « avril », p. 663.

${ }_{19}$ Sur les maladies mentales au Moyen Âge, voir Foucault, Histoire de la folie.

${ }^{20}$ GEREMEK, Les marginaux, p. 225.
} 
Selon LEGUAY, le mal des ardents «annoncé par l'érythème de la peau (apparition de tumeurs noirâtres), a tué, jusqu'à sa disparition, des milliers de personnes et en a laissé d'autres, infirmes paralysées ou estropiées ». ${ }^{21}$ Dans cette catégorie, ajoutons le cas de ce mendiant, probablement hémiplégique, qui déclare "mon cbief pers, le bras et le coude » [je perds la tête, ainsi que l'usage de mon bras et jusqu'au coude], ou de son compagnon, qui a les jambes paralysées et qui ajoute « aller ne puis par maladie » [la maladie m'empêche de marcher] ; «je ne me puis gesir» [je ne peux pas me mouvoir] (Ballade 1230). Pour finir, Eustache Deschamps décrit un dernier mendiant, qui est clairement difforme, puisqu'il a «la jambe route» [la jambe rompue], c'est-à-dire coupée.

Nous voyons donc bien que les maladies et les infirmités qui frappent les mendiants sont nombreuses et plus ou moins graves. Toutes affectent l'aspect extérieur des malades et déforment leurs corps de façon plus ou moins spectaculaire. Certaines semblent toutefois mener irrémédiablement à un handicap permanent, voire à une difformité. Sans les énumérer tous, Eustache Deschamps évoque trente maux et douleurs dont se plaignent les mendiants qu'il a observé (Ballade 1299). Nous pouvons dès lors nous demander de quelle façon Eustache Deschamps percevait ces transformations physiques, apparemment courantes parmi les mendiants qui encombraient les porches des églises. Comment perçoit-il ces maladies et difformités qui frappent les mendiants ?

Eustache Deschamps consacre deux ballades ${ }^{22}$ et deux rondeaux ${ }^{23}$ à la seule description physique de mendiants. L'image qui transparait de ces portraits pose les mendiants sous un jour monstrueux. Le ton est parodique, l'humour est sans concession, ironique et corrosif, l'infirme est ainsi tourné en ridicule : «Ventre a soufflet, cuisses de coqmarant / Hanches de buef et jambes de heron, / Cul d'estourneau, gros genoulz. d'oliphant: /Qui oncques vit corps de telle façon?» (Ballade 1356) [Ventre à soufflet, couisses de cormoran / Hanches de bœuf et jambes de héron / Cul d'étourneau, gros genoux d'éléphant: / Qui donc a vu un corps ainsi déformé ?]. Une longue tête pointue, un visage au teint livide avec, en son centre, un groin de "pourcel» [pourceau], des membres difformes, un dos bossu, une silhouette concave, un corps trop court, porté par des jambes grêles, des bras démesurés comparés à des griffes de chien, en guise de bouche un « bec» de «pellicant» [pélican], orifice béant laissant entrevoir une dentition pourrie, qui permet au "gourmant» [gourmand] glouton d'abuser de nourriture et de vin.

Son pendant féminin n'est pas non plus épargné (Ballade 1349). Elle est décrite comme « courte et grosse» [petite et grosse], elle aussi a un groin de cochon, des cheveux comme « bure de sanglier» [tête de sanglier], sa «denture» [dentition] se compose de chicots noirâtres, et elle a de la barbe. Ses yeux sont "gros et noirs ", ses seins sont énormes «troiz piez, en a, qui a droit les mesure / jusqu'es jambes li voit on ava-

\footnotetext{
${ }^{21}$ Leguay, Pauvres et Marginaux, p. 183.

22 Notamment, Ballade 1349 et Ballade 1356.

${ }^{23}$ Rondeau 607 et Rondeau 609.
} 
ler» [trois pieds de long, si on les mesure / ils lui tombent jusqu'aux jambes]. Elle a le « cul d'une jument », et son corps est recouvert d'ulcères, c'est un " trumeaux plein d'enflures» [laideron pleine d'ulcères]. Ses bras sont « rons, cours et gros» [ronds, courts et gros], ses pieds sont comme ceux d'un «crapand». En un mot, pour le poète, cette femme est une boule immonde " qui ne fust faite que pour rouler» [qui ne fut faite que pour rouler].

Ce qui ressort avec le plus de force de ces descriptions peu flatteuses est le nombre important de comparaisons et de métaphores animales, car les mendiants qui sont ici décrits ne sont plus présentés comme des êtres humains, mais davantage comme des bêtes. Si la littérature médiévale utilise souvent les métaphores animales pour refléter les comportements des hommes, notons ici que le choix de certains animaux comme le chien ou le crapaud n'est pas anodin. En effet, l'image du chien peut parfois servir à évoquer une nuisance que l'on cherche à éliminer, ${ }^{24}$ le crapaud «est associé à ce qu'il y a de plus vil et de plus maléfique. Son aspect hideux en fait déjà un objet de repulsion. ». ${ }^{25}$ Leur corps est difforme, leurs traits sont déformés et démesurés, ils sont assimilés a des bêtes immondes dont l'aspect extérieur est l'indice d'une nuisance universelle. Le poète dit de ces mendiants qu'ils sont " bideux, rongneux, noirs, velus, contrefaitz," [hideux, colériques, noirs, velus, contrefaits] (Rondeau 609). Notons dans ce texte la présence du terme «contrefaitz ", qui apparait dans la langue française au $11^{\text {ème }}$ siècle et signifie « rendu difforme ", et dont l'usage nous semble particulièrement intéressant et révélateur du sentiment qui habite Eustache Deschamps à la vue de ces mendiants accablés par la maladie : un dégoût cristallisé par le poète dans la description de leurs corps déformés.

Le regard d'Eustache Deschamps nous apparait donc sans concessions. Toutefois, le fait que l'infirmité soit un sujet de dérision semble cependant indiquer qu'il n'est pas tabou et que le Moyen Âge utilise volontiers l'humour pour parler du handicap. Pourtant, chez Eustache Deschamps, la dérision cède rapidement le pas au mépris. Dans un dialogue avec des mendiants, ${ }^{26}$ à chaque fois qu'un misérable lui demande l'aumône, Eustache Deschamps répond sur le ton de la plaisanterie, mais avec tout le mépris et la haine qu'il éprouve à leur contact. Il conseille ainsi à un aveugle d'aller se coucher sans allumer de bougie pour être sûr de ne pas brûler son lit: "va t'en sanz chandoille couchier, / D'ardoir ton lit es hors de doubte » [va te coucher sans chandelle / ainsi tu seras sûr de ne pas mettre le feu à ton lit] (Ballade 1230). Dans ce même texte, à un paralytique qui se lamente de ne pas pouvoir bouger, il répond : " tu as d'estre droit bon loisir / Atten encor jusqu'à demain » [tu n'as qu'à rester assis / Attends encore jusqu'à demain]. Puis, au mendiant qui se lamente de l'amputation de sa jambe, il suggère de la raccrocher avec un drap, et à

\footnotetext{
${ }^{24}$ GONTHIER, «Sanglant coupaul! », p. 108. « [Au Moyen Âge,] le chien est l'animal que l'on tue par mesure de salubrité publique, afin d'écarter le danger des meutes errantes. On saisit en quoi la comparaison peut meurtrir; elle sous-entend que la personne a qui elle s'applique ne vaut pas plus qu'une de ces bêtes, considérée comme nuisibles, dont on se débarrasse, en général, de façon peu élégante. » 25 Op. cit., p. 46.

${ }^{26}$ Ballade 1230.
} 
celui qui déclare souffrir de "frénésie» [folie], il rétorque : "Doncques te doit chascuns fuir» [il vaut donc mieux te fuir]. Le poète va même jusqu'à suggérer au mendiant qui souffre du mal des ardents, et qui a donc de fortes fièvres, de "faire son lit en Seine » [dormir dans la Seine] «pour refroider» [refroidir]. Enfin, à celui qui ne fait que souffrir, il dit : «pense de mourir. / Tout seroit perdu en ta main » [Pense à mourir / Tout serait perdu en ta main]. À quoi bon faire l'obole à un homme qui annonce sa mort imminente?

Le mépris et la haine du poète à l'égard de ces mendiants malades et difformes apparaissent encore davantage à travers une autre caractéristique que leur attribue le poète, puisque, pour Eustache Deschamps, ces mendiants sont avant tout des êtres nuisibles. Ce caractère « nuisible » est particulièrement visible dans le vocabulaire utilisé par le poète et relève du registre de la perception sensorielle pour décrire les mendiants. Ils sont, dans un premier temps, des nuisances visuelles, comme nous l'avons vu à travers les descriptions physiques peu flatteuses qu'en donne le poète. Mais celui-ci insiste aussi beaucoup sur leur nombre, en insistant sur les attroupements de mendiants devant et à l'intérieur des églises où ils gênent les fidèles : "En l'Eglise, c'est grant esclande / l'en ne peut s'agenoillier / Qu'il n'en ait devant et derrier / L'un tend sa main, l'autre l'escuelle. » Dans l' Église, c'est grande esclandre / l'on ne peut s'agenouiller / Il y en a devant et derrière / L'un tend sa main, l'autre une écuelle] (Ballade 1233).

Outre le mépris que lui inspire ce spectacle visuel, ce fourmillement, Eustache Deschamps dénonce les nuisances sonores. Le Moyen Âge, et en particulier la ville médiévale, sont un monde de bruits, de clameurs et de cris. Selon la Ballade 1233, parmi ces cris figurent les suppliques des mendiants: "Lasse! donnez-moi une offrande / En l'onneur la Vierge Marie » [Lasse! donnez-moi une offrande / En l'honneur de la Vierge Marie] ; «Donnez, an pawre qui languit» [Donnez au pauvre qui souffre]; «pour Dieu, donnez, maille ou denier» [pour Dieu, donnez maille ou denier] ; «donnezmoi pour avoir du pain » [donnez-moi pour acheter du pain]. Le poète affirme même ne pas être en mesure d'entendre la messe, tant il y a de bruit : «l'on ne peut au moustier messe oir / Pour leur annuy, tant sont fort emparlez." ['on ne peut entendre la messe dans l'église / Ils dérangent (la messe) tant ils parlent fort]. Enfin, aux demandes d'aumônes s'ajoutent les plaintes, les «cris et horrible plour» [cris et horrible pleurs]. Dans la Ballade 1299 précise Eustache Deschamps : «l'un crie et l'autre bret» l'un crie et l'autre brait]. Après le bruit vient l'odeur. Pour Eustache Deschamps, les mendiants sont «puans comme une orde ruelle» [puant comme une ruelle sale] (Ballade 1233). À une mendiante, il déclare: " A vostre ort cul qui tant me desconforte, / Qu'il n'est chambre qui tel pueur raporte!» [À votre sale cul qui me dégoûte tant / Qu'il n'est de chambre qui supporte une telle puanteur!] (Rondeau 609). « La force de l'injure lui vient soit de la vérité qu'elle met au jour, soit de l'accusation infamante et injustifiée qu'elle contient. Que ces allusions soient véridiques ou non, la victime en est salie aux yeux de ses contemporains. ${ }^{27}$ Or, au Moyen Âge, la réputation d'infamie

${ }^{27}$ GONTHIER, « Sanglant coupaul! », p. 16. 
d'une personne, sa bona fama, se construit de façon irréversible. Celui qui est doté d'une mauvaise réputation a toutes les chances d'être condamné ou rejeté, parfois même exclu définitivement du corps social.

Comment expliquer ce mépris, cette haine, ce dégoût? Ces sentiments de répulsion viennent pour l'essentiel de la suspicion de simulation qui plane sur ces mendiants. À la difformité physique s'ajouterait une autre forme de difformité, morale, consistant dans une mise en scène, un simulacre de maladie. Tous ces maux ne seraient que mensonges, et les mendiants dont parle Eustache Deschamps seraient tous des escrocs à la charité.

\section{Infirmité, mendicité, criminalité : le vocabulaire d'un amalgame}

L'image du mendiant souffrant de difformités physiques qui émerge des poèmes d'Eustache Deschamps est, nous l'avons dit, plutôt négative. À travers ses portraits de mendiants difformes, le poète diffuse l'image du faux mendiant, qui feint divers maux pour susciter la pitié et vivre de l'aumône. Ces mendiants sont des professionnels et des simulateurs, ils sont de "mauvais pauvres", et ne méritent pas, selon le poète, d'obtenir une quelconque obole. Ils s'opposent donc aux «vraiz. poures» [vrais pauvres], en "faingnans estre en grant tristour / Mais ce sont tuit larron a Dieu » [feignant être dans une grande souffrance / Mais ce sont tous des larrons à Dieu] (Ballade 1230). Le poète mentionne également « ceuls qui des maulx des sains se donnent titre » [ceux qui des maux des saints se donnent le titre] (Ballade 1229). Il est donc évident qu'il les perçoit comme des usurpateurs, puisqu'ils sont par ailleurs «comme faulx» [comme faux]. L'auteur insiste longuement sur ces prétendues maladies, simulées par de faux pauvres qui sont tous, à ses yeux, des «larrons a Dieu, qui faingnez divers maulx» [larrons à Dieu, qui feignent divers maux] (Ballade 1299). En plus, dans d'autres textes, il rajoute que «Pluseurs font le potencier / Qui sont sain, couchans en bon lit» [Plusieurs font semblant de boiter / Alors qu'ils sont sains, dormant dans un bon lit] (Ballade 1300), et que ceux qui prétendent être affamés « soubz leur chemise / Sont bien nourris et plains de cresse» [sous leur chemise / Sont bien nourris et pleins de graisse] (Ballade 1259). Eustache Deschamps entend ainsi dénoncer de «tele abusion» [tels abus] (Ballade 1259), car, pour le poète, c'est Dieu et le peuple qu'ils volent.

En effet, les poèmes sont explicites quant à l'attitude à adopter vis-à-vis de ces « faux malades », préconisant à la place d'une aumône de les poursuivre en leur donnant des coups de bâton, ce qui aurait pour conséquence de leur faire très vite oublier leurs béquilles, puisqu'ils "s'enfuiraient sanz chauces et deschaux, / En demoustrant que gueri sont et net» [s'enfuiraient sans chaussures / En démontrant qu'ils sont guéris et sains] (Ballade 1299). Les plaintes et l'apparence repoussante des mendiants seraient ainsi construites de toutes pièces dans le but d'éveiller la peur et/ou 
la pitié des passants - leurs maladies et leurs difformités n'étant que faux-semblants et habiles tromperies.

Par ailleurs, cette suspicion de fraude est également très visible dans les termes utilisés par le poète pour qualifier ces faux mendiants. En ce qui concerne les mendiants de sexe masculin, Eustache Deschamps nous apprend qu'ils ne sont pas de «vrais pauvres», mais qu'ils sont en vérité «truant» ${ }^{28}$ [truand], « caymant» ${ }^{29}$ [caïman] et «coquin $»^{30}$ [coquin]. Ils sont aussi «ribaulx $»^{31}$ [ribauds], «paillars $»^{32}$ [paillards], "houlier $»^{33}$ [souteneur] et «devin $»^{34}$ [sorcier]. Les mendiantes, quant à elles, sont des «ribaudes $»^{35}$ [ribaudes], «maquerelles $»^{36}$ [maquerelles], "repenties $»^{37}$ [repenties], « sorcières $»^{38}$ [sorcières]. Elles sont aussi «truandes $»^{39}$ [truandes], «fetardes $»^{40}$ [fêtardes] et $«$ putains $»^{41}$ [putains].

Nous pouvons remarquer que les termes «truant» et «truande » figurent parmi le vocabulaire qui revient le plus fréquemment sous la plume d'Eustache Deschamps. L'étymologie du mot «truand» est d'ailleurs éclairante, celui-ci étant issu d'une part du latin médiéval «trudere » qui signifie «pousser» et, de l'autre, d'un mot du jargon ancien, «trucher» ou «truquer» signifiant mendier. ${ }^{42}$ Le truand, et par extension le mendiant, seraient proprement des "intrus », ceux qui " pénètrent en poussant ». Ce mot désignait au Moyen Âge le mendiant professionnel, mais, dès le $13^{\text {ème }}$ siècle, il prend le sens injurieux de «vaurien ». Le verbe «truander», ${ }^{43}$ également très présent dans les poèmes de Deschamps, signifie à la fois «mendier » et «vagabonder». Le mot recouvre donc la notion de misère et celle de profonde malhonnêteté.

Dans un autre registre, le terme «ribaud» ou de «ribande» est issu du verbe « riber», qui signifie «se livrer à la débauche ». L'auteur évoque ici «les piliers de bordels, proxénètes à l'occasion, capables de viols collectifs ou de troubles publics, vivant de rapines ou de profits illicites $\gg .{ }^{44}$ Le terme traduit le comble de la colère et

\footnotetext{
28 Ballade 1233 ; Ballade 1259 ; Ballade 1299 et Ballade 1300.

${ }^{29}$ Ballade 1259 et Ballade 1299.

30 Ballade 1229 ; Ballade 1233 ; Ballade 1259 ; Ballade 1299 et Ballade 1300.

31 Ballade 1229 ; Ballade 1233 ; Ballade 1259 et Ballade 1299.

32 Ballade 1229 ; Ballade 1233 ; Ballade 1299 et Ballade 1300.

33 Ballade 1233.

34 Ballade 1299.

35 Ballade 1299.

36 Ballade 1233 ; Ballade 1259 ; Ballade 1299 et Ballade 1300.

37 Ballade 1300 .

38 Ballade 1299.

39 Ballade 1229 ; Ballade 1233 ; Ballade 1259 ; Ballade 1299 et Ballade 1300.

40 Ballade 1349.

41 Ballade 1259.

${ }^{42}$ En ce qui concerne les définitions des termes injurieux employés par Eustache Deschamps, nous renvoyons à GONTHIER, « Sanglant Coupaul !».

43 Ballade 1229 ; Ballade 1259 et Ballade 1299.

44 GonTHIER, « Sanglant Coupaul !», p. 148.
} 
de la haine. Le mot devient vite passe-partout, lorsqu'il est au masculin, tandis que sa forme féminine conserve l'acception première de "dépravée » et équivaut à « putain ». Enfin, pour le poète, un « faux » mendiant est aussi un « coquin », c'est-àdire quelqu'un «qui se livre à des actions peu recommandables ».45 On dit qu'il « coquine ». Selon GONTHIER, il est donc tour à tour « escroc, coupeur de bourses, proxénète, joueur de dés. Le 'coquin' simule la misère, préférant mendier plutôt que de peiner au travail, il va de ville en ville pour échapper aux rigueurs de la justice, il fait souvent partie des bandes menaçantes $\gg .{ }^{46}$ Ces bandes hantent les forêts, à l'affût d'un riche marchand à dépouiller, et traversent les campagnes à la recherche d'une ferme prospère à piller. Le sens du mot se rapproche de celui de «larron », ${ }^{47}$ qui signifie «voleur», mais contient une nuance de tromperie qui se rapporte à la filouterie.

Il n'est pas possible de présenter ici toutes les définitions de l'impressionnant éventail d'insultes utilisées par Eustache Deschamps pour parler des professionnels de la mendicité. Cependant, nous pouvons observer l'amalgame que fait le poète entre mendicité, infirmité et criminalité, d'où la difficulté d'étudier la question de l'infirmité indépendamment de la notion de pauvreté, ou sans prendre en compte le phénomène de la criminalité. Cet amalgame ne se situe pas seulement dans le vocabulaire employé, mais également dans la description des artifices utilisés par les mendiants pour simuler leurs infirmités. Ainsi, selon la Ballade 1300, pour simuler toutes sortes de maux : " toute nuit leurs jambes saingnier / Font par sang et herbes qu'on frit» [toute la nuit font saigner leurs jambes / avec du sang et de l'herbe qu'ils font frire], "par sablon qu'ilz. ont et par sieu» [ils utilisent du sable et de la suif]. D’après le poète, ces faux mendiants passent donc la nuit à préparer des mixtures faites de sang, d'herbes, de sable et de suif, dont ils s'enduisent ensuite le corps pour susciter «grant paour» [grande peur] et «freour» [frayeur].

Un autre témoignage majeur de la littérature sur le monde des malfaiteurs est

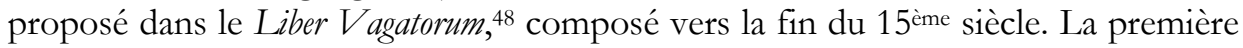
partie de ce traité énumère les différentes catégories de faux mendiants, en prescrivant à chaque fois la conduite à suivre à leur égard. À qui peut-on faire l'aumône, et qui abuse et simule? Ce texte, qui a connu un succès immense, comme en témoignent les nombreuses rééditions dont il fut l'objet au 16 ème siècle, fut notamment, dans une de ces éditions, préfacée par Luther, ce qui augmenta considérablement sa portée. ${ }^{49}$ Ceci montre l'aboutissement, un siècle plus tard, de l'image du faux mendiant, fourbe et simulateur d'infirmités, comme l'avait décrit Eustache Deschamps. Cette image est alors devenue un lieu commun.

\footnotetext{
45 Op. cit., p. 63.

46 Op. cit., p. 63.

${ }^{47}$ Ballade 1229 ; Ballade 1233 ; Ballade 1259 ; Ballade 1299 et Ballade 1300.

48 Liber Vagatorum, Le livre des gueux, (pour la traduction française).

${ }^{49}$ Voir le paragraphe consacré par GEREMEK au Liber Vagatorum dans Inutiles au monde, pp. 192197.
} 
Les poèmes d'Eustache Deschamps nous montrent encore que les simulacres de handicap cachent, en réalité, toute une économie souterraine. Le poète écrit que ces faux mendiants vont « espier le Lendit / Et le marchiez, pour leur proufit, / Robans et tuans chascun jour / Les bons marchans, c'est grant horrour. » (Ballade 1300) [épier la foire du Lendit / Et le marché pour leur profit / Volant et tuant chaque jour / Les bons marchands, c'est grande horreur]. De simulateurs d'infirmités, ils deviennent donc des criminels : ils volent et ils tuent. Les femmes qui mendient ne sont pas en reste, puisque le poète leur attribue également des activités criminelles : «Les truandes font maqueleries (...) / Et pour rober sont maintefoiz espies » [Les truandes font du racolage (...)/ Et sont souvent surprises en train de voler] (Ballade 1299). Elles aussi « robent et tuent» [volent et tuent] (Ballade 1299), puis elles déambulent dans les lieux saints, en exhibant de jeunes enfants : «De maquerelles, de putains, / Truandes, qui font leur devise / De porter enfans en leurs mains. » (Ballade 1259) [des maquerelles, des putains, / Truandes qui mendient / avec un enfant dans leurs bras]. La vue d'un enfant étant plus propre à éveiller la charité, l'enfant constituait donc un instrument important dans la pratique de la mendicité. Dans Marginaux parisiens aux 14ime et $15^{\text {ème }}$ siècles, GEREMEK a démontré l'existence, dans les archives judiciaires et les chroniques, de bandes de mendiants spécialisées dans le rapt d'enfants. Accompagnés de femmes " pour tromper la vigilance des sergents », la bande allait de ville en ville, " passait quelques jours à l'hôtel, enlevait sa proie et prenait le large. On crevait ensuite les yeux de l'enfant, on lui coupait un pied ou une jambe et l'instrument propre à éveiller compassion, pitié et charité était prêt ». ${ }^{50}$

Vol, meurtre, proxénétisme, prostitution, enlèvement d'enfants, mutilations, simulations: dans les vers d'Eustache Deschamps, l'amalgame entre mendiant, infirme - qu'il soit réel ou simulé -, et criminel est complet. Mais le poète va encore plus loin. Le plus grand grief qu'il reproche aux mendiants n'est pas seulement lié à leurs activités criminelles mais, dans certains cas, à leur absence d'activité - en d'autres termes, à leur « oisiveté » : « Et chascun d'eulx d'oiseuse vit» [et chacun d'eux vit oisivement] (Ballade 1300) ; "ilz, sont puissans, larrons, atraundez, / Oyseux, faillis, dont nul bien ne peut ystre » [ils sont nombreux, larrons, truands / oisifs, faux, dont nul bien ne peut résulter] (Ballade 1229). Ce que dénonce l'auteur, c'est leur oisiveté : bien qu'ils soient aptes au travail, ils «faingnent non powvoir labour » [feignent de ne pas pouvoir travailler] (Ballade 1300). Le poète les exhorte donc au travail : «Faites devoir, / Oeuvrez, gagnez sur vostre selle » [Faites votre devoir / Travaillez, gagnez votre pitance] (Ballade 1233). Eustache Deschamps s'attaque à leur fainéantise et à leur mode de vie, qu'il juge méprisable. Ils ne sont que des profiteurs, des assistés qu'il faut dénoncer.

Le peuple doit pouvoir distinguer les vrais pauvres, malades et impotents, des vagabonds oisifs, sains et valides. Cette distinction est nouvelle dans la conception de la mendicité médiévale: il faut encadrer les marginaux, les mettre au travail. Comment distinguer, dans cet amalgame entre infirmité, pauvreté et criminalité, la

${ }^{50}$ GEREMEK, Les marginaux, p. 231. 
place des marginaux et, plus spécifiquement, celle des infirmes, dans l'ordre social ? Que nous révèle l'étude des poèmes d'Eustache Deschamps sur la place de la difformité dans la société des derniers siècles du Moyen Âge ? Exclusion ou intégration?

\section{La place des corps déformés dans la société médiévale : les raisons d'une marginalisation}

Nous avons parlé de la perception sensible et des représentations sociales des mendiants infirmes dans les poèmes d'Eustache Deschamps. L'étude du thème de la perception sensorielle nous amène à tirer des conclusions sans équivoque au sujet du dégoût physique que les mendiants inspirent au poète. Or, cette haine est primaire, quasi instinctive. La laideur, la difformité, le bruit et l'odeur sont autant de facteurs qui renvoient au domaine de la perception sensible. L' "Autre» est perçu avec les yeux, le nez, les oreilles et les tripes, et non pas avec la tête. La haine éprouvée est évidente, primitive et violente. Il est toutefois intéressant de noter que le sens tactile est totalement absent dans la perception du littérateur. Les mendiants, seraient-ils des «intouchables »? Eustache Deschamps espère en tout cas les chasser le plus loin possible et va d'ailleurs jusqu'à exhorter les prêtres de chasser les mendiants loin des églises : "gens d'Eglise, on doit purgier / D'entrez." [gens d'Église, on doit empêcher / d'entrer (les mendiants)] (Ballade 1233). Il va même jusqu'à solliciter qu'ils «soient traiz hors a une less / Du temple ou font polucion » [soient traînés à une laisse hors/ Du temple où ils sont une pollution] (Ballade 1259). Ce dernier mot, "pollution », ne cristallise-t-il pas parfaitement cette image du mendiant qui, pour le poète, n'est que nuisance ? Cependant, la haine de l'auteur est aussi liée à ses modes de représentation sociale, et probablement aussi à son expérience des milieux judicaires qui viennent entretenir la suspicion qu'il éprouve à l'égard des mendiants. Il est toutefois évident que la question de la difformité et de ses causes le préoccupe.

Dans Le Miroir de Mariage, le poète consacre un chapitre entier au problème que constitue la naissance d'un enfant difforme. Ce chapitre, intitulé «Cy moustre que c'est pou de gloire d'avoir enfans difformés » [Ce qui suit montre que c'est peu de gloire d'avoir des enfants difformes],51 dit : "Et si tesmoigne l'Escripture / Que homs de membre contrefais / Est en sa pensée meffais, / Plains de pechiez et plains de vices. » [Les Ecritures témoignent / Qu'un homme au corps difforme / Est en sa pensée mauvais, / Plein de péchés et plein de vices] (Le Miroir de Mariage, 24). Ce qui est important de souligner ici, c'est qu'Eustache Deschamps place la cause de la difformité dans le déformé lui-même, et introduit les concepts du mal, du péché et du vice, les érigeant en qualités intrinsèques à l'individu difforme, et fixe ainsi le mal sur un être qu'il peut exclure.

51 Le Miroir de Mariage, 24. 
Dans ce passage du Miroir de Mariage, Eustache Deschamps affirme qu'il se réfère aux Écritures. Nous pouvons dès lors nous demander quelles représentations et quelles situations sociales du handicap nous fournissent les textes bibliques.

Le chapitre 21 du Lévitique explique qu'il faut être sans tare pour approcher le lieu de résidence de Dieu ${ }^{52}$ - c'est pourquoi les infirmes, les corps déformés, sont exclus du temple et du sacerdoce. Le statut de l'infirme dans l'Ancien Testament correspond donc à une impureté cultuelle. Reste la question de l'origine de l'infirmité et la notion de péché. Dans l'Ancien Testament, il est impensable que Dieu soit responsable de la difformité dans la mesure où la Nature qu'il a créée est supposée parfaite. ${ }^{53}$ La notion de péché permet donc de rattacher la tare à l'homme et non à Dieu. Nous pouvons dès lors nous demander si, pour le poète, la difformité est la conséquence d'une faute individuelle ou si elle est collective, incombant donc à la communauté. La perception qu'Eustache Deschamps a de la mort permet d'apporter quelques éléments de réponse. L’idée de l’inéluctabilité de la mort est génératrice d'une peur universelle, très présente dans son œuvre. Elle est d'ailleurs palpable dans l'extrait du Miroir de Mariage, où le poète y exprime son angoisse d'avoir un enfant difforme, signe pour lui de l'extinction prochaine de sa lignée: «S'après la mort enfans n'avons / Qui nous puissent representer / Et nostre nom puissent porter » [Si lorsque nous mourrons, nous n'avons pas d'enfant / Qui puisse nous représenter /Et notre nom porter] (Le Miroir de Mariage, 24). Avoir un enfant difforme équivaut donc selon le poète à ne pas avoir d'enfants du tout. Ainsi, dans la pensée d'Eustache Deschamps, un enfant difforme est indigne de porter son nom, il n'est pas sien, il n'est pas son semblable. Il est Altérité. Il est l'« Autre », l'étranger, le différent. Il est porteur du mal, de la faute. La naissance d'un enfant difforme renvoi donc le poète à sa propre stérilité et, à plus grande échelle, à la peur de l'extinction de l'humanité.

Le thème de l'Apocalypse est d'ailleurs présent avec plus ou moins d'intensité dans la littérature tout au long du Moyen Âge, mais il l'est particulièrement à la veille d'un changement de siècle. Pour comprendre les changements de mentalités qui affectent la société de la fin du 14ème siècle, il nous faut remonter le cours du temps et revenir aux origines de ce qui constitue l'élément central de tout le système de pensée médiéval : le Christianisme. Les Évangiles sont porteurs d'un message nouveau : le mal n'est pas dans les souillures extérieures, mais dans la conduite vis-à-vis d'autrui. Ce sont donc les hommes qui créent et fixent les limites de l'impur. La décision d'intégrer les infirmes à la vie sociale devient dès lors une responsabilité individuelle et collective.

Dans le chapitre 16 de La Cité de Dieu, Saint Augustin « intègre l'anomalie dans le normal et la différence dans l'ordre des choses ».54 Pour Saint Augustin, les infirmes font donc partie du dessein de Dieu, d'une vue d'ensemble qui échappe aux

\footnotetext{
52 Lévitique, 21, 23.

53 Sur ce sujet, voir aussi l'article d'ANTUNES à apparaître au deuxième volume de cette édition.

54 STIKER, Corps infirmes, p. 80.
} 
hommes, et le corps déformé ne représente plus la différence métaphysique et biologique qui met en cause l'espèce et le groupe social. L'infirme est devenu celui qu'il faut aimer et secourir. À la fin du $12^{\text {ème }}$ siècle, le statut du pauvre change encore considérablement avec l'émergence des mouvements dits «de pauvreté ». De personne à secourir, le misérable devient porteur de la plus haute dignité. L'infirme est magnifié, exalté, surévalué. Paradoxalement, c'est au même moment qu'émerge l'image du «pauvre dangereux ». L'assistanat et l'aumône risquaient de tourner en haine et en mépris. Ce revirement radical s'opère au 14ème siècle, et est tout à fait visible sous la plume d'Eustache Deschamps. Les pauvres, les mendiants et les infirmes, les gens de la marge, deviennent des « inutiles au monde ». Cette expression, relevée par GEREMEK, 55 accompagne la sentence prononcée par les juges du Châtelet de Paris à un condamné à mort. GEREMEK écrit au sujet de cette sentence qu'elle est révélatrice « du jugement que la société porte sur des individus et des groupes qui refusent de réaliser leurs rôles sociaux $»{ }^{56}$ Par conséquent, l'infirme, assimilé au « mauvais pauvre » se retrouve au cœur d'une nouvelle politique sociale. Ce durcissement à l'égard des marginaux et des infirmes est surtout visible dans la répression sévère de la mendicité à partir de la seconde moitié du 14ème siècle. Eustache Deschamps nous en fourni un témoignage, lorsqu'il recommande aux fidèles et aux prêtres de chasser les mendiants à coups de bâton. Finalement, il va même jusqu'à souhaiter leur mort, en exigeant qu'on les envoie à la corde, qu'on les accroche à la queue d'un cheval : "D'orrible mort puisse chascuns mourir, / Par tout sient haiz et diffamez, / Chiens enrragiez leur puissent sus courir, / Fuitis soient de l'eglise et chaciez, / Et au gibet panduz et trainez. " [D'horrible mort puisse chacun mourir, / Par tous les siens haï et diffamé, / Que des chiens enragés les poursuivent, / Qu'ils soient chassés de l'église, / Et au gibet pendus et traînés] (Ballade 1229). Il recommande ainsi aux fonctionnaires royaux : "Advisez-y, baillis et sénéchaulx, / Prenez, pandez, et ce sera bien fet » [Baillis et sénéchaux, / Prenez, pendez, et ce sera bien fait] (Ballade 1299).

Eustache Deschamps juge donc que les hommes et les femmes souffrant de difformités physiques sont à bannir des églises, et par extension, de la communauté des fidèles à laquelle le poète les considère indignes d'appartenir. Il les condamne ainsi à une double mort, à la fois sociale et physique.

\footnotetext{
55 GeremeK, Inutiles au monde, pp. 9-11.

${ }^{56}$ GEREMEK, Inutiles au monde, p. 10.
} 


\section{Conclusion}

Au terme de cette étude, il apparaît que la littérature médiévale constitue pour l'historien une porte d'accès majeure sur les modes de penser, de ressentir et de percevoir la réalité sociale dans sa multiplicité. Nous avons voulu réunir, en parcourant l'œuvre d'Eustache Deschamps, les fragments épars de son regard sur les corps déformés, afin de reconstituer une image de ces individus et de ces groupes, et de comprendre quelle était leur place dans la société de son temps. L'étude des poèmes d'Eustache Deschamps met en lumière le durcissement des représentations et de la pratique sociale à l'égard des mendiants et des marginaux à la fin d'un 14ème siècle qui voudrait nier la misère, la souffrance et la différence. Pour le poète, l'infirme est un "Autre», une souillure. Il est un sujet de dérision, certes, mais l'humour masque chez Eustache Deschamps le dégoût et la haine qu'il éprouve au contact d'un corps déformé. Ainsi convaincu que la difformité est une a-normalité, le poète rejette les corps déformés sur les marges. Son discours les rend coupables de leur infirmité pour justifier la légitimité de leur exclusion.

Il est impossible pour nous de ne pas tenter de prolonger cette réflexion dans le monde contemporain. Nous avons parlé dans la présente étude des « inutiles au monde » et de la condamnation sociale sans commune mesure contenue dans cette notion qui semble d'un autre temps à un lecteur du $21^{\text {ème }}$ siècle. Dans un article paru dans le journal Le Monde en date du 8 mars 2010 étaient rapportés les propos de Monsieur Robert Fico, Premier Ministre slovaque, au sujet de la minorité rom de Slovaquie. «Le principal objectif du prochain gouvernement devrait être d'envoyer le plus d'enfants possible dans des internats et de les détacher progressivement de la vie qu'ils mènent dans les camps roms ", a-t-il déclaré à trois mois des élections législatives, «Sinon, nous allons élever une autre génération de gens incapables d'être utiles à la société ». La haine sociale a encore de beaux jours devant elle.

\section{Sources}

Eustache Deschamps, Euvres complètes d'Eustache Deschamps. Édité par A. H. E. MARQuis DE QueuX DE SAINT-Hilaire et G. RAYNAUd, 11 vol. (Société des Anciens Textes Français). Paris 1878-1903.

Liber Vagatorum. Le livre des gueux. Traduction française de PAUl RistelHUEBER. Strasbourg 1862.

Christine de Pisan, Euvres poétiques de Christine de Pisan, t. 2. Édité par M. RoY (Société des Anciens Textes Français). Paris 1891.

Saint Augustin, CEuvres : La cité de Dieu. Édité par LuCIEN Jerphagnon, vol. 2. Paris 2000. 


\section{Littérature secondaire}

Alexandre-Bidon, Daniele et Riviere, Remi, La santé au Moyen Âge. Paris 2008.

ANTUNES, GABRIELA, Entstellte Schönheiten : Überlegungen zum mittelalterlichen Bezug zwischen Hässlichkeit des Körpers und Schönheit der Seele. À apparaître : ANTUNES, GABRIELA et REICH, BJÖRN (sld.), (De)formierte Körper, die Wahrnehmung und das Andere im Mittelalter 2, Göttingen 2012.

Berkeley, George, Principes de la connaissance humaine. Paris 1920.

Boudet, Jean-Patrice et Millet, Helene, Eustache Deschamps en son temps. Paris 1997.

Foucault, Michel, Histoire de la folie à l'âge classique. Paris 1972.

GEREMEK, BRONISLAW, Inutiles au monde. Truands et misérables dans l'Europe moderne (1350-1600). Paris 1980.

GeremeK, Bronislaw, Les marginaux parisiens aux 14 $4^{\text {ème }}$ et $15^{\text {ème }}$ siècles. Paris 1976.

GeremeK, Bronislaw, Les fils de Caïn. Paris 1991.

GogLIn, JEAN-LOUIS, Les misérables dans l'Occident médiéval. Paris 1976.

Gonthier, NiCOLE, «Sanglant Coupaul!» «Orde Ribaude!» Les injures au Moyen Âge. Rennes 2007.

Leguay, JEAn-PIERre, Pauvres et marginaux au Moyen Âge. Paris 2009.

Merleau-Ponty, Maurice, Phénoménologie de la perception. Paris 1945.

Mollat, Michel, Les pauvres au Moyen Âge. Paris 1978.

SABAtier, Robert, Histoire de la poésie française, La poésie au Moyen Âge. Paris 1975.

SAUNIER, ANNIE, «Le pauvre malade » dans le cadre hospitalier médiéval : France du Nord, vers 1300-1500. Paris 1993.

StIKer, Henri-JacQues, Corps infirmes et sociétés. Paris 1982.

Vies des Saints et des Bienheureux par les RR. PP. Bénédictins de Paris, vol. 12 (janvier à décembre). Paris 1952.

Touati, François-Olivier, Maladie et société au Moyen Âge : la lèpre, les lépreux et les léproseries dans la province ecclésiastique de Sens jusqu'au milieu du XIVe siècle. Paris/Bruxelles 1998. 



\title{
Les difformités corporelles des lépreux : Aspects de l'imaginaire social au Moyen Âge
}

\author{
Nikoletta Giantsi
}

\begin{abstract}
:
The human body owns a particular place in medieval societies. In general, it constitutes the antipode of the soul and probably the natural obstacle for human salvation. The body constitutes a temptation, therefore it must be hidden, disciplined and subjected to the needs and deeper desires of the soul. The distorted body is capable of protecting someone from any sin or temptation, but proves at the same time the existence of a sinful behavior. These perceptions are confirmed through the observation of the place of leprosy and that of its victims in medieval sources. Leprosy stigmatized its victims and presented them as sinful, guilty of a sexual offense. Nevertheless, the leprous has not always been seen as repulsive; he has also been considered as holy and as an expression of repentance and patience, the most representative of all Christian virtues.
\end{abstract}

\section{Introduction}

Les monstres et le monstrueux, en tant que des déviations du normal ou de ce qui est perçu comme normal, constituent un sujet intéressant aussi bien pour les écrivains ecclésiastiques que pour les écrivains séculiers. En effet, les sociétés européennes médiévales développent leur imaginaire sous l'influence de leurs peurs et de leur incertitude liées à une vie précaire ${ }^{1}$ et au sentiment de culpabilité. Le christianisme a joué un rôle prépondérant en ce qu'il a tenté d'exercer un contrôle à la fois au niveau du conscient (par exemple, en condamnant la richesse, l'acte de chair et le luxe comme des péchés) que du subconscient (par exemple, des mauvaises

${ }^{1}$ Voir en particulier Delumeau, La peur. 
pensées). La peur de l'au-delà a été d'abord et surtout le tragique privilège d'une élite chrétienne, formée de religieux, de théologiens et de pieux laïcs. Celui qui a peur a besoin de faire peur. ${ }^{2}$ L'élément-clé du contrôle était la définition la plus précise possible de ce qui devait être perçu comme erroné, donc péché et interdit. Dans ces conditions, il existe de nombreux textes comprenant une description exacte de tout ce que les chrétiens doivent éviter. Même dans les textes qui ne font pas partie de l'éducation morale, mais qui sont destinés au divertissement ou à la critique, se glisse le concept de l'acceptable ou de l'interdit. Au Moyen Âge, l'irrégularité monstrueuse est due à des causes surnaturelles. De fait, celle-ci est considérée comme fruit de la faute, et le monstre devient la trace et la preuve du péché. La difformité physique révèle les craintes liées au corps : peur de contamination, fantasmes de métamorphose.

Le point de départ du présent article est la réalité d'une maladie - une réalité terrible, présente de diverses manières et à plusieurs reprises en Europe : la lèpre. Nous nous limiterons à analyser la conscience du patient souffrant de la lèpre et la perception générale de la maladie par la société médiévale. Notre attention ne se concentrera pas sur le plan médical et sur les remèdes que les gens cherchaient vainement contre la lèpre, mais plutôt sur ses interprétations non-médicales; en d'autres termes, on cherchera à comprendre la perception propre de la lèpre par le biais des difformités corporelles qu'elle entraîne. Le lépreux était une personne réelle, tant dans la vie quotidienne médiévale en Europe, que dans l'enseignement moral de l'époque. Toutefois, la perception de la maladie comme telle, aussi bien que la perception de cette maladie comme la raison essentielle d'une difformité corporelle, ont varié aux différentes époques de la période médiévale.

\section{Le corps et la maladie}

L'histoire du corps en Occident semble être une histoire de confrontations. Les distinctions entre le corps et l'âme, la matière et l'esprit, la passion et la tempérance, le désir et les fonctions de contrôle, caractérisent des conceptions anciennes mais aussi actuelles et appuient un large éventail de pratiques scientifiques, philosophiques et religieuses concernant le corps. Les sécrétions, la passion et la sexualité ainsi que le contact avec d'autres corps forment des domaines de contrôle et de régulation par des pratiques religieuses, des processus culturels et de nouveaux modes d'intimité. Selon la vision chrétienne, le corps est associé davantage à l'homme comme une création imparfaite. ${ }^{3}$ Ainsi, le corps humain se transforme en chair, renvoie à la partie bestiale de la nature humaine et devient un lourd obstacle au processus d'intégration et d'évolution spirituelle. ${ }^{4}$

Au Moyen Âge, le christianisme a tenté et réussi, concernant la conception du

\footnotetext{
${ }^{2}$ Delumeau, Le péché, pp. 363-369.

3 Turner, The Body, p. 12

${ }^{4}$ BurkitT, Bodies of Thought; SHILling, The Body.
} 
corps, à rapprocher deux résultats exclusifs l'un de l'autre. D’un côté, il sanctifie le corps et contribue au développement d'un sentiment de respect envers la partie matérielle de l'existence humaine. Dans l'Évangile selon Jean, on lit « Et la Parole a été faite chair $»,^{5}$ ou «Je suis le pain vivant qui est descendu du ciel. Si quelqu'un mange de ce pain, il vivra éternellement; et le pain que je donnerai c'est ma chair, que je donnerai pour la vie du monde $\gg .{ }^{6}$ De cette façon, le christianisme oblige le chrétien du Moyen Âge, qui souvent n'oublie pas son passé païen, à «voir » le corps - tant le sien que celui des autres - sous une perspective différente. ${ }^{7}$ D’un autre côté, Saint Paul, dans ses Épîtres aux Romains, introduisait une légère différence $:^{8}$ " Car chose impossible à la Loi parce qu'il était affaibli par la chair, Dieu, en envoyant son propre Fils dans une chair semblable à celle du péché, a condamné à cause du péché le péché dans la chair ». ${ }^{9}$ Cette différence en utilisant le clivage paulinien de la chair et de l'esprit, renforcé par la doctrine du péché originel, conduit Saint Augustin à admettre et à conseiller: "non in comissationibus et ebrietatibus, non in cubilibus et inpudicitiis, non in contentione et aemulatione, sed induite dominum Iesum Christum, et carnis providentiam ne feceritis in concupiscentiis $\gg .^{10}[\mathrm{Ne}$ vivez pas dans les festins, dans les excès de vin, ni dans les voluptés impudiques, ni dans les querelles et les jalousies; mais revêtez-vous de Notre-Seigeur Jésus-Christ, et ne cherchez pas à contenter la chair dans ses convoitises.]. C'est à lui que l'on attribue l'identification du péché originel avec le péché charnel, ${ }^{11}$ une opinion qui sera dominante pendant tout le Moyen Âge.

À l'opposé, il est possible de citer de nombreux éléments sur la présence positive de la chair et les relations sexuelles dans la vie quotidienne médiévale. Il est largement admis que nos connaissances sur la sexualité au Moyen Âge sont pauvres. On ignore presque totalement comment vivaient les gens à cette époque. Nous pouvons seulement imaginer la façon dont ils parlaient, la manière dont ils portaient leurs vêtements, ainsi que le sentiment qu'ils avaient de leur propre corps. Néanmoins, il est amplement attesté dans les sources médiévales comment les gens jouissaient de l'amour. ${ }^{12}$ De surcroît, et en dehors de ces informations éparses, on dispose de toute une série de traités de médecine fournissant des conseils sur le plaisir résultant de l'acte sexuel. ${ }^{13}$

\footnotetext{
${ }^{5}$ Jean $1,14$.

${ }^{6}$ Jean 6, 51.

7 Par exemple, pendant la famine qui a frappé la France entre 1032-1033, selon description du moine clunisien Raoul, les gens ont mangé de la chair humaine : "Quod olim raro audiri contigerit, tunc rabida inedies compulit vorari ab hominibus humanas carnes» [les fureurs de la faim renouvelèrent ces exemples d'atrocité si rares dans l'histoire, et les hommes dévorèrent la chair des hommes]. Raoul Glaber, Les cinq livres, 4, 4, 9-10.

8 LE GOFF, L'imaginaire médiéval, p. 212.

${ }^{9}$ Romains 8, 3 .

${ }^{10}$ Augustin, Confessiones, 8, 12, 29. Traduction Labriolle, Les confessions, p. 200.

${ }^{11}$ Selon Le Goff, L’Imaginaire médiéval, p. 216, l'idée provient de Clément d'Alexandrie.

12 DuBY, Le chevalier.

${ }^{13}$ Sur ce sujet, voir Rossiaud, La prostitution, p. 257.
} 
Le corps est, par conséquent, un point de conflit tant pour les gens du Moyen Âge que pour les historiens travaillant sur cette période. Le sujet devient encore plus compliqué si l'on y ajoute un axe supplémentaire : la maladie. Pendant le Moyen Âge, les attitudes envers les malades oscillaient entre deux tendances : d'un côté, l'exclusion totale, si la maladie était considérée comme contagieuse ; de l'autre côté, la marginalisation dangereuse, si la faiblesse empêchait d'exercer une activité professionnelle afin d'assurer leur subsistance. Le premier cas était le plus accablant : la maladie visible sur le corps même stigmatisait aussi l'identité, fait qui constituait « un élément de désorganisation sociale et simultanément de réorganisation ». ${ }^{14}$

\section{La lèpre}

En ce qui concerne le corps, deux perceptions traversaient l'histoire médiévale. Tout d'abord, celle de la maladie culpabilisée qui devenait une obsession. D'un point de vue pratique, cela signifie que, dans la mentalité médiévale, la maladie se situait au fond de l'âme, sous la forme de péché. Avec la manifestation de la maladie, le péché remontait de la profondeur de l'être humain à la surface du corps et devenait visible et reconnu par tous. La deuxième façon de percevoir la maladie concerne le lien de celle-ci avec le péché provenant d'une zone particulière de l'énergie humaine, avec un péché particulier : c'est-à-dire, l'acte sexuel.

La lèpre combine ces deux concepts. Les lépreux ne sont généralement pas considérés comme des enfants nés d'hommes sages, ${ }^{15}$ qui gardent leur chasteté le jour des célébrations religieuses, mais ils sont, au contraire, le fruit de relations sexuelles de rustres qui ne peuvent pas rester continents.

La lèpre n'est pas une maladie banale et commune, mais c'est une maladie qui provoque des difformités. La description de la difformité dans des textes ou à travers des images permet sa bonne perception. D’un point de vue pratique, selon plusieurs historiens, le terme 'lèpre' décrivait une expression diagnostique assez large, se référant à une multiplicité de maladies dermatologiques. Telle est l'opinion de BODY, BONDER, CRIGHTON et MCNEILl. ${ }^{16}$ On a ainsi longtemps considéré que la lèpre désignait une variété de maladies qui avaient des symptômes semblables. Cependant, les données osseuses provenant des excavations des léproseries médiévales ont conduit à supposer que presque la totalité des enterrés portaient les

\footnotetext{
14 Peter/ReVel, Le corps, p. 72.

15 Brundage, Law, Sex, p. 385, en accord avec Van HoecKe/WelKenHuYesen, Love and Marriage, admet que les rapports charnels pratiqués hors mariage étaient également interdits et considérés comme facteur d'infection : «The perils of extramarital sex were non limited to legal penalties. Physicians cautioned their patients to abstain for nonmarital sex, warning that it would expose them to numerous diseases and affections, especially leprosy. » [Les dangers de rapports sexuels hors mariage ont été limitées non seulement par de sanctions pénales. Les médecins consultaient à leurs patients de s'abstenir de relations sexuelles hors mariage, en avertissant que ce serait les exposer à de nombreuses maladies et affections, notamment la lèpre.]. Voir aussi Césaire d'Arles, Sermones, p. 339-341.

16 ElL, Leprosy and Social Class, p. 302.
} 
traces de la lèpre lépromateuse. ${ }^{17}$ Le squelette le plus ancien d'un lépreux provenant d'Europe Occidentale a été enseveli dans un cimetière du Haut Moyen Âge au nord-ouest de l'Angleterre. Ses restes, portant des difformités osseuses dues à la lèpre, ont été exhumés dans un cimetière anglo-romain près de Poundsbury (Dorset).

Quelle est la nature des difformités provenant de la lèpre ? Il s'agit de difformités graves, à cause desquelles, selon les conceptions d'alors, les caractéristiques humaines cédaient souvent leur place à des caractéristiques bestiales. C'est pourquoi certaines variantes de la lèpre étaient associées à des animaux. Les termes fréquemment utilisés pour les nommer reprenaient des caractéristiques animales, donc monstrueuses : la léonine, en raison du faciès léonin et hideux qui affectait les malades et les rendait extrêmement difformes ; la vulpine ou allopicia, à cause de la perte des cheveux et des sourcils, le patient ressemblant aux renards $(\dot{\alpha} \lambda \omega \dot{\omega} \eta \xi$, gr. anc., 'renard') ; l'éléphantiasis, dans ce cas, parce que le patient ressemble aux éléphants ; et la psoriasis à cause de ressemblances à la peau des reptiles. ${ }^{18}$ La lèpre avec les monstrueuses difformités, la laideur et les mutilations qu'elle provoquait représentait un malaise terrible dans la vie et était également " un emblème visible des bornes corporelles, étant donné que le lépreux était simultanément l'agent et l'image de la peur qui conduisait à la dissolution physique $»{ }^{19}$ En même temps, elle présentait des grandes similarités avec la description du satanique et du monstrueux. Selon Raoul Glaber (985-1047), il ne s'agit pas de décrire un lépreux, mais Satan :

\begin{abstract}
Astitit mibi ex parte pedum lectuli forma homunculi teterimae specie. Erat enim, quantum a me diagnosci potuit, statura mediocris, collo gracili, facie macilenta, oculis nigerrimis, fronte rugosa et contracta, depressis naribus, ore exporrecto, labellis tumentibus, mento subtract ac perangusto, barba caprina, auribus birtis et praecutis, capillis stantibus et incopositis, dentibus caninis, occipitio acuto, pectore tumido, dorso gibbato, clunibus agitantibus, vestibus sordidis, conatu aestuans ac toto corpora praeceps. 20

Jje vis au pied de mon lit un petit monstre à forme humaine. Il avait, autant que j'ai pu le reconnaitre, le cou grêle, la face maigre, les yeux très noirs, le front étroit et ride, le nez plat, la bouche énorme, les lèvres gonflées, le menton court et effilé, une barbe de bouc, les oreilles droites et pointues, les cheveux raides et hirsutes, des dents de chien, l'occiput en poire, la poitrine et le dos en bosse, les vêtements sordides, il s'agitait, se démenait furieusement].
\end{abstract}

La lèpre est une maladie, qui, selon l'opinion de certains historiens, pourrait caractériser même toute une période longue et étendue comme le Moyen Âge ; maladie qui « donne corps » à une époque :

\footnotetext{
${ }^{17}$ Cule, The Diagnosis ; DubÉ, Medieval Medicine, p. 239 ; Müller, Sieche, Seuchen, p. 14 ; PAWELETZ, Lepradiagnostik, p. 5 ; PÉTOURAUd, Les léproseries, p. 451 ; SCHELl, Zur Geschichte ; SCHIPPERGES, Der Garten, p. 71.

${ }^{18}$ Beriac, Histoire des lépreux, p. 20 ; KeIL, Aussatz ; KURTH, La Lèpre, p. 39, introduit une distinction chronologique, supposant que jusqu'au $8^{\mathrm{ème}}$ siècle on rencontre les termes misellus, mesiaus, mesellerie, masel, miselsubt, aussatz, aussätzig, et plus tard le terme mésel.

19 Zimmerman, Leprosy, p. 564: « a visible emblem of the instability of bodily boundaries, the leper served as both agent and illustration of the fearsomeness of physical dissolution ».

${ }^{20}$ Raoul Glaber, Les cinq livres, 5, 1, 1-5.
} 
Aucune (affection) enfin n'accompagne aussi 'corporellement' la vision d'un 'Moyen' Âge personnifié, non pas un temps de mort rapide mais celui d'un long pourrissement, d'une crispation sur soi, d'une boursouflure, d'une chrysalide préparatoire a un homme nouveau qui serait libéré de sa vieille peau, ou encore une période condamné sans rémission a rester a part, entre parenthèses, de l'Antiquité a la Modernité. Pour bien des esprits, le Moyen Âge c'est la lèpre. ${ }^{21}$

FOUCAULT, à son tour, a forgé un modèle compréhensif du Moyen Âge à partir de la lèpre :

Ce qui va rester sans doute plus longtemps que la lèpre, et se maintiendra encore a une époque ou, depuis des années déjà les léproseries seront vides, ce sont les valeurs et les images qui s'étaient attachées au personnage du lépreux; c'est le sens de cette exclusion, l'importance dans le groupe social de cette figure insistante et redoutable qu'on n'écarte pas sans avoir trace autour d'elle un cercle sacré. 22

Chez les Arabes, le terme utilisé pour décrire la lèpre est 'amputation' (djudham) Sa trace sur le corps était encore plus terrifiante aux yeux des musulmans, car, en blessant le corps, pour lequel l'Islam demandait un respect absolu, elle abîmait la créature de Dieu. ${ }^{23}$ On remarquera aussi une assimilation de la tradition arabe avec celle des Juifs et des chrétiens qui ont imposé le stigmate résultant de la maladie. Les communautés chrétiennes, nourries et élevées avec la Bible, ont partagé avec l'Islam l'horreur de la maladie sacrée qui portait la mort. Ainsi, elles ont considéré la lèpre comme une marque divine de l'impur et du péché. ${ }^{24}$

La conception de la lèpre dans l'Ancien Testament préfigure cette tradition du Moyen Orient, en présentant une image semblable dans le livre des Nombres:

La colère de l'Éternel s'enflamma contre eux. Et il s'en alla. La nuée se retira de dessus la tente. Et voici, Marie était frappée d'une lèpre, blanche comme la neige. Aaron se tourna vers Marie; et voici, elle avait la lèpre. Alors Aaron dit à Moïse: De grâce, mon seigneur, ne nous fais pas porter la peine du péché que nous avons commis en insensés, et dont nous nous sommes rendus coupables! ». ${ }^{25}$ Après les prières de Moïse, Dieu lui a répondu: «Qu’elle soit enfermée sept jours en dehors du camp; après quoi, elle y sera reçue. ${ }^{26}$

Cela veut dire que le stigmate de la maladie était visible pour rappeler à tous que celui qui le portait était pécheur et devait se purifier avant d'être accepté à nouveau au sein de sa communauté. Ainsi, la lèpre pénètre en Europe et devient une punition marquant le corps du malade avec le signe du péché. Sans entrer dans des argumentations théologiques, il convient toutefois d'en analyser les termes, afin de

\footnotetext{
21 Tounti, Maladie et société, p. 19.

${ }^{22}$ Foucault, Histoire de la Folie, p. 15-16.

${ }^{23}$ Le Coran, Sourate 30, v. 30 ; Boz, Tout esprit, p. 63 ; Boubakeur, Commentaire, p. 821. Spécialement à propos des opinions des Arabes concernant la lèpre, voir DOLS, Djudham, p. 270-274.

24 Brody, The Disease.

${ }^{25}$ Nombres 12, 9-11.

26 Nombres 12,14. Voir aussi Lévitique 13, 45-46 : « Le lépreux, atteint de la plaie, portera ses vêtements déchirés et laissera flotter ses cheveux, il se couvrira la barbe et criera: Impur! Impur! Aussi longtemps que durera sa plaie, il sera impur. Il est impur; il habitera seul; sa demeure sera hors du camp ».
} 
définir les contours du problème. D’une façon générale, le péché se définit comme un manque personnel de fidélité aux commandements divins. Ambroise Paré (1510-1590), un des médecins les plus importants de la Renaissance, ne pensait pas autrement. Selon lui, ce sont les péchés d'idolâtrie et les superstitions qui déclenchent les foudres divines. Le médecin peut s'efforcer de soulager le malade, voire tenter de le guérir, mais, au bout du compte, le traitement de fond consiste en une stricte obéissance aux commandements de l'Évangile : "Concluons donc que la peste et autres maladies dangereuses sont tesmoignages de la fureur divine sur les pechés d'idolatrie et superstitions qui regnent en la terre ». ${ }^{27}$ Pourtant, quatre siècles plus tôt, Hugues de Fouloi (1096-1141) conseillait aux victimes, même si leur maladie était causée par des vices moraux ou par l'imprudence dans l'acte sexuel, un traitement à base de myrobalan, de violette et d'absinthe. ${ }^{28}$

Ces opinions étaient généralement connues et admises partout en Europe médiévale. Cependant, la perception de la lèpre varie selon les différentes périodes du Moyen Âge. ELL, qui s'est demandé pourquoi les classes supérieures mettaient tant d'intérêt à construire des léproseries, admet que, pendant le Haut Moyen Âge, lorsque la lèpre était une pathologie mal connue, celle-ci était assimilée à l'hérésie. Plus tard, lorsque la pathologie de la lèpre lépromateuse était bien définie, les sources l'imputent au matérialisme, à la vanité, à l'orgueil, à l'avarice, à la gourmandise et aux abus charnels. Selon le tableau dressé par l'auteur, pendant le Haut Moyen Âge, la lèpre était liée plutôt à l'hérésie qu'aux mondanités. L'échantillon du Bas Moyen Âge assimile la lèpre à la laïcité quatre fois plus souvent qu'a l'hérésie. Dans le premier cas, l'exemple le plus probant est l'empereur Constantin ; infecté par la lèpre, a sollicita l'aide du Pape Sylvestre II ; en échange d'un traitement, l'empereur accorda le pouvoir séculier à la papauté : c'est la base de la Donation de Constantin. Au $6^{\mathrm{ème}}$ siècle, Grégoire de Tours reprend la même histoire. Cette foisci, la personne primordiale est le roi Clovis au moment de son baptême. La description de Grégoire de Tours ne laisse aucun doute: «Procedit novus Constantinus ad lavacrum, deleturus leprae» [Il s'avance, nouveau Constantin pour se guérir de la lèpre]. Remi lui dit: "Mitis depone colla, Sigamber; adora quod incendisti, incende quod adorasti ${ }^{29}$ [Dépose humblement tes colliers, Sicambre, adore ce que tu as brûlé, brûle ce que tu as adore]. Plus tard, au 9ème siècle, d'autres écrivains, comme Raban Maur, qui a présenté en détails les différentes formes de lèpre, admettent que

\footnotetext{
27 Ambroise Paré, Euvres complètes, t. 2, 24, chap. 2, p. 355. Dans le même ouvrage (p. 354), Paré écrivait : "c'est la main de Dieu qui, par son juste jugement, darde en ciel ceste peste et contagion, pour nous chastier de nos offenses et iniquités, selon le menace qui est contenue en l'Escriture. Le Seigneur dit ainsi : le feroy venir sur vous la glaine executeur, pour la vengeance de mon alliance, et quand vous serez rassamblès en vos villes, ie vous enuoyeray la pestilence au milieu de vous, et serez. iurés en la main de l'enemy (Lenit. 26). Qu'on lise aussi ce qui est escrit en Habacuc, chapitre 3. Le Seigneur des armées dit: Voivy, i'envoye sur eux l'espée, la famine et la peste (leremie 29)». Voir aussi BRENOT, La peste, p. 555.

${ }^{28}$ Hugues de Fouloi, De medicina animae, col. 1201.

${ }^{29}$ Grégoire de Tours, Libri historiarum. Traduction de Rouche, dans : Clovis, p. 280-281.
} 
l'hérésie peut être manifestée par la lèpre et que les lépreux étaient des hérétiques parce qu'ils blasphémaient contre le nom de Jésus Christ. ${ }^{30}$

Le pape Grégoire le Grand, ainsi qu'Isidore de Séville, ont utilisé le terme « lèpre » pour designer l'hérésie comme une maladie qui infecte « le corps sain » des fidèles. La métaphore de cette maladie est très souvent utilisée pour décrire l'hérésie ;31 par exemple, chez Eckbert de Schönau (c. 1132-1184) : «nam sermo eorum serpit ut cancer, et quasi lepra volatilis longe lateque discurrit $\aleph^{32}$ [Leur sermon rampe comme un cancer et se repend comme la lèpre volatile, loin et partout]. Le même schéma est utilisé chez d'autres auteurs, comme Origène (c. 185-254), Bède le Vénérable (c. 672-735) et Césaire d'Arles, qui accusait les juifs d'infecter les chrétiens avec la lèpre du péché. Même plus tard, au 11 ème siècle, la relation entre lèpre et hérésie reste prédominante dans la pensée chrétienne: le moine Guillaume, s'adressant à Henri de Lausanne, lui reprochait d'être un lépreux exclu de la communion par le jugement du prêtre. En plus, il l'obligeait à proclamer qu'il était un lépreux, un hérétique, un sale et qui devait vivre loin de l'Église. ${ }^{33}$

\section{L'isolement et le rejet}

Rejet, isolement et exclusion : ces termes, simples mais aussi très catégoriques, décrivent jusqu'aujourd'hui, avec de très rares exceptions, les caractéristiques de l'histoire des lépreux et des léproseries tout au long du Moyen Âge. Le maladepécheur, stigmatisé par la maladie, était aussi stigmatisé d'un point de vue social par la persécution rituelle des lépreux par les représentants de l'Église. ${ }^{34}$

Un rite de passage conduisait le malade d'une certaine situation physique et sociale à une autre, celle de l'effacement et de la disparition non seulement sociale, économique, juridique, mais aussi physique. C'était une cérémonie, décrite dans l'édit intitulé Modus pro ejectione leprosorum par Rainaldus de Chartres, évêque de Reims (1414-1444), pendant laquelle le lépreux se tenait devant son tombeau ouvert et tandis que l'assistance jetait de la terre. Ensuite, le prêtre le conduisait à l'église, l'aspergeait d'eau bénite et acceptait sa confession. Enfin, le prêtre disait : «Tu es mort selon les mortels, et vivant selon Dieu ». La cérémonie s'achevait par l'énumération des prohibitions que le malade devait observer pour le reste de sa vie : il leur était interdit d'entrer dans les églises et dans les lieux publiques. Ils n'avaient pas le droit de se laver partout ni d'utiliser les mêmes habits que les autres. Il était défendu également d'entrer dans les tavernes et dans la maison de personnes saines. Il leur était interdit d'avoir pour autre compagne que leur épouse et de tou-

\footnotetext{
${ }^{30}$ Raban Maur, De Universo, col. 502.

31 MoOre, The Formation, p. 77.

32 Eckbert de Schönau, Sermones, col. 13.

${ }^{33}$ MoOre, The Formation, p. 62.

${ }^{34}$ DunCAN, Leprosy and procreation.
} 
cher des objets sans porter de gants. Enfin, ils pouvaient manger et boire seulement en compagnie d'autres lépreux.

En même temps, la peur envers le monstrueux représenté par la victime de la lèpre se transforme en préjugé et fait naître des fantasmes, d'où la naissance, entre 1320 et 1321, du mythe d'un complot international entre Musulmans, Juifs et lépreux pour anéantir la Chrétienté par le poison. ${ }^{35}$ En cette même période, caractérisée comme «the most psychically disturbed era in European history » [la période la plus perturbée du point de vue psychologique], ${ }^{36}$ les lépreux ont été associés à tous les groupes considérés comme dangereux pour la communauté des Chrétiens. On les conduisait, donc, au bûcher pour les purifier. ${ }^{37} \mathrm{Ce}$ rituel de purification cache en soi la peur sociale envers la maladie, considérée comme contagieuse. Ces deux paramètres - la condamnation et la peur de la contamination - ne constituent pas obligatoirement une condition préalable à l'apparition d'un comportement d'évitement et d'isolement des lépreux. L'étude des sources montre qu'au sein de la société, la lèpre était présente à divers niveaux de conscience, et entraînait différents types de comportements. C'est ainsi que, tout au long du Moyen Âge, on rencontre aussi bien des manifestations d'un phénomène qui, de nos jours, est qualifié d'aaphobie', c'est-à-dire d'absence de peur dans la fréquentation des malades considérés comme contagieux, que des manifestations de répulsion extrême, voir même d'indignation.

Dans le premier cas, on rencontre l'expression du soutien aux lépreux, la cohabitation et la familiarité avec ceux-ci. Par exemple, au Gème siècle, sainte Radegonde servait des femmes lépreuses et embrassait leurs visages déformés. ${ }^{38} \mathrm{Au} 77^{\mathrm{ème}}$ siècle, Saint Richard, selon Alcuin, son biographe, ne craignait pas le contact naturel avec leprosos vel elefanticos et utilisait pour son bain l'eau que ces derniers avaient utilisé, sans avoir été contaminé. ${ }^{39}$ Au début du 12 ème siècle, la reine Mathilde, femme du roi Henri I d'Angleterre, a réuni, dans le palais royal, une multitude de lépreux. Elle s'en occupait elle-même, lavant leurs pieds, les étreignant et les embrassant ${ }^{40}$. La familiarité d'Elizabeth de Thuringe (1207-1231), qui allait jusqu'à toucher leurs ulcères, est légendaire, bien que son confesseur «timens nobilem ejus teneritatem infici vel corrumpi» [avait peur que ceci pût détériorer sa nature polie et délicate]. ${ }^{41}$

Certainement, ceux-ci ne peuvent pas être pris comme des exemples d'un comportement social de l'époque: Il s'agit de légendes, donc de textes à fort caractère "littéraire ", qui veulent illustrer les faits héroïques de la vie des Saints. Ils peuvent, cependant être utilisés comme points de vue d'un imaginaire collectif représentant non seulement les peurs les plus intimes de la société, mais en même

\footnotetext{
35 RiCHARDS, Sex, Dissidence, p. 19.

36 White JR., Death and the Devil, p. 26.

37 Beriac, La persécution ; NirenberG, Communities of Violence.

38 Venance Fortunat, Vita s. Radegundis, p. 499-500.

39 Alcuin de York, Vita Richarii, p. 392.

40 Matthieu Paris, Chronica maiora, p. 130.

${ }^{41}$ Libellus de dictis quatuor, p. 49.
} 
temps tout ce qu'elle considérait comme dangereux et responsable de la contamination, c'est-à-dire les causes de la maladie. En même temps, dans le cadre d'une description plus réaliste et pragmatique, il faut mentionner les comportements qui émergent d’après les règles des léproseries médiévales. Ces textes confirment la peur de la contamination provenant de la familiarité avec les lépreux, mais, simultanément, montrent la cohabitation de lépreux et de sains entre les murs des léproseries médiévales. ${ }^{42}$

D'autre part, conformément aux pratiques médicales concernant la prévention de la lèpre, le plus grand risque de diffusion provenait de la fréquentation des lépreux, résultat de la cohabitation (cohabitatio), de la discussion (confabulatio) ou du coït (coitus). Trois des manifestations les plus importantes de sociabilité ont été, donc, considérées comme dangereuses. L'air pollué, tant celui que l'on pouvait respirer en contact avec un lépreux que celui contaminé par des blessures ouvertes et des ulcères, était considéré comme un facteur aggravant de contamination.

\section{L'inversion de la perception : le lépreux en tant qu'expression de bénédiction divine}

La symbolique du péché et de l'impur prend une toute autre dimension dans l'épisode où Jésus Christ montre sa bonté en guérissant des lépreux ; ceux-ci deviennent alors l'image de Jésus Christ qui, lui-même, leur a emprunté les traits durs. ${ }^{43}$ Dans la mentalité et la conception médiévales, les maladies et la faiblesse réfléchissaient l'image du Christ affligé, mais c'était exclusivement la lèpre qu'Isaie avait choisi pour décrire dans sa prophétie la cruauté de la persécution que le serviteur souffrant, considéré comme image du fils de Dieu subissait pour le salut de l'humanité : "Comme si il était lépreux et chassé par le Dieu et humilié ». ${ }^{44}$ Si Dieu afflige le corps de souffrances, son but est de purifier et de soulager l'âme. Ainsi s'explique peut-être pourquoi plusieurs saints du Moyen Âge ont été eux-mêmes lépreux, comme Alice de Schaerbeke (c. 1225-1250)45 ou Angèle de Foligno (12481309), qui, dans un cas extrême, assimile le corps abîmé des lépreux au corps du Christ :

Après avoir obtenu cela, nous lavâmes les pieds des femmes et les mains des hommes, surtout d'un lépreux qui avait les mains fort abîmées, pourries et perdues, et nous bûmes de l'eau utilisée pour ce lavement. Nous ressentîmes une telle douceur que nous avons fait tout le chemin de retour dans une grande douceur, comme si nous avions communie. En fait il me semblait vraiment que j'avais communie, car je ressentais une grande douceur comme si j'avais communie. Une petite croute de plaies du lépreux était restée dans ma gorge, et je m'efforçais de

\footnotetext{
42 Lallemand, Histoire de la Charité, surtout p. 278ff. ; Le Grand, Statuts d'Hôtels-Dieu, p. $181 \mathrm{ff}$.

43 Dans ce cas, on peut parler de l'ambiguité fondamentale du christianisme, selon AGRIMI/ CRISCIANI, Charity and Aid, p. 194.

${ }^{44}$ Isaïe 53, 4.

${ }^{45}$ Bynum, Holy Feast, p. 121. Voir aussi ALBERT, Le corps défait, p. 37.
} 
l'avaler. Ma conscience m'interdisait de la rechercher, comme si j’avais communie, encore que je ne voulais pas la cracher pour la rejeter, mais pour la détacher de ma gorge. ${ }^{46}$

Le lépreux est aussi associé à Job et à ses malheurs. Cependant, dans l'Europe du $12^{\text {ème }}$ siècle, ils - plus nombreux qu'auparavant ou moins ignorés - étaient, dans l'optique chrétienne, l'image de Lazare, qui se présentait sous ses deux versions. D'un côté le pauvre, couvert d'ulcères, qui gisait à la porte du riche impitoyable, abandonné aux chiens qui lui léchaient les plaies, et conduit par des anges dans le sein d'Abraham ;4 de l'autre, Lazare de Béthanie, ami de Jésus, ressuscité par celuici et devenu le saint protecteur de plusieurs léproseries. ${ }^{48}$

\section{Conclusion}

Les deux aspects - d'une part, l'isolement et le rejet; d'autre part, le lépreux comme expression de la bénédiction divine -, montrent que dans la société médiévale, il existait aussi une réception positive du lépreux malgré sa difformité ? Les lépreux étaient-ils aussi une preuve de bénédiction, et non seulement de malédiction ? Il convient de répondre à cette question en avançant la réflexion qui résulte de l'approche initiale de cet exposé.

Nous mentionnerons à ce titre les qualificatifs de Bernard de Clairvaux concernant les 'horribles beautés et les belles horreurs' : "Clamat ad vos mea monstruosa vita, mea aerumnosa conscientia. Ego enim quaedam Chimaera mei saeculi, nec clericum gero nec laicum. Nam monachi jamdudum exui conversationem, non habitum » [L'étrangeté de la vie que je mène et les agitations de ma conscience m'obligent à réclamer vos prières. Je suis comme la chimère de mon siècle, ni clerc ni laïque; moine par l'habit et bien moins du religieux par la façon dont je vis]. ${ }^{49}$ Nous ne pensons pas que Bernard de Clairvaux fût partisan d'une beauté couverte par la laideur ; mais plutôt que, au quotidien, aucune malformation n'était ni acceptable ni accueillie comme indication de grâce. La régularité et la symétrie, l'équilibre et la mesure, étaient liés au Moyen Âge à l'action divine. On a déjà montré que, s'éloigner du normal, de l'équilibre et du régulier était perçu comme un danger, une menace. La dissymétrie était signe du diable. Pourtant, nous pourrions expliquer l'approche de Bernard de Clairvaux comme le résultat de son époque, d'une époque de confusion et de doute, qui pourrait être invoquée par plusieurs exemples, dans un espace plus long.

Il paraît intéressant de rapprocher l'alternative ci-dessus d'une autre contradiction : le cas d'Abélard, l'opposant par excellence de Bernard de Clairvaux, qui constitue l'exemple-même du conflit entre l'ancien et le moderne et de la confusion qui touchait même les génies les plus élevés et fins. Comme professeur, il était

\footnotetext{
46 GODET, Le Livre de l'Angèle de Foligno, p. 104-105.

${ }^{47}$ Luc. 16, 19-31.

48 Tounti, Maladie et société, p. 384.

49 Bernard de Clairvaux, S. Bernardi Opera omnia, Lettre 250, 1-3.
} 
fasciné par la ville, mais n'a pas osé s'intégrer aux nouveaux courants particuliers à la vie urbaine ; comme moine, il était séduit par un idéal auquel il s'est dévoué avec franchise - l'enseignement -, mais n'a pas pu choisir la forme particulière et exclusive qui lui était convenable. Il s'est donc tenu toujours hésitant et incertain entre la ville et l'isolement, entre l'école et le monastère. Nous pensons que son histoire avec Héloïse n'est que la conclusion tragique de cette attitude balancée et hésitante entre deux tendances, dont aucune n'est devenue exclusive. Héloïse, agissant comme un troisième facteur équilibrant, s'est finalement perdue dans ce conflit.

Ne s'agit-il pas ici d'une hésitation analogue à celle entre le beau et le laid ? Et cette histoire, ne constitue-t-elle pas une preuve que la beauté - c'est-à-dire, l'amour - est incluse aussi dans la laideur - c'est-à-dire, la désobéissance aux lois de Dieu -, aussi bien que dans l'incertitude ? Abélard représente lui-même, ainsi que Bernard de Clairvaux, la perplexité face aux changements que de nouvelles conditions de vie développaient sous ses yeux. Par ailleurs, son œuvre la plus importante n'est-elle pas le Sic et Non, l'essai de l'ambiguité par excellence?

\section{Sources}

Alcuin d'York, Vita Richarii confessoris Centulensis. In : Passiones vitaeque sanctorum aevi Merovingici. MGH, SRM 4. Édité par BRUNO KRUSCH. 1902, pp. 381-401.

Ambroise Paré, Oeuvres complètes, t. 1-2. Édité par JosEPH FRANÇOIS MALGAIGNE. Paris 1840.

Augustin, Confessiones (Tituli capitulorum ex editione J.-P. MignE, Paris 1861, PL 32). Turnhout 1981.

Augustin, Les Confessions de Saint Augustin, t. 1. Édité par PIERRE DE LABRIOLLE. Paris 1969.

Bernard de Clairvaux, S. Bernardi Opera omnia, t. 8. Édité par JEAN LECLERQ. Rome 1957.

Césaire d'Arles, Sermones, t. 1. Édité par GERMAIN MORIN. Turnhout 1953.

Eckbert de Schönau, Eckberti Schonaugiensis Sermones. In : PL 195, col. 11-98C.

Grégoire de Tours, Libri historiarum. MGH, SRM 1. Hanovre 1937-1951.

Hugues de Fouloi, De medicina animae. In : PL 176, col. 1183-1202.

Libellus de dictis quatuor ancillarum S. Elisabeth confectus. Édité par ALBERT HUYSKENS. Munich 1911. 
Mathaeus Parisiensis, Chronica maiora. Édité par FELIX LIEBERMANN et REINHOLd PAUli. Monumenta Germaniae historica 28, t. 2. Stuttgart 1888.

Raban Maur, De Universo. In : PL 111, col. 9-614.

Raoul Glaber, Les cinq livres de ses histoires (900-1044). Édité par MAURICE PROU. Paris 1886.

Venance Fortunat, Vita s. Radegundis. In : Venantius Honorius Clementianus Fortunatus presbyteri Italici opera pedestria. Édité par BRUNO KRUSCH. MGH, SRM AA 4, 2. Berlin 1885, pp. 38-49.

\section{Littérature sécondaire}

Agrimi, Jole et Crisciani, ChiarA, Charity and Aid in Medieval Christian Civilization. In : Western Medical Thought from Antiquity to the Middle Ages, Édité par MIRKO GRMEK. Harvard 1998, pp. 170-197.

AlBert, JEAN-PIERre, Le corps défait. De quelques manières pieuses de se couper en morceaux. In : Terrain 18 (1992), pp. 33-45.

Beriac, Françoise, Histoire des lépreux au Moyen Âge. Paris 1988.

BERIAC, FRANÇOISE, La persécution des lépreux dans la France méridionale en 1321. In : Le Moyen Âge 93/2 (1987), pp. 203-221.

Boubakeur, Hamza, Commentaire du Coran. Paris 1972.

BOZ, PIERRE, Tout esprit devra goûter la mort. Avec nos frères musulmans devant la souffrance et la mort. Paris 1980.

Brenot, AnNe-MARIE, La peste soit des Huguenots. Étude d'une logique d'exécration au XVIe siècle. In : Histoire, économie et société 11/4 (1992), pp. 553-570.

Brody, SAul NATHANIEL, The Disease of the Soul. Leprosy in Medieval Litterature. Ithaca/Londres 1974.

Brundage, James A., Law, Sex and Christian Society in Medieval Europe. Chicago/Londres 1987.

BURKITT, IAN, Bodies of Thought. Embodiment, Identity and Modernity. Londres 1999.

Bynum, Caroline Walker, Holy Feast and Holy Fast. The Religious Significance of Food to Medieval Women. Berkeley et. al. 1987. 
Cule, JoHn, The Diagnosis, Care and Treatment of Leprosy in Wales and the Borders in the Middle Ages. In : Transactions of the British Society for the History of Pharmacy 1 (1970), pp. 29-58.

Delumeau, JEAN, La peur en Occident. Paris 1978.

Delumeau, JEAN, Le péché et la peur. La culpabilité en Occident. Paris 1983.

Dols, Michael W., Djudham. In : Encyclopédie de l'Islam. Paris 1982, suppl. 5-6.

DubÉ, Waltraut F., Medieval Medicine in Middle High German Epics. Ann Arbor 1981.

DuBy, GEORGES, Le chevalier, la femme et le prêtre. Paris 1981.

Duncan, M. E., Leprosy and Procreation. A Historical Review of Social and Clinical Aspects. In : Leprosy Revue 56 (1985), pp. 153-162.

ELL, STEPHEN R., Leprosy and Social Class in the Middle Ages. In : International Journal of Leprosy 54/2 (1986), pp. 300-305.

Foucault, Michel, Histoire de la folie. Paris 1972.

GODET, JEAN-FrAnÇOIS, Le livre de l'Angèle de Foligno. Grenoble 1995.

LE GOFF, JACQUES, L’imaginaire médiéval. Paris 1985.

LE GRAND, LEON, Statuts d’Hôtels-Dieu et des léproseries. Paris 1901.

VAn Hoecke, Willy, et WelKenhuyesen, Andries, Love and Marriage in the Twelfth Century. Leuven 1981.

KEIL, G., Aussatz. In : LexMA, t. 1, col. 1255-1256.

Kurth, Godefroid, La lèpre en Occident avant les Croisades. In : Compte rendu du Congrès scientifique international des Catholiques, avril 1891. Paris 1891, pp. 125-147.

Lallemand, LeOn, Histoire de la Charité, t. 3. Paris 1906.

MOORE, ROBERT I., The Formation of a Persecuting Society. Oxford 1987.

MÜller, IRMgARD, Sieche, Seuchen und Spitaldienst im Spiegel der Heiltätigkeit Elisabeths von Thüringen. In : Hessisches Jahrbuch für Landesgeschichte 32 (1982), pp. 1-17.

Nirenberg, David, Communities of Violence. Persecution of Minorities in the Middle Ages. Princeton 1998.

PAWELETZ, ALOIS, Lepradiagnostik im Mittelalter und Anweisungen zur Lepraschau. Leipzig 1915. 
PETER, JEAN-Pierre, et REVEL, JACQUES, Le corps. L'homme malade et son histoire. In : Faire de l'histoire. Nouveaux objets. Édité par JACQUES LE GOFF et PIERrE NorA. Paris 1974.

Petouraud, Charles, Les léproseries lyonnaises au Moyen Âge et à la Renaissance. In : Cahiers d'Histoire 7 (1962), pp. 425-464.

RiCHARDS, JEFFREY, Sex, Dissidence and Damnation. Minority Groups in the Middle Ages. Londres 1990.

RossIAUd, JACQUES, La prostitution médiévale. Paris 1988.

Rouche, MicheL, Clovis. Paris 1996.

SCHELl, OtTo, Zur Geschichte des Aussatzes am Niederrhein. In: Sudhoffs Archiv für Geschichte der Medizin 3 (1910), pp. 335-346.

SCHIPPERGES, HeINRICH, Der Garten der Gesundheit. Medizin im Mittelalter. Munich/Zurich 1985.

SHILLING, CHRIS, The Body and Social Theory. Londres 1993.

Touati, François-Olivier, Maladie et société au Moyen Âge. La lèpre, les lépreux et les léproseries dans la province ecclésiastique de sens jusqu'au milieu du XIVe siècle. Paris 1998.

TURNER, BryAN S., The Body and the Society. Londres 1997.

White JR., LYNN, Death and the Devil. In: The Darker Vision of the Renaissance. Édité par ROBERT KINSMAN. Berkeley 1974, pp. 25-47.

ZIMMERMAN, SUZAN, Leprosy in the Medieval Imaginary. In : Journal of Medieval and Early Modern Studies 38/3 (2008), pp. 559-587. 



\title{
Auf der Suche nach Behinderung: Gedanken zur Wahrnehmung von deformierter Körperlichkeit in der bildlichen Überlieferung des Mittelalters
}

\author{
Sarab Harms
}

\begin{abstract}
:
Disability Studies explore 'disability' as a construct - different understandings persist within society depending on time, culture and region. The goal of this paper is to find out how this complex relation is constructed. I $\mathrm{n}$ the network that shapes 'disability', visual aspects are of great importance. This paper examines empirically as well as methodologically how to handle the vast medieval visual sources where one can find bodies with disability. It is not easy to decide on a picture's relevance: the nonexistence of disability as a concept in the Middle Ages and the lack of proper terminology are acute problems and imply that there is not a clear object for scholarly research. This leads to the question of which picture is relevant and which is not. Our aim is not to give a definite answer, but to challenge perception of disability's visualisation and to start a discussion on how to handle the difficult analysis of disability in medieval visual sources.
\end{abstract}

\section{Grundlagen}

Der wissenschaftliche Forschungsansatz der Dis/ability Studies setzt sich kritisch mit dem Begriff der ,Behinderung' auseinander.' Sein theoretischer Grundzug besteht darin, Beeinträchtigungen, Benachteiligungen und Ausgrenzungen, die mit der Zuschreibung ,Behinderung' verknüpft sind, als Konsequenzen materieller Barrieren, sowie als Produkte kultureller Werte, Erwartungen und Praktiken zu

\footnotetext{
1 Zur Einführung: AlBRECHT, Handbook; Dederich, Körper, Kultur und Behinderung; WeISSER/ RENGGLI, Disability Studies.
} 
verstehen. ,Behinderung' ist unter diesem Blickwinkel ein soziokulturelles Konstrukt, das einem kulturellen und zeitlichen Wandel unterliegt.

Am Anfang einer Untersuchung von ,Behinderung ${ }^{6}$ in der Bilderwelt des Mittelalters steht somit die Frage, inwiefern sich überhaupt Visualisierungen von ,Behinderung ${ }^{6}$ finden lassen und in welchen Bildmedien sie auftauchen. Zwar sind die Bilder, die für diesen Problemkontext Relevanz besitzen, zahlreich und der Forschung keineswegs unbekannt. Was bisher weitgehend fehlt, ist allerdings ein Forschungsansatz, der sich mit den Erkenntnissen der Dis/ability Studies auseinandersetzt und sie in diesen Untersuchungszusammenhang einbringen kann. ${ }^{2}$ Welche Hindernisse sich einem solchen Anliegen in den Weg stellen und wie ihnen produktiv entgegen gearbeitet werden kann, davon sollen die folgenden Überlegungen einen Einblick liefern. Dabei ist es nicht die Absicht dieses Beitrags, definitive Antworten und Erklärungen formulieren zu wollen, sondern zeitgenössische Vorstellungen und wissenschaftliche Methoden zu hinterfragen.

\section{Wahrnehmung und Behinderung}

Jede Forschung besitzt eine „doppelte Kulturalität und Geschichtlichkeit“, zum einen „die Geschichtlichkeit und Kulturalität des untersuchten Gegenstandes“, zum anderen „die des untersuchenden Forschers". 3 Trotzdem wird oft vergessen (oder stillschweigend vorausgesetzt), dass diese verschiedenen Perspektiven sich nicht nur mit unterschiedlichen Fragen an die Vergangenheit wenden, sondern dass sich aus diesen auch andere Antworten ableiten lassen.

Im Falle einer Untersuchung von ,Behinderung' in der mittelalterlichen Bilderwelt spielt diese Doppelung eine entscheidende Rolle. Einerseits liegt es an den spezifischen Eigenschaften der Bilder, die oft dazu führen, andererseits ist es das Thema der ,Behinderung' selbst.

Welche Rolle der ,Körper‘ innerhalb der Dis/ability Studies spielt, unterliegt einer ständigen Diskussion. Es kann aber davon ausgegangen werden, dass ,Behinderung ${ }^{6}$ immer auch an ihn gedacht wird, denn gerade der ,Körper', speziell der andere (visualisierte), wird erst über die Referenz zum eigenen Körper wahrgenommen. Bilder und ,Köper' (und damit auch ,Körper mit Behinderungen') werden

jeweils vor dem Zeithintergrund und dem individuellen Erfahrungshorizont betrachtet, [...] nicht im leeren Raum erfahren. Ob, wie und warum Kunst [Bilder; ,Körper'] wahrgenommen wird ist stets vorstrukturiert und bedingt durch herrschende Denkmodelle der Zeit: Wahrnehmung von Kunst [Bildern; ,Körper'] ist vom Wissen des Betrachters abhängig, von zeitge-

\footnotetext{
2 Am ehesten werden die jüngeren Beiträge HeLas und VAVRA diesem Forschungsansatz gerecht. Einzige Monographie ist momentan von MÜRNER.

${ }^{3}$ WuLf, Anthropologie, S. 134, zit. n. DeDERICH, Körper, Kultur und Behinderung, S. 60.
} 
nössischen Vorstellungen über Wahrnehmung, von kulturellen Kontexten, von ästhetischen Vorannahmen. ${ }^{4}$

Genauso ist sie auch von der Wahrnehmung des Urhebers abhängig. Die Spannbreite der Faktoren, die Einfluss auf solche Wahrnehmungsprozesse haben, ist weit.

Ein wesentlicher Faktor ist die doppelte Eigenschaft der Bilder als materielle und immaterielle Bilder des Rezipienten. Dieser Doppelcharakter des Bildes entspringt nicht den Ideen einer modernen Bildwissenschaft, sondern findet sich (mit differenten Erklärungen) bereits in den antiken Bilddebatten. Ausdruck der vielseitigen Auseinandersetzungen sind die ständigen Bilderstreitigkeiten, die das Mittelalter seit dem Beginn des Christentums durchziehen. Es sind genau diese Kontroversen, die die so oft geäußerten Vorstellungen an eine bilderarme Zeit revidieren, denn ohne das Vorhandensein von Bildern hätte es diese Konflikte nicht geben können. Bilder, die von Körpern durchzogen sind, die zum gegenwärtigen Zeitpunkt als ,behindert' wahrgenommen werden.

LENTES geht davon aus, dass die Reichweite von Imaginationsverfahren weit über den religiösen Raum hinausging und das Wissen um imaginative Vorgänge „letztendlich zum Kernbestand einer Kultur des Sehens gehör[t]e[, die ihr gesamtes Denken, ihre Religiosität ebenso wie ihren Gefühlsapparat und die ethische Verfasstheit des Menschen über das Sehen innerer und äußerer Bilder bestimmte“. 5 Schon aus diesem Grund erscheint die Untersuchung der visuellen Kultur im Rahmen der ,Disability History` notwendig.

Ich möchte mich hier aber auf die inneren Bilder des heutigen Betrachters, des Forschers und seiner Wahrnehmung von sichtbarer „Behinderung' in überlieferten Bildzeugnissen beschränken. Wahrnehmungen sind nun einmal keine isomorphen Abbildungen, sondern „vielmehr das Ergebnis hochkomplexer Konstruktionen und Interpretationsprozesse [...], die sich sehr stark auf gespeichertes Vorwissen stützen. Dieses Vorwissen wiederum speist sich aus unterschiedlichen Quellen, wobei sowohl evolutionäre Prozesse als auch individuelle Seherfahrungen, die das Gesehene zu interpretieren erlauben, von Bedeutung sind"..6 Das rein visuelle Artefakt des Bildes gibt es nicht. Bilder erhalten für uns erst eine Bedeutung dadurch, dass ihre Wahrnehmung als ein „Bildakt ${ }^{67}$ geschieht, für den der Betrachter verantwortlich ist. Das Bild ist weder nur an der Wand noch allein im Kopf, sondern es ist das Ergebnis der Interaktion zwischen Betrachter und Artefakt. ${ }^{8}$

\footnotetext{
${ }^{4}$ AlBRECHT, Kunst-Geschichte-Wahrnehmung, S. 10.

${ }^{5}$ LENTES, Inneres Auge, S. 191.

${ }^{6}$ SINGER, Das Bild in uns, S. 114. Forschungen der Neurobiologie bestätigen, dass das Gehirn ein aktives selbstreferentielles System ist, das auf sein eigenes Wissen zurückgreift.

7 Belting, Die Herausforderung, S. 11-23, bes. S. 16.

8 Ders., Bildanthropologie, S. 19.
} 


\section{Zwei Bilder}

Das Bild „The Existence of a Cripple No. 1“ [Abb. 1] von Gottfried Brockmann ist ein kleinformatiges, vielleicht sogar unscheinbares Bild, das zusammen mit zwei weiteren Bildern aus dieser Serie an einer kleinen Seitenwand im Museum of Modern Art in New York ausgestellt ist. Die drei zu sehenden Figuren heben sich nur leicht farblich von dem dunkleren braunen Hintergrund ab. Ihre formale Gestaltung erinnert an Gliederfiguren, die ein wiederkehrendes Motiv in Brockmanns Werk darstellen. Die auf wenige Glieder stilisierten Körper lassen sich trotz ihrer Abstraktheit als Menschen identifizieren. Aufgrund fehlender Füße, können sie sich nur kriechend und mithilfe von Handbänken fortbewegen. ${ }^{9}$

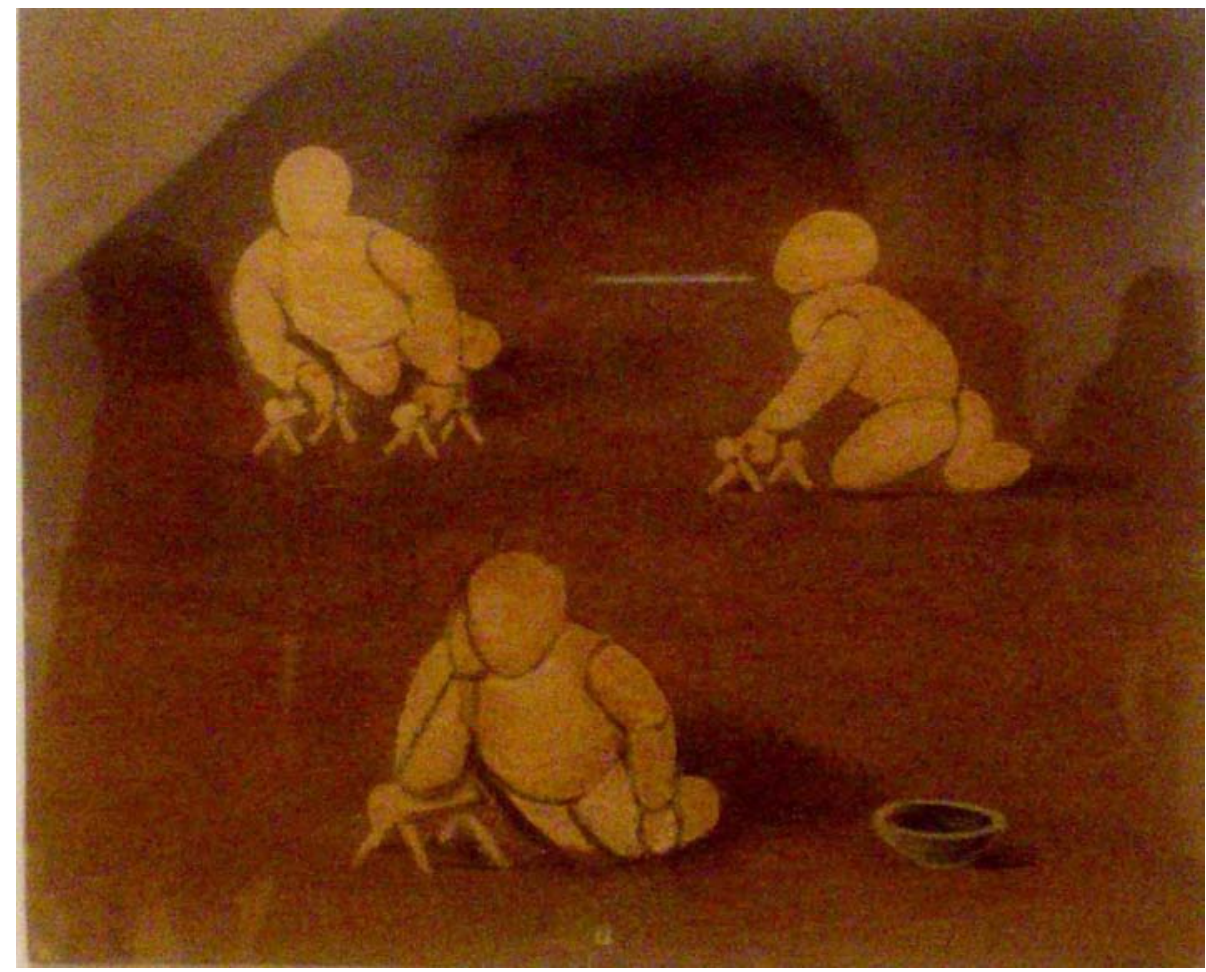

[Abb. 1, Gottfried Brockmann, The Existence of a Cripple N. 1]

Das Bild mag in diesem Zusammenhang ungewöhnlich erscheinen, da es nicht in den Untersuchungsrahmen der Vormoderne fällt. Doch lässt es sich nicht vermeiden, dass das gespeicherte immaterielle Bild die Wahrnehmung beeinflusst, wenn ein weiteres materielles hinzukommt. In der Kombination mit dem Freskenzyklus des 15. Jahrhunderts [Abb. 2], in dem das Wirken und die Martyrien der Heiligen

${ }_{9}^{9}$ Zur weiteren Vertiefung Brockmanns, s. THIELE, [...] zu der Frage. 
Laurentius und Stephanus erzählt werden und sich in der Privatkapelle Nikolaus' V. im Vatikan befindet, beginnen die sich die Wahrnehmungsmechanismen zu verzahnen.

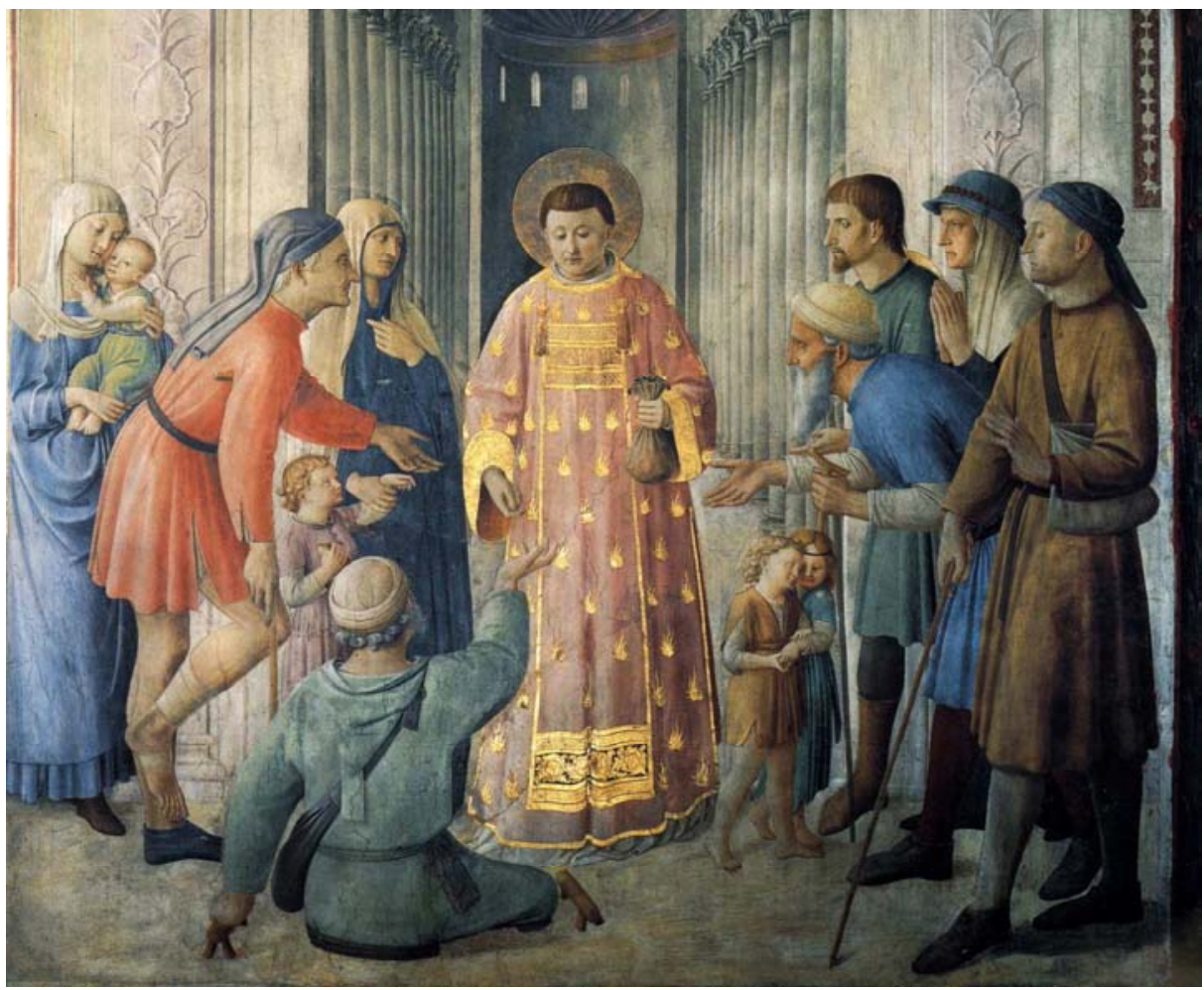

[Abb. 2, Fra Angelico, Der Hl. Laurentius verteilt den Kirchenschatz an die Armen]

Das Bild von Fra Angelico zeigt einen Ausschnitt aus dem Leben des H1. Laurentius. Zu sehen ist der Moment, in dem der Heilige den ihm übergebenen Kirchenschatz an Bedürftige verteilt. ${ }^{10}$ In der Mitte, vor dem Hintergrund des perspektivisch weit in die Tiefe gehenden Kirchenraumes, steht der Hl. Laurentius dem Be-

\footnotetext{
10 KelLer, Lexikon, Eintrag Laurentius, S. 388: „Seinem Archidiakon L. gibt Papst Sixtus II. (257258), als L. ihm zutiefst bekümmert zur Hinrichtung folgen will, den Auftrag, den Kirchenschatz Leidenden und Armen auszuteilen. Er tröstet seinen Lieblingsschüler mit der Verheißung, daß er ihm in drei Tagen nachfolgen werde. Kaiser Valerian (253-56?) erhebt Anspruch auf die Schätze. Um L. zur Herausgabe zu zwingen, wird er mehrfach gegeißelt. Er erbittet sich 3 Tage Zeit, lässt die durch den Verkauf der Schätze geheilten [dieser Aspekt der Heilung scheint mir wichtig zu sein. Stellt er nicht einen grundlegenden Unterschied zur Moderne dar?] und christlich gewordenen Armen kommen und weist auf die nun vorhandenen wahren Schätze des Himmels hin. Der erboste Valerian lässt L. mit Bleiklötzen schlagen, zwischen glühende Platten legen, versucht vergeblich, ihn zum heidnischen Opferdienst zu zwingen, und befiehlt, den Unerschütterten über stetig unterhaltenem Feuer auf einem Rost langsam zu Tode zu martern."
} 
trachter frontal gegenüber. Der Heiligenschein und die prachtvolle klerikale Kleidung grenzen ihn deutlich von der ihn umringenden Figurenschar ab. In der linken Hand des Heiligen befindet sich der Kirchenschatz und mit der rechten Hand ist er gerade dabei, Teile davon zu vergeben. Die im Dreiviertelprofil dargestellten Figuren um Laurentius herum erscheinen uns bedürftig und richten ihre ganze Aufmerksamkeit auf ihn. Nur die links im Bild stehende weibliche Figur mit einem Säugling auf dem Arm wirkt unbeteiligt am Geschehen. Im flüchtigen Blick lässt sich keine ,Behinderung' an ihr wahrnehmen, im Gegensatz zu den zwei deutlich gekrümmten männlichen Figuren, die sich jeweils auf eine Gehhilfe stützen. Die am rechten Bildrand stehende Figur zeigt zwar keine sichtbare relevante deformierte Körperlichkeit, jedoch wird sie durch den Stab, der als Blindenstock gedeutet werden kann, als blind wahrgenommen. Unterstützt wird diese Annahme durch die Darstellung der Augenpartie. Im Vordergrund des Bildes hebt sich eine sitzende Figur besonders hervor. Das Gesicht ist dem Betrachter verborgen, nur der Hinterkopf ist sichtbar und trotzdem erscheint es uns, als dass sich die Blicke dieser Figur mit denen Laurentius' treffen. Der rechte Arm ist gehoben und mit der geöffneten Handfläche nimmt sie goldene Münzen des Kirchenschatzes entgegen. Diese bildlich konstruierte Verbindung stellt die beiden Figuren in das Zentrum des Bildes.

Die im Mittelpunkt gesetzte Figur hockt am Boden und kann sich nur mithilfe von Handbänkchen und einer flachen Sitzhilfe fortbewegen. Gestik, Körperhaltung und das Handbänkchen animieren schnell unser Bildgedächtnis, sich an die Gliederfiguren von Brockmann zu erinnern [Abb 1.]. Der komplexe Apparat von Wahrnehmungs- und Vorstellungswelt hat somit angefangen zu arbeiten und es stellt sich die Frage: Ist die Figur nun tatsächlich als gelähmt sichtbar gemacht worden oder beruht diese Annahme eben auf diesen Mechanismen? Die angesprochenen beiden Bilder aus zwei weit entfernten Epochen zeigen Körper, die aufgrund ihres Beinverlustes und nach den Klassifikationen von Behinderung und Normalität der Weltgesundheitsorganisation ${ }^{11}$ heute als behindert eingestuft werden. Wir haben die stilisierten Gliederfiguren bei Brockmann [Abb.1], die zwei gebückten Figuren mit Krückstock, die kriechende Figur im Vordergrund und die stehende Figur, die blind erscheint [Abb. 2]. Kaum ein moderner Betrachter würde diese Figuren nicht der Kategorie Behinderung zuschreiben.

Wie schon angedeutet, muss das Phänomen der ,Behinderung' also komplexer gedacht werden. Für die Untersuchung der Vormoderne gibt es allerdings ein schwerwiegendes Problem: Das Phänomen der ,Behinderung', nach unserem heutigen Verständnis, lässt sich erst in den modernen bürgerlichen Gesellschaften Europas seit der Aufklärung nachweisen. Für frühere, vormoderne Zeiten, lässt sich eine solche heterogene Gruppe, wie Menschen ,Behinderung ${ }^{6}$ sie heute darstellen, nicht festmachen.

${ }^{11}$ Vgl. http://www.who.int/classifications/icf/en/ (Stand: 07.03.2011). 
Wenn es den Begriff und das Phänomen der ,Behinderung' nun in der mittelalterlichen Sprachenwelt nicht gibt, stehen wir vor dem Problem, etwas für die Zeitgenossen anscheinend Unbekanntem auf die Spur zu kommen und etwas benennen zu wollen, dass es für sie so gar nicht gab. . Begriffe, wie bresthaft, siech, mangelhaft, gebrechlich, infirmus, debilis und auch krippl abgeleitet von mhd. kriechen Bezeichnungen für jemanden, der als krumm, lahm und arm galt - sind Versuche, ein entsprechendes mittelalterliches Vokabular ausfindig zu machen. ${ }^{12}$ Homo debilis ist eine Benennung, die $\mathrm{m}$. E. noch am ehesten dem Phänomen gerecht werden kann, da debilitas sich

nicht nur auf Krankheiten (und, mehr noch, allgemein auf Schwäche) bezieht, sondern vielfältige weitere Ursachen haben konnte (wie Alter, Verwundung, Mangel) und letztlich eine ,Behinderung $^{6}$ jeglicher Art anzeigt. Nach mittelalterlicher Vorstellung ordneten sich die ,debiles demnach in eine umfassende Sicht von (allgemeiner) Einschränkung der natürlichen menschlichen Lebenskraft ein. ${ }^{13}$

Damit kommt homo debilis dem heutigen allgemeinen Verständnis von Behinderung nahe. Jedoch kann auch er letztendlich nicht zufriedenstellend sein.

\section{Medizinischer vs. kultureller Blick}

Die Diskussion der sprachlichen Benennung ist zu einer Grundsatzdiskussion der Dis/ability Studies avanciert. Teilweise führt sie dazu, neue Begriffe zu verwenden, wie ,Menschen mit einer Beeinträchtigung' oder ,Menschen mit besonderer Begabung'. ${ }^{14}$ Die oft benutzte Verwendung von ,Beeinträchtigung ${ }^{6}$ verweist sicherlich auf einen kritischen Umgang mit ,Behinderung“. Im Endeffekt sind sie beide jeweils austauschbar und (auf gleiche Art und Weise) konstruiert. ${ }^{15}$ Die Problematik der Benennung erweitert sich im Falle der Erforschung der mittelalterlichen Bilderwelt um eine dritte Komponente, die auf eine weiteren bildspezifischen Eigenschaft beruht: das immer wiederkehrende Problem, die Bildsprache in eine verbale Sprache übertragen zu wollen.

Die Szenerie der Mantelteilung des Hl. Martins, ein Tafelbild in der Nachfolge Konrad Witz [Abb. 3], findet vor der Kulisse einer Stadtlandschaft auf der linken, und einer aus Feldern bestehenden Landschaft auf der rechten Bildhälfte, statt. Am Horizont lässt sich im Dunst der Verblauungsperspektive die Silhouette einer wei-

\footnotetext{
12 MÜRnER, Bildnis und Behinderung, S. 173.

13 GOETZ, Debilis, S. 50.

${ }^{14}$ FELKENDORFF, Ausweitung; SCHNOOR, Über die Schwierigkeit, S. 171-173.

15 ,Trotz Belastungen, Negativismen und Verengungen, die der Begriff Behinderung transportiert, und trotz der mit ihm verbundenen praktisch-gesellschaftlichen Folgen wird er in den Disability Studies weitgehend beibehalten. Dies nicht nur deshalb, weil sich andere Begriffe als ungeeignet erwiesen haben, sondern vor allem mit dem positiven Ziel, ihm einen veränderten Sinn zuzuweisen." DEDERICH, Körper, Kultur und Behinderung, S. 50.
} 
teren Stadt ausmachen. Insgesamt sind sieben Figuren auf dem Bild, wobei zwei den Mittelpunkt des Bildes einnehmen. Die als relevant wahrgenommene Figur befindet sich am unteren mittleren Bildrand. Sie stellt den nach der Legende beschriebenen Armen dar, „der kaum Kleidung an sich trug und noch von keinem ein Almosen empfangen hatte“. ${ }^{16}$

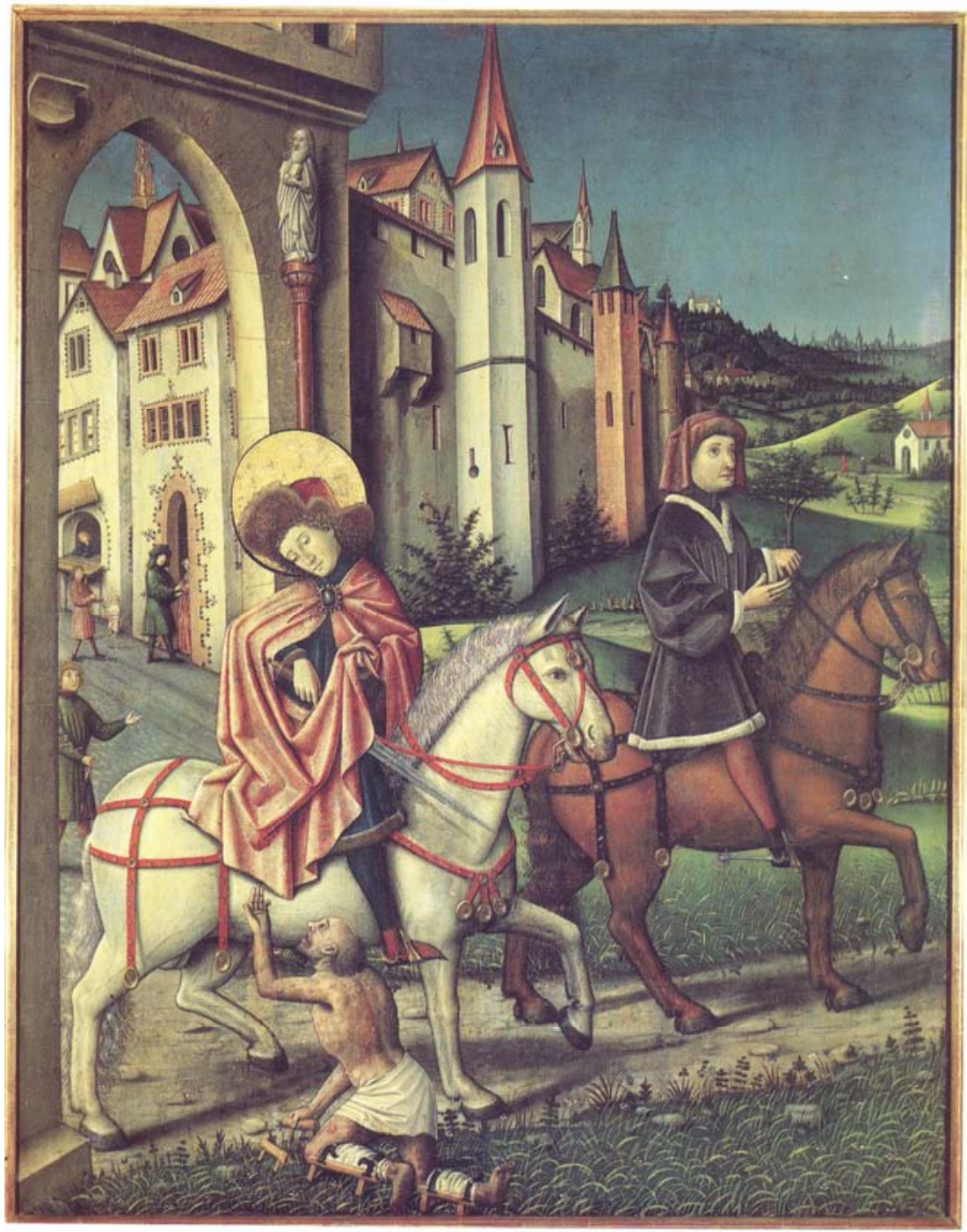

[Abb. 3, Konrad Witz Nachfolge, Meister von Sierentz, Hl. Martin teilt seinen Mantel]

${ }^{16}$ Jacobus von Voragine, Legenda aurea, S. 217. 
Nur mit einem Lendentuch bedeckt, kniet die ikonographisch als Bettler ausgeschriebene Figur vor dem Hl. Martin, der - hoch über ihm auf einem Pferd sitzend - in diesem Moment das Schwert zum Teilen seines Mantels ansetzt. Der Bettler kann anscheinend seine Beine nicht bewegen, was durch eine Verdrehung des rechten Beines dem Betrachter sichtbar wird. Als Hilfsmittel lassen sich auch hier die aus den vorherigen Bildern bekannten Handbänkchen vermuten. In ähnlicher Art finden sich diese auch als Beinschienen an den Unterschenkel der Figur wieder. Die Haut der nackten Figur ist übersät von Pusteln und kleinen Wunden, und so wie der kahle Kopf mit seinen großen Augen sich dem Heiligen zuwendet, lässt er sich möglicherweise mit dem von HELAS gebrauchten Begriff, erbarmungswürdig ${ }^{17}$ beschreiben. Was ist jedoch ,erbarmungswürdig' für eine Bezeichnung für diese sichtbar wahrnehmbar körperlich deformierte Figur?

Der Begriff ,erbarmungswürdig' lässt sich keineswegs mit ,Behinderung' gleichsetzen; genauso wenig können die Figuren, die für eine Untersuchung des Phänomens ,Behinderung' als relevant angesehen werden können, damit zusammenfassend beschrieben werden. Auch wenn manche der als ,erbarmungswürdig ${ }^{6}$ gesehenen Gestalten Einzug in das Quellenkorpus erhalten, kann der Begriff keine adäquate Bezeichnung darstellen. Weder kann er bei der Bildrecherche hilfreich sein, geschweige denn einem Forschungsansatz gerecht werden, der davon ausgeht, „dass ,Behinderung" nicht einfach vorhanden ist, sondern hergestellt wird, produziert und konstruiert in wissenschaftlichen und alltagsweltlichen Diskursen, in politischen und bürokratischen Verfahren und in subjektiven Sichtweisen und Identitäten. "18 Im Grunde erfasst der Begriff ,Behinderung" höchst vielfältige körperliche Erfahrungen und Fähigkeiten. Letztendlich ist ,Behinderung' keine fixe Kategorie, sondern eher eine Art Oberbegriff, der ,eine bunte Mischung von unterschiedlichen körperlichen und kognitiven Merkmalen vereint, die oft nichts anderes gemein haben als das soziale Stigma der Begrenzung, Abweichung und Unfähigkeit" ${ }^{19}$ Erst die gemeinsame Assoziation dieser Merkmale stellt die gesellschaftliche Identität von Menschen her, die dann unter ,Behinderung' gefasst wird, eine Assoziation, die konsequenterweise auch bei einer Zusammenstellung des überlieferten Bildmaterials erfolgt.

„Behinderung', gedacht als soziokulturelles Konstrukt, eröffnet die Hinterfragung dieser Kategorie - ,Behinderung neu denken' ist eine oft geäußerte Forderung. Im Grunde ist es der Versuch, dem bisherigen ,klinischen Blick', wie es FOUCAULT formuliert, ${ }^{20}$ einen ,kulturwissenschaftlichen Blick ${ }^{6}$ entgegen zu halten. Eine Form des ,medizinischen Blicks' lässt sich auch verstärkt in der bisherigen mediävistischen, kunstwissenschaftlichen Forschungsliteratur ausmachen, die sich im weitesten Sinn dem Thema ,Behinderung's stellt. Hauptsächlich von Medizinern

\footnotetext{
${ }^{17}$ Helas, Der Körper des Bettlers, S. 369.

18 WALDSCHMIDT, ,Behinderung' neu denken, S. 13.

${ }^{19}$ Ebd.

${ }^{20}$ Foucault, Die Geburt der Klinik.
} 
verfasst, sind diese Bildanalysen oft ein Versuch, eine nachträgliche Diagnose stellen zu wollen. Eine Herangehensweise, die der Gefahr unterliegt, (mittelalterliche) Bilder als ein Abbild der Wirklichkeit zu sehen und in ihnen ,naturwissenschaftliche“ Abbildungen ${ }^{21}$ von körperlichen Krankheitssymptomen ausmachen zu können, wobei es hinlänglich bekannt ist, dass „bildliche Krankendarstellungen und deren Interpretation als Nachweismittel am aussageschwächsten" sind.22

Ein Beispiel für eine solche Vorgehensweise ist SEIDENBusCHS Analyse des Bilds [Abb.4] „Fürbitte des seligen Luca Belludi“ aus der Conti-Kapelle in Padua.

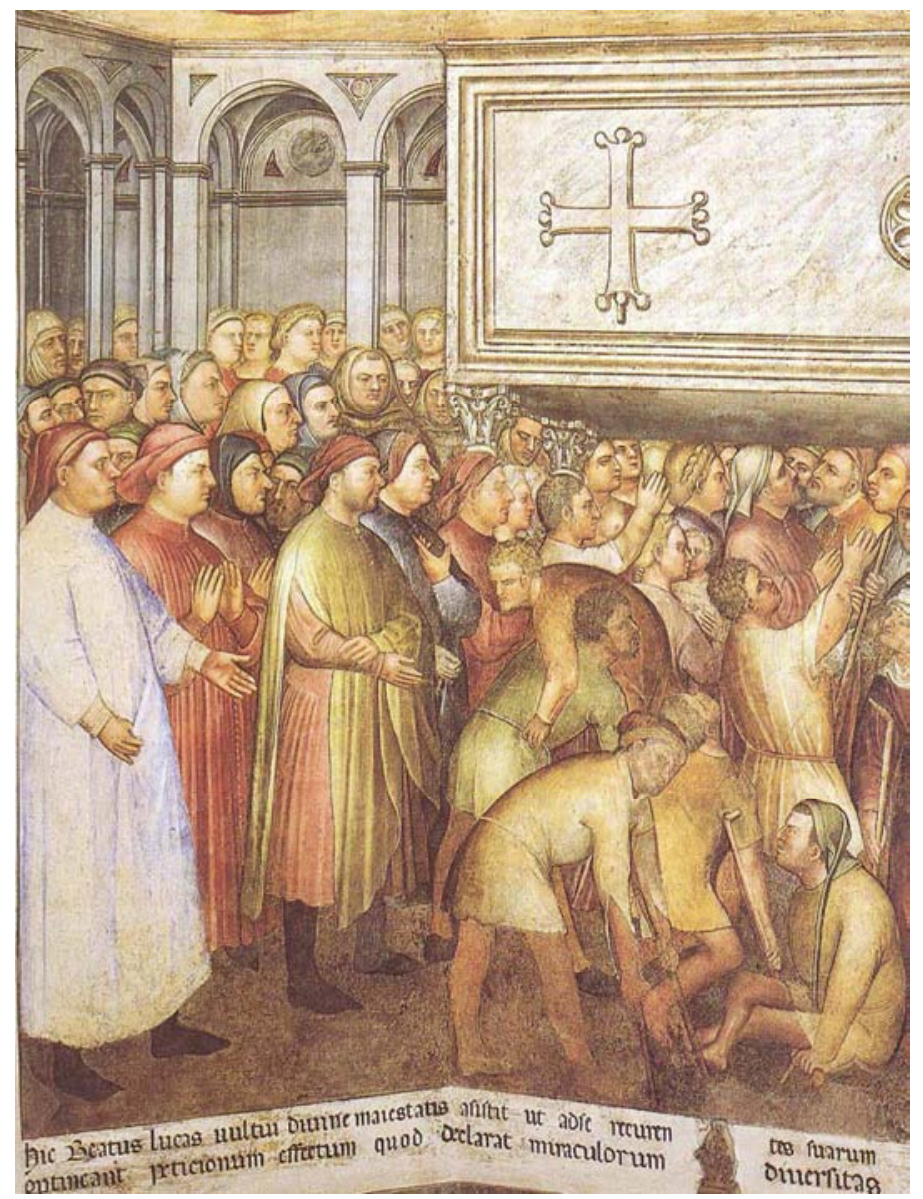

[Abb. 4, Giusto de’ Menabuoi, Fürbitte des Seligen Luca Belludi]

\footnotetext{
${ }^{21}$ Es gilt zu bedenken, dass wir uns in einer Zeit befinden, in der die Anatomiestudien noch in ihren Kinderschuhen stecken.

22 SCHELBERG, Leprosen.
} 
Am rechten unteren Bildrand befinden sich mindestens drei Figuren, die sich in die bisher vorgestellte Gruppe ,behinderter' Figuren einreihen. Die beiden vorderen, stehenden Figuren stützen sich gebückt auf zwei Gehhilfen. Auf gleicher Bildebene ist eine sitzende Figur wahrnehmbar, deren Beine ungewöhnlich übereinander geschlagen sind. Die Beine wirken verkürzt gegenüber dem Rest des Körpers, und auch hier finden sich die Handbänkchen, die in allen besprochenen Bildern auftauchen. SEIDENBUSCHS Bilduntersuchung zu den Figuren klingt dann wie aus dem Vokabular einer Krankenakte entnommen. „Varus-Stellung“, „Anklyklose des Kniegelenks“ oder „spastische Lähmung“ sind Begriffe für die Figurenbeschreibungen unterhalb des Sarges von Luca Belludi. ${ }^{23}$ SEIDENBUSCH bleibt so der Diagnose von Symptomen verhaftet und dezimiert damit die Erkenntnismöglichkeiten, da ein solcher Blick sich einzig auf den Mangel richtet und auf der überholten Ansicht beruht, es handele sich um zeitlich universale Annahmen.

Im Gegensatz zum ,medizinischen' soll der ,kulturwissenschaftliche Blick', deren Ansatz auch die Autorin verfolgt, aufzeigen, dass es große Unterschiede in den Sichtweisen von ,Behinderung ${ }^{6}$ und im Umgang mit behinderten Menschen gegeben hat. METZLER ${ }^{24}$ hat mit ihrer Arbeit den ersten Anlauf genommen, diesen tradierten Vorstellungen ein Bild vom Mittelalter gegenüber zu stellen, das sich keineswegs durchgängig durch Vernachlässigung, Verstoßung oder Ermordung von Behinderten auszeichnet. ${ }^{25}$ Es wird deutlich, dass die Bandbreite der familiären und gesellschaftlichen Reaktionen groß gewesen ist, die auch die Sorge und Pflege miteinschloss, wie HORN in seiner Auswertung von frühmittelalterlichen Mirakelberichten aufgezeigt hat. ${ }^{26}$

\section{Wahrnehmbarer Ansatzpunkt}

,Beeinträchtigung', ,Schädigung ${ }^{6}$ und ,Behinderung' sind soziokulturell konstruierte Phänomene, ${ }^{27}$ die für die Untersuchung mittelalterlicher Bilderwelten nicht oder nur bedingt geeignet sind.

Das daraus resultierende Problem des fehlenden Ansatzpunktes ist nicht nur ein Problem der Historiker. Innerhalb der ,Dis/ability Studies' muss sich ihm der Teil der Forscher stellen, der ,Behinderung' und ,körperliche Schädigung' auf zwei getrennten Ebenen untersucht. ${ }^{28}$ Den ,Körper ${ }^{`}$ auszuschließen birgt jedoch die Gefahr, das überholte individuelle Modell (bzw. medizinische Modell) letztlich unter neuen Vorzeichen zu reproduzieren und die Körper als ahistorische Objekte zu degradieren. Es ist zwar richtig, dass die Abweichung am Körper nicht unbe-

\footnotetext{
${ }^{23}$ SeIDEnBusCH, Kunst und Medizin, S. 55-56.

24 MeTZLer, Disability.

${ }^{25}$ FANDREY, Krüppel, Idioten, Irre.

${ }^{26}$ HORN, Überleben in der Familie.

${ }^{27}$ Hughes, The Social Model.

28 WALDSCHMidT, Macht-Wissen-Körper, S. 61.
} 
dingt eine Behinderung hervorrufen muss, allerdings ist der Körper in seiner wahrgenommenen Andersheit durchaus zentral. Die Ebenen der Schädigung und der Behinderung sind zwar nicht identisch, sie sind aber auch nicht strikt voneinander getrennt, sondern auf eine Weise, die viel mit der sichtbaren Wahrnehmung zu tun hat, miteinander verbunden. ${ }^{29}$

Besonders WALDSCHMIDT plädiert dafür FOUCAULT'sche Theorien und Methoden in die Herangehensweisen der Dis/ability Studies aufzunehmen. Da mit ihm gesprochen, die Schädigung eines Körpers zwar auch ein Effekt, und somit „abgeleitet aus und hergestellt in Diskursen“,30 doch sage er selbst, dass man gleichzeitig - wie bei jedem diskursiven Effekt - auch immer einen konkreten, materiellen Ansatzpunkt benötige. Mit FOUCAULT den ,behinderten' Körper zu analysieren heißt zuzugestehen, dass es ihn als definierbare, abgrenzbare und erkennbare Einheit gibt. ${ }^{31} \mathrm{Um}$ für die mittelalterliche Bilderwelt, in diesem Sinn einen ,Ankerpunkt ${ }^{`}$ festmachen zu können, kann das Konzept der ,verkörperten Andersheit ${ }^{`}$ Abhilfe schaffen. Dieses versucht nun den visuell und phänomenal wahrnehmbaren ,Körper ${ }^{6}$ und ,Behinderung' zusammen zu führen, um dann die historischen Prozesse untersuchen zu können, ohne den Körper und die Behinderung dabei gleich zu setzen. Konkret heißt das, die sichtbar wahrnehmbare deformierte/andersartige Verkörperung im überlieferten Bild zum Gegenstand der Untersuchung zu machen. Wichtig ist dabei zu betonen, dass dieser Ansatz zunächst nur bedeutet, dass körperliche Merkmale als auffällig oder anders wahrgenommen werden ,können'. Aus dieser Wahrnehmung kann dann, muss aber nicht, die Zuordnung, Behinderung' hervorgehen. ${ }^{32}$

In fast keinem Beitrag der den Dis/ability Studies nahe stehenden Wissenschaftler fehlt der Hinweis, dass die wahrgenommene körperliche Andersheit (von der Norm, Normalität) vor allem über den Blick hergestellt wird. ${ }^{33}$ Obwohl man sich darüber einig ist, das „Behinderung [...] in der sinnlichen [visuellen] Wahrnehmung [existiert]“" und ,,[d]er behinderte Körper [sich in ihr] verkörpert" ${ }^{34}$ gibt es erst wenige Analysen, von vormodernen Untersuchungen ganz zu schweigen, die sich mit der „materialisierten visuellen Kultur" auseinandersetzen. ${ }^{35}$ Schon GOFFMAN hat festgestellt, dass Visualisierungsprozesse eine bedeutende Rolle bei der Konstruktion von Behinderung spielen, indem er davon ausgeht, dass es die visuelle Aufmerksamkeit ist, die eine evidente Abweichung feststellt und festmacht. ${ }^{36}$ Das sichtbare „Stigma“ kennzeichnet den Körper, ob es die fehlenden,

\footnotetext{
${ }^{29}$ Hughes, The Social Model, S. 325-340.

30 WALDSCHMIDT, Macht-Wissen-Körper, S. 60.

${ }^{31}$ Ebd.

32 Zur Bedeutung des Blicks und der Sichtbarkeit für die Konstitution des ,behinderten Körpers' siehe DAVIS, Enforcing Normalcy; MöHRING, Kriegsversehrte Körper.

33 BösL, Dis/ability History.

${ }^{34}$ DAVIS, Enforcing Nomalcy, S. 13.

35 Ausnahme: MöHring, Kriegsversehrte Körper.

${ }^{36}$ Goffman, Stigma, S. 64.
} 
verkürzten oder unförmigen Gliedmaßen, die eigenwilligen Gestaltungen des Rumpfes, oder aber die Prothesen, Blindenstöcke oder Rollstühle sind. Es ist die auf diese Weise sichtbar gewordene deformierte Körperlichkeit, die eine Person im Sichtfeld hervorhebt und die Aufmerksamkeit auf sich lenkt. ${ }^{37}$

Über die sichtbare verkörperte Andersheit und die Wahrnehmung einer deformierten Körperlichkeit werden dann auch mittelalterliche Bilder für die Untersuchung relevant oder nicht. Die visuell wahrnehmbare ,deformierte Körperlichkeit‘ als Ansatzpunkt für eine Untersuchung des Phänomens Behinderung in mittelalterlichen Bildern ist der Versuch, das Hindernis, das sich aus der spezifischen Quelle (Bild) und dem spezifischen Thema (Behinderung) ergibt, zu überwinden. Allerdings soll weder die wahrgenommene ,deformierte Körperlichkeit' mit ,Behinderung' gleich gesetzt werden, noch soll behauptet werden, dass Figuren mit ,deformierter Körperlichkeit' nicht ,behindert' sind. Es geht um die materiell sichtbar gemachte Form von Körpern, von ,deformierter Körperlichkeit‘, die in Bildzeugnissen überliefert ist.

\section{Was bleibt}

Der Ausschnitt einer englischen Illumination zeigt [Abb.5], dass letztendlich auch dieser Ansatz nie eindeutig sein kann. Nach HÄGERMANN wird hier ein „Kind mit einer am Stock befestigten Tierblase“, einem beliebtem zeitgenössischem Spielzeug, gezeigt. ${ }^{38}$ Der Oberkörper ist frontal zum Betrachter hin ausgerichtet, der Kopf ist zur Seite gedreht und die Augen verweisen in eine Blickrichtung nach rechts oben zum Bildrand hin. In der rechten Hand hält das ,Kind' den Stock, die linke Hand hat es so zum Mund geführt, dass mindestens der heutige Betrachter den Eindruck gewinnt, es schaue erstaunt und fragend. Die Beine erscheinen ungewöhnlich verdreht und der linke Fuß weist nur zwei Zehen auf.

Handelt es sich bei dieser menschlichen Figur nun um eine deformierte Körperlichkeit oder handelt es sich um ein ,Unvermögen' des Zeichners? Die Frage lässt sich hier nicht eindeutig beantworten. Wieso mittelalterliche Bilder immer mit einer gewissen Vorsicht zu behandeln sind, beschreibt HELAS passend, wenn sie sagt: „Bilder sind niemals planer Spiegel der Wirklichkeit - jeweils bedingt durch die Interessen und Fähigkeiten von Auftraggeber und/oder Künstler konstruieren sie eine eigene Welt, die ihrerseits aber wiederum zum Verständnis großer sozialhistorischer Zusammenhänge beitragen kann“.39

\footnotetext{
37 Ebd.

38 Hägermann, Das Mittelalter, S. 160.

39 Helas, Bilder der Armut, S. 20.
} 


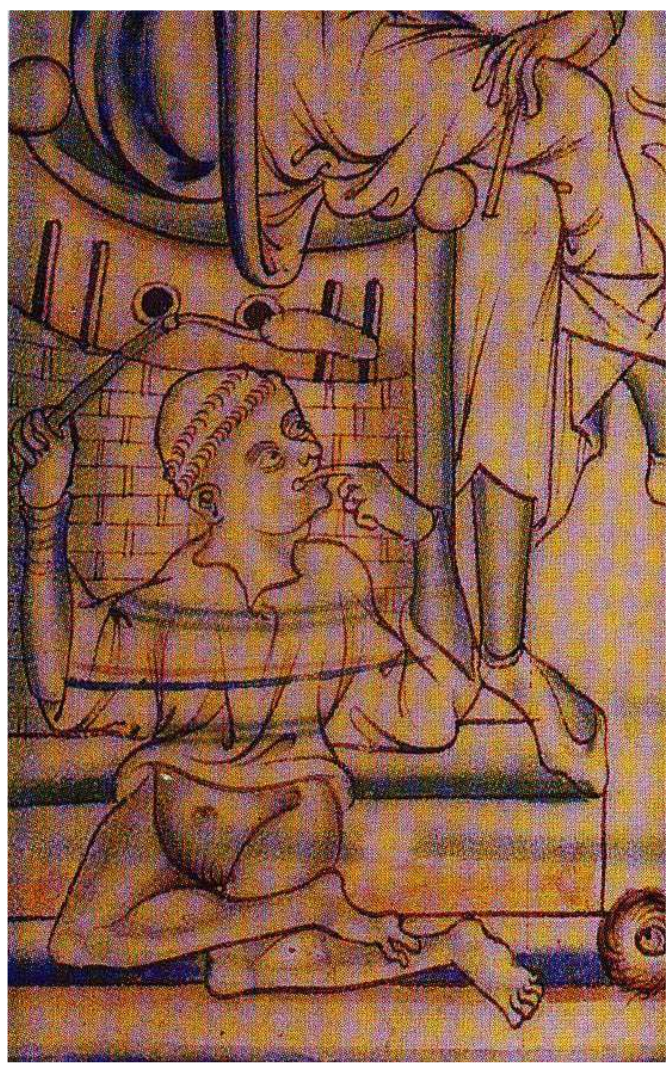

[Abb. 5, Englische Miniatur]

Mit den vorangegangenen Überlegungen soll aufgezeigt werden, dass die eigene körperliche Fremd- und Selbstwahrnehmung, verbunden mit den gegenwärtigen Bedingungen der Wahrnehmungen und Vorstellungen von Behinderung, eine große Rolle spielt. Die Sicht von ,Behinderung' in der Welt des Mittelalters kann nur über den (Um)Weg unserer eigenen Vorstellungen untersucht werden. Um der Gefahr zu entgehen, tradierten Vorstellungen nachzulaufen, muss also auch unser eigenes ,Bild“ (Vorstellung) von ,Behinderung' hinterfragt werden. Erst auf diesem Wege kann ein Ansatzpunkt der sichtbaren deformierten Körperlichkeit eine Perspektive einnehmen, die neue Erkenntnisse über das Bild von und die Sicht auf deformierte Körperlichkeit von visualisierten Menschenfiguren erbringen kann, die sich aus umfassenden bild-, kunst- und sozialwissenschaftlichen Kontextuntersuchungen ergeben. 


\section{Abbildungen}

[Abb. 1] Gottfried Brockmann, The Existence of a Cripple N. 1 (1922/23) - New York, Museum of Modern Art, Gouache auf Tafel, 17,8 x 21,9 cm. Bildnachweis: Sarah Harms.

[Abb.2] Fra Angelico, Der Hl. Laurentius verteilt den Kirchenschatz an die Armen (1448/50) - Vatikan, Cappella Niccolina; Freskomalerei; unteres Register, rechte Szene. Bildnachweis: Foto Servizio Fotografico dei Musei Vaticani - (C) Musei Vaticani.

[Abb.3] Konrad Witz Nachfolge (Meister von Sierentz), Hl. Martin teilt seinen Mantel (um 1450) - Basel, Kunstmuseum Basel, Inv. Nr. 32, Tempera auf Holz. Bildnachweis: Bildarchiv Foto Marburg.

[Abb.4] Giusto de' Menabuoi, Fürbitte des Seligen Luca Belludi (1382) - Padua, Sant'Antonio, Conti-Kapelle. Bildnachweis: HelAS, der Körper des Bettlers. Abb. 4, S. 384-385.

[Abb.5] Englische Miniatur (14. Jh.) MS. Auct. D.4.17 Apocalypse fol. 002v Oxford, Bodleian Library. Bildnachweis: HÄGERMANN, Das Mittelalter, S. 160, Abb. 163.

\section{Literatur}

Jacobus von Voragine, Legenda aurea. Die Heiligenlegenden des Mittelalters. Hrsg. v. MatTHias HaCKEMANN. Köln 2008.

\section{Forschung}

Albrecht, Gory u. a. (Hrsg.), Handbook of Disability Studies. London 2000.

Albrecht, StePhan u. a., Kunst-Geschichte-Wahrnehmung. In: Dies. (Hrsg.) Kunst-Geschichte-Wahrnehmung. Strukturen und Mechanismen von Wahrnehmungsstrategien. Berlin/München 2008, S. 9-26.

Belting, Hans, Bildanthropologie. Entwürfe einer Bildwissenschaft. München 32007.

DERS., Die Herausforderung der Bilder. Ein Plädoyer und eine Einführung. In: DERS. (Hrsg.), Bilderfragen. Bildwissenschaften im Aufbruch. München 2007, S. 11-23.

BÖSL, ELSBETH, Dis/ability History: Grundlagen und Forschungsstand. In: http:/ hsozkult.geschichte.hu-berlin.de/forum/id=1113\&type=forschungsber ichte\&sort $=$ datum\&order $=$ down\&search $=b \% C 3 \% B 6 s l$ (Stand: 07.03.2011). 
DAvis, Lennard J., Enforcing Normalcy: Disability, Deafness, and the Body. London 1995.

Dederich, Markus, Körper, Kultur und Behinderung. Eine Einführung in die Disability Studies. Bielefeld 2007.

FANDREY, WALTER, Krüppel, Idioten, Irre. Zur Sozialgeschichte behinderter Menschen in Deutschland. Stuttgart 1990.

FELKENDORFF, KAI, Ausweitung der Behinderungszone: Neuere Behinderungsbegriffe und ihre Folgen. In: ClOERSKE, GÜNTHER (Hrsg.), Wie man behindert wird. Texte zur Konstruktion einer sozialen Rolle und zur Lebendsituation behinderter Menschen. Heidelberg 2003, S. 25-52.

FOUCAUlT, MiCHEL, Der Wille zum Wissen. Sexualität und Wahrheit. Frankfurt a. M. 1983.

DERS., Die Geburt der Klinik. Eine Archäologie des ärztlichen Blicks. Frankfurt a. M. ${ }^{8} 2008$.

GOFFMAN, ERving, Stigma. Über Techniken der Bewältigung beschädigter Identität. Frankfurt a. M. 1974.

GOETZ, HANS-WERNER, Debilis. Vorstellungen von menschlicher Gebrechlichkeit im frühen Mittelalter. In: NOLTE, CORDulA (Hrsg.), Homo debilis. Behinderte - Kranke - Versehrte in der Gesellschaft des Mittelalters (Studien und Texte zur Geistes- und Sozialgeschichte des Mittelalters 3). Korb 2009, S. 21-56.

HÄgermann, Dieter u. SCHneIDER, Rolf (Hrsg.), Das Mittelalter. Die Welt der Bauern, Bürger, Ritter und Mönche. München 2001.

Helas, Philine, Bilder der Armut und gesellschaftliche Praktiken. Einleitung. In: DIES. (Hrsg.), Armut und Armenfürsorge in der italienischen Stadtkultur zwischen 13. und 16. Jahrhundert. Bilder, Texte und soziale Praktiken. Frankfurt a. M. 2004, S. 13-28.

DIES., Der Körper des Bettlers. Zur Darstellung und Ausblendung von körperlicher Versehrtheit in der italienischen Kunst zwischen dem 14. und frühem 16. Jahrhundert. In: NOLTE, CORDulA (Hrsg.), Homo debilis. Behinderte Kranke - Versehrte in der Gesellschaft des Mittelalters (Studien und Texte zur Geistes- und Sozialgeschichte des Mittelalters 3). Korb 2009, S. 369-392.

HORN, KLAus PETER, Überleben in der Familie - Heilung durch Gott. Körperlich beeinträchtigte Menschen in den Mirakelberichten des 9. und 10. Jahrhunderts. In: Nolte, Cordula (Hrsg.), Homo debilis. Behinderte - Kranke Versehrte in der Gesellschaft des Mittelalters (Studien und Texte zur Geistesund Sozialgeschichte des Mittelalters 3). Korb 2009, S. 303-316. 
Hughes, Bill u. Paterson, Kevin, The Social Model of Disability and the Disappearing Body: Towards a Sociology of Impairment. In: Disability and Society 12 (1997), S. 325-340.

KelLer, HiltgarT, Lexikon der Heiligen und biblischen Gestalten. Legende und Darstellung in der bildenden Kunst. Stuttgart 102005.

LENTES, ThOmAs, Inneres Auge, Äußerer Blick und heilige Schau. Ein Diskussionsbeitrag zur visuellen Praxis in Frömmigkeit und Moraldidaxe des späten Mittelalters. In: SCHREINER, KLAUS (Hrsg.), Gesellschaftliche, körperliche und visuelle Dimensionen mittelalterlicher Frömmigkeit. München 2002, S. 179219.

MellinkOFF, Ruth: Outcasts. Signs of Otherness in Northern European Art of the Late Middle Ages, Bd. 2. Berkeley u. a. 1993.

METZLER, IRINA, Disability in Medieval Europe: Physical Impairment in the High Middle Ages, c. 1100 - c. 1400 . London 2006.

MÖHRING, MAREN, Kriegsversehrte Körper. Zur Bedeutung der Sichtbarkeit von Behinderung. In: WALDSCHMIDT, ANNE u. SCHNEIDER, WERNER (Hrsg.), Kultursoziologie und Soziologie der Behinderung. Erkundungen in einem neuen Forschungsfeld. Bielefeld 2007, S. 175-197.

MÜRNER, CHRISTIAN, Bildnis und Behinderung - Wege der Interpretation zum Bildnis eines behinderten Mannes. In: FliEgER, PETRA u. SCHÖNWIESE, VOLKER (Hrsg.), Das Bildnis eines behinderten Mannes. Bildkultur der Behinderung vom 16. bis ins 21. Jahrhundert. Neu-Ulm 2007, S. 171-210.

Roettgen, StefFi, Wandmalerei der Frührenaissance in Italien. Bd. 1: Anfänge und Entfaltung 1400-1470. München 1996.

SCHELBERG, ANTJE, Leprosen in der mittelalterlichen Gesellschaft. Physische Idoneität und sozialer Status von Kranken im Spannungsfeld säkularer und christlicher Wirklichkeitsdeutungen. Göttingen 2000.

SCHNOOR, HEIKE, Über die Schwierigkeit, anders zu sein. Der behinderte Körper im Spannungsfeld zwischen Konstruktions- und Dekonstruktionsprozessen. In: Abraham, ANKE u. MÜller, BEATRICE (Hrsg.), Körperhandeln und Körpererleben. Multidisziplinäre Perspektiven auf ein brisantes Feld. Bielefeld 2010, S. 165-180.

Seidenbusch, ANTON, Kunst und Medizin in Padua. Würzburg 1972.

SINGER, WOLF, Das Bild in uns. Vom Bild zur Wahrnehmung. In: SACHSHOMBACH, KLAUS (Hrsg.), Bildtheorien. Anthropologische und kulturelle Grundlagen des Visual Turn. Frankfurt a. M. 2009, S. 104-127. 
Thiele, Gernot, [...] zu der Frage nach einer allgemein verbindlichen Aussage der Kunst. Strategien, Programme und Ideen im Werk Gottfried Brockmanns. Diss. Kiel 2003.

VAVRA, ElisabeTH (Hrsg.), Bild und Abbild vom Menschen im Mittelalter. Akten der Akademie Freisach. Stadt und Kultur im Mittelalter. Klagenfurt 1999.

Waldschmidt, AnNe, ,Behinderung' neu denken. Kulturwissenschaftliche Perspektiven der Disability Studies. In: Hermes, Gisela u. KöBSELl, Swantje (Hrsg.), Disability Studies in Deutschland - Behinderung neu denken! Kassel 2003, S. 11-22.

DIES. (Hrsg.), Kulturwissenschaftliche Perspektiven der Disability Studies: Tagungsdokumentation. Kassel 2003.

DIES., Macht-Wissen-Körper. In: DIES., Kultursoziologie und Soziologie der Behinderung. Erkundungen in einem neuen Forschungsfeld. Bielefeld 2007, S. $55-78$.

Weisser, Jan u. RengGli, Cornelia (Hrsg.), Disability Studies. Ein Lesebuch. Zürich 2004.

WUlf, Christoph, Anthropologie: Geschichte, Kultur, Philosophie. Reinbeck 2004.

\section{Internet}

Beschreibung des Forschungsprojektes „Homo Debilis“: http://www.geschichte.uni-bremen.de/?tag=homo-debilis (Stand 7.3.2011).

Bildindex der Kunst und Architektur: www.bildindex.de/\#|0 (Stand: 7.3.2010).

Weltgesundheitsorganisation; Klassifizierung von Behinderung: http://www.who.int/classifications/icf/en/ (Stand: 7.3.2011). 


\title{
Der Schnitt am Körper: Die Wirkung des malerischen und plastischen Sujets der Enthauptung
}

\author{
Katrin Weleda
}

\begin{abstract}
:
Death by decapitation, carried out by sword or axe, was considered as a merciful form of execution during the Middle Ages and therefore reserved for kings, knights, peers and, also, for martyrs. After the body had been separated from the head in a public execution, it was presented to the audience as evidence of the delinquent's death. This procedure has been termed ostentatio. Following the thesis that deformed bodies reveal new dimensions of perception of the self, but particularly of divinity, the article analyses Rogier van der Weyden's Altar of St. John the Baptist, Lucas Cranach's Salome and Judith and the Heads of St. John the Baptist by Andrea Solario and Juan de Mesa. It tries to outline in what way the subjects' spectator is involved in the transfer or interaction between the medium, including the knowledge of the narration, and his own body.
\end{abstract}

Der Tod durch Enthauptung mittels Schwert oder Beil galt im Mittelalter als ein leichter und gnadenvoller Tod. Aufgrund der Tatsache, dass der Delinquent vom Henker nicht direkt berührt wurde, war diese Art der Exekution sogar ehrenhaft, weshalb die Enthauptung auch privilegierten Gesellschaftsschichten vorbehalten war und als Strafe der Könige, der Adeligen und Ritter, sowie der Märtyrer galt. ${ }^{1}$

Nachdem Haupt und Körper voneinander getrennt waren, wurde der abgeschlagene Kopf bei einer öffentlichen Exekution als Beweis der Enthauptung dem

${ }^{1}$ Vgl. OHLER, Sterben und Tod, S. 215. 
Volk gezeigt. Dieser Vorgang, der zur drastischen Abschreckung diente, war Teil der Hinrichtung. Erst das Zur-Schau-stellen des Kopfes - der Gestus der ostentatio ${ }^{2}$ - ermöglicht eine Rezeption im Sinne des Forschungsansatzes dieser Tagung: „Deformierte Körper eröffnen neue Dimensionen der Wahrnehmung des eigenen Selbst, aber vor allem auch des Göttlichen“.

Die Deformierung des Körpers durch Enthauptung geschah als eine ,Strafe am Leib', die vom Henker oder Scharfrichter vollstreckt wurde. Er führte den Vorgang der Hinrichtung und die in vielen Fällen vorausgehende Folter durch. Die Qual der Folter und die anschließende Hinrichtung wurden bereits als Teil der ansonsten im Jenseits abzuleistenden Buße für das Verbrechen erachtet. Die entscheidende Rolle dabei spielt der Körper des Delinquenten, den FOUCAULT als den Ort der Wahrheit benennt, der durch die Folter als Methode der Wirklichkeitsproduktion erzeugt wird. ${ }^{3}$ Die Untersuchungen von BERGMANN verorten den Zusammenhang des Körpers mit dem Ort der Wahrheit konkret im historischen Kontext: „Diese Wahrheit, die das Unheil und vor allem die kollektive Erfahrung des Massentodes durch die Pest spiegelte und verkündete, schaffte der Henker aus der Welt, indem er - wie es damals hieß - eine Ent-Leibung des Hinzurichtenden vornahm und somit die Inkarnation des Unheils und des Todes, nämlich den Körper, vernichtete. “4 Das bedeutet, dass im Hinrichtungsritual der ,böse' in einen ,heilbringenden' Leib verwandelt wurde. Der Akt der Tötung wirkte demzufolge reinigend, und die positive oder auch ,heilende' Wirkung übertrug sich auf das Kollektiv. Der Henker hatte daher während der Hinrichtung nicht nur den sündigen Verurteilten von seiner Schuld zu befreien, sondern auch das Übel an sich, in Bezug auf die Gemeinschaft des Volkes, zu tilgen. Damit wäre die erste Berührung mit dem ,Göttlichen' angesprochen, denn, wie BERGMANN schreibt: „Der Scharfrichter vollstreckte eine heilige Handlung, er agierte als Opferpriester. In seiner Funktion des Erlösers tötete er den Sündenbock [...] ${ }^{\text {‘5 }}$.

Die Darstellungen der Enthaupteten Johannes und Holofernes, die ich hier vorstellen möchte, gehören zu der Kategorie des religiösen Bildes. Die Funktionen religiöser Bildwerke sind vor allem, das Göttliche oder Heilige sichtbar erscheinen zu lassen, zu vergegenwärtigen, in Erinnerung zu bewahren, über Inhalte der Religion zu belehren sowie zur Meditation einzuladen. ${ }^{6}$ Die Heiligkeit des Wortes und der Schrift stand im Christentum fest, die Haltung zum Bild war dagegen ein Problem und musste eigens definiert werden. Eine grundlegende Position zu diesem Thema formulierte Gregor I. bereits $600 \mathrm{n}$. Chr.: „Aliud est enim, picturam adorare, aliud, per picturae historiam quid sit adorandum, addiscere.“ („Eines ist es, ein Bild zu verehren, ein anderes, mit Hilfe eines Bildes eine Geschichte zu erzählen, die zu

\footnotetext{
2 KRÜGER, Gesichter ohne Leib, S. 202.

${ }^{3}$ Foudcault, Überwachen und Strafen, S. $44 f$.

${ }^{4}$ Bergmann, Töten, Opfern, Zergliedern, S. 50.

${ }^{5}$ Ebd., S. 52.

${ }^{6}$ Vgl. SCHOLZ, Bild, S. 632; SuCKale, Rogier, S. 52.
} 
verehren ist." ${ }^{7}$ Und ferner: „Idcirco enim pictura in Ecclesiis adhibetur, ut hi qui litteras nesciunt, saltem in parietibus videndo legant, quae legere in Codicibus non valent.“ („Die Bilder sollen deshalb in den Kirchen angebracht werden, damit jene, die nicht lesen können, wenigstens durch Betrachten der Wände lesen können, was sie in den Büchern nicht zu lesen verstehen." $)^{8}$ Wäre es dabei geblieben, hätte es den großen Bilderstreit im 8. und 9. Jahrhundert n. Chr. nicht gegeben, in dessen Folge es zu einer von gewaltsamen Ausschreitungen geprägten Auseinandersetzung zwischen Ikonodulen (Bilderverehrer) und Ikonoklasten (Bilderstürmer) kam.

Hervorzuheben für den angewandten bildtheoretischen Ansatz ist der Zusammenhang von Bilderstreit und Reformation, den ich hier kurz skizzieren möchte: Im Jahre 1522 brach in Wittenberg der Bildersturm aus. Andreas Bodenstein, genannt Karlstadt, forderte ein Bilderverbot, das sich aus dem im ersten Gebot enthaltenen Verbot der Fremdgötterei ergab. Aber viel bedeutender für das Volk war die Polemik gegen die Position Gregors I., wonach die Bilder als Bücher der Laien und Analphabeten fungierten. Nach der Meinung Karlstadts würde in der Konsequenz ein derartiger Bildgebrauch die unwissende Menge auch weiterhin vom Studium der Bücher fernhalten.

Nach Martin Luthers Ansicht - inzwischen erschien auch seine illustrierte Bibelübersetzung - seien die Bilder neutral und gehörten unter die Adiaphora, denn in ihrer Bedeutung des ,nicht Unterschiedenen', hätten sie weder als gut, noch als böse zu gelten. Luther hob sogar die verstärkte Wirkungskraft von Darstellungen des gekreuzigten Jesus hervor, bei deren Betrachtung die Leiden Christi stärker nachvollzogen werden könnten als durch die reine Textlektüre. ${ }^{9}$

Technische Neuerungen in der Darstellung, wie zum Beispiel die Einführung der Perspektive, die Entwicklung der Tafelmalerei oder eben auch Fragen nach der Intentionalität und Wirkungskraft, die auf den Bilderstreit übertragbar sind, werden in MiTCHELLS aktuellen bildwissenschaftlichen Forschungen als turn bezeichnet und eine Trope interpretiert, die zu verschiedenen historischen Anlässen auftaucht. ${ }^{10}$ Der pictorial turn ist gewöhnlich einer von Worten zu Bildern. Hierbei stehen die Worte in Verbindung mit dem Ausüben von Gesetzen und mit Lesekompetenz, die Bilder sind hingegen eher dem volkstümlichen Aberglauben und der Unbildung zugeordnet. Jede Zeit hat nach MiTCHELL ihren eigenen turn, der jeweils der besonderen historischen Situation entspreche.

An diesem Punkt, wo es um die Dar- und Zurschaustellung von Leiden in Verbindung mit dem Heiligen geht, komme ich auf den Kern meiner Untersuchung zurück: Der besonderen Ausdruckskraft und der damit verbundenen Wahrnehmung von Enthauptungsszenen und dem Vorzeigen des abgeschlagenen

\footnotetext{
7 Gregor an Bischof Serenus von Marseille (Okt. 600), in: Denzinger/Hünermann (Hrsg.), Enchiridion symbolorum definitionum [...]. Kompendium der Glaubensbekenntnisse und kirchlichen Lehrentscheidungen, S. 217. Zitat und Übersetzung nach SCHOLZ, Bild, S. 636.

8 Gregor, Registrum epistolarum 9, 105, S. 1027f. Zitat und Übersetzung nach ScHOLZ, Bild, S. 635.

${ }^{9}$ Luther, Wider die himmlischen Propheten, S. 82f.

${ }^{10}$ Mitchell, Vier Grundbegriffe, S. 322.
} 
Hauptes. Bei den mittelalterlichen und frühneuzeitlichen Darstellungen sind die kanonischen Modi und die Narration von besonderem Interesse.

Als erstes Beispiel möchte ich den Johannesaltar von Rogier van der Weyden (1399-1464) vorstellen. Er befindet sich in der Berliner Gemäldegalerie, stammt vermutlich aus der Brügger Jakobskirche und wurde wohl im Jahre 1456 angefertigt oder vollendet. Das Altarbild besteht aus drei Tafeln, von denen jede $77 \mathrm{x}$ $48 \mathrm{~cm}$ misst. Ich konzentriere mich im Folgenden auf die rechte Tafel des Triptychons.
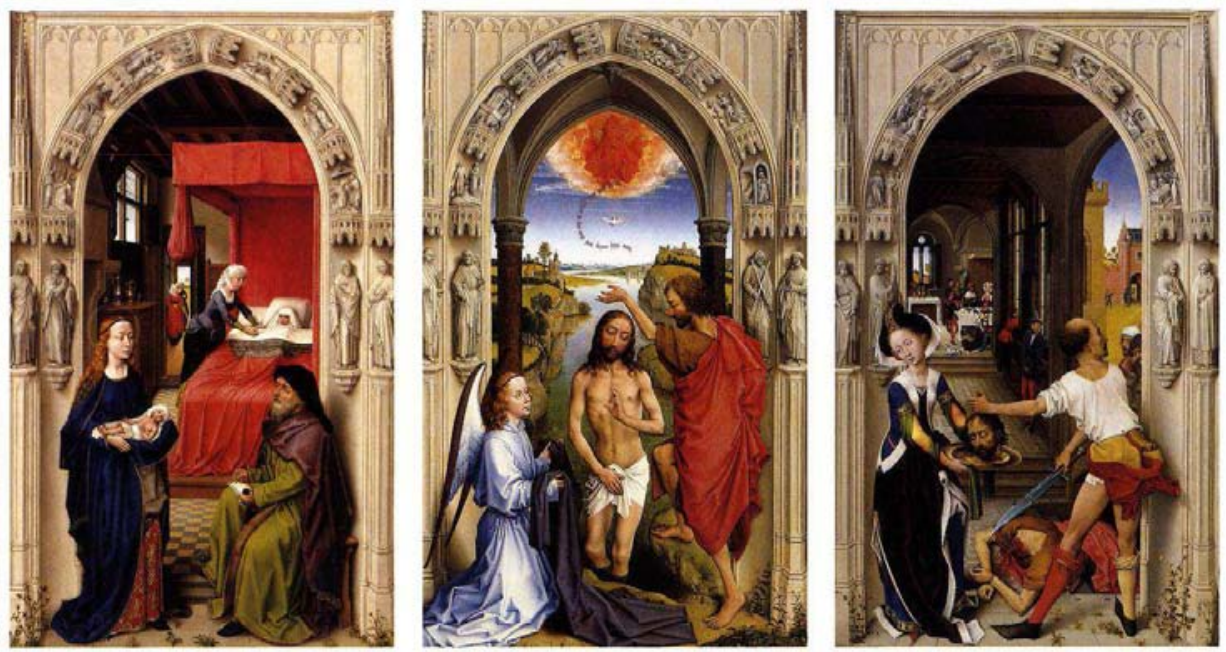

[Abb. 1, Rogier van der Weyden, Johannesaltar]

Durch ein Kirchenportal erhält der Betrachter Einblick in den Palast des Herodes. Drei hintereinander gestaffelte Räume unterteilen die Abschnitte der Narration von der Enthauptung Johannes' des Täufers in eine Haupt- und verschiedene Nebenbühnen, weshalb der Kopf des Johannes in zwei Momenten der Erzählung gleichzeitig im Bild zu sehen ist. Zudem spiegelt sich die gesamte Handlung in der den dargestellten Raum umfangenden Archivolte, auf die hier nicht näher eingegangen wird. ${ }^{11}$

11 Vgl. SuCKaLE, Rogier, S. 29. 


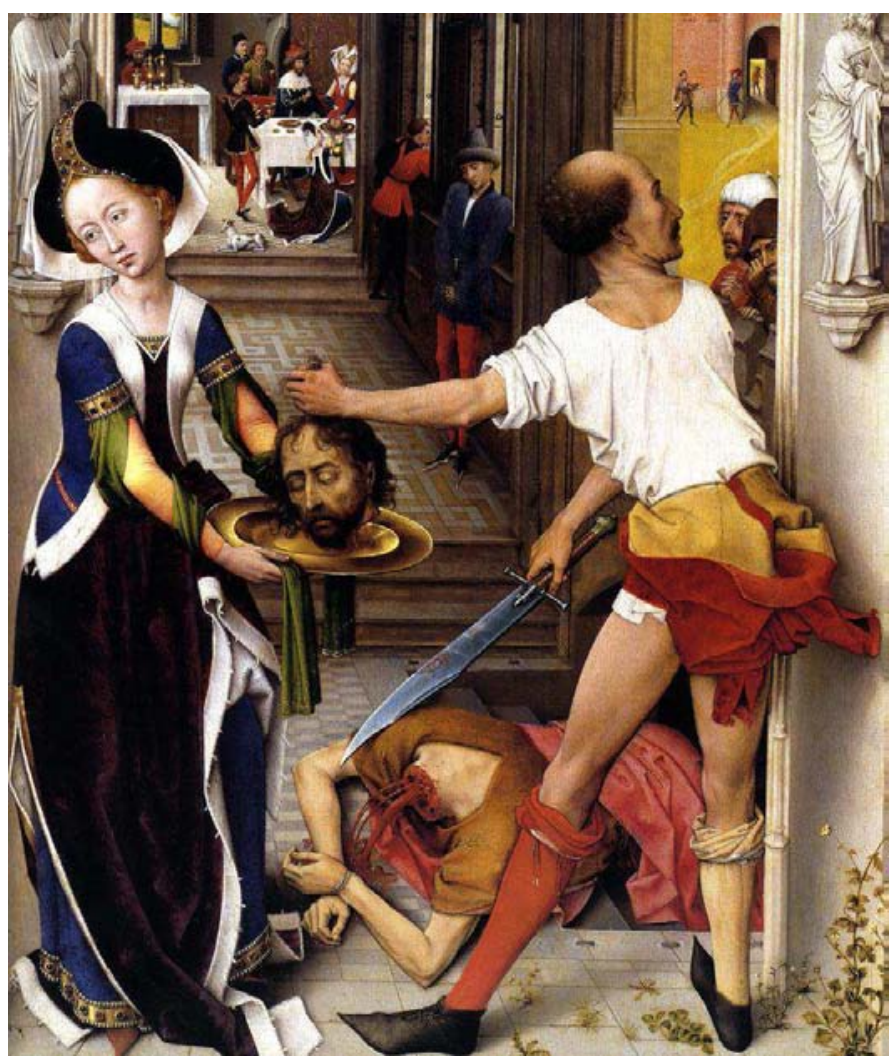

[Abb. 2, Rogier van der Weyden, Detail des Johannesaltars]

Als Betrachter ist man bereits beim Eintritt mit dem Moment nach der Hinrichtung konfrontiert. Versucht der Blick den Raum zu durchdringen, muss er zwischen dem am Boden liegenden Körper, dem Schwert des Henkers und dem gerade abgetrennten Kopf hindurch. Aus dem Hals des Toten ergießt sich das Blut in einem Bogen bis zu seinen gefesselten Händen. Der Unterkörper des Johannes ist von einem roten Tuch bedeckt und scheint auf der rechten Seite des Retabels und des Portals aus dem Bildfeld zu verschwinden. Über dem blutenden Stumpf hält der Henker in seiner Rechten ein Schwert, auf dessen Schneide nur noch schwache Blutspuren von der Tat zeugen. Mit seiner linken Hand hält er den Kopf des Johannes über eine Buckelschüssel aus Messing, um ihn dort abzulegen. Der mit Gold abgesetzte Kopfschmuck und die kostbare Gewandung der jungen Frau, die das Haupt in Empfang nimmt, deuten darauf hin, dass es sich um die Königstochter Salome handelt. Weder Salome noch der Henker sind dem Leichnam oder dem Kopf des Täufers zugewandt. Lediglich der Blick von Salome korrespondiert 
mit der mittleren Bildtafel, in der Johannes Christus tauft. ${ }^{12}$ Der Henker dreht seinen Kopf nach rechts über die Schulter zu dem trauernden Gefolge, das sich im Innenhof befindet, den der Betrachter durch einen Rundbogen aus dem mittleren Raum, einem gegenüber dem Vordergrund leicht höher gelegenen Gang, betrachten kann. Vor jedem der Fenster ist der Durchgang an der rechten Seite von zwei wartenden Höflingen gesäumt, bevor der Blick in den hintersten Raum vordringen kann. Dort wird der an einer Tafel sitzenden Herodias, der Mutter von Salome, das Haupt des Johannes auf der Schüssel dargeboten. Im Moment der Übergabe kniet die Königstochter vor ihrer Mutter nieder, während diese mit einem spitzen Gegenstand in den abgetrennten Kopf sticht, um scheinbar letzte Gewissheit über Johannes' Tod zu erlangen. ${ }^{13}$ In der Bildtafel vereinen sich zwei kanonische Darstellungen: Die Enthauptung Johannes' des Täufers und das Gastmahl des Herodes, die hier narrativ überblendet werden.

Als Quelle für den zum Mythos gewordenen Stoff ist in erster Linie die Aufzeichnung des Geschichtsschreibers Flavius Josephus aus dem ersten nachchristlichen Jahrhundert zu erwähnen. Weitere Versionen liefern die Evangelien von Markus und Matthäus, wobei in ihnen der Name ,Salome' nicht genannt wird und lediglich von der Tochter der Herodias die Rede ist. RHODE merkt dazu an, dass es ,,...] die weitere literarische Entwicklung des Salomethemas wohl eher beflügelt, daß seine evangelische Quelle nicht nur sehr kurzgefaßt, sondern auch offensichtlich unhistorisch ist. Desto mehr Freiheit hatten die Bearbeiter, die Leerstelle, die der Text lässt, mit ihren Phantasien zu füllen." ${ }^{14}$

Im Unterschied zu den Evangelien ist bei Flavius Josephus die Hinrichtung von Johannes dem Täufer nicht überliefert. Übereinstimmend berichten die Quellen jedoch von den familiären Voraussetzungen für die dramatische Entwicklung. Bei Josephus heißt es: „Herodias nun [...] vermählte sich mit Herodes, dem Sohne Herodes' des Großen und der Mariamne, [...] und gebar ihm eine Tochter Salome, nach deren Geburt sie den väterlichen Gesetzen zum Trotz Herodes, den Tetrarchen von Galiläa und Stiefbruder ihres Gatten, heiratete, von dem sie sich indes noch bei Lebzeiten lossagte." ${ }^{15}$ So ist das Geflecht der familiären Beziehungen bei Josephus überliefert, das im Markusevangelium $(M k .6,18)$ die Kritik von Johannes dem Täufer auf sich zieht: „Es ist nicht recht, daß du [Herodes] deines Bruders Frau hast." Damit spricht Johannes sein eigenes Todesurteil, denn Herodias wird diesen Tadel nicht hinnehmen und schickt ihre Tochter vor, um die Bestrafung des Johannes zu erreichen. Nachdem Salome vor Herodes getanzt hat und dieser sie dafür belohnen will, fragt sie ihre Mutter um Rat, worum sie nun bitten soll. Diese schlägt das Haupt des Täufers als Preis vor, das die Tochter sogleich bei Herodes auf einer Schüssel einfordert, um es danach der Mutter zu überbringen.

\footnotetext{
12 Vgl. Interpretation des Zusammenhanges und der Vorausdeutung der Hinrichtung von Johannes auf Christus: BAERT, A Head on a Platter.

$13 \mathrm{Vgl}$. SuCKaLE, Rogier, S. 32.

${ }^{14}$ Rhode, Mythos Salome, S. 267.

${ }^{15}$ Josephus, Jüdische Altertümer, V. 136-138, S. 888.
} 
In der frühen Kirchenlehre der ersten Jahrhunderte nach Christus diente der Salome-Stoff vornehmlich zur Verbreitung von Moralvorstellungen, die dem Volk im Gewand von Mysterienspielen und Moralitäten dargeboten wurden; dafür wurden die Evangelien mit der Josephus-Quelle kombiniert. Das Hauptanliegen hierbei war, die „Frau als Urübel“"16 darzustellen und durch Herodias ein „Bild weiblicher Hinterlist, Intriganz und verrufener Leidenschaftlichkeit" ${ }^{\prime 17} \mathrm{zu}$ konstruieren. Salome diente dabei als ihr von kindlich-weiblicher Unschuld charakterisiertes Gegenbeispiel, um deutlich zu machen, dass die Tochter lediglich im Auftrag der Mutter handelt.

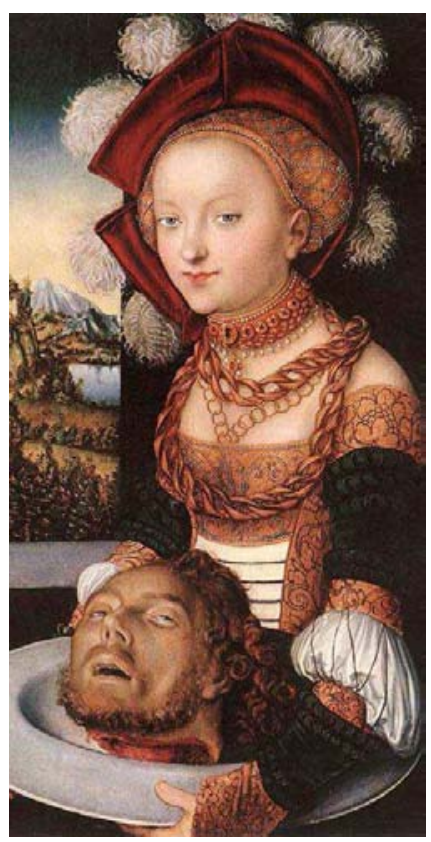

[Abb. 3, Lucas Cranach d. Ä., Salome]

Im Gegensatz zu Rogier van der Weyden konfrontiert der Blick, den Lucas Cranach d. Ä. (1472-1553) auf und in die Schnittstelle am Kopf des enthaupteten Johannes des Täufers [Abb. 3] sowie Holofernes in seinen Darstellungen von Salome und Judith freigibt [Abb. 4], den Betrachter direkt mit dem Umstand der Separierung von Kopf und Körper.

\footnotetext{
16 RHODE, Mythos Salome, S. 267.

17 Ebd.
} 


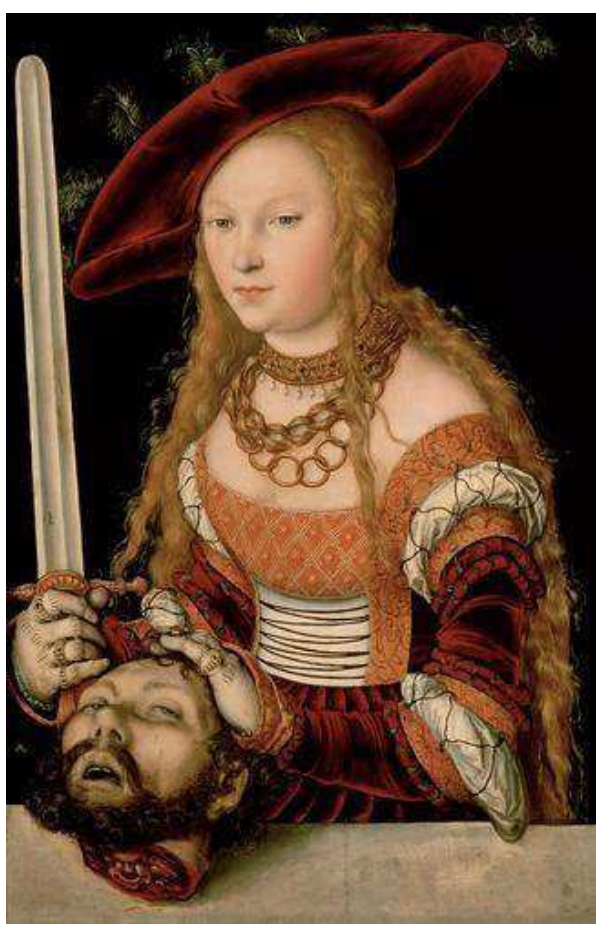

[Abb. 4, Lucas Cranach d. Ä., Judith]

Die Enthauptung als Bildgegenstand bei Cranach stellt den Bezug zum Heiligen aus zwei Blickwinkeln dar, wobei die abgeschlagenen Köpfe gleichermaßen zu losgelösten Objekten werden, zu ,Trophäen', die den reizvoll ausstaffierten und geschmückten Frauen passiv gegenübertreten und die demütigenden Umstände ihres jeweiligen Todes versinnbildlichen. Es scheint, als wird das abgeschlagene Haupt darüber hinaus in beiden Fällen durch den präsentierenden Gestus zu einem ,magischen' Gegenstand, der wie das Haupt der Medusa die apotropäische Fähigkeit besitzt, im Vorgang des Betrachtens und Betrachtetwerdens Unheil abzuwehren: Der Blick beider Frauen richtet sich auf den Betrachter, ihre Hände jedoch weisen auf den Kopf im unteren Bildteil. Dieser Akt des Sehens markiert bereits eine neue Dimension der Wahrnehmung durch die Selbstreflexivität des Mediums und seines Gegenstandes, die sich auch in den plastischen Darstellungen der Johannesschüssel wiederfindet. Beide Enthauptungsszenen sind in Cranachs Werkstatt in serieller Produktion entstanden und weisen eine so starke Ähnlichkeit auf, dass lediglich anhand der Attribute Rückschlüsse auf das Sujet möglich werden. Die Inszenierung des abgeschlagenen Kopfes ist auf beiden Gemälden Cranachs identisch angelegt. Die offene Wunde am Hals ist dem Betrachter zugewandt, während der Kopf mit einem Gestus präsentiert wird, der die Macht der Frauen hervorhebt. Bei Judith nimmt diese ostentatio mit dem aufgestellten Schwert 
beinahe die Züge eines Königsporträts an; der Kopf des Täufers erinnert an die Präsentation des Reichsapfels.

KRÜGER liefert durch seine Feststellung zum Begriff der ostentatio in diesem Zusammenhang eine Basis für weitere Interpretationen. Als Gestus über „Triumphbezeugungen“ hinausgehend, führt KRÜGER aus, „dass der Enthauptete der ,Trägerschaft' seiner Person verlustig gegangen ist und diese Autorität nunmehr als disponibles Signum seines Todes an eine fremde Verfügungsgewalt abgetreten hat." "18

Die Johannesschüssel in dem Gemälde von Andrea Solario (tätig 1495-1522) und die Plastik des vom Attribut losgelösten Hauptes Johannes' des Täufers bei Juan de Mesa (1583-1627), verdeutlichen die Unterschiede dieser expliziten Inszenierungen auf der Schwelle zwischen Mittelalter und Früher Neuzeit.

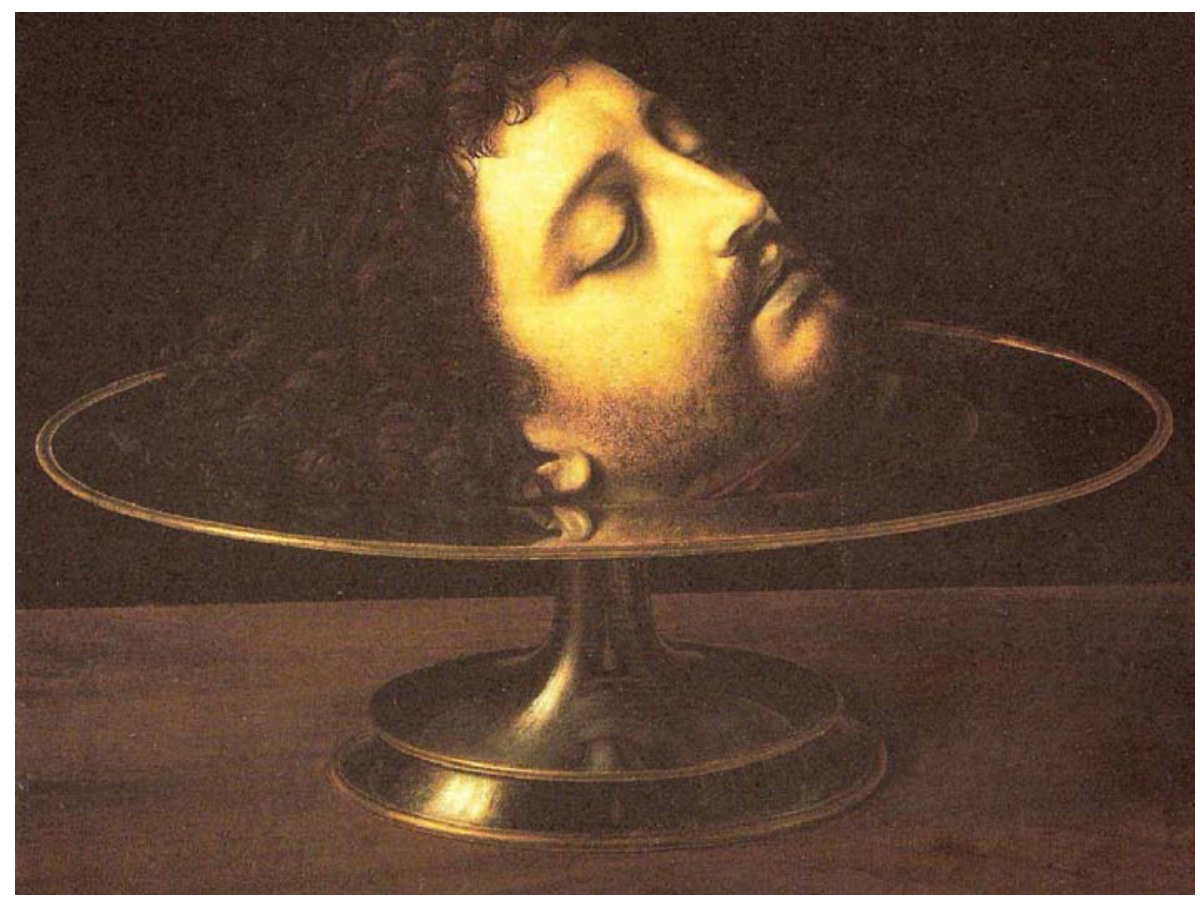

[Abb. 5, Andrea Solario, Kopf Johannes' des Täufers]

18 KRÜGER, Gesichter ohne Leib, S. 202. 


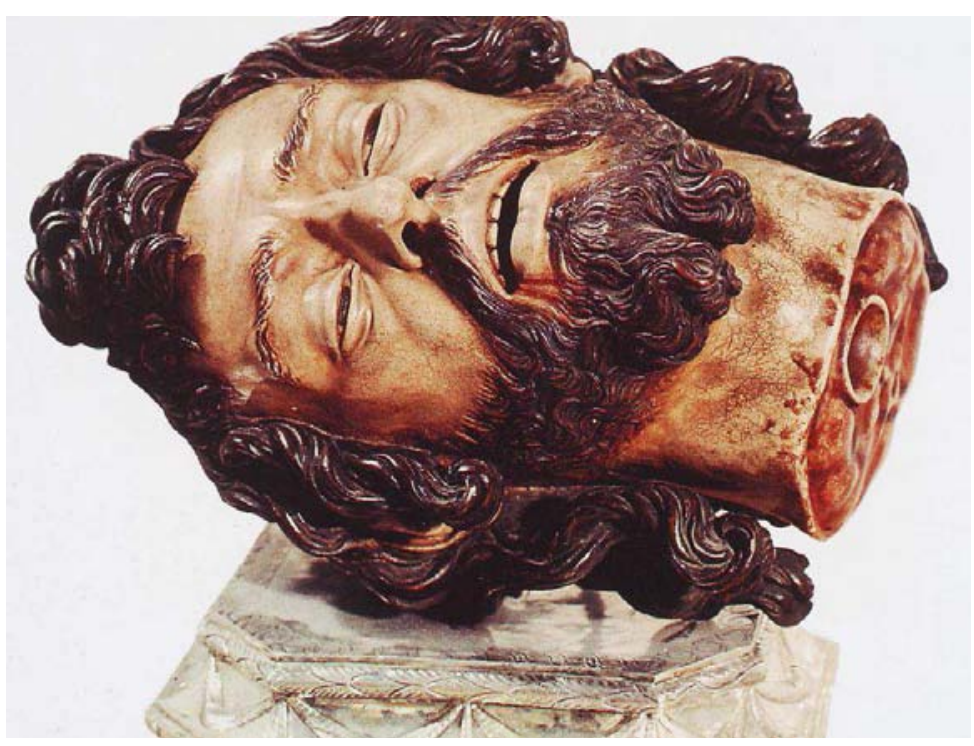

[Abb. 6, Juan de Mesa, Kopf Johannes‘ des Täufers]

Die Johannesschüssel wurde seit dem 13. Jahrhundert zu einem eigenständigen plastischen Symbol, dem nicht nur die Versinnbildlichung des Todes von Johannes als dem Vorboten Jesu Christi zugrunde liegt, sondern auch das Kopfreliquiar in Schalenform. Als Prototyp gilt eine silberne Rundplatte, in der sich eine sichtbar eingelassene Antlitzreliquie des Johannes befindet; sie gelangte 1206 aus Byzanz in die Kathedrale von Amiens. ${ }^{19}$

Bei den Darstellungen der Johannesschüssel kommt ebenfalls vor allem der Schnittstelle am Hals eine besondere Bedeutung zu. Die Wunde scheint dabei entweder durch den Kontakt mit der Schüssel versiegelt zu werden, oder die Inszenierung zeigt explizit die Schnittstelle am Hals. Der Kopf geht bei der erstgenannten Möglichkeit eine Verbindung mit dem Gegenstand ein, als imago clipeata, ein Phänomen in der Bildenen Kunst, das sich auch bei Darstellungen des Medusenhauptes auf einem Schild und dem festgenagelten Kopf des Orpheus auf seiner Leier feststellen lässt. Während Solario den Kopf auf der Schüssel so inszeniert, dass ihre runde Form das Haupt wie eine Aureole umfängt und somit eine Atmosphäre des Sakralen und der Innerlichkeit erzeugt, wirkt das auf einem Sockel balancierte Haupt aus der Kathedrale von Sevilla drastischer. Dieser Eindruck verstärkt sich durch den rictus, den geöffneten Mund, und die anatomisch genaue Nachbildung der Schnittstelle.

\footnotetext{
19 „Kostbare Ausnahmestücke gelten als Reliquie der Schale Salomes, so die 1492 von Papst Innozenz VIII. dem Dom zu Genua vermachte antike Achatplatte mit winzigem Goldemaillekopf um 1420/30 und die 1402 im Inventar des Herzogs Jean de Berry erwähnt Achatschale im Museum von Bourges." BAUTIER, LexMA, S. 661.
} 
Die hier angeführten Werke sind darüber hinaus Beispiele für den zu einem ,Zeichen' gewordenen Kopf dar, einen Vorgang, den SYKORA in der Auseinandersetzung mit Totenfotografie und ihrem sozialen Gebrauch folgendermaßen charakterisiert: „Dieses durch die Tötung frei gewordene Zeichen der Macht ist daher in der Lage, etwas Neues hervorzubringen. Der ostentatio wohnt somit eine komplexe metamorphotische und zugleich eine bannende Kraft inne. “20

LABOUVIE hält in dem von VON DÜLMEN herausgegebenen Sammelband Entdeckung des Ich. Die Geschichte der Individualisierung vom Mittelalter bis zur Gegenwart für die Frühe Neuzeit fest:

Der Blick auf den anderen Körper war Mittel zur Schaffung von Abgrenzung, Distanz, aber auch zur Erlangung von Selbstvergewisserung und Identifikation. Körperliche Andersartigkeit, hervorgerufen durch Krankheit und Tod, Verletzung, Tortur, Besessenheit oder Mißbildung, rief zuweilen jedoch Schaulust, Neugier und Spott auf den Plan. ${ }^{21}$

LABOUVIES These lässt sich anhand der psychoanalytischen Untersuchungen von LACAN erläutern. LACAN definiert das Spiegelstadium als Identifikation, bei der sich „eine beim Subjekt durch die Aufnahme eines Bildes ausgelöste Verwandlung“"22 vollzieht. Dabei spielt der antike Begriff imago, der die Funktion benennt, eine Beziehung zwischen der Innen- und der Umwelt oder von einem Organismus zu seiner Realität herzustellen, eine entscheidende Rolle. Der Begriff leitet sich von den antiken imagines maiorum ab. Er bezeichnet zum einen jedes Abbild, aber auch Porträtbüsten aus jeglichem Material sowie besondere Wachsbilder, die als Stellvertreterfiguren verwendet wurden und sogar an Leichenzügen teilnahmen. ${ }^{23}$

LACAN hingegen entwickelt seine Theorie, die ich abstrahierend gebrauchen möchte, anhand der Beobachtung von Verhaltensaspekten bei Kindern: Durch das eigene Erkennen des Spiegelbildes wird ein Prozess in Gang gesetzt, der sich in dem Erkunden der gespiegelten Umgebung und dem Verhältnis des ganzen virtuellen Komplexes zur Realität ausdrückt.

Daraus ableiten ließe sich, dass die Wahrnehmung des Selbst und des eigenen Körpers beim Betrachten von deformierten Körpern, Enthaupteten und abgetrennten Köpfen eine intentionale Verknüpfung aufweist, die LABOUVIE folgendermaßen skizziert: „Der tote, blasse, von Krankheiten ausgezehrte Körper schien [...] weder Abscheu noch Ekel, weder Abgrenzung noch Meidung hervorzurufen. Ganz im Gegenteil übertrug sich das wahrgenommene ,Elend' des toten Leichnams auf den Körper des Betrachters, je näher er dem Verstorbenen gestanden hatte. "24

\footnotetext{
${ }^{20}$ SYKORA, Die Tode der Fotografie, S. 476.

${ }^{21}$ LABOuvie, Individuelle Körper, S. 173.

22 LACAN, Schriften I, S. 64.

${ }^{23}$ Vgl. CAnCIK/Schneider, Der Neue Pauly, S. 947.

${ }^{24}$ Labouvie, Individuelle Körper, S. $173 \mathrm{f}$.
} 
Nun ist die Darstellung eines deformierten Körpers oder eines separierten Kopfes ein Bildinhalt, der über die Bezeichnung der ,Andersartigkeit ${ }^{\star}$ deutlich hinausgeht. Das, was in einem derartigen Körperbild als das ,Andere' wahrgenommen werden kann, artikuliert sich vor allem durch die darin dargestellte Todesursache. SCHOLZ hält in diesem Zusammenhang für das ,Bild‘ in seinem Beitrag zu den Ästhetischen Grundbegriffen fest, dass „das Dogma von der Gottebenbildlichkeit des Menschen [...] zu einer christlichen Imago-Lehre [führte], die Bezüge zum metaphysischen Bildbegriff aufweist.“' ${ }^{25}$ Dabei bezieht er sich nicht nur auf die Genesis, sondern auch auf das leibhaftige Individuum als das Unteilbare, welches das griechi-

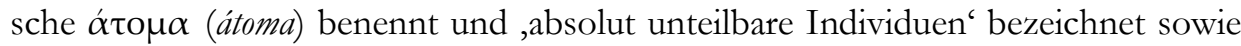
in der Tradition der unteilbaren Einheiten der Atomisten steht.

Durch den Einsatz oder das Opfer ihres Körpers, genauer ihres Leibes, stehen Johannes und Holofernes also in Verbindung mit dem Göttlichen. Während Johannes als Märtyrer stirbt und darin zugleich einen Verweis auf das Schicksal von Jesus Christus verkörpert, wird Holofernes durch die Kraft überwältigt, die der Glaube der bethulischen Witwe Judith verlieh.

Zum Ende möchte ich noch einmal auf die Ausgangsthese zurückkommen: „Deformierte Körper eröffnen neue Dimensionen der Wahrnehmung des eigenen Selbst, aber vor allem auch des Göttlichen“. In diesem Fall werden das ,Selbst" und das ,Göttliche ' mittels eines Bildes wahrgenommen. Das Charakteristikum von Fragmenten, beim Betrachten die Möglichkeit zu bieten, sie in ihrer Vollständigkeit zu imaginieren, verdeutlicht die Zerstörung des menschlichen Lebewesens im Bild des Enthaupteten umso klarer, und damit einhergehend die Kraft der ,heiligen Handlung der Hinrichtung. Dem hinzu kommt die Feststellung von KRISTEVA, dass dieser Art von deformierten Körpern auch das Grauen der Beschneidung oder der Kastration anhaftet und dass die Macht des Schreckens dieser Darstellungen geringer wäre ohne die weibliche Komponente. ${ }^{26}$ Letztlich tragen die Enthaupteten und abgetrennten Köpfe in ihrer Darstellung den Akt der Hinrichtung in sich, sie stehen für das Gesetz und den göttlichen Willen, der sich in ihnen ausdrückt.

Zusammenfassend ist festzustellen, dass vom Bilderstreit über LACANS psychoanalytische Argumentation bis hin zu aktuellen Positionen der Bildwissenschaft über die Bedeutung des Zusammenhanges vom Bild, Abbild und Körper Theorien entwickelt werden, die eine gewisse ,Durchlässigkeit ${ }^{`}$ und ,Übertragbarkeit ${ }^{`}$ des Mediums auf den Körper postulieren, wodurch Darstellungen von Körperfragmenten und besonders von Enthauptungen eine Brisanz erlangen, die im Rahmen weiterer Forschung in Augenschein zu nehmen sind. ${ }^{27}$

\footnotetext{
25 SCHOLZ, Bild, S. 634.

${ }^{26}$ Kristeva, Visions Capitales, S. 94f.

27 Unter dem Arbeitstitel „Wie der Verlust von Ganzheit neue Zeichen erzeugt. Enthauptung als Paradigma künstlerischer Reflexivität in der französischen Malerei des 19. Jahrhunderts“ entsteht zur Zeit meine Dissertation.
} 


\section{Abbildungen}

[Abb. 1] Rogier van der Weyden, Johannesaltar (um 1456) - Staatliche Museen zu Berlin, Gemäldegalerie, je Tafel 77 x $48 \mathrm{~cm}$, Öl auf Eichenholz. Bildnachweis: SuCKALE, Rogier, Falttafel im Anhang. Bildrecht: Stiftung Preußischer Kulturbesitz, Staatliche Museen zu Berlin.

[Abb. 2] Rogier van der Weyden, Detail des Johannesaltars (um 1456) - Staatliche Museen zu Berlin, Gemäldegalerie, je Tafel 77 x 48 cm, Öl auf Eichenholz. Bildnachweis: SuCKALE, Rogier, Falttafel im Anhang. Bildrecht: Stiftung Preußischer Kulturbesitz, Staatliche Museen zu Berlin.

[Abb. 3] Lucas Cranach d. Ä., Salome (um 1530) - Budapest, Szépmüvészeti Muzéum, 86,5 x 57,5 cm, Öl auf Holz. Bildnachweis: FRIEDLÄNDER/ RosenberG, Cranach, Abb. 230, S. 116. Bildrecht: Szépmüvészeti Muzéum, Budapest.

[Abb. 4] Lucas Cranach d. Ä., Judith (um 1530) - Wien, Kunsthistorisches Museum, 87 x $56 \mathrm{~cm}$, Öl auf Holz. Bildnachweis: SCHADE, Die Malerfamilie, Tafel 153. Bildrecht: Kunsthistorisches Museum, Wien.

[Abb. 5] Andrea Solario, Kopf Johannes' des Täufers (1507) - Paris, Musée du Louvre, 46 x $43 \mathrm{~cm}$, Öl auf Leinwand. Bildnachweis: KRISTEVA, Visions Capitales, 1998, S. 77. Bildrecht: Musée du Louvre, Paris.

[Abb. 6] Juan De Mesa, Kopf Johannes' des Täufers ( um 1625) - Sevilla, Kathedrale, farbig gefasstes Holz. Bildnachweis: DuBY/DAvaL, Skulptur, S. 778. Bildrecht: Kathedrale Sevilla.

\section{Literatur}

Gregor der Große, Registrum Epistolarum 9, 105. In: PL 77, col. 1027 f.

Josephus, Flavius, Jüdische Altertümer. Übersetzt und mit Einleitung und Anmerkungen versehen v. HeINRICH CLEMENTZ. Mit Paragraphenzählung nach Flavii Josephi Opera recognovit BENEDICTUS NIESE (Editio minor). Wiesbaden 22006.

Lacan, Jacques, Schriften I. Hrsg. v. NORBERT HAAS. Freiburg i. Br. 1973.

Luther, Martin, Wider die himmlischen Propheten, von den Bildern und Sakrament (1525). In: Werke. Kritische Gesamtausgabe, Abt. 1, Bd. 18. Weimar 1908. 


\section{Forschung}

BAERT, BARBARA, A Head on a Platter: The 'Johannesschüssel' or the Image of the Mediator and Precursor. In: Jaarboek/Koninklijk Museum voor Schone Kunsten 2003 (2006), S. 8-41.

BAuTIER, Robert-Henri (Hrsg.), LexMA, Bd. 5. München/ Zürich 1991.

Bergmann, AnNA, Töten, Opfern, Zergliedern und Reinigen in der Entstehungsgeschichte des modernen Körpermodells. In: metis, Zeitschrift für historische Frauenforschung und feministische Praxis 6 (1997), S. 189-217.

CAncik, Hubert u. Schneider, Helmuth (Hrsg.), Der Neue Pauly, Enzyklopädie der Antike, Altertum, Bd. 5. Stuttgart/Weimar 1998.

DENZINGER, HEINRICH u. HÜNERMAN, PETER, Enchiridion symbolorum, definitionum et declarationum de rebus fidei et morum. Kompendium der Glaubensbekenntnisse und kirchlichen Lehrentscheidungen. Freiburg i. Br. u. a. ${ }^{37} 1991$.

Duby, GeOrges u. DAval, JeAN-LuC (Hrsg.), Skulptur von der Renaissance bis zur Gegenwart, 15. bis 20. Jhd., Bd. 2. Köln 2006.

FOuCAult, MiCHEL, Überwachen und Strafen. Die Geburt des Gefängnisses. Frankfurt a. M. 1977.

FRIEDLÄNDER, MAX J. u. RosenBERG, JAKOB, Die Gemälde von Lucas Cranach. Basel/Stuttgart 21979.

Kristeva, JUliA, Visions Capitales, Katalog zur gleichnamigen Ausstellung im Musée du Louvre, Paris, vom 27.4. bis 3.11.1998. Paris 1998.

KRÜGER, KLAUS, Gesichter ohne Leib. Dispositive der gewesenen Präsenz. In: SuTHOR, NiCOLA u. FisCHER-LiCHTE, ERIKA (Hrsg.), Verklärte Körper. Ästhetiken der Transformation. München 2006, S. 183-202.

LABOUVIE, EvA, Individuelle Körper. Zur Selbstwahrnehmung „mit Haut und Haar“. In: VON DÜlMEN, RICHARD (Hrsg.), Entdeckung des Ich. Die Geschichte der Individualisierung vom Mittelalter bis zur Gegenwart. Köln 2001, S. 163-196.

MitCHELl, William J. T., Vier Grundbegriffe der Bildwissenschaft. In: SACHSHOMBACH, KLAUS (Hrsg.), Bildtheorien, Anthropologische und kulturelle Grundlagen des Visualistic Turn. Frankfurt a. M. 2009, S. 319-327.

OHLER, NorberT, Sterben und Tod im Mittelalter. München 1994.

Rhode, Thomas (Hrsg.), Mythos Salome. Vom Markusevangelium bis Djuna Barnes. Leipzig 2000. 
SCHADE, WERnER, Die Malerfamilie Cranach. Dresden 1974.

Scholz, Oliver RoBert, Bild. In: BARCK, KARlHEINZ (Hrsg.), Ästhetische Grundbegriffe, Bd. 1. Stuttgart 2000, S. 618-669.

SuCKALE, ROBERT, Rogier van der Weyden. Die Johannestafel. Das Bild als stumme Predigt. Frankfurt a. M. 1995.

SYKORA, KATHARINA, Die Tode der Fotografie, Bd. 1, Totenfotografie und ihr sozialer Gebrauch. München 2009. 



\title{
Lupus in fabulis et in templo: Les métamorphoses étranges du Saint Christophe dans l'Église Orthodoxe
}

\author{
Vesselina Vatchkova
}

\begin{abstract}
:
The paper focuses on several major issues: How was the monstrosity of St. Christopher understood in medieval times - whether he was the dog-headed saint or the saint giant? Which traditions allowed for the amazing vitality (from the $6^{\text {th }}$ up to the $20^{\text {th }}$ century) of depicting St. Christopher as a dogheaded/wolf-headed saint in the Eastern Orthodox world? When and why the official Church in the East and West renounced the monstrous saint but didn't succeed in establishing a new, less shocking, iconography of St. Christopher, being able only to soften the features and reduce the size of ancient representations of the saint (paintings and statues)?
\end{abstract}

\author{
Qui totum inspicere non potest, \\ tanqum deformitate parties offenditur, \\ quoniam cui congruat et quo referatur ignorat. \\ Saint Augustin, De civitate Dei, 16, 8.
}

Dans son livre sur les saints guerriers, WALTER a commencé l'examen de Saint Christophe par une citation de BARDY : "St. Christophore est un des plus populaires, mais aussi un des moins connus parmi les saints martyrs de l'antiquité ».1 Cette observation de BARDY sur la popularité de Saint Christophe ne l'empêche pas de qualifier Saint Christophe comme un 'petit saint', et de consacrer à ce «mi-

\footnotetext{
${ }^{1}$ BARDy, St. Christophe, p. 777ff., cité d'après : WALTER, The Warrior Saints, pp. 214-216.
} 
neur saint » un faible nombre de pages - deux et demie. ${ }^{2}$ Donc, la première question qu'il faut se poser est: Qui est ce saint mystérieux, à la fois populaire et peu connu ? Puisqu'il s'agit d'un saint chrétien, la tradition exige de présenter en premier lieu les données biographiques, conservées dans les Vies de Saint Christophe.

\section{Qui est Saint Christophe?}

D’après les Vitae primitives grecques (8ème-11ème s.), Saint Christophe a vécu au milieu du 3ème siècle sous le règne de l'empereur Decius. Il était un soldat du peuple des cynocéphales, qui sont aussi androphages (cannibales). Il a reçu le don de parler la langue grecque, en même temps que le don de devenir chrétien (ainsi son nom est devenu Chrétien). Son éloquence et son apparence terrifiante ont fait se convertir des milliers de païens (48 000 selon Saint Ambroise de Milan). Le roi (un certain Dagnus) a essayé de séduire le saint avec deux filles de joie et l'a fait sacrifier aux dieux paiens, mais le saint a converti ces filles au christianisme et elles sont devenues des martyres avant lui (la fête des deux martyres Nicée et Callinique/Aquiline est toujours le 9 mai, le jour de la mémoire de Saint Christophe selon l'Église Orthodoxe). Christophe a subi de terribles supplices et fini par être décapité.

Selon la Légende dorée (13 ème s.), Reprobus/Réprouvé (Abominable) était un Cananéen, ce qui explique qu'il ait été pris pour un cynocéphale. ${ }^{3}$ Il était de la taille énorme, voire gigantesque de 12 coudées de hauteur $(5,4 \mathrm{~m})$ et d'un visage effrayant. Christophe voulut servir au plus fort des maitres. Ainsi, il a été le servant d'un roi chrétien, puisque ce dernier faisait le signe de la croix, puis du diable dans le désert et, enfin, d'un ermite qui lui a recommandé de devenir le servant de JésusChrist en aidant les gens à traverser une rivière dangereuse - parce que le géant avait dit qu'il ne pouvait guère jeûner et réciter les prières comme le faisaient tous les chrétiens. Un jour, il lui est arrivé de porter un enfant. Celui-ci était si lourd que le géant avait peine à traverser la rivière. Cet enfant n'était autre que Jésus-Christ lui-même et, à partir de ce moment, Christophe est devenu le vrai Christophoros celui qui porte le Christ. Enfin, Christophe est arrivé à une certaine ville de Samos en Lycie et, après avoir converti beaucoup de monde par ses gestes et paroles, y compris les deux filles de joie déjà mentionnées, il y a été martyrisé et décapité. La fête du saint, selon l'Église Catholique, est le 25 juillet.

\footnotetext{
2 Op. cit.

${ }^{3}$ Une confusion entre le toponyme Cynocéphalae (Les têtes de chiens, en Tessalie) et l'apparence du saint est bien probable, compte ténue de la grande popularité, jusqu'au présent, du St. Christophe cynocéphale dans la région des Balkans.
} 


\section{Saint Christophe selon l'art médiéval}

De ces deux récits bien différents découlent deux types iconographiques qui, au premier abord, ne se ressemblent pas du tout. En Orient, du $6^{\text {ème jusqu'au } 19 \text { ème }}$ siècle, on représente Saint Christophe comme un soldat à tête d'animal (Tabl. 1).

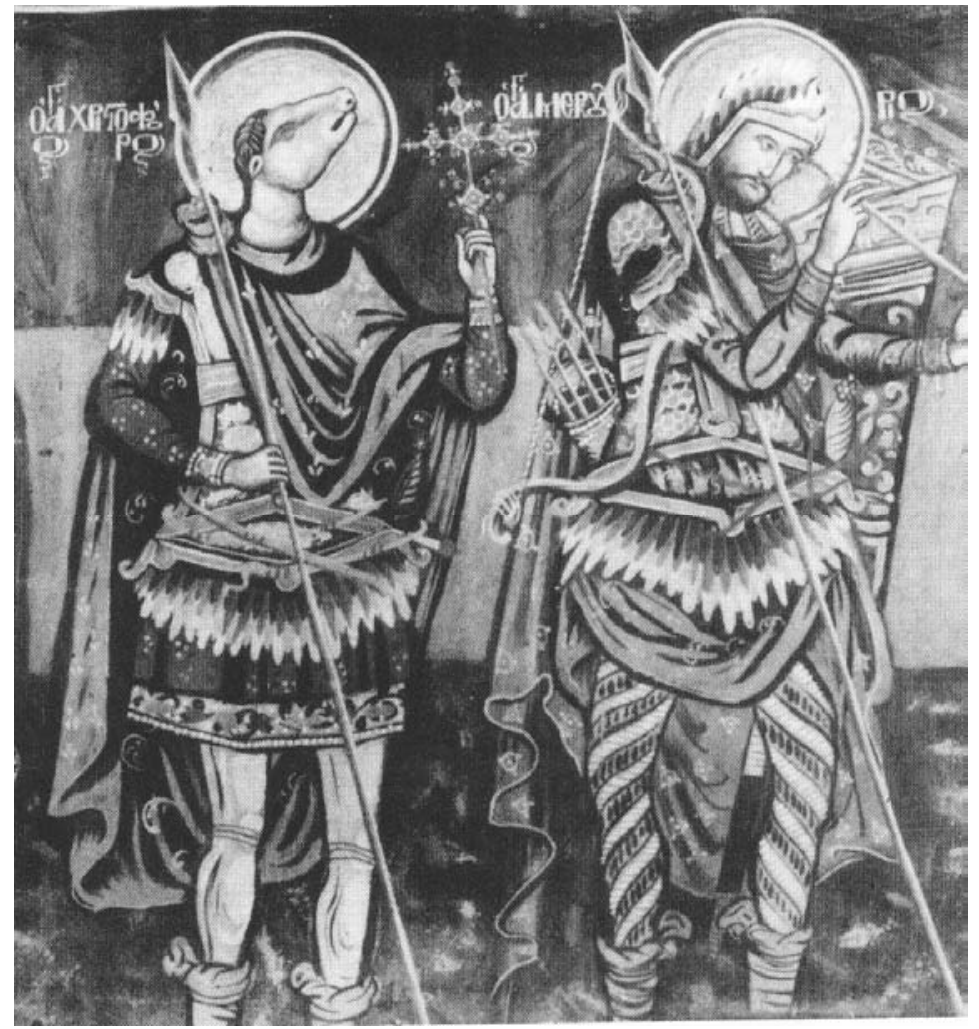

[Tabl. 1, Saint Christophe et Saint Mercure, anonyme, 18 ${ }^{\text {ème s. }}$

En Occident, Saint Christophe est un géant qui traverse une rivière en portant Jésus-Christ enfant sur son épaule. En regardant ces images de l'homme-animal et de l'homme-géant, il ne faut pas oublier que, selon l'imagerie médiévale, les hommes à tête de chien (cynocéphales) et les géants sont parfois de la même race monstrueuse. Il faut souligner aussi que même si les Vitae grecque et latine paraissent tout à fait différentes, certains traits communs assez importants existent entre elles :

1) Le saint a vécu à l'aube de l'ère chrétienne - époque assez éloignée, voire mythique ; 


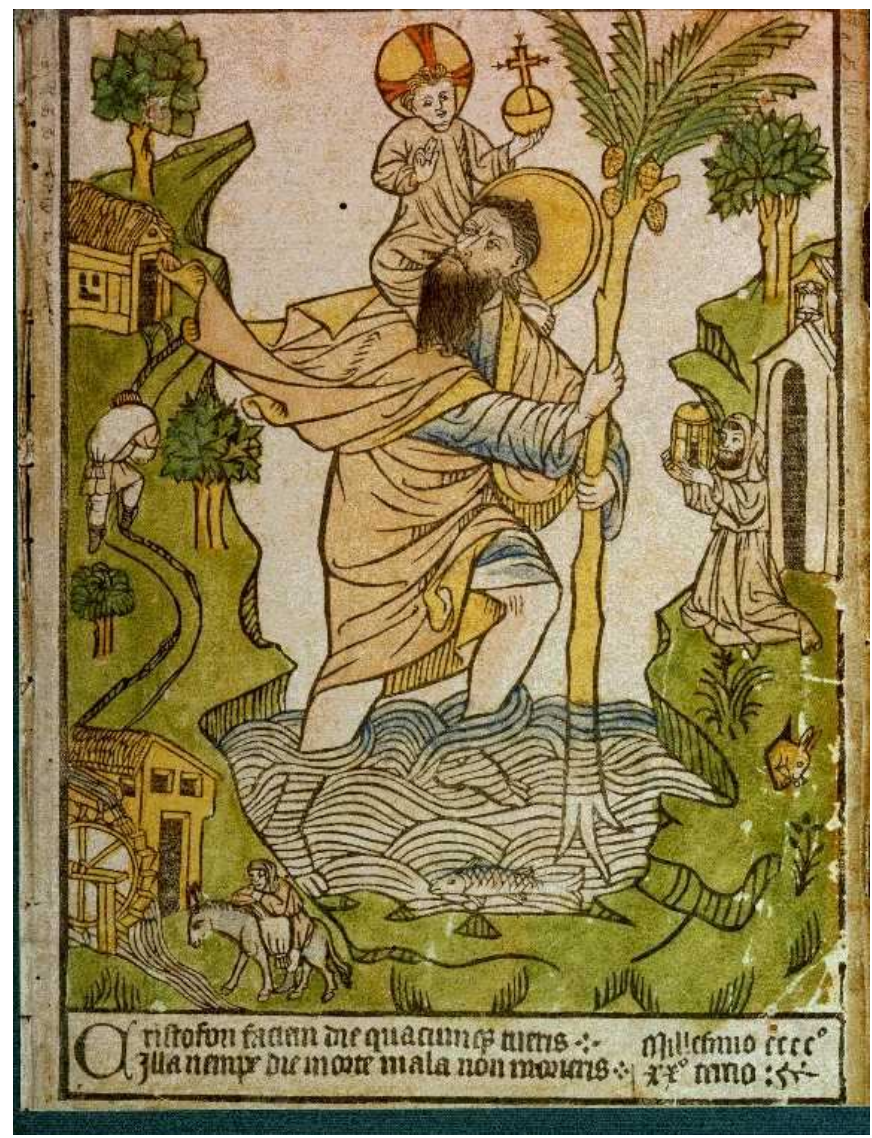

[Tabl. 2, Saint Christophe, anonyme, 15 $5^{\mathrm{èm}} \mathrm{s}$.]

2) Il est un étranger venu du bout du monde, appartenant à un peuple presque légendaire (peu importe si ce peuple est de la race des cynocéphales ou des géants) ;

3) Puisqu'il est étranger, venu d'un lieu et d'une époque étrange, saint Christophe est terrible. Il est un monstre terrifiant pour tout le monde excepté les chrétiens, qui ne trouvent pas, dans la logique de la légende, que sa tête d'animal et sa taille soient extraordinaires. Pour les chrétiens, Saint Christophe est un être exceptionnel, mais aussi un homo sacer (homme sacré) ${ }^{4}$ par excellence, parce que la perception médiévale de sainteté, aussi bien que de dévotion complète et suprême à Dieu, exige qu'un homme sacré et dévoué ne soit point pareil aux hommes ordinaires.

\footnotetext{
${ }^{4}$ En ce qui concerne certains aspects sociopolitiques du problème, voir AGAMBEN, Homo Sacer.
} 
Dans cette optique, les questions principales qui se posent sont : a) Quels sont les limites de la monstruosité acceptable pour l'église chrétienne en Orient et en Occident? b) Dans quelle mesure l'homme européen contemporain est capable d'accepter, voir de comprendre la 'monstruosité naturelle' des choses sacrales, c'est-à-dire, dans quelle mesure la perception du sacré a changé ?

\section{Saint Christophe était-il un monstre terrible pour les croyants médiévaux?}

D'après la tradition médiévale, l'homme à tête d'animal est un exemple «classique » de monstre. La monstruosité consiste, dans ce cas, dans l'hybridation, ${ }^{5}$ qui est contre les lois de la nature (anomalia) et qui provoque un désordre. Elle consiste aussi dans le fait que l'homme-animal n'appartient ni au monde cultivé des hommes, ni au monde sauvage des bêtes. 6 Mais le cas des hommes-loups est bien particulier, parce que l'aperception (dans l'esprit de Kant) médiévale de ces êtres étranges était tout à fait différente de l'aperception de la plupart des autres monstres, aussi bien que de notre perception moderne au sujet de l'apparence d'un saint chrétien (plus spécialement d'un saint militaire et guérisseur). Voyons donc quelles sont les traditions relatives - pas seulement mythologiques et hagiographiques, mais aussi scientifiques, iconographiques et rituelles - qui ont permis l'apparition, mais aussi la propagation très large et durable, de l'image de Saint Christophe à tête d'animal dans l'Église Orthodoxe d'Orient.

\section{$4 \quad$ Lupus in fabulis: Les mythes des peuples cynocéphales}

La cynocéphalie (du grec ancien $\kappa v v o \kappa \varepsilon ́ \phi \alpha \lambda o \varsigma$, 'tête du chien') désigne le fait de posséder une tête de chien, et caractérise surtout des humanoïdes possédant une tête canine ou celle d'un animal apparenté, comme les hyènes ou les chacals. Cette particularité peut concerner aussi bien des divinités que des créatures humanoïdes et thériantropes, c'est-à-dire, en partie humaines et animales. Le terme est utilisé de manière générale pour désigner ces catégories de divinités et de créatures. 'Cynocéphale' est aussi le nom d'une créature spécifique, présente dans les bestiaires médiévaux. On dit souvent que la symbolique cynocéphale sert généralement à mettre en avant la sauvagerie et la bestialité. En fait, l'image du cynocéphale est loin d'être un simple symbole de la sauvagerie et de la férocité, même si les grands héros légendaires comptent parmi leurs exploits un combat réussi contre ces 'hommes-bêtes'.7 On peut s'en convaincre, par la lecture du premier texte détaillé

\footnotetext{
${ }^{5}$ KAPPLER, Monstres, démons et merveilles, pp. 146-156 (plus spécialement pp. 154-156).

${ }^{6}$ Agamben, Homo Sacer, pp. 124-132.

7 Voir Green, Arthuriana, p. 61.
} 
sur les cynocéphales, écrit au $5^{\text {ème }}$ siècle av. J.-C. par le médecin grec Ctésias et conservé dans la Bibliothèque de Photios :

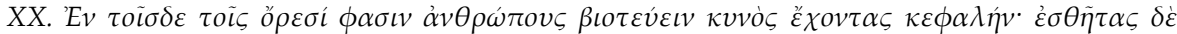

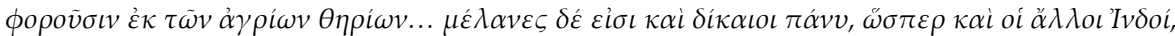

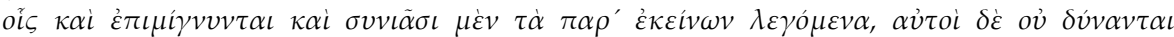

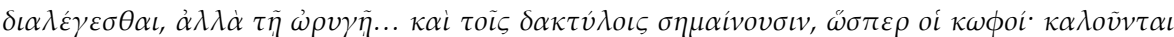

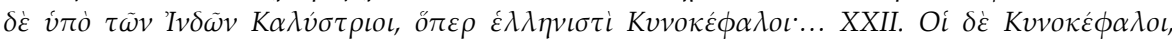

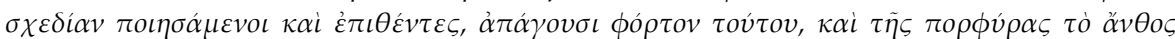

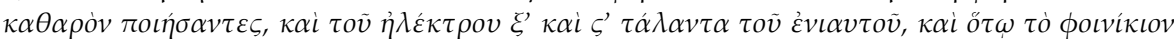

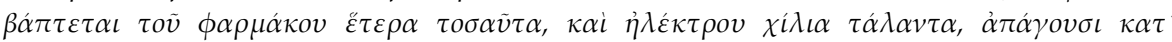

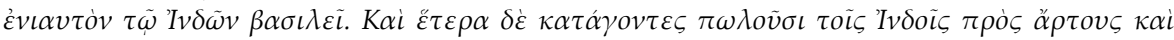

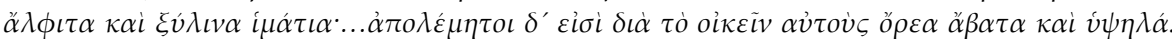

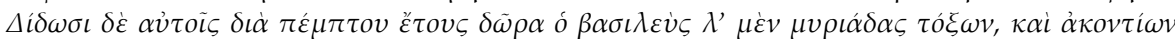

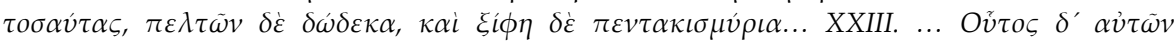

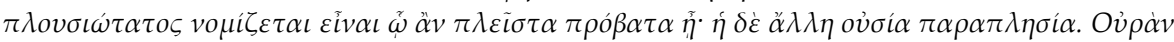

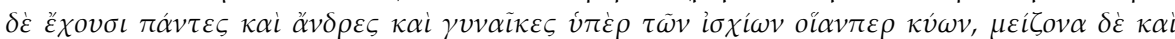

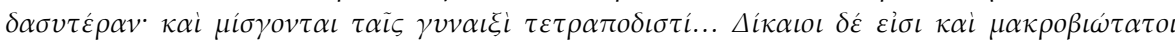

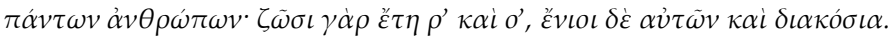

(XX. Dans ces montagnes il y a des hommes qui ont une tête de chien, dont les vêtements sont de peaux de bêtes sauvages. .... Ils sont noirs et très justes, de même que le reste des Indiens avec qui ils sont en commerce ; ils entendent la langue indienne, mais ils ne peuvent répondre que... par des signes qu'ils font avec les mains et les doigts, comme les sourds et muets. Les Indiens les appellent dans leur langue Calystriens, ce qui signifie Cynocéphales. ...XXII.... Ils offrent aussi tous les ans au Roi d'une quantité égale de teinture rouge et de mille talents d'ambre. Ils vendent le reste aux Indiens, et tirent en échange du pain, de la farine et des étoffes de coton... Ils sont invincibles, parce qu'ils habitent des montagnes... Le Roi leur envoie tous les cinq ans en présent trois cent mille arcs, autant de javelots, cent vingt mille peltes, et cinquante mille épées... XXIII... Ils ont tous, hommes et femmes, une queue au-dessus des fesses, comme les chiens ; mais elle est plus longue et plus velue... Ils sont justes, et ce sont de tous les hommes ceux qui vivent le plus longtemps. Ils poussent leur carrière jusqu'à cent soixante-dix ans, et quelques-uns jusqu'à deux cents. $)^{8}$
\end{abstract}

Des célèbres voyageurs médiévaux, comme Giovanni de Pian del Carpine et Marco Polo, mentionnent tous des cynocéphales, étant en désaccord seulement sur le point des têtes humaines des femmes cynocéphales, qui les distinguent des hommes cynocéphales possédant les museaux des chiens. Même si les savants, comme l'éditeur des géographies médiévales CORDIER, insistent sur l'influence dominante du Roman d'Alexandre sur l'imaginaire des voyageurs médiévaux, l'influence plus forte est sans doute celle de Ctésias, dont le récit est incomparablement plus riche et contradictoire, permettant l'apparition d'une iconographie relative, où nous pouvons trouver le cynocéphale dans le rôle du 'méchant sauvage', mais aussi du 'bon sauvage' et d'un homme tout à fait ordinaire (qui par exemple habite dans les villes et paye comme tous les autres des impôts au roi) qui se distingue seulement par sa tête d'animal.

8 Photios, Bibliothèque, 72. 
Dans cette optique, on doit ajouter que, pour l'homme médiéval, les cynocéphales étaient des êtres réels, pour ne pas dire familiers. Ainsi, Saint Augustin déclare que, dans sa sagesse, Dieu a créé les « races monstrueuses »- y compris la race des cynocéphales - pour donner à la Création une harmonie parfaite :

Quid dicam de Cynocephalis, quorum canina capita atque ipse latratus magis bestias quam homines confitetur? [...] Verum quisquis uspiam nascitur homo, id est animal rationale mortale [...]. Qualis autem ratio redditur de monstrosis apud nos hominum partubus, talis de monstrosis quibusdam gentibus reddi potest. Deus enim creator est omnium, qui ubi et quando creari quid oporteat uel oportuerit, ipse nouit, sciens uniuersitatis pulchritudinem quarum partium uel similitudine uel diuersitate contexat.

(Que dirai-je des cynocéphales que leur tête de chien et même l'aboiement rangent plutôt parmi les bêtes que parmi les hommes ? [...] Mais quelque part et de quelque figure que naisse un homme, c'est-à-dire un animal raisonnable et mortel [...]. La raison que l'on peut rendre de certains enfantements monstrueux, on peut s'étendre à certaines races monstrueuses. Dieu, créateur de toutes choses, sait par quelles nuances de similitudes et de contrastes il doit ordonner la beauté de l'ensemble.) $)^{9}$

Quelques siècles plus tard (vers la fin du 8ème siècle), Paul le Diacre témoigne d'une stratégie lombarde utilisée contre les Assipites, dont l'armée était beaucoup plus forte et nombreuse que celle des Lombards: « Simulant [Langobardi], se in castris suis habere cynocephalos, id est canini capitis homines. Divulgant apud hostes, hos pertinaciter bella gerere, humanum sanguinem bibere et, si hostem adsequi non possint, proprium potare cruorem. » (Ils [les Lombards] prétendent qu'ils ont dans leurs camps des Cynocéphales, c'està-dire des hommes à tête de chien. Ils répandent la rumeur chez l'ennemi que ces hommes font la guerre obstinément, boivent du sang humain et leur propre sang s'ils ne peuvent pas atteindre l'ennemi). ${ }^{10}$ La peur des Assipites était si forte qu'ils refusèrent le combat et laissèrent passer les Lombards à travers leurs terres. De plus, les cynocéphales étaient un peuple christianisé dès l'époque des apôtres (d'après l'opinion orientale), ${ }^{11}$ ou bien prêt à être évangélisé (selon les auteurs occidentaux)..$^{12}$ Cette familiarité de l'homme médiéval avec les cynocéphales explique pourquoi Saint Christophe est qualifié librement de cynocéphale, provenant du pays ou bien du peuple des cynocéphales.

Une espèce spécifique de cynocéphales, le lycanthrope, présente peut-être la figure la plus contradictoire et fascinante dans les mythes et l'imagerie antiques et médiévaux. Puisque notre saint est représenté dans l'art byzantin, bulgare et russe le cas de l'art roumain est un peu différent, nous nous attarderons sur lui cidessous - surtout comme un homme à tête de loup et non pas de chien, voyons donc quelle est la portée symbolique de cette image.

\footnotetext{
${ }^{9}$ Augustin, De Civitate Dei, 22. Traduction : JeAn-Claude EsLin.

10 Paul le Diacre, Historia, $1,11$.

11 Voir plus bas l'iconographie des cynocéphales dans la scène de Pentecôte.

${ }^{12}$ Les prouves et les arguments savants et théologiques de Ratramne (fin du 9ème siècle) sur ce sujet sont plus qu'éloquentes. Ratramne de Corbie, Epistola de Cynocephalis, col. 1153-1156. Voir aussi les cynocéphales gravés sur le grand tympan de la cathédrale Sainte-Marie-Madeleine de Vézelay. Pour un commentaire détaillé de cette image dans la perspective de l'attitude originale médiévale vers les cynocéphales, voir Friedman, The Monstrous Races, pp. 77-81 (sur les cynocéphales, pp. 61-86).
} 
Dans ce contexte, bien entendu, on ne doit pas oublier que l'homme antique et médiéval ne faisait pas de différence de taille entre lupus et canis lupus ( $\kappa \hat{v} \omega v$ / $\sigma \kappa v ́ \lambda o \varsigma$ et $\lambda \hat{v} \kappa o \varsigma)$, ce dernier ne signifiant que 'chien libre', 'pas domestiqué'. Voilà pourquoi on distingue, au niveau des images, le lycanthrope du cynocéphale surtout par deux traits : le lycanthrope garde ses yeux d'homme et n'a pas de queue.

\section{$5 \quad$ La portée symbolique du lycanthrope, ou bien Lupus in fabula}

Il semble que les lycanthropes (des mots grecs $\lambda \dot{v} \kappa o \varsigma$ et $\ddot{\alpha} v \theta \rho \omega \pi o \varsigma$, c'est-à-dire 'loup-homme') n'appartiennent pas à une race spécifique. Le lycanthrope est une créature qui change sa forme. Il est donc un être 'magique' et un 'être de passage' par excellence. Ce changement de la forme humaine vers une forme de loup peut être naturel et temporaire/périodique, comme par exemple chez le peuple des Neures décrit par Hérodote au $5^{\text {ème }}$ siècle av. J.-C. : « $\Lambda \dot{\varepsilon} \gamma o v \tau \alpha \iota \gamma \dot{\alpha} \rho \dot{v} \pi \dot{o} \Sigma \kappa v \theta \dot{\varepsilon} \omega v$

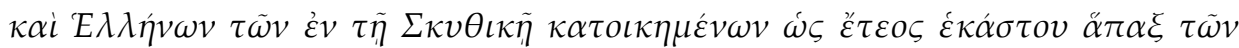

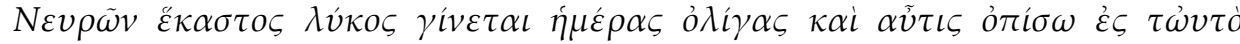
$\kappa \alpha \tau i \sigma \tau \alpha \tau \alpha \iota . »$ (En effet, s'il faut croire les Scythes et les Grecs établis en Scythie, chaque Neure se transforme une fois par an en loup pour quelques jours, et reprend ensuite sa forme primitive). ${ }^{13}$

Mais la mutation peut être constante, une déformation provoquée par une force divine - tel est le cas de Lycaon, puni par Zeus. D’après le mythe, le roi d'Arcadie Lycaon ${ }^{14}$ et ses cinquante fils édifièrent un temple en l'honneur de Zeus au sommet du mont Lycée. Pour les remercier, Zeus vint leur rendre visite sous l'apparence d'un pauvre hère. Aussi comme dans le mythe de Tantale, Lycaon décida de défier le dieu et, au cours du repas, lui a servi un plat à base de la chair du plus jeune de ses fils. Indigné, Zeus foudroya tous les fils du roi (sauf Nyctimos qui monta sur le trône d'Arcadie), et Lycaon fut transformé en loup :

in villos abeunt vestes, in crura lacerti:

fit lupus et veteris servat vestigia formae;

canities eadem est, eadem violentia vultus,

idem oculi lucent, eadem feritatis imago est.

(Ses vêtements se changent en poils, ses bras en jambes, devenu un loup il conserve encore des vestiges de son ancienne forme. Il a toujours le même poil gris, le même air farouche, les mêmes yeux ardents ; il est toujours l'image de la férocité. $)^{15}$

\footnotetext{
${ }^{13}$ Hérodote, Enquêtes, 4, 105.

${ }^{14}$ D'ailleurs, c'est le même Lycaon qui a bâti un temple (et un palais) sur les collines de la montagne Lycaeus, où le dieu principal était le dieu-loup Apollon Lycaeus. Pour ce qui concerne les dieux loups et dieux chiens dans la mythologie grecque et romaine, voir FrankLIN, The Lupercalia; sur le culte d'Apollon Lycaeus, pp. 24-26.

15 Ovide, Métamorphoses, 1, 235-239. Traduction : G. T. Villenave.
} 
L'apparence de loup peut être aussi un maquillage, une ruse guerrière. Le récit le plus ancien et le plus célèbre est lié au troyen Dolon, fils d'Eumédès (dont le nom

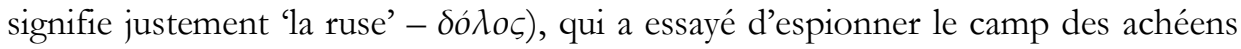
'transformés' en loups blancs. ${ }^{16}$

Se masquer en loup pour combattre non seulement un ennemi, mais aussi les forces du Mal, est un rite très ancien et bien vivant aujourd'hui encore dans les Balkans, par exemple dans la région de Sofia. Ainsi, on voit sur un relief à l'amphithéâtre de Serdica, probablement de la fin du 3ème siècle, plusieurs hommes à tête de loup lutant symboliquement contre des bêtes sauvages et faisant des sacrifices. Même aujourd'hui, tous les ans, au mois de janvier, des hommes habillés comme des loups et appelés кукерu font des processions afin de chasser le Mal de leurs villes ou villages.

Évidemment, les auteurs antiques grecs et romains n'ont pas très bien compris le rite qu'ils ont observé assez souvent et par lequel les hommes guerriers se transformaient - réellement ou symboliquement - en loups et mangeaient de la chair crue (voire de la chaire humaine). Par ailleurs, ce rite était bien répandu chez les peuples thraces - ce que démontre ELIADE dans son enquête sur l'origine du peuple dace (qui fait partie de la recherche monumentale sur les religions de l'Europe du Sud-Est, ${ }^{17}$ intitulée d'une manière bien éloquente "Les Daces et les loups »). D'après ELIADE, les Daces, c'est-à-dire le peuple des gens-loups, ne sont autre que les guerriers thraces, passés par le rite ici commenté et devenus les soldats gardiens de la frontière danubienne de l'œcoumène. Les auteurs grecs et romains racontèrent pendant longtemps les histoires des hommes-loups, parce qu'elles expliquaient au moins la toponymie et les ethnonymes issus du mot 'loup' ou du mot 'chien', si répandus dans la péninsule balkanique et dans les Apennins comme par exemple la Laconie en Messénie ou la Cynocéphalae en Thessalie, les 'villes des loups' - Vukovo et Valchedram en Bulgarie.

\section{Valeur apotropaïque et compromis religieux de l'image du saint à la tête du loup}

Le fait que les peuples balkaniques, parmi lesquels se forment les canons du dogme et de l'art orthodoxe, sont bien accommodés à de pareilles histoires et aux pratiques liées aux soldats-loups, nous donne la clé pour comprendre à la fois l'énigme de leur attachement à l'image de Saint Christophe lycanthrope et la sauvegarde de son rôle de saint militaire et gardien. Si en Occident le géant Christophe ressemble à un soldat en retrait qui a changé son métier de mercenaire pour aider les gens à passer le fleuve dangereux, Christophe l'orthodoxe est en premier lieu un guerrier, et ensuite un saint. C'est la raison pour laquelle on ne le voit presque pas, sur les

\footnotetext{
${ }^{16}$ Homère, Iliade, 10, 199-456. Traduction : Eugene BARESTE.

17 Eliade, De Zalmoxis.
} 
représentations orthodoxes, dépourvu d'armes - comme, par exemple, sur l'icône du Musée Byzantin à Athènes (Tabl. 3) -, mais on peut voir très souvent le saint soldat ne portant que ses armes, c'est-à-dire, sans la croix légitimant sa sainteté (Tabl. 4).

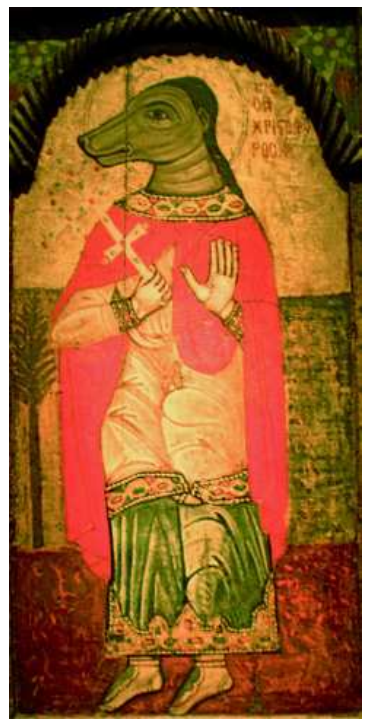

[Tabl. 3, Icone avec Saint Christophe, auteur anonyme, 17ème siècle.]

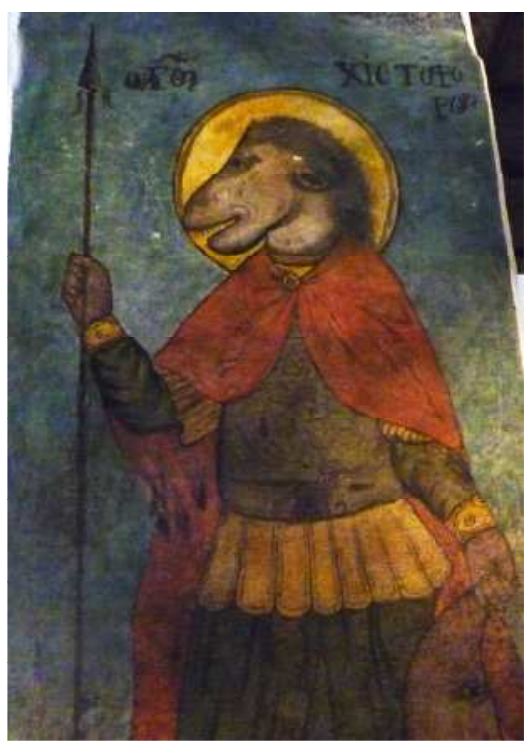

[Tabl. 4, Saint Christophe, anonyme, milieux du 19ème s.] 
Comme dans le cas de la représentation de Saint George tuant le dragon, on observe une sacralisation secondaire par l'introduction d'une main, d'un ange, ou de Dieu lui-même qui bénit Saint Christophe. On peut voir le même désir de la part de l'Église Catholique de confirmer que le bon géant est également un de ses saints officiels par l'introduction de la représentation d'un moine portant une lanterne. Autrement dit, Saint Christophe à tête de loup garde son caractère original mixte de guerrier redoutable et de saint chrétien. Et, si étranges qu'elles nous semblent, ses représentations sont en effet des images invocatrices bien traditionnelles : on prie pour que le terrible saint vienne au secours contre des choses aussi terribles les ennemis, les maladies, les catastrophes naturelles. Chercher une autre explication de l'image du saint-lycanthrope serait pareil au travail long et stérile des savants qui ont essayé de trouver le contexte littéraire de la célèbre anecdote de Térence «Lupus in fabula», ${ }^{18}$ parce que la sentence porte son sens en soi: Lupus in fabula ne signifie rien d'autre que le loup dans le mot 'loup' - autrement dit, le loup qui apparaît tout de suite quand on prononce son nom.

Le saint guerrier est une figure qui a été et reste toujours, dans la pensée orthodoxe, problématique. Tuer est un péché capital, mais le métier du soldat est justement celui de tuer. C'est pour cette raison que l'Église Constantinopolitaine a refusé d'accepter même l'image de Saint George tuant le dragon, dont la représentation reste provinciale, c'est-à-dire profondément marquée par les traditions locales. Ne parlons pas d'autres types de saints guerriers, tuant non pas un monstre l'image métaphorique du $\mathrm{Mal}$-, mais un ennemi humain ou un personnage précis - tel Saint Mercure tuant Julien Apostat ou bien Saint Démétrios tuant le roi bulgare Kaloyan. Dans cette optique, il nous semble beaucoup plus acceptable que le fait que le saint peut aussi tuer soit masqué sous une image mixte de l'homme chrétien qui ne tue point et de la bête gardienne qui peut le faire. En d'autres termes, si les autres saints sont 'les agneaux au milieu des loups', selon les paroles de JésusChrist - «Allez: voici que je vous envoie comme des agneaux au milieu des loups »; $1^{19}$ "Voici, je vous envoie comme des brebis au milieu des loups. Soyez donc prudents comme les serpents, et simples comme les colombes $»^{20}-$, le saint guerrier est un agneau en peau de loup, un antipode aux hérétiques dans le vocabulaire néotestamentaire, qui sont des loups dans des peaux d'agneau. Grâce à cette rhétorique, propre aux textes chrétiens primitifs, l'image de Saint Christophe à tête de loup devient tout à fait normale.

Il semble que l'Église roumaine a compris la sentence biblique des agneaux au milieu des loups d'une manière particulière. D'après MARIN-BARUTCIEFF, des 120 images de Saint Christophe en Roumanie, plus de 50 sont d'un saint à tête d'agneau. ${ }^{21} \mathrm{Il}$ ne reste qu'à demander si les pères roumains ont suivi la même lo-

\footnotetext{
${ }^{18}$ Voir à ce sujet l'article d'Aввотт, Lupus in Fabula, pp. 117-122.

${ }^{19} \mathrm{Luc} .10,3$.

20 Mattbieu 10, 16.

${ }^{21}$ Marin-BarutciefF, Insuportabila, pp. 32-34.
} 
gique pieuse que Grégoire de Tours qui, dans la Vie de Saint André, 'corrige' le texte original en effaçant le détail de la mission de Saint Mathias, accomplie avec l'aide de Saint André, d'aller justement chez les androphages et cynocephales. ${ }^{22}$

Par ailleurs, dans l'art chrétien primitif, à part le saint guerrier, tous les grands saints ont été également dépeints comme des êtres surnaturels à travers des images d'hommes-animaux. Sans aucun doute, le cas le plus connu est la représentation des évangélistes, dont l'iconographie en Orient et en Occident est très proche de celle de Saint Christophe à tête de chien/loup.

Il est impossible de préciser dans quelle mesure la tradition hébraïque, selon laquelle tous les êtres célestes qui hantent le monde terrestre sont dépeints sous une forme anthropo-zoomorphe, a influencé la tradition chrétienne. D'après AMEISENOWA, c'est justement la tradition juive (infiltrée auparavant par les traditions égyptiennes et chaldéennes/perses) qui se reflète d'une manière directe dans l'iconographie des évangélistes et, plus tard, dans celle de Saint Christophe. ${ }^{23}$ En tout cas, nous pouvons affirmer que l'existence de l'iconographie zoomorphe des évangélistes était la légitimation nécessaire et la sanctification obligatoire au sein de la tradition chrétienne, permettant non pas l'apparition mais la perduration de l'image relative à Saint Christophe. Dans cette logique, il est plus qu'évident que l'iconographie de Saint Christophe repose sur des textes sacrés existants, comme les récits bibliques d'Ezéchiel, de Daniel et de l'Apocalypse, des quatre animaux qui ont légitimé et sacralisé l'iconographie 'tetramorphe' des évangélistes. ${ }^{24}$

Dans notre cas, les textes donnant légitimité suffisante à l'image spécifique anthropo-zoomorphe de Saint Christophe cynocéphale sont Les Actes des apôtres Andrée et Mathias et Les Actes des apôtres Bartholomé et Andrée. D'ailleurs, ils peuvent être qualifiés d' 'apocryphes', dans la mesure où un texte pareil - Voyages des Apôtres - a été proclamé 'interdit' au cours de la cinquième session du septième concile œcuménique en 787. «Quoiqu’il fût favorable au culte des images, le concile défendit de le transcrire, et le condamna au feu $\gg .{ }^{25}$ Cette remarque brève à propos de la condamnation en question démontre le fait que ce texte était bien répandu au moins jusqu'à la fin du $8^{\text {ème }}$ siècle et, de plus, qu'il était considéré jusqu’à cette époque comme bien canonique. Quels ont été les arguments des pères du Septième concile pour prohiber la traduction du texte, et en quelle langue était cette traduction, nous l'ignorons. Mais nous pouvons être sûrs que la condamnation n'était pas prise très au sérieux, parce que le nombre des copies des Voyages au Moyen Âge était bien impressionnant - par exemple, on connaît plus de 60 manuscrits des Actes des apôtres Andrée et Mathias en langues slaves, c'est-à-dire, les copies faites après le Septième concile œcuménique.

\footnotetext{
22 Grégoire de Tours, Liber de Miraculis, pp. 34-39.

23 AmeISENOWA, Animal-Headed Gods, pp. 34-45.

${ }^{24}$ Ézéchiel 1, 1-14 ; Daniel 7, 1-8 ; Apocalypse 4, 7-8. Sur ce sujet, voir aussi l'article d'ANDERSEN dans ce même volume.

${ }^{25}$ Sacrorum Conciliorum, vol. 13, col. 158-204 ; SEILLIER, Histoire générale, t. 20, p. 807.
} 
Il est vrai que les peuples orthodoxes, et plus particulièrement les peuples des pays slaves, ont été plus touchés par les récits des actes apocryphes, dans la mesure où il s'agit dans ces récits des missions évangélisatrices des apôtres justement dans leurs pays - les Balkans et la Scythie. Ces missions placent la christianisation des futures 'terres slaves' parmi les premières régions où la foi chrétienne a été semée par les apôtres eux-mêmes. Le fait que l'auteur anonyme des Actes trouve ces pays lointains, fort sauvages et peuplés de cynocéphales n'offense point l'auditoire en question. N'oublions pas que les bulgares, dans la dite Légende de Thessalonique, racontant la mission de Saint Constantin le Philosophe en Bulgarie, se caractérisent euxmêmes comme 'androphages', et que même en plein dixième siècle Liutprand, l'évêque de Crémone, affirme que les membres de la famille royale bulgare étaient magiciens et pouvaient se transformer en loups, en chiens et en n'importe quelle bête. ${ }^{26}$ Voilà pourquoi, par exemple, les peintres arméniens situent la figure d'un cynocéphale au milieu de la scène de Pentecôte, leurs collègues russes font prêcher Jésus-Christ parmi les hommes-chiens et les représentations du Saint Christophe cynocéphale ne semblent guère déplacées même sur les colonnes près de l'autel. Ce contexte néotestamentaire justifie aussi l'apparition de Saint Christophe en compagnie non seulement d'autres saints guerriers, comme Saint George et Saint Mercure, mais aussi de Saint Étienne, le premier martyr, de l'Archange Saint Michel et de Saint Nicolas, de Sainte Sophie (La Sagesse) et ses trois filles - la Foi (Vjara), l'Éspérance (Nadejda) et l'Amour (Ljubov), en compagnie de Saint Pantaléon et Saint Jean Batiste, des 'saints russes choisis', etc.

En ce qui concerne les représentations occidentales, Saint Christophe, qui est toujours en compagnie de Jésus-Christ, partage parfois aussi la compagnie de certains docteurs de l'Église Catholique, comme Saint Jérôme, Saint Augustin et Saint Thomas d'Aquin, et des plus célèbres saints comme Saint Antoine et Saint Sébastien. À propos des rapports entre Saint Christophe et Saint André, il suffirait de dire que la fête de Saint Christophe dans le monde Orthodoxe, le 9 mai, coïncide avec la fête de la translation de la dépouille du Saint André de Patras à Constantinople (le 9 mai 357). Du même, la fête de Saint André, appelé dans la tradition populaire des Balkans « le pasteur des loups »- le 30 novembre - ferme la période des «jours des loups », qui commencent le 11 novembre - le jour de Saint Menas, dont le culte, selon certains chercheurs, double celui de Saint Christophe.

\section{Du « saint par excellence » au « saint mineur »}

Nous nous contenterons de citer la conclusion de SAINTYVES : «St. Christophe devint au Moyen Âge le saint par excellence $\gg .{ }^{27}$ En Orient, les gens placent les images de Saint Christophe partout - dans les églises, mais aussi sur les ponts et

${ }^{26}$ Liutprand de Crémone, Antapodosis, 3, 29.

27 SAINTYVES, Saint Christophe, p. 35. 
même dans leurs maisons. En Occident, les statues du saint, parfois gigantesques (la plus grande étant probablement celle de la cathédrale de Strasbourg, d'une hauteur de 36 pas, ${ }^{28}$ c'est-à-dire, un pas plus haute que la statue de Notre-Dame de Paris) ont fait un élément obligatoire du paysage urbain. ${ }^{29}$ On trouve Saint Christophe même parmi les images mystérieuses gravées sur les murs de la grotte de Royston en Angleterre, où il était vénéré, peut-être, par les templiers avant leur condamnation par le pape Clément V en 1312. On pourrait néanmoins supposer qu'un jour l'apparence étrange de Saint Christophe allait provoquer la protestation de gens ne pouvant pas comprendre le sens symbolique et la portée historique d'un saint géant ou d'un saint à tête d'animal. Cette réaction apparait au 17 ème et surtout au 18 ème siècles.

En Russie, deux rescrits officiels - de 1667 et de 1722 - essayent d'interdire la représentation du saint à tête de chien en remplaçant la tête d'animal, qui est 'contre la nature', par une tête d'homme ordinaire et privée de traits spécifiques. Cela est très clair sur la fresque de Yaroslaval Spasko-Preobrajenskij monastère du $17^{\mathrm{ème}}$ siècle, où transparait la réfection bien visible de la tête du saint (Tabl. 4). En Byzance, ou bien par exemple en Bulgarie médiévale et contemporaine, on ne peut trouver aucune réaction officielle contre cette iconographie très particulière et, apparemment, non-chrétienne. On garde une distance de ce saint inquiétant et, dans la plupart des Vies de Saint Christophe publiées dans les recueils modernes, on peut voir une note de la sorte : «On dit parfois que St. Christophe a eu la tête du chien. Le Synaxaire orthodoxe refuse l'apparence canine du saint $» .^{30}$ En général, dans les pays orthodoxes aujourd'hui, les fidèles sont très étonnés d'entendre que dans 'leur' église existe une pareille image d'un saint cynocéphale. Cet étonnement est visible dans l'avant-propos de toutes les recherches dont les auteurs se croient obligés de raconter qui était Saint Christophe et quelle était, 'parfois', au Moyen Âge son iconographie. Autrement dit, on ignore ou bien on essaye d'ignorer le fait que cette iconographie n'était pas accidentelle et curieuse, mais bien commune et officielle, compte tenu que le saint cynocéphale se trouve non seulement sur les icônes (objets sacrés mais moins chers, portables et échangeables, faits souvent par des peintres pas très habiles et instruits, ce qui permet des aberrations du canon), mais surtout sur les murs et les colonnes des églises.

Il est inutile d'expliquer que les images de Saint Christophe à tête d'homme, modernes et estimées comme plus convenables aux églises, ainsi que l'image occidentalisée du Saint Christophe portant sur son épaule l'enfant Jésus, dépersonnalisent le saint en question et le présente comme n'importe quel saint dans le premier cas et, dans le deuxième, comme un saint dont l'image ne correspond point à sa vie connue grâce à l'hagiographie traditionnelle orthodoxe. De la même

\footnotetext{
28 36x30, $48=12,50 \mathrm{~m}$. D'ailleurs, c'est l'hauteur d'un des 'miracles' du monde ancien : la statue de Zeus en Olympie.

${ }^{29}$ Voir par exemple Home, The Evolution, p. 122-126.

30 Жития на светиите, сьставени, t. 5, p. 241, note 2.
} 
façon, les pères d'un Concile catholique du milieu du 20ème siècle (le célèbre Vatican II) ont destitué Saint Christophe - le bon géant qui a porté l'enfant Christ et dont le culte désormais n'est plus 'universel' mais seulement admissible comme un culte local et qui n’appartient pas à la tradition romaine, bien que les récits hagiographiques soient très anciens. D’ailleurs, déjà au début du 16ème siècle, Erasme de Rotterdam, dans L'Éloge de la folie, ridiculise Saint Christophe : "His rursum adfines sunt $i i$, qui sibi stultam quidem, sed tamen iucundam persuasionem induerunt, futurum, ut si ligneum, aut pictum aliquem Polyphemum Christophorum adspexerint, eo die non sint perituri» (Il existent des gens qui, par une folle mais douce persuasion, se figurent que la rencontre d'une statue ou d'une peinture de ce Polyphème de St. Christophe les assure de ne point mourir dans la journée). ${ }^{31}$ Si on fait confiance à la statistique noire faite par SAINTYVES, au 18 ème siècle, même avant la Révolution, les esprits 'illuminés' de l'époque ont commencé une 'guerre' contre les statues monstrueuses de Saint Christophe, desquelles n'ont survécu probablement que la statue de Cologne (qui avait des dimensions assez modestes par rapport aux statues démolies) ${ }^{32}$ et la fresque de l'église Saint-Pierre-et-Saint-Paul à Wissembourg. Si l'on regarde les talismans contemporains portant l'image du Saint Christophe - les porte-clés, les tire-bouchons, les médaillons etc. -, on peut se rendre compte de l'évolution énorme du culte du saint. Elle a fait du terrible saint géant protecteur de la communauté un saint 'privé' et 'du poche', dans le sens propre et figuré du terme. Les processions des géants, dans lesquelles Saint Christophe, occupent une place centrale, n'apparentent qu'au dit 'patrimoine culturel', et ne présentent qu'une attraction touristique même dans certaines régions, comme par exemple au Pérou. ${ }^{33}$

Quant au Christophe le cynocéphale, l'Église Occidentale ne trouve pas important de s'arrêter sur ce sujet, qualifié de 'proprement oriental'. Ce qui mérite l'attention est que la même opinion - le Saint Christophe cynocéphale est un phénomène oriental - est partagée aussi par les savants, y compris les savants laïcs qui

\footnotetext{
${ }^{31}$ Erasme de Rotterdam, L'Éloge de la folie, 40, p. 70. L'analogie avec Polyphème de la mythologie grecque est bien adéquate non seulement parce que Christophe est un géant - il avait 12 coudés (environ 5, $4 \mathrm{~m}$ ) -, mais aussi car, selon la Légende Dorée, le miracle le plus célèbre qu'il ait achevé post mortem fut la guérison miraculeuse de l'œil crevé de son bourreau. Voir la fresque d'Andrea Mantegna (1448-1457) à l'Église des érémitiques de Padoue.

32 SAINTYVES, Saint Christophe, pp. 22-26.

33 À ce propos, on peut admettre que même les processions des géants sont parfois expliquées par une tradition d'origine orientale. Par exemple, le culte de Saint Christophe à Flobecq se développa pendant la deuxième moitié du $13^{\text {ème }}$ siècle, quand la comtesse Marguerite de Constantinople a donné les reliques de ce saint, apporté par un évêque allemand (qui en toute évidence se les est appropriées après la chute de la capitale byzantine en 1204) à l'église de Flobecq en 1260 (cf. LEDOUx, Un autre saint). Une légende pareille explique le culte de Saint Christophe à l'Île de Rab en Croatie : selon la tradition locale, c'est le patriarche Nicéphore qui a envoyé les reliques de Saint Christophe à l'évêque de l'Église de Rab en 806. Il ne resta qu'à demander si ces dépouilles, venues de Constantinople, ont été des restes d'un cynocéphale ou bien d'un géant. D'après la tradition occidentale, toutes les reliques de Saint Christophe ont été considérés comme authentiques à cause de leurs dimensions gigantesques (cf. Coldin de Plancy, Dictionnaire critique, pp. 142-145). Par ailleurs, peut-être à cause de son image étrange, le culte de Saint Christophe en Orient n'était pas lié à ces reliques.
} 
ne s'intéressent pas trop à la position officielle de l'Église. Ainsi, on peut voir les constatations suivantes : «En Occident, où la dévotion à saint Christophe a été très répandue au Moyen Âge, il n'apparaît pas que ce saint ait jamais été représenté en cynocéphale $»^{34}$; "Dans l'art byzantin Saint Christophe à tête de chien était largement répandu mais en Occident existe-il seulement un exemple $»^{35} ;$ «En Occident on peut trouver seulement deux pareilles images [de Saint Christophe à tête de chien] ${ }^{36}$; «L'image de St. Christophe à tête de chien, par exemple celle qui se trouve sur un vitrail de la cathédrale d'Angers résulte sans doute 'd'une restauration mal effectuée' » ${ }^{37}$; "Le fait qu'un bon nombre des plus anciennes représentations du St. Christophe cynocéphale se trouve dans les manuscrits illuminés occidentaux est dû à l'iconoclasme byzantin qui a détruit les images prototypes orientales $»^{38}$.

Le même processus de dépersonnalisation marque les recherches scientifiques. Elle est assez nette, même chez les auteurs impressionnés par l'image du saint cynocéphale, comme par exemple SAINTYVES, AMEISENOWA et WHITE. SAINTYVES insiste sur l'idée que Saint Christophe reprend l'image des dieux égyptiens et grecs. AMEISENOWA et WHITE cherchent dans l'image du saint cynocéphale des répliques des divinités hébraïques, perses et égyptiennes, transformées via la philosophie gnostique. Aucun des ces auteurs ne perçoit une origine européenne du culte.

Il semble que ROSENFELD est le premier à avancer la thèse selon laquelle la légende provient d'un récit gnostique, où l'on parle d'un monstre anthropophage à tête de chien qui, par le baptême, prend le nom de Christianus ou Christophorus. ${ }^{39}$ Dans la même direction sont orientées les conclusions de GEERARD, qui voit dans Saint Christophe une image tardive de Christomaios, un des premiers disciples de Saint André selon les Actes apocryphes de St. André et St. Matthieu. Il n'est pas impossible que l'auteur anonyme des Actes ait été un philosophe gnostique de l'Antiquité tardive. ${ }^{40}$ Les chercheurs contemporains sont plus inclinés à penser en Saint Christophe comme un homme réel, caché sous l'image hagiographique héroïsée. Ainsi, WOODS insiste sur l'identité entre Saint Christophe et Saint Menas, un autre martyr des premiers siècles de notre ère, qui est devenu un des assez célèbres saints militaires byzantins. ${ }^{41}$ À son tour, NAKONECHNIJ croit à une contamination entre

\footnotetext{
34 Voir Laroque, Annales archéologiques, t. 21, pp. 121-125 (plus spécialement p. 122).

35 STRICKLAND, Monsters, p. 45 : «Dogheaded St. Christopher portraits are fairly common in Byzantine art, but in the West there is only one known example».

36 Les deux exemples cités par Ameizenowa sont : Saint Christophe à tête de chien dans un manuscrit du $12^{\text {ème }}$ siècle et Saint Christophe représenté sur la fenêtre de la Cathédrale d'Angers, au même temps à tête de chien et géant, portant l'enfant Jésus sur son épaule. AmEISENOwA, Animal-Headed Gods, p. 43.

37 Augereau, Angers mystérieux, p. 33.

38 White, Myths of the Dog-Man, p. 35.

39 Rosenfeld, Der Hl. Christophorus.

40 Geerard, Clavis Apocriphorum, pp. 141-144.

41 Woods, The Military Martyrs. Chez WoODS, on aperçoit aussi une tendance d'affiliation du culte de Saint Christophe à la personnalité de Théophile l'Indien.
} 
Saint Christophe, un personnage légendaire du temps de Decius, et Saint Chris-

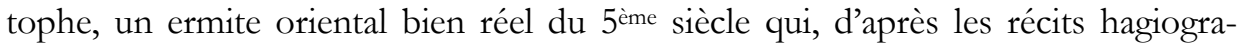
phiques, se caractérisait aussi par une grande taille. ${ }^{42}$ Le chercheur russe ne s'inquiète pas du fait que Saint Christophe, dans l'iconographie orientale dont il parle, se caractérisait non pas par sa grande taille - c'est le cas du géant Saint Christophe de récits occidentaux -, mais bien d'une apparence zoomorphe. D'autres, comme par exemple WALTER, refusent toute historicité à la légende du saint à tête de chien. ${ }^{43}$

En conclusion, l'européen contemporain ne peut guerre accepter l'image médiévale de Saint Christophe, soit l'image du cynocéphale soit celle du géant. La conception de 'notre' religion et de 'nos' propres traditions culturelles exclut le saint terrifiant, en voyant en lui un monstre incompatible avec 'nos' valeurs religieuses et humaines, aussi bien qu'avec 'nos' critères esthétiques. Et tout cela pose la question bien sérieuse : est-ce que cette religion et ces traditions sont les mêmes que nous avons réellement hérité de 'nos' ancêtres médiévaux, ou bien notre mémoire collective moderne a-t-elle crée une autre 'réalité médiévale', moins choquante pour l'homme contemporain, pour lequel la déformation monstrueuse du corps humain ne peut provoquer que le dégoût, la confusion, le malentendu ou la pitié ?

\section{Index des illustrations}

[Tabl. 1] Saint Christophe et Saint Mercure, anonyme, 18 ème s., Monastère de Rojen, Église de la Nativité, Bulgarie. Photo : B. PENKOVA.

[Tabl. 2] Saint Christophe, anonyme, $15^{\text {ème }}$ s., gravure sur bois. Source : site web de DAVID WOODS sur http://www.ucc.ie/milmart/chrswstart7l.jpg (consulté le 7 mars 2011).

[Tabl. 3] Icone avec Saint Christophe, auteur anonyme, Asie Mineure, 17ème siècle (d'après l'inscription du musée). Musée Byzantin, Athènes. Photo: G. ANTUNES.

[Tabl. 4] Saint Christophe, anonyme, milieux du 19ème s., Église de la Dormition, Chiroka Laka, Bulgarie. Photo : V. VATCHKOVA.

${ }^{42}$ НАКОНЕЧНЫЙ, Святой псеглавец, рр. 172-179.

43 WALTER, The Warrior Saints, p. 214ff. 


\section{Sources}

Augustin, Sancti Aurelii Augustini Hipponensis Episcopi De civitate Dei. Leipzig 1825.

Augustin, La Cité de Dieu. Traduction française de Louis Moreau, revue par JEANClaude EsLin. Paris 1994.

Erasme de Rotterdam, L'Éloge de la folie. Avec les illustrations de HANS HOLBEIN. Paris 1964.

Grégoire de Tours, Liber de Miraculis Beati Andreae Apostoli. In : Libri Miraculorum aliaque Opera Minora. Paris 1874.

Hérodote, Enquêtes. Édition bilingue. Traduction française de: PIERRE-HENRI LARCHER : http://mercure.fltr.ucl.ac.be/Hodoi/concordances/intro.htm\#Herodote. (Stand: 7/3/2011).

Homère, Iliade. Édition bilingue. Traduction française de : EUGENE BARESTE : http://remacle.org/bloodwolf/poetes/homere/table.htm (Stand: 7/3/2011).

Jacques de Voragine, La légende dorée. Florence 1998.

Liutprand de Crémone, Antapodosis. In : Opera omnia (Antapodosis, Homelia Paschalis). MGH, SRM 3. Bonn 1838.

Ovide, Métamorphoses. Texte latin: http://www.thelatinlibrary.com/ovid/ ovid.met1.shtml. (Stand: 7/3/2011).

Ovide, Métamorphoses. Traduction française de G.T. VILlenAve: http://bcs.fltr.ucl.ac.be/meta/01.htm. (Stand: 7/3/2011).

Paul le Diacre, Historia gentis Langobardorum. In : MGH, SRLI. Hanovre 1878.

Photios, Bibliothèque, 72. Édition bilingue: http://remacle.org/bloodwolf /erudits/photius/table.htm. (Stand: 7/3/2011).

Ratramne de Corbie, Epistola de Cynocephalis ad Rimbertum presbyterum scripta. In : PL 121, col. 1153-1156.

Sacrorum Conciliorum nova et amplissima collectio, vol. 13. Édité par JEAN MANSI. Florence 1767.

Жития на светиите, съставени от свети Аимитрий митрополит Ростовски, t. 5, Май. Света Гора, Атон 2001. 


\section{Littérature secondaire}

Аввотт, KenNeth M., Lupus in Fabula. In: The Classical Journal, vol. 52, 3 (1956), pp. 117-122.

Agamben Giorgio, Homo Sacer. Il potere sovrano e la nuda vita. Torino 1995.

Ameisenowa, ZofiA, Animal-Headed Gods, Evangelists, Saints and Righteous Men. In : Journal of the Warburg and Courtauld Institutes 12 (1949), pp. 21-45.

Augereau, Pierre-Louis, Angers mystérieux. Grasse 2002.

COllin De Plancy, JACQUes-Albin Simon, Dictionnaire critique des reliques et des images miraculeuses. Paris 1821.

Eliade, MirCEA, De Zalmoxis à Gengis-Khan. Études comparatives sur les religions et le folklore de la Dacie et de l'Europe orientale. Paris 1970.

FrankLin, Alberta Mildred, The Lupercalia. New York 1921.

Friedman, John Block, The Monstrous Races in Medieval Art and Thought. Cambridge et. al. 1981.

GeERARD, MavritiI, Clavis Apocriphorum Novi Testamenti, Conversio Christomaei. Turnhout 1992.

Green, Thomas, Arthuriana. Early Arthurian Tradition and the Origins of the Legend. Louth 2009.

Home, Gordon, The Evolution of an English Town. Londres 1905.

KaPPler, Claude, Monstres, démons et merveilles à la fin du Moyen Âge. Paris 1980.

LAROQUe, JEAN-BAPTISTE EdOUARD, Saint Christophe. In : Annales archéologiques, t. 21. Édité par DIDRON AINE. Paris 1861, pp. 121-125.

LEDOUX, CLAUdE, Un autre saint, un autre village, Flobecq. Extraits des annales du CHER n 5 (2004). http://www.ellezelles.com/cher/saint-christophe.html. (Stand: 7/3/2011).

MARIN-BARUTCIEFF, SILVIA, Insuportabila uşurătate a frumuseții. Hristofor, sfântul cu chip de miel. In : Idei in dialog 9 (2008), pp. 32-34.

НАКОНЕЧНЫЙ, СЕРГЕЙ, Святой Псеглавец. In : Начало 14 (2007), pp. 172-179.

Rosenfeld, Hans Friedrich, Der Hl. Christophorus. Seine Verehrung und seine Legende. Leipzig 1937.

SAINTYVES, PIERRE, Saint Christophe successeur d'Anubis, d'Hermès et d'Héraclès. Paris 1936. 
SEILLIER, REMI, Histoire générale des auteurs sacrés et ecclésiastiques 20. Paris 1747.

Strickland, Debra Higgs, Monsters and Christian Enemies. In : History Today, vol. 50 (2000), pp. 45-51.

Walter, Christopher, The Warrior Saints in Byzantine Art and Tradition. Aldershot/Burlington 2003.

White, David Gordon, Myths of the Dog-Man. Londres 1991.

Woods, DAVID, The Military Martyrs. St. Christophe. http://www.ucc.ie/milmart /index.html. (Stand: 7/3/2011). 


\section{Register}

\section{Personennamen}

Abel 42

Abélard 131f.

Abraham 131

Absalom 84

Albertus Magnus 43f., 46

Albrecht III. 72f.

Alcuin 129

Alexander (der Große) 17f., 42, 6577

Alexander von Hales 43f., 46

Alice de Schaerbeke 130

Ambroise de Milan (saint) 172

Ambroise Paré 127

André (saint) 182f., 186

Andrea Mantegna 185

Andreas Capellanus 86

Angèle de Foligno 130

Angelico, Fra 141

Antipater 67, 75

Antoine (saint) 107, 183

Aristoteles 39, 44, 46, 54, 88, 91, 96
Arrian 66

Asaf 69

Äsop 68

Augustinus, Aurelius / Augustin 18, 33, 40-46, 88f., 96, 116, 123, 171, 177,183

Averroes 54

Avicenna 54

Babiloth siehe Wigbold

Baldo degli Umbaldi 38

Bartholomäus Anglicus 54

Bède le Vénérable 128

Belludi, Luca 146f.

Bernardus Silvestris 54

Bernhard von Clairvaux / Bernard de Clairvaux 9, 14, $131 \mathrm{f}$.

Bodenstein, Andreas siehe Karlstadt

Brockmann, Gottfried 140, 142

Césaire d'Arles 124, 128

Cham 42, 44

Charles VI (roi) 105 
Chaucer, Geoffrey 105

Chrétien de Troyes 53

Christine de Pisan 105

Christomaios 186

Christophorus / Christophe (Heiliger / saint) 19, 37, 171-175, 177, 179-187

Christus siehe Jesus Christus

Clément d'Alexandrie 123

Clément V (pape) 184

Clovis (roi) 127

Constantin (empereur) 127

Constantin le Philosophe (saint) 183

Cranach, Lucas d. Ä. 155, $161 \mathrm{f}$.

Ctésias 176

Curtius, Quintus 66, 76

Daniel (Prophet) 68ff., 72f., 182

Darius 75

Decius (empereur) 172, 187

Démétrios (saint) 181

Diadochen 65f.

Diodor 66

Dolon 179

Eckbert de Schönau 128

Elizabeth de Thuringe 129

Erasme de Rotterdam 185

Étienne (saint) 183

Eumèdes 179

Eustache Deschamps 18, 103-118

Fiacre (saint) 106

Friedrich II. $76 f$.

Frutolf von Michelsberg 42

Galthen, Peder Pedersen 79

Gautier d'Arras 86, 97

Gautier de Châtillon 76

George (saint) 181

Gervasius von Tilbury 41

Giovanni de Pian del Carpine 176

Giusta de Menabuoi 146

Grégoire de Tours 127f., 182

Gregor I. (der Große) $156 f$.

Gregor von Montesacro 54

Guido von Baysio 39
Guillaume (moine) 128

Hartlieb, Johannes 72f., $78 f$.

Heinrich von dem Türlin 51, 58

Héloïse 132

Henri de Lausanne 128

Henri I (roi d'Angleterre) 129

Herodes 158, 160

Herodias 160f.

Herodot 42, 178

Herrand II. von Wildonie 18, 83ff., 87ff., 94, 96ff.

Hieronymus 69ff.

Holofernes 19, 156, 161, 166

Homer 68, 179

Horaz 54

Innozenz III. (Papst) siehe Lothar von Segni

Innozenz VIII. (Papst) 164

Isaïe 130

Isidor von Sevilla 33f., 42, 47, 70, $74,80,128$

Isidore de Seville

Jean (saint, évangéliste) 123

Jean Baptiste (saint) 183

Jean de Berry 164

Jesus Christus / Jésus-Christ 11, 14, 123, 128, 130f., 157, 160, 164, 166, 172f., 181, 183f., 186

Johannes (Priesterkönig) 42

Johannes der Täufer 19, 156, 158164, 166

Josephus, Flavius $160 \mathrm{f}$.

Juan de Mesa 155, $163 \mathrm{f}$.

Judith 155, 161f., 166

Julien l'Apostat 181

Jupiter 71,75

Justinus 66, 74, 78, 80

Kain 42, 44

Kallisthenes 68

Kaloyan (roi) 181

Karlstad 157

Katarina, Äbtissin zu Vadsten 79

Konstantin (der Große) 68ff. 
Lamprecht (Pfaffe) 75, 78

Laurentius (Heiliger) $141 \mathrm{f}$.

Lazare de Béthanie 131

Leo (Erzpriester) 72ff.

Liutprand de Crémone 183

Lothar von Segni 34-37, 164

Luther, Martin 113, 157

Lycaon 178

Mariamne 160

Markus (Evangelist) 160

Martin (Heiliger) $143 \mathrm{ff}$.

Mathilde (reine) 129

Matthäus (Evangelist) 160

Maur (saint) $106 f$.

Medusa 162, 164

Meister von Sierentz 144

Menas (saint) 183, 186

Mercure (saint) 173, 181, 183

Michel (archange, saint) 183

Nebukadnezar 68f.

Nicolas (saint) 183

Nikolaus V. 141

Noah 42

Nyctimos 178

Origène 128

Orosius 74

Orpheus 164

Otto von Freising 42

Ovid 68ff., 72, 178

Pantaléon (saint) 183

Paul (saint) 123

Paul le Diacre 177

Paulus, Julius 38

Perchta von Liechtenstein 84

Petrarca, Francesco 36

Philippe Mézières 105

Photios 176

Pietro d'Abano 39

Plinius 33, 42

Plutarch 66

Polo, Marco 65, 176

Quilichinus von Spoleto 76ff., 80
Raban Maur $127 f$.

Radegonde (sainte) 129

Rainaldus de Chartres 128

Raoul Glaber 123, 125

Ratramnus von Corbie 43, 45, 177

Richard (saint) 129

Ried, Hans 85

Rimbert, Erzbischof von HamburgBremen 43

Rudolf von Ems 76

Saint-Exupéry, Antoine de 83

Salome 155, 159ff., 164

Samson 84

Scylla 17, 67-71, 77

Sébastien (saint) 183

Seifrit 75f., 78, 80

Seleuziden 69

Sixtus II. (Papst) 141

Solario, Andrea 155, $163 f$.

Solinus 33

Sophie (sainte) 183

Stephanus (Heiliger) 141

Sylvestre II (Pape) 127

Tantale 178

Térence 181

Thomas von Aquin 54, 183

Thomas von Cantimpré $53 \mathrm{f}$.

Ulrich von Eschenbach 76

Ulrich von Liechtenstein 84f., 97

Valerian (Kaiser) 141

Valerius, Julius 65, 67-71, 73f., 78ff.

Villani, Giovanni 36

Vincenz von Beauvais 41

Weyden, Rogier van der 155, 158f., 161

Wigbold (Meister) 76, 78, 80

Wilhelm von Conches 53

Wirnt von Grafenberg 51, 56

Witz, Konrad 143f.

Wolfram von Eschenbach 15, 51ff., $54 \mathrm{ff}$.

Zeus 178 


\section{Begriffe}

abbominationes 34, 36

Adiaphora 157

Affe 44, 53, $77 \mathrm{f}$.

agneau 181

Alter, alt 15, 66, 90, 143

altérité 103,116

âme 122, 124, 130

amputation 107, 109, 126

Ancien Testament 116, 126

Andersartigkeit 10, 32, 34, 40, 43, 147ff., $165 \mathrm{f}$.

androphage (v. cannibale)

ange 131, 181

animal rationale et mortale $42 \mathrm{f}$.

Anthropologie 88

antipode 121, 181

apocryphe $182 \mathrm{f}$.

Apokalypse / apocalypse,

apokalyptisch 10, 116, 182

Apotropäisch 162, 179

apparence 104, 106, 111, 172, 175, 178f., 184, 187

Arabes 126

Artusroman 51ff., 55, 57, 59

Assipites 177

Ästhetik, ästhetisch 43, 85, 97, 139, 166

Atomist 166

Auge 9f., 18, 53, 58, 69, 73, 83-92, 94ff., 142, 145, 149

Ausgrenzung 137

Aussatz 18, 125

Außen, Äußeres, äußerlich 10, $12 f$., 18f., 42, 45, 51f., 56-59, 84, 8894, 96f., 139

Autoaggression 97

aveugle 107,109

Bär 53, 56, 67-71

beau, beauté 118, 131f., 177

Beeinträchtigung 90, 137, 143, 147
Behinderung 19, 137ff., 142f., 145150

Besessenheit 165

Bestiarien 42, 57, 171

bête, bêtes 109, 175ff., 179, 181, 183

Bettler 18, $144 \mathrm{f}$.

blemmyae 33

Blick, Anblick 34, 57, 89, 91f., 9497, 142f., 145, 147f., 159-162, 165

blind 13, 16, 142, 148

bresthafft 143

Cananéen 172

cannibale $172,182 \mathrm{f}$.

chacal 175

chien 108f., 117, 125, 131, 172f., 175-179, 182ff., $186 f$.

Chimäre, chimärisch $17,51-55,58$, 60, 131

Contemptus-Mundi-Lehre 35

crapaud 109

Création 122, 177

criminalité $111,113 \mathrm{f}$.

croix 172, 180

curiositas, Neugier 11, 25, 36, 75, 165

cynocephalus, cynocéphale 33f., 43f., 172-179, 182-187

debilis 143

dépersonnalisation 184, 186

Der-Ventrikel-Modell 15, 53

désobéissance 132

Diagnose 146, 148

Dieu 106f., 110f., 116, 123, 126ff., 130, 132, 174, 177f., 183

dieux 172, 178, 186

difforme, difformité 103-112, 115118, 121-125

Dis/ability Studies, disability 17f., 137ff., 143, 147f. 
divin 126f., 130f., 175, 178, 186

douleur 106, 108

Drache / dragon 17, 56-59, 71, 79, 181

Eber 52f., 56, 69

einäugig 92, 94, 96

Einbildungskraft siehe imaginatio

éléphant 108, 125

éléphantiasis 125

enérgeia, enárgeia 11, 13, 17, 53

Entstellung, entstellt 11, 13, 15, 52, 59, 66, 76, 84, 97

épilepsie 107

Epistemologie, epistemologisch 10, 13f., 17f., 53, 55, 57, 60

Erkenntnis(prozess) 10f., 14ff., 18f., 52, 54f., 83, 88f., 91-94, 96ff., $138,147,150$

essence 104

esthétique 187

Ethik, ethisch 85, 97, 139

étranger 116, 131, 171, 174f., 181, $184 f$.

Évangile, évangéliste 116, 123, 127,182

evidentia, Evidenz, evidenzialisierend $11,53,85,97,139$

exclusion 115, 118, 124, 126, 128

Exempel 73f., 86

fantasme 122, 129

folie 107,110

Folter 156

forma deformis 38

forma bomines 38

Fragment 15, 118, 166

Fremdwahrnehmung 59, 98

frénésie 125

géant 172ff., 179, 181, 184-187

Gebrechlichkeit, gebrechlich 35, 143

Gestus, Gestik 142, 156, 162f., 172

göttlich 10f., 14, 16f., 33, 36f., 40, $46,156,166$ goutte $106 \mathrm{f}$.

Hagiographie, hagiographisch 97, $175,184-187$

haine $109 \mathrm{ff} ., 113,115,117 \mathrm{f}$.

handicap, handicapant 106-109, 114, 116

Hässlichkeit, hässlich 12, 40, 43, 52f., 55f., 59, 84, 88-93, $95 \mathrm{ff}$.

Heide, heidnisch 69-72, 141

hémorroïdes 106

hérésie, hérétique $127 \mathrm{f} ., 181$

Hermaphrodit 39f.

homines monstruosis 31

homme-animal 173, 175

homme-loup 175, $178 \mathrm{f}$.

bomo sacer 174

humanoid 53, 175

humour 106, 108f., 118

Hund 16, 33, 53f., 67f., 71f., 74

Hybrid 17, 51ff., 56, 60, 175

hyène 175

hygiène 104

Hypersomie 51

icône, iconographique 107, 173, 175ff., 180, 182, 184, 187

Ikonodul 157

Ikonoklast, iconoclasme 157, 186

Illustrationen 9, 42, 52

imaginatio 11ff., 16f., 52-56, 58, 88, 91, 98, 139

imago clipeata 164

imago 58, 164ff., 178

impotent 13, 16, 114

impur 116, 126, 130

infamie 34,110

infirmité, infirmes, infirmus 104109, 111, 113-118, 143

Innen, Inneres, innerlich 12f., 16, 44ff., 53, 56, 58f., 88f., 91, 96f., 139, $164 \mathrm{f}$.

intellectus 15

Intensität, intensivierend 11, 53, 66 
Inversion, inversiv 58, 130

Islam 126

Johannesschüssel 159f., $162 \mathrm{ff}$.

Juifs 126, $128 \mathrm{f}$.

Kalokagathie 56, 59f., 90, 97

Krankheit 15f., 18, 94, 143, 146, 165

krippl 143

laid, laideur 115, 125, $131 \mathrm{f}$.

Lasterallegorie $9 f$.

légende 129, 172, 174, 183, $185 \mathrm{ff}$.

Leopard 67-70, 73

lèpre, léproserie 121-131

Lévitique 116

Lombards 177

loup 177, 179, $181 \mathrm{ff}$.

Löwe 53, 67-71

lycanthrope $177 \mathrm{ff} ., 181$

Magier, Magie, magisch 13, 16, 58, 162

mal 106ff., 110, 115f., 127, 179, 181, 186

malade, maladie 105-112, 114, 122, 124-130, 181

malformation 104, 131

malnutrition 104

mangelhaft 143

marginalisation, marginalité 103f., 115, 124

Märtyrer / martyr, Martyrium / martyre $11,97,140,155,166$, 171f., 183f., 186

Meditation 14, 156

mélancolie 107

memoria 11, 53, 57f., 88

mendiant 103-115, $117 \mathrm{f}$.

mépris 106, 109ff., 117

Mikrosomie 51

Minne, Minnesang 52, 57, 86f., 97

mirabilia mundi 9f., 14, 16, 31, 35, 41,45

Mirakel / miracle, miraculum 55, $86,147,184 f$.
Missbildung 32

Missgeburt 16ff., 33f., 36, 41, 45, 6568, $70-80$

Mitleid 35, 90

monere 10, 32, 40, 55

monestrum 55

Monster / monstre, monstreux, monstrum, monstrositas 10, 17, 31-46, 52, 55f., 58, 60, 65ff., 68, 70f., 104, 121f., 125, 174f., 181, $186 f$.

monstrare 10, 40, 55

mort 105, 110, 116f., 126, 128

Musulmans 126, 129

mutation 178

mythe 129, 175, $177 \mathrm{f}$.

Neugier siehe curiositas

Norm / norme, Normalität /

normalité, normal $66,103 f$.,

116, 118, 121, 131, 142, 148, 181

oculi cordis 18, 83, 89

oisiveté 114

Omen 79

ordo $40 \mathrm{f}$.

ostentum, ostentus, ostentatio 32, 34, 36f., 155f., 162f., 165

païen 123,172

paralytique 109

pauvre, pauvreté 104, 107, 110 $114,117,123,131,181$

péché 115f., 121-124, 126ff., 130, 134,181

péché originel 123

perception $31,51,83,103 \mathrm{ff} ., 110$, 115f., 121f., 124, 127, 130, 137, $155,174 f$.

périphérie 103

peur 111, 113, 116, 121f., 125, 129f., 177

phantasma 13, 51, 53f., 56f., 60

pictorial turn 157

Pneuma 12f., 53 
poetologisch $53,55,57,62$

politique sociale 117

portentum 32, 37, 55, 67

prodigium 32, 34, 36f., 40

Prothese 149

psoriasis 125

pygmaei 33, 44

ratio $17,41,53 \mathrm{f} ., 57,88,177$

réalité $103 \mathrm{ff} ., 118,122,187$

Reflexion / réflexion, reflexiv 10f., 13f., 55, 88, 92, 96, 118, 131, 162, 166,182

religion 179,187

Renaissance 127

renard 125

reptile 125

révolution 185

Rhetorik / rhétorique, rhetorisch $11,19,51,53,98,181$

ridicule 108,185

Riese 13, 19

rite de passage 128

sanctification 182

sanglier 108

Schädigung, Schaden 15, 88, 93f., $147 f$.

Scham 43, 90

Schönheit, schön 9f., 12, 40, 43, 56, 59f., 75, 84, 88-97

Schwäche 143

Schwein 67-71

Seele 12f., 38f., 44, 53f., 88, 92, 96

Seher 13, 16

Selbstwahrnehmung 59, 90f., 150

sensus corporeus 88

Sheela na Gigs 9

Siamesische Zwillinge 36f., 39

siech 143

Signum siehe Zeichen

skiapodes 33

soldat 172f., $179 \mathrm{ff}$.
Spiegel(bild), spiegeln, spiegelbildlich 10, 12ff., 19, 46, 53, 55, 60, 88ff., 96f., 149, 156, 158, 165

stérilité 116

Stigma 145, 148

Sünde, Sündhaftigkeit 9f., 36f., 42, 44f., 156

Sündenbock 156

Sündenfall 28, 35

surdité 107

Symbol / symbole, symbolisieren, symbolisch / symbolique 31, 45, 66, 68, 72, 130, 164, 175, $177 \mathrm{ff} ., 184$

Symptom / symptome 15, 18, 103, 124, $146 f$.

talisman 185

templiers 184

Teufel 9f., 71

thaumaturge 106

tradition $106,126,172,175,181$ -

185, 187

translatio imperii 70, 73, 76

truand 104, 112, 114

Turnier 87

túter 10

ungebiure, Ungeheuer 9, 12, 52f., 55,57

unsichtbar 59, 83

Vatican II (concile) 185

Verletzung, verletzt 15f., 87f., 90f., 94f., 165

Versehrtheit, versehrt 15, 79, 87, 90

Verstümmelung, Selbstverstümmelung 14ff., 18f., 34, 37, 67f., 70, 73, 75, 85, 87-98, 147, $165 f$.

Vision / vision 14, 122, 126

visuell / visuel 110, 139, $148 \mathrm{f}$.

Weltkarte 40, 42

Wolf 19, 67f., 71

Wunde, Verwundung 19, 87, 94, $143,145,162,164$ 
Wunder(wesen), Verwunderung 9ff., 33, 41, 45, 55, 75, 88

Zeichen, Vorzeichen, Signum 10, 15ff., 33-37, 40ff., 44f., 47, 86, 97, 163 zoomorph / zoomorphe 51, 53, 182, 187

Zwerg 13 
'importance du corps dans la culture du Moyen-Âge, ainsi que l'influence des mécanismes de perception dans la littérature et l'art, ont été, dans les dernières années, souvent placées au centre de l'intérêt scientifique. Le fait que ces deux domaines soient étroitement liés peut être perçu dès l'Antiquité, une fois que la rhétorique attribue au corps déformé une fonction de stimulation de la perception. Aussi la relation - complexe et parfois controversée - entre l'intérieur et l'extérieur indique surtout que le corps déformé réveille certaines attentes, en même temps qu'il suscite chez l'observateur des processus de perception très spécifiques. À côté de l'idée de corps et de perception, il est également possible de remarquer la présence d'un troisième élément : l'Autre. Celui-ci est parfois aperçu en tant que l'Étrange et apparaît dans la contemplation de la difformité peu familière, parfois en tant que I'Intime, l'âme, un complément de la housse corrompue. Le présent ouvrage - ainsi que le volume suivant - contient non seulement des contributions dans les domaines de la littérature et de l'histoire de l'art, mais aussi de l'histoire de la médecine, Dis/ability Studies, etc., afin de montrer que non seulement les corps déformés artificiels/artistiques, mais aussi les >vrais، déformés, ne peuvent être compris qu'à travers leur rapport avec les théories de perception de leur temps.

ie Bedeutung des Körpers in der Kultur des Mittelalters ist in den letzten Jahren immer wieder ins Zentrum der Forschung gerückt - ebenso wie Fragen nach dem Einfluss von Wahrnehmungsmechanismen und -vorgängen auf die Literatur und Kunst dieser Zeit. Dass beide Forschungsgebiete eng zusammen gehören, wird bereits durch die antiken Rhetoriken, in denen der deformierten Körperlichkeit eine besondere wahrnehmungsstimulierende Funktion zugesprochen wird, gestützt. Auch das komplizierte und immer wieder kontrovers diskutierte Wechselverhältnis von ,Innen“ und ,Außen“, deutet darauf hin, dass insbesondere der deformierte Körper bestimmte Erwartungen bezüglich des zugehörigen Inneren weckt, zugleich aber auch bei einem Betrachter dieses deformierten Körpers sehr spezifische Wahrnehmungsvorgänge auslöst. Neben Körper und Wahrnehmung wird so ein Drittes sichtbar - das Andere, einmal verstanden als das Fremde, das in der Betrachtung und Reflexion der halbvertrauten Deformation aufscheint, einmal als das Ur-Eigene, die Seele selbst, als das Komplement der korrumpierten Hülle. Der Band (ebenso wie der Folgeband) vereint dabei nicht nur literaturwissenschaftliche und kunstgeschichtliche Beiträge, sondern schlägt zugleich die Brücke zur Medizingeschichte, zu den Dis/ability Studies u.ä., um so zu zeigen, dass nicht nur der künstlich-künstlerisch entworfene, sondern auch der ,reale“ deformierte Körper erst in seinem Verhältnis zu den Wahrnehmungstheorien seiner Zeit zu verstehen ist. 